\title{
Development of a Fast-Response Variable-Amplitude Programmable Reaction Control System
}

Building and Fire Research Laboratory

Gaithersburg, Maryland 20899

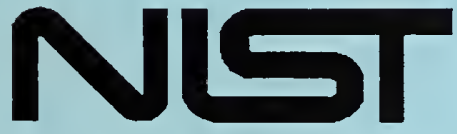

United States Department of Commerce Technology Administration

National Institute of Standards and Technology 



\section{Development of a Fast-Response Variable-Amplitude Programmable Reaction Control System}

William C. Stone

January 1993

Building and Fire Research Laboratory

National Institute of Standards and Technology

Gaithersburg, MD 20899

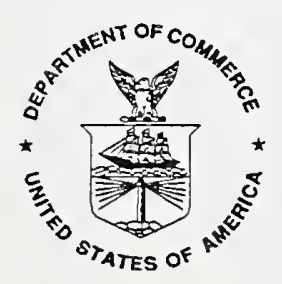

U.S. Department of Commerce

Ronald H. Brown, Secretary

National Institute of Standards and Technology John W. Lyons, Director 


\begin{abstract}
This report describes a high speed loading system comprised of: a piezoelectric stack and an associated microprocessor-based programmable DC power source; a low-loss mechanical displacement amplifier; a high pressure spring-loaded axial valve; an integral high pressure valve seat; an expansion nozzle; and a high pressure gas supply. A half square wave voltage signal of varying duration and amplitude was used to drive the piezoelectric stack in such a manner as to produce changing displacements which were subsequently amplified by a monolithically milled hinged anvil. The anvil is connected to a valve core which seats upon, and is normally forced closed upon a specially hardened throat of an expansion nozzle by means of a compression spring. The interior side of the thruster nozzle communicates with a high pressure gas supply. The flow of gas through the nozzle is normally prohibited by the spring loaded valve core. As the piezoelectric stack expands under computer control the valve core is lifted off the nozzle throat permitting gas to expand through the nozzle and create thrust that is directly proportional to the control signal from the microprocessor. The device is designed to operate as a stand-alone unit with a dedicated onboard microcontroller system and onboard energy storage system. Minimum pulse width resolution (base-to-base) was shown to be $0.98 \mathrm{~ms}$ with a lag time of $0.37 \mathrm{~ms}$ relative to the initiation of the drive pulse. Linear amplitude response was achieved beyond a threshold drive voltage of $80 \mathrm{vdc}$ and was maintained through the limit of testing at $240 \mathrm{vdc}$. Thrust change rates of 12000 $\mathrm{N} / \mathrm{s}$ were achieved. The demonstration unit developed for this study produced a peak thrust level of $15 \mathrm{~N}$ at operating pressures of $41 \mathrm{MPa}$.
\end{abstract}

Keywords: active control; amplitude control; cold gas thruster; microprocessor control; piezoelectric stack; pulse width resolution; reaction control system; system identification; 


\section{List of Symbols and Acronyms}

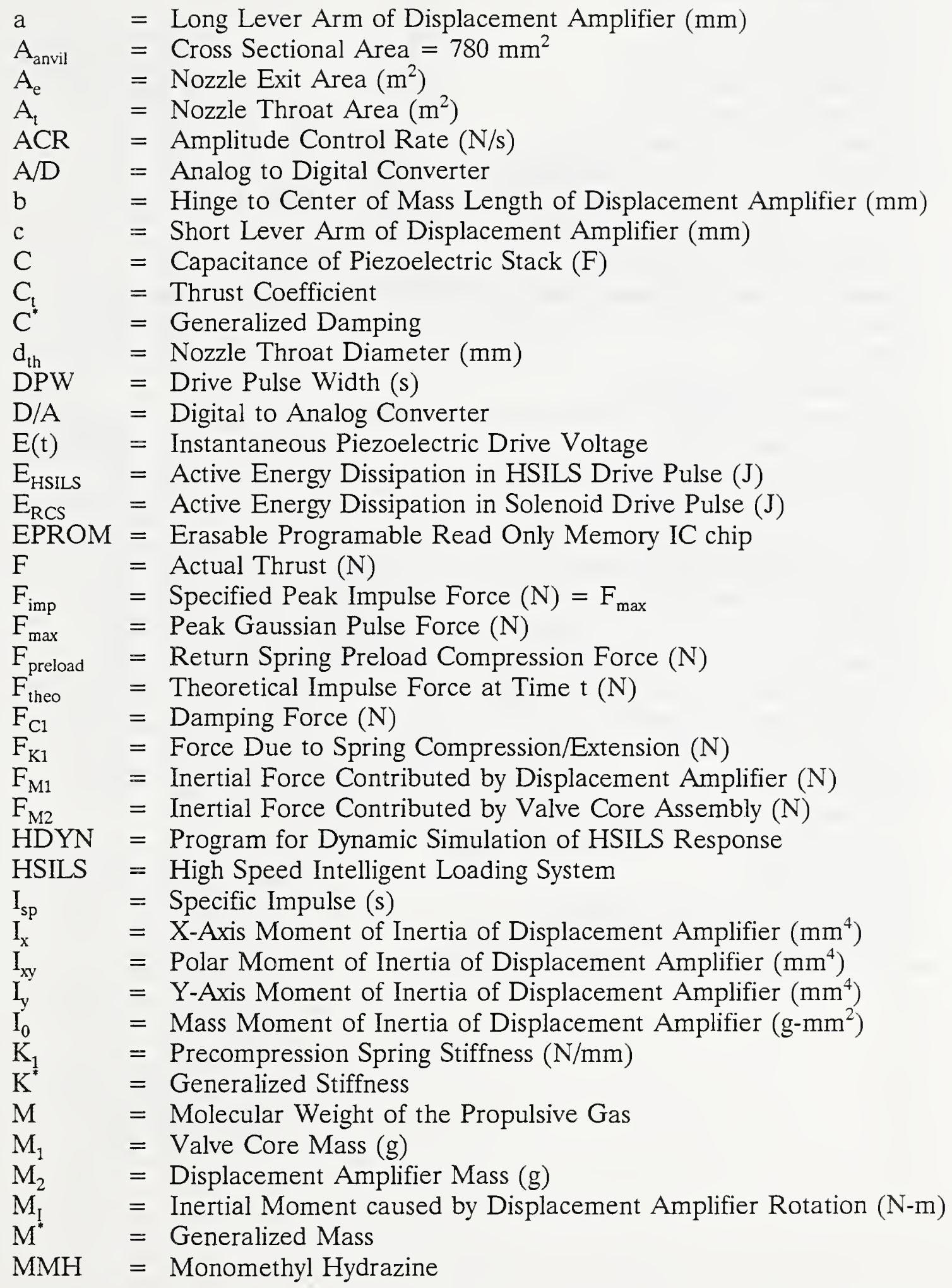




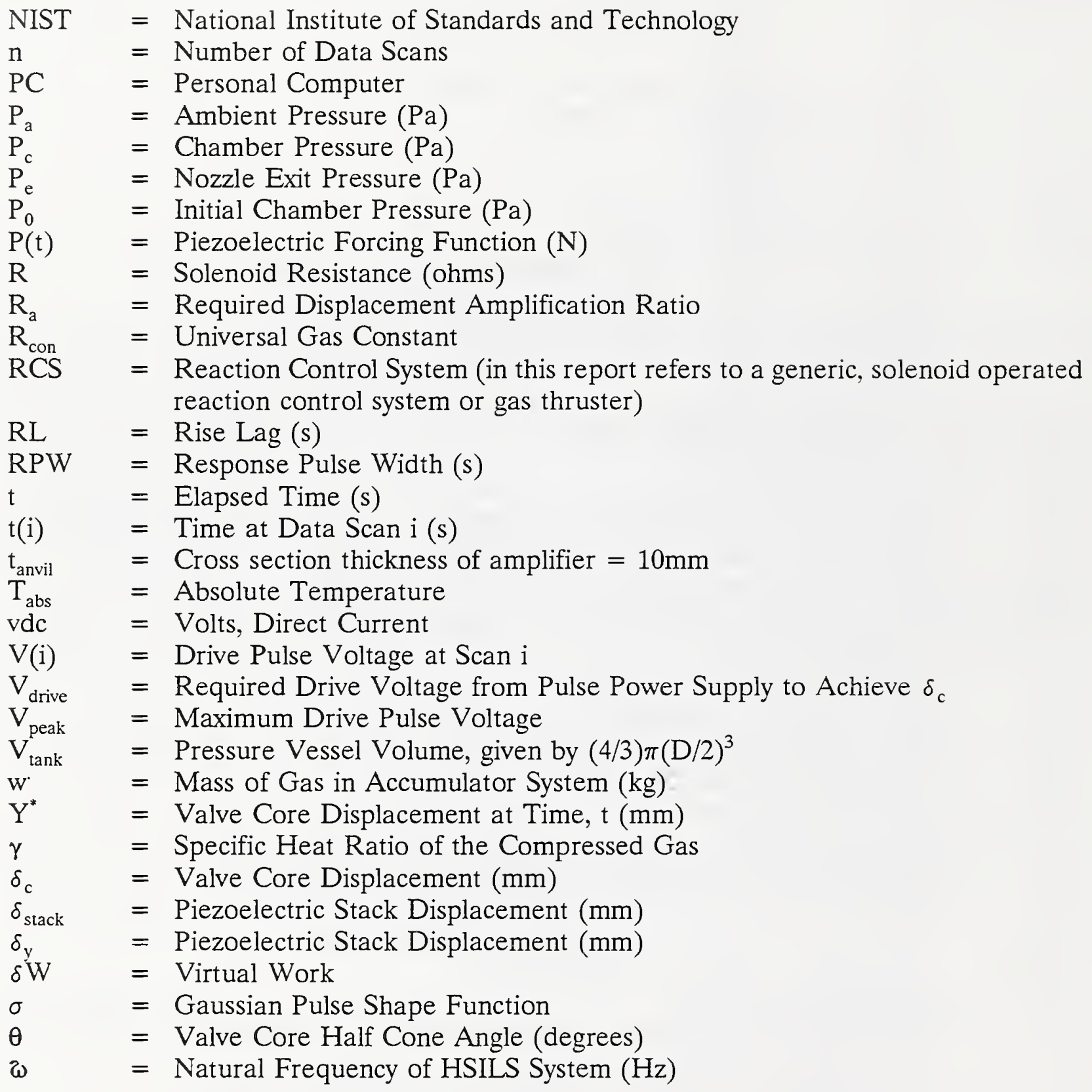


$\begin{array}{ll}1.0 \text { Introduction } & 1.1\end{array}$

$\begin{array}{ll}1.1 \text { Background } & 1.1\end{array}$

1.1.1 Servo-hydraulics $\quad 1.2$

1.1.2 Pneumatic Solenoids 1.3

1.1.3 Piezo-pumped Reaction Control System 1.4

1.1.4 Piezoelectric Metering Valves and Fuel Injectors $\quad 1.5$

1.1.5 Mechanically Amplified Piezoelectric Valves, Actuators, $\quad 1.6$

Electrical Relays and Dot Matrix Printers

1.1.6 Microprocessor Controlled Harmonic Force Actuator $\quad 1.8$

$\begin{array}{ll}1.2 \text { Summary } & 1.9\end{array}$

1.3 Scope and Limitations of NIST Research $\quad 1.10$

2.0 Design of a High Speed Intelligent Loading System (HSILS) 2.1

2.1 Concept Development $\quad 2.1$

2.1.1 HSILS Overview $\quad 2.2$

2.2 Hardware and Software Design 2.4

2.2.1 HSILS Mechanical Description (Operation) 2.4

2.2.2 Onboard Microprocessor Subsystem Functional Overview $\quad 2.10$

2.2.3 Microcontroller Hardware Description 2.11

2.2.4 Onboard Programmable Pulse Power $\quad 2.12$

2.2.5 HSILS Driver Software 2.13

2.3 RCS Control Thruster $\quad 2.14$

2.4 Analytical Modeling $\quad 2.15$

2.4.1 Force, Duration, and Gas Storage Requirements 2.15

2.4.2 Typical Limiting Design Conditions $\quad 2.20$

2.4.3 Dynamic Simulation of HSILS 2.21

3.0 Experimental Testing 3.1

3.1 Onboard Sensors $\quad 3.1$

3.1.1 Acoustic $\quad 3.2$

3.1.2 Static Pressure $\quad 3.2$

3.2 Pulse Width Tests $\quad 3.2$

3.2.1 RCS Tests 3.3

3.2.2 HSILS Tests 3.3

3.3 Amplitude Control Tests $\quad 3.4$

3.3.1 RCS Tests 3.4

3.3.2 HSILS Tests 3.4 
4.1 Minimum Repeatable Pulse Width Parameters

4.2 Parameter Correlations

4.2.1 RCS Results

4.2.2 HSILS

4.3 Amplitude Control Using HSILS

4.4 HSILS Amplitude Control Rate (ACR)

4.5

4.5 Damping Effects

4.6

4.6 Mechanical Design Observations

5.0 Conclusions 


\subsection{Introduction}

A series of mathematical investigations were carried out at NIST between 1986 and 1989 [Carasso \& Simiu (1988); Carasso and Simiu (1989); Simiu and Cook (1989); and Carasso (1991)] with the objective of developing robust system identification techniques for the response of flexible structures. These techniques are likely to be particularly useful for structural systems with non-collocated active control, where noise is present in the sensor data used as input to the active control algorithm. Examples of such structural systems include flexible robotic manipulators, tension-guyed deep water offshore oil platforms, active hook control for construction cranes, and large orbiting spacecraft.

The research reported by Carasso and Simiu was based on the finding that it is advantageous to recover the dynamic characteristics of a structure by deconvolution of an output due to an excitation by a pulse defined by an inverse Gaussian function or an approximation thereof. Where identification of higher order mode shapes and frequencies is sought the drive pulse must be short. In the case of certain spacecraft, for example, it is apparent that active control systems should accomodate structural response at frequencies of vibration of several hundred Hertz (Belvin, 1986). This would, in turn, imply the need to impart to the structure a smooth, uni-directional, mathematically defined test pulse whose total duration is less than, e.g., $0.001 \mathrm{~s}$.

The need for such a device motivated research, started in 1988, with the goal of developing a working prototype High Speed Intelligent Loading System, or HSILS (HSIS, 1990), and to ascertain: its pulse width resolution; its ability to interactively vary amplitude (force applied to the test structure); and the feasibility of generating mathematically definable force-time histories using either closed or semi-closed loop control. Implicit in the latter objective was the necessity of employing an onboard, programmable microprocessor control system which could be used to drive the device as a stand-alone thruster (e.g. as might be used on a space craft). Note also that a required characteristic of such a control/identification loading system is that it be capable of operating without the presence of a reaction surface, frame, or other interacting structure. The reason for this requirement is obvious for the case of the control of spacecraft and orbiting structural systems.

In the present paper we discuss the background of the design that was ultimately developed, the rationale behind the selected technology, and the experimentally observed pulse width resolution and amplitude control behavior of the system. The capability of the system to impart random shape, pre-defined impulses to a test structure will be discussed in a subsequent report.

\subsection{Background:}

The present report relates to the problem of providing a means for introducing a force with a predetermined variation in time (harmonic or non-harmonic) into a mechanical or structural system. The system is assumed to consist of one or more rigid bodies or flexible elements, and the force is used for active control or structural dynamics identification. 
The first phase of the work reported here consisted of an extensive search on existing valves and on independent actuator technologies that might be integrated to form an amplitude controllable, high speed valve. The results of this search are presented below.

\subsubsection{Servo-hydraulics}

Closed loop servo-hydraulic and servo-pneumatic loading equipment is now in common use for structural testing and industrial fabrication. Such equipment works on the principle of directing a pressurized fluid (either hydraulic oil, or compressed air) from a pressurized reservoir to a bi-directional actuator which may be made to extend, contract, or remain stationary depending upon the state of an electronically controlled servovalve. While it is possible to program these actuators to impart an "intelligent" forcing function into a test structure, the response time to an instantaneous change in the command signal is generally about $1 / 30$ second or longer, although special high speed versions have been developed.

Fig. 1.1 shows an exploded schematic of one such valve (a Moog Series 760 electrohydraulic servovalve). A typical limiting response under ideal conditions for such an actuator is shown in Fig. 1.2 in which it can be seen that there is approximately a $10 \mathrm{~ms}$ rise time to an impulsive loading with approximately the same time $(10 \mathrm{~ms})$ lag time between the initiation of the electronic drive pulse to the initiation of actuator movement. Generally there will also be an associated termination or fall lag which is similar in duration to the rise lag. From this it may be inferred that the minimum pulse width resolution is about three times the rise time, or $30 \mathrm{~ms}$.

An important additional drawback of servo-hydraulic valves is evident from Fig. 1.2, where it can be seen that there is no direct correlation between the drive signal and the actuator response. This makes this type of system particularly unsuitable for active control of short period structures. It may be further noted that such actuators require a reaction system and are therefore unsuitable for active control of free bodies.

\subsubsection{Pneumatic Solenoids}

Several loading systems presently exist for spacecraft which require no reaction surface. These fall into a broad classification known as Reaction Control Systems (RCS). Of particular interest to the present discussion are those reaction control systems which comprise small rocket thrusters that may be used for translational as well as rotational control of spacecraft and orbiting structural systems. Classical RCS thrusters employ a pressurized supply of liquid fuel, an electronically controlled solenoid-type valve, a combustion chamber (if the thruster is of a bi-propellant variety), and an expansion nozzle. Alternatively, the propellant may simply be an elemental inert gas, such as nitrogen, in which case the RCS is known as a "cold gas thruster."

These control solenoids (e.g. Fig. 1.3) are normally closed and only the duration of the open time is subject to variation. There is typically a threshold voltage which is required to activate motion of the solenoid core but beyond that further increases in voltage generally yield no further increase in the amplitude of the flow nor do they influence the minimum 
pulse width of the system (experimental data showing this behavior is presented later in this paper).

While solenoid controlled RCS thrusters can impart differing levels of thrust duration, there is no means of varying the thrust level (which is controlled by the fixed diameter of the thruster nozzle) and therefore no "intelligence" can be imparted to the load-time history. Furthermore, such systems suffer from significant lag times in response to changes in a control signal. An example response from a typical RCS solenoid, used in a cold gas thruster configuration, is given in Fig. 1.4 (Hallauer and Smith, 1990).

Hallauer and Smith made use of a Mac Valves, Inc. Model 113B-551BA solenoid valve which, in their specific application was referred to as an AJT (Air Jet Thruster). The response shown in Fig. 1.4 was achieved using this particular valve although others (as will be described below) could have been used that would have yielded similar responses. Regarding lag times (between the leading edge of the drive pulse and the initiation of valve opening) for solenoids, Hallauer and Smith report that:

"[there are] time delays between the control signal stimuli at the zero-crossing instants and the realization of either full-on or full-off thrust. The full-on and full-off delays are about $10 \mathrm{~ms}$ and $5 \mathrm{~ms}$, respectively. Time delays are very important relative to application of AJTs for active vibration control, because they tend to destabilize closed-loop control systems. These delays are due primarily to the fluid and mechanical dynamics of the solenoid valve itself."

The issue of binary amplitude response is also commented upon:

"The thrust of AJTs built from standard solenoid valves cannot easily be modulated, because these valves have only two stable states, fully closed and fully opened."

It has been observed (Kattchee,1967) that RCS solenoid operated thrusters

"lack of precise impulse bit repeatability due to the opening and closing characteristics of the valves, manifold fill times, and chemical ignition delay times."

The term "impulse bit" is defined as the integral of the force $(\mathrm{N})$ applied by the thruster over the domain of its minimum pulse width (s).

\subsubsection{Piezo-Pumped Reaction Control System}

A second type of RCS thruster (see Figs. 1.5 and 1.6) employs a piezoelectric pump for the two fuel components of a bi-propellant thruster (Kattchee, 1967). This is known as the pulse-pumped vernier engine concept and operates on the principle of pulsing a piezoelectric stack with a specified voltage waveform which then causes a metered amount of propellants to be injected into a combustion chamber, thereby producing thrust. The threshold "impulse bit" is determined when measurable thrust is just produced at the shortest possible drive pulses at the lowest possible amplitude (voltage). 
There are strong reasons for using piezoelectrics in fast valve technology. A typical modern piezoelectric element will reach maximum extension in response to a step change in applied voltage in approximately the time required to propagate sound through the piezoelectric material in the direction of expansion. Thus, for a Lead Zirconate Titanate (PZT) stack measuring approximately $75 \mathrm{~mm}$ in height, the response time to a change in drive voltage is approximately 10 microseconds. Under ideal conditions this would translate to a minimum pulse width (triangular pulse) of 20 microseconds. As will be discussed below, mechanical, acoustic, viscous damping, and chemical reactant delays will degrade the performance. The degree to which such speed can be approached depends on the skill of the mechanism designer, on the required thrust amplitude, and on other performance characteristics.

The concept of a piezoelectric stack has changed somewhat during the past 25 years. Originally, due to material processing considerations, the size of a "high performance" piezoelectric element was severely limited and high axial strains were only achievable in relatively thin elements, usually in the form of either disks, and rectangular or annular wafers. For the particular proof-of-concept program reported by Kattchee, PZT-5H (Lead Zirconate Titanate) ceramic disks were stacked one on top of the other to assemble a cylindrical piezoelectric "stack". This particular material has a maximum axial strain of approximately $0.02 \%$ (Piezoelectric Ceramics, 1974), which, for example, would result in a maximum $0.004 \mathrm{~mm}$ total extension for a $20 \mathrm{~mm}$ high stack.

The piezoelectric stack used in Katchee's thruster is connected to a series of inlet and outlet valves which permit the piezoelectrically operated pulse-pump to draw propellant into a holding chamber during a constriction of the stack and to expel the propellant through the outlet valve during an expansion of the stack. Each such cycle delivers a finite, measurable quantity of fuel to a combustion chamber and subsequently to an expansion nozzle. The frequency and duration of the arrival of the electrical pulses which drive the piezoelectric stack thus determine the total impulse delivered by the thruster during a specified length of time. This type of operation is analogous to the manner in which pulse-width modulation can be used to turn a light on for specified periods of time at the same illumination level.

The approach described above appears to be a highly effective method for metering precise RCS impulses. The shortest pulse width measured by Katchee (see Fig. 1.7) was on the order of 3-5 ms with corresponding lag (response) times of approximately $3 \mathrm{~ms}$. Both of these performance indicators are considerably superior to the solenoid RCS systems previously described. In this particular situation, lag time is comprised of a number of components including a) the expansion/contraction rate of the piezoelectric stack; b) viscosity related flow resistance delays; and c) ignition delay.

Two points are worth discussing with respect to this type of control system. First, the amplitude variance (peak force) of the thrust which can be achieved in this manner is severely limited by the maximum stroke of the piezoelectric stack and thus relatively large stacks must be used to achieve significant valve displacements. Second, because the fuel charge must be replenished after each firing, and because the volume is essentially predetermined by the geometry of the pump system, there is a further limitation on the ability to control amplitude: once the stack has achieved maximum stroke it can displace no further 
fuel. Thus amplitude modulation, over a wide range of both pulse durations and amplitudes -- necessary to achieve an "intelligent" force-time pulse -- is not practicable with this approach.

\subsubsection{Piezoelectric Metering Valves and Fuel Injectors}

There are a number of similar piezoelectric stack-driven valve systems in use for purposes other than aerospace reaction control systems. The two most striking examples are injection valves for atomic spectrophotometers and the more commonly known application in fuel injectors for engines. For spectrophotometers, the metering of usually minute amounts of trace or reactant elements into a carrier stream is of interest. Injection of large quantitities is not of great importance and hence axial stacks, similar to that described by Katchee (Katchee, 1967) have been used and improved upon. Examples of such valves are shown in Figs. 1.8, 1.9, and 1.10 (from Weber \& Blanckenhagen, 1987; Kippenhan, 1962; and Yamauchi, Nogi, \& Ohyama, 1991, respectively). All of these have the common elements of a piezoelectric stack, an expansion nozzle, and a spring loaded valve means which normally prevents pressurized fluid or gas from escaping through the nozzle. Webber and Blanckenhagen employ a separate valve core (Fig. 1.8) which is unseated from the nozzle throat when the piezoelectric stack expands. Kippenhan (Fig. 1.9) attaches the valve seat directly to the end of the piezoelectric stack. In a minor variation, Yamauchi, Nogi, and Ohyama (Fig. 1.10) allow a spring loaded metal sphere to lift off the valve seat when the piezoelectric stack expands.

All of these valves have minimum pulse widths on the order of 5-7ms. However, unlike the valve utilized by Katchee, each of the valves shown in Figs. 1.8, 1.9, and 1.10 is pressure-fed and therefore can maintain, for as long as fuel and pressure remain, a fixed mass flow rate (and therefore, in the RCS sense, a thrust amplitude). All of these valves exhibit the limitation on amplitude range common to all axial stack valves described above. Similar designs, with minor variations to suit a particular set of needs, are described by Kushida, 1986; Hiratsuka, Kawasaki \& Yashuhiko, 1991; and Janner \& Gregorius, 1984.

\subsubsection{Mechanically Amplified Piezoelectric Valves, Actuators, Electrical Relays and Dot Matrix Printer Drivers}

As mentioned above, direct axial valve control using a piezoelectric stack imposes a severe restriction on the range of motion of the valve core. One means of circumventing this problem is to use a mechanical displacement amplifier, such as shown in Fig. 1.11 and as described by (Moloney, 1986). The device depicted in Fig. 1.11 is an exhaust valve for an internal combustion engine. Unlike the previous injectors, in which fairly high pressure is maintained on the fuel resevoir side to offset the displacement limitations of the axial stack, the valve shown in Fig. 1.11 must operate under reverse pressure and also deliver relatively large opening displacements in order for the vent to operate properly.

The displacement amplifier used by Moloney is in essence a lever in which the centerline of the force generated by the piezoelectric stack is located a slight distance from the lever hinge and, in the particular configuration shown in Fig. 1.11, on the same side of the hinge 
as the actuator element which is to be the recipient of the enhanced displacement. Moloney provides no performance data on this actuator design in his patent, but specific reference is made to the piezoelectric stack as being comprised of a series of piezoelectric disks. From this it might be inferred that the device will exhibit similar response characteristics to axial stack designs; that is, in the range of 5 ms pulse widths. The presence of sliding valve guides will introduce damping into the dynamic system which, in general, increase the minimum achievable pulse width. The effects of damping will be discussed in detail later in this report.

Other, less intuitive, displacement amplifiers have been developed by (Knappe, 1972; Mitsuhashi, Wakamatsu, Aihara, \& Okihara, 1985; and Takahashi, 1985). Fig. 1.12 shows an "operating device for high speed reciprocating machine parts," described by Knappe in which two opposing piezolelectric stacks are used to move a hinged actuating plate. In this particular design a second piezoelectric actuator is used to create a moment couple that in turn causes pure flexural loading of an actuator beam. The amplification factor is thus determined by the ratio of the half-length of the flexural beam divided by the centerline to centerline distance between the two stacks.

Mitsuhashi et al. describe a piezoelectrically operated electronic relay, shown in Fig. 1.13. Its heart is a piezoelectric stack and an associated displacement amplifier. As part of this study Mitsuhashi et al. investigated the performance of various piezoelectric devices, including both bimorphs and the more modern version of an axial stack known as a "monolithic" or "cofired" stack. Fig. 1.14 shows two types of flexural bimorph actuators and a modern monolithic stack.

A bimorph, in its most simple form, can be envisioned as a bilaminar cantilevered beam. It consists of two thin piezoelectric strips bonded together in a fashion analogous to that of a bimetalic strip thermocouple. As shown in Fig. 1.14 the strips can be poled either in parallel or in series. When a voltage $V$ is applied between the electrodes on their outer surfaces the upper strip contracts lengthwise while the lower one expands lengthwise. This differential strain causes the cantilever to bend. The cofired stack shown in Fig. 1.14 uses internal and external electrodes to join hundreds of very thin, but high strain rate, planar elements which are then fused to form a monolithic stack. This technique results in an improved performance, as measured by maximum axial strains of $0.1 \%$ compared with $0.02 \%$ from a series of stacked individual disks.

Table 1.1 presents typical laboratory results obtained by Mitsuhashi et.al. These clearly indicate that bimorph type actuators are capable of achieving substantially greater absolute deflections than a stack. However, the maximum force that can be achieved using a bimorph type element is quite limited and this factor essentially disqualifies it from use as a high pressure valve component. The monolithic stack, on the other hand, while having superior force and energy capacity characteristics, clearly suffers from the drawback of limited deflections, in spite of the improvements in axial strain capacity.

Mitsuhashi et.al. determined that the strain limitations of the monolithic stack could be overcome (as others concluded above) by means of mechanical amplifiers: 
"multilayer piezoelelectric actuators themselves displace very little, $7.8 \mathrm{um}$, at a rated drive voltage $(E=1000 \mathrm{~V} / \mathrm{mm})$, and the displacement has to be magnified at least more than 60 times to obtain a displacement of $0.5 \mathrm{~mm}$ or more, as the driving source of relays."

A few of the concepts they investigated are shown in Fig. 1.15. Most of these are numerically machined single metal systems containing low resistance flexural hinges. They go on to point out that:

"the most important point in designing a high efficiency magnification mechanism is the lengths among the point of force, fulcrum, and point of application of each arm, namely, the lever ratio, and spring stiffness of each hinge spring."

Using these concepts and parametric finite element analysis, Mitsuhashi et al. developed a working prototype electronic relay as shown in Fig. 1.13 with a magnification factor of 70 . The minimum opening time, including bounce, was shown to be $2.5 \mathrm{~ms}$ and the authors claim a peak switching speed of $300 \mathrm{~Hz}$ (implying $3.3 \mathrm{~ms}$ minimum pulsewith).

A final example of an amplified piezoelectric stack system is shown in Fig. 1.16, as described by Takahashi. The operation of this amplifier, as used in a dot matrix printer, is as follows:

"the actuator stroke is amplified by a two stage hinge-lever mechanical linkage. When the actuator expands upwards, levers I and II simultaneously rotate in clockwise and counter-clockwise directions, respectively. Lever III then rotates in a counter-clockwise direction and the wire attached to the lever III end moves. An impact matrix printer head can be constructed with these elements, where the ends of wires are arranged in a line through wire guides. The wire ends strike a paper through an inked ribbon. The printer head thus-obtained has higher printing speed, lower power consumption, and less heat generation, compared with a conventional electromagnetic drive printer head."

The last statement above is particularly important since it underscores the superior speed of piezoelectric actuators over electromagnetically operated systems (as, for example, the solenoid operated pneumatic RCS thrusters previously described). The project undertaken by Takahashi was more fundamental than the end-product development of an impact matrix printer. The primary scope of the research was to develop an integrated monolithic stack with performance superior to a discrete stack assembly of the type used by Katchee. The new manufacturing technique is shown graphically in Figs. 1.17 and 1.18. The specific process was as follows:

"piezoelectric ceramic calcined powder with some organic binder, plasticizer and solvent is milled into a slurry. The slurry is cast into a "green" sheet several tens of micrometers thick on an organic film using a spatula. After drying, the green sheet is stripped from the organic film and is cut into appropriate sizes. Metal paste is printed on it as the internal electrode. A number of green sheets with metal paste are laminated and pressed together. The pressed body is heated to about $500^{\circ} \mathrm{C}$ for 
more than 100 hours to break down the organic materials included as binder and plasticizer. The ceramic body is then sintered in place at $1000-1300^{\circ} \mathrm{C}$. The sintered body is cut into appropriate sizes, according to the various projected uses, and an individual internal electrode is electrically connected in parallel with two external electrodes."

Takahashi was able to achieve a 15 um displacement from a $9 \mathrm{~mm}$ long stack at $300 \mathrm{~V}$, roughly a $0.2 \%$ strain. Further properties are presented in Table 1.2 in which comparisons are drawn between bimorph and cofired stack actuators developed from similar materials. The chief advantages of the stack, as previously noted, are high force, and high response speed.

\subsubsection{Microprocessor Controlled Harmonic Force Actuator}

Zimmerman et.al. (Zimmerman, Horner, \& Inman, 1986) developed an autonomously controlled proof-mass actuator for active vibration control of lightweight, relatively flexible, lightly damped spacecraft as shown in Fig. 1.19. The proof-mass actuator applies to the structure (spacecraft) a cyclic force in a manner analogous to that used for tuned-mass dampers now commonly used to control the motions of office buildings in seismic regions. Zimmerman et.al. explain:

"The force applied to the structure by the actuator is equal and opposite to the force exerted on the proof-mass. The finite motion of the proof-mass is controlled by an electromagnetic field [generated by coils located within the apparatus; see Fig. 1.19]. The proof-mass actuator is used only for vibration control since the finite motion of the proof-mass does not allow it to be used for rigid body control. The low frequency force output of the actuator is limited by the displacement of the proof-mass, whereas the high frequency force output is limited by the maximum allowable coil current. The allowable coil current is such that the coil does not overheat.

The force output of the proof-mass actuator is equal and opposite to the force applied by the electromagnetic field on the proof-mass. The actuator is comprised of a movable proof-mass, a fixed coil, two collocated sensors, a digital microcontroller, and a power amplifier. All of the components are mounted as a single unit which minimizes the interconnecting cable lengths. The use of external cables required in implementing control would greatly affect the dynamics of the structural system. Additionally, the effects themselves may change on a daily basis. Therefore, the actuator was designed such that power lines are the only required external lines for the actuator to operate."

The actuator developed by Zimmerman et al was capable of generating steady state force output of $2.75 \mathrm{~N}$ from $2 \mathrm{~Hz}$ through $1000 \mathrm{~Hz}$. Although this device cannot produce monotonic (non-cyclic) impulses of the type required for rigid body motion control, several of its concepts, namely the use of onboard sensors, power conversion, and microcontrollers for the implementation of adaptive control algorithms (Figs. 1.18 and 1.19), are particularly useful in considering the design of a more robust thruster. 


\subsection{Summary}

Of all the potential actuator technologies reviewed here the piezoelectric, cofired stack has the highest performance characteristics in terms of response speed and deliverable axial force. It does, however, have the drawback of providing these at the expense of axial extension. The use of a piezoelectric stack for the purposes of valve operation (in which finite displacements are required in order to achieve effective mass flow) requires the presence of a mechanical displacement amplifier. As will be described in Chapter 2 there are tradeoffs in performance that result from the mechanical design details of the displacement amplifier (its natural frequency, damping, and hinge stiffnesses) and from the selected amplification ratio.

For purposes of practical engineering utility a reaction control system must be capable of being mounted at the control point of interest on the target structure (for example, at the end of a flexible beam which contains an effector at that location) without significantly affecting the dynamic characteristics of the structure. This demands the use of compact, lightweight hardware in combination with an onboard active control system and sensors, as well as primary power storage for short term operation of the actuator. The means by and degree to which these attributes were achieved in the NIST prototype HSILS unit are discussed in Chapters 2, 3 and 4.

There are extensive appendices at the end of this report which discuss simulation software used to model the performance of candidate HSILS designs; electronic schematics for the onboard microcontroller and associated energy storage and power conversion electronics for driving a cofired stack; low level software for the microcontroller subsystem; and complete shop drawings for the HSILS prototype unit constructed at NIST.

\subsection{Scope and Limitations of NIST Research}

An extensive review of the available literature indicated that precision identification and control of flexible structures is predicated upon the ability to provide an "intelligent" forcing function with as short a pulse width resolution as possible and in which amplitude control is feasible. Several sources indicated that active control may be desirable to frequencies of $1000 \mathrm{~Hz}$. This implies the generation of a minimum pulse width of less than .001 seconds and yet of sufficient amplitude so as to be useful for control of real life engineering structures.

Accordingly, the following objectives were identified at the inception of the NIST project to develop a prototype HSILS:

a) to provide a thruster-type loading system which is capable of achieving "intelligence" in a force-time pulse of short duration (i.e. a high speed intelligent loading system).

b) to provide a high speed intelligent loading system for which the amplitude of the force-time pulse is capable of being varied over a wide spectrum of force levels in a continuous manner. 
c) to provide a high speed intelligent loading system which has the capability of applying an arbitrary force-time pulse to a structure without the need of a reaction surface nor any support infrastructure.

d) to provide a highly responsive, programmable high speed loading system which is controlled locally by an embedded microcontroller with onboard memory and is capable of being operated in either open or closed-loop control, without and with force and/or acceleration feedback, respectively.

e) to provide a highly responsive, programmable cold gas reaction control thruster which may be used for precision control of spacecraft and orbiting structures.

The degree to which each of the above objectives was met is discussed in Chapter 4. Although the electronics control system described in this report is capable of synthesizing any voltage-time history (and thereby causing the HSILS output thrust to track accordingly), the initial laboratory data reflect experimental behavior of the HSILS device when driven by half square wave voltage-time histories of varying pulse width and amplitude. 


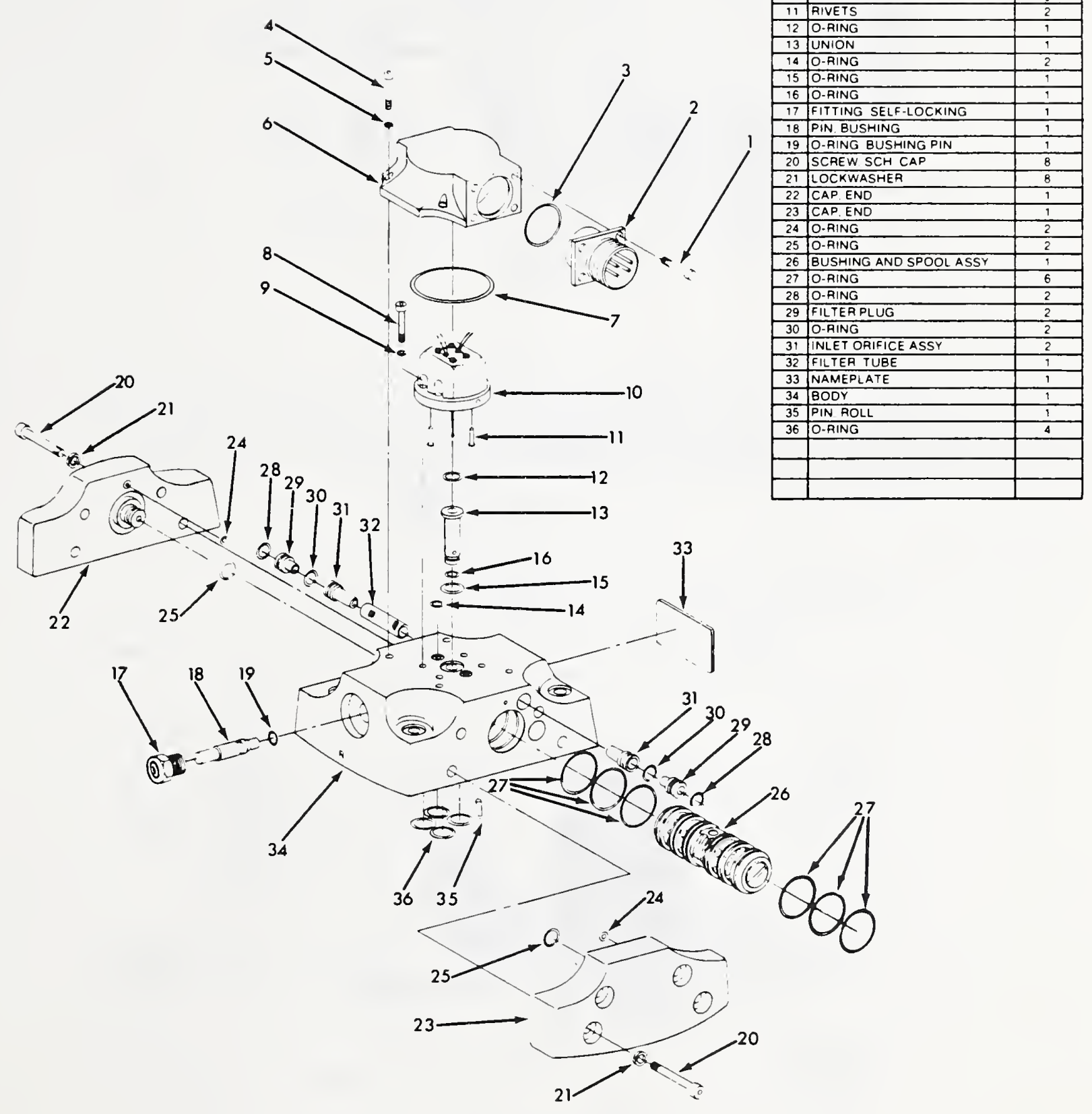

Fig. 1.1: Typical electrohydraulic servovalve and its components. 


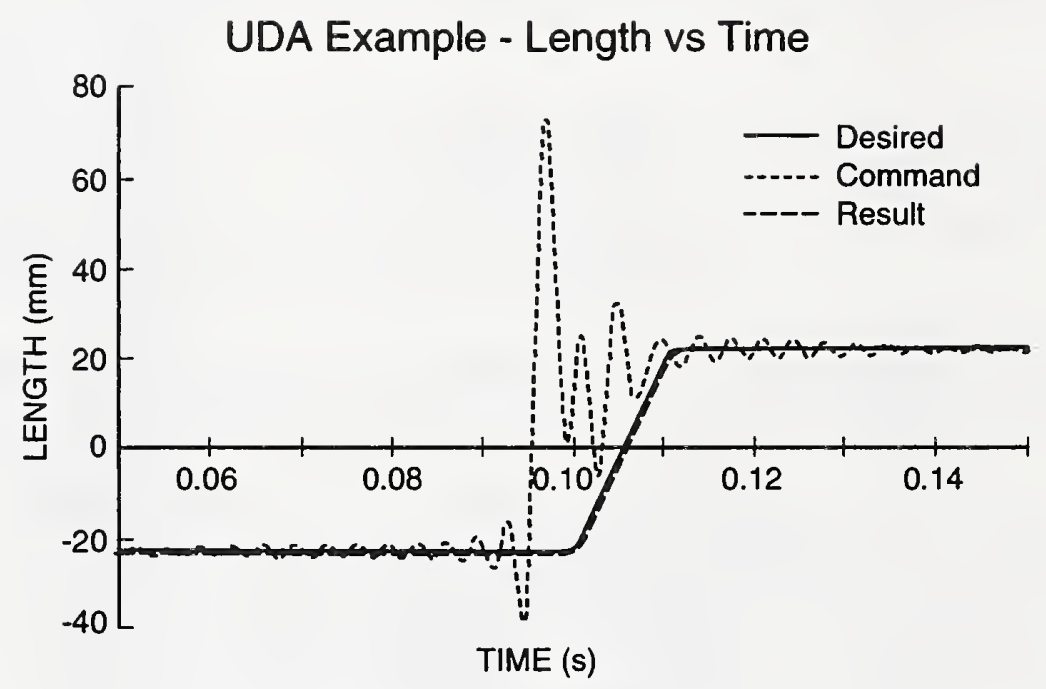

Fig. 1.2: Limiting electrohydraulic (servohydraulic) performance characteristics.

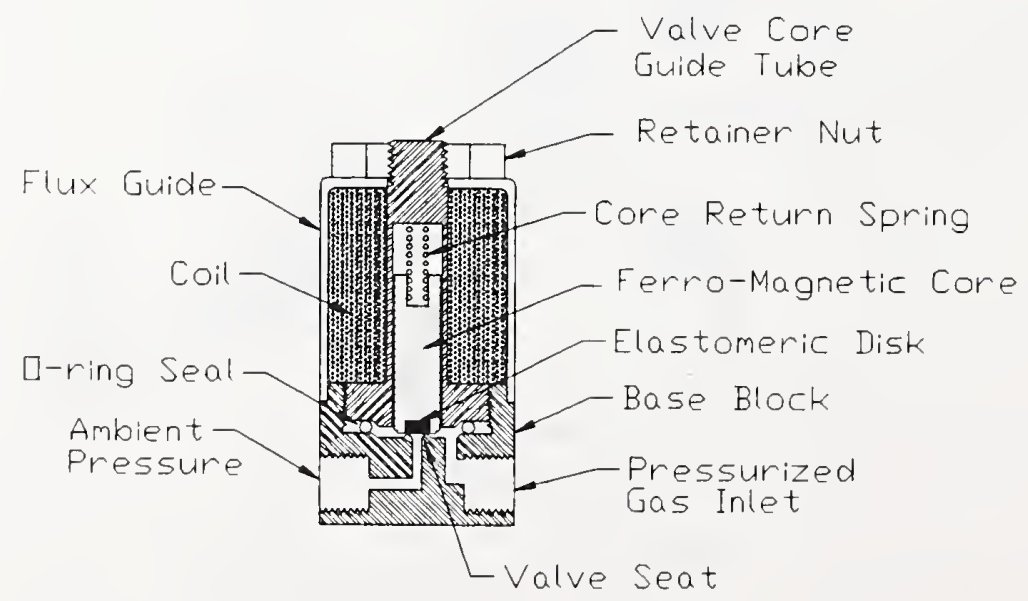

Fig. 1.3: Cross sectional view of typical pneumatic solenoid valve. 


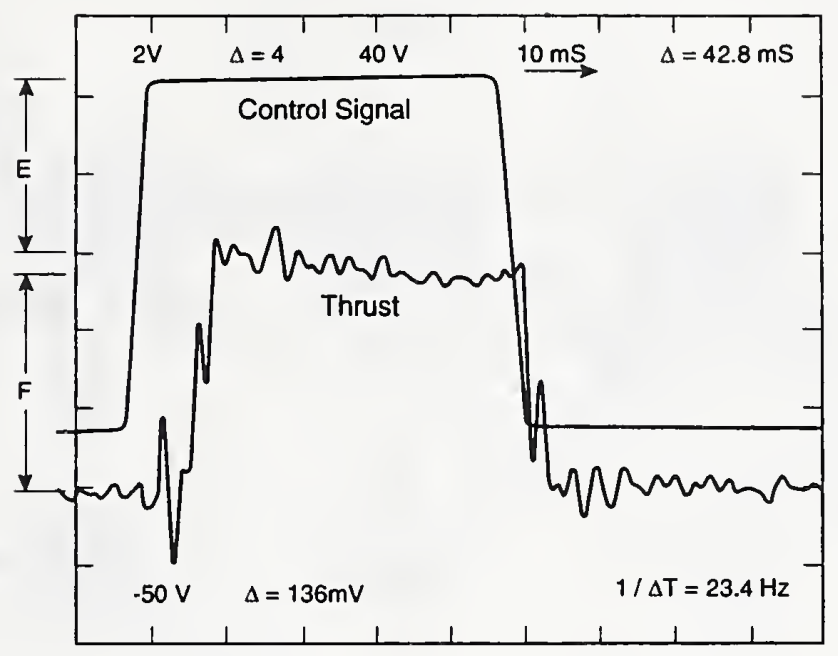

Fig. 1.4: Typical calibration data for air-jet thruster magnitude and time delays reported by Hallauer and Smith. The input voltage was a $10-\mathrm{Hz}, 20-\mathrm{mV}$ peak sine wave.

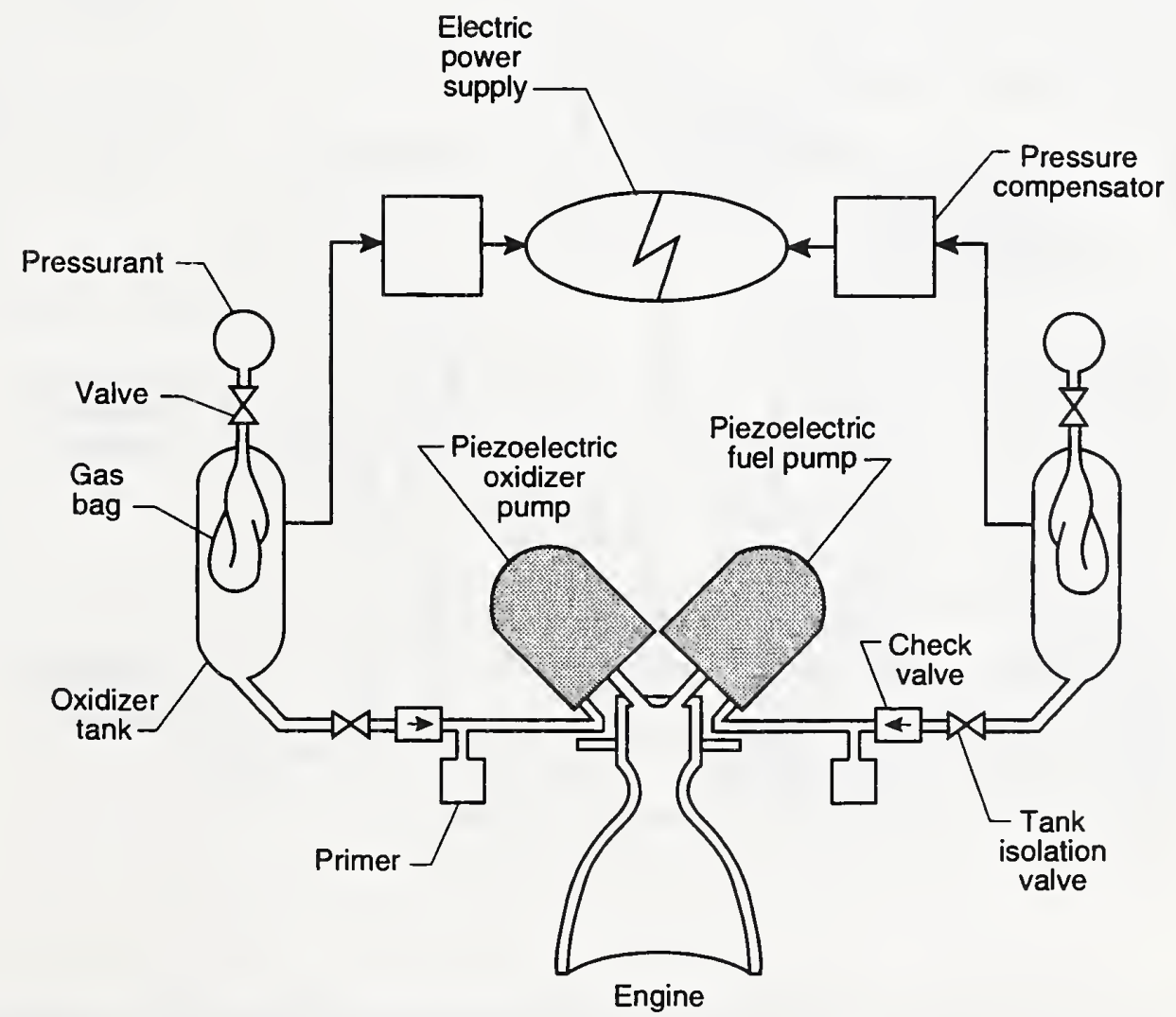

Fig. 1.5: Piezoelectric vernier thruster system developed by Katchee. 


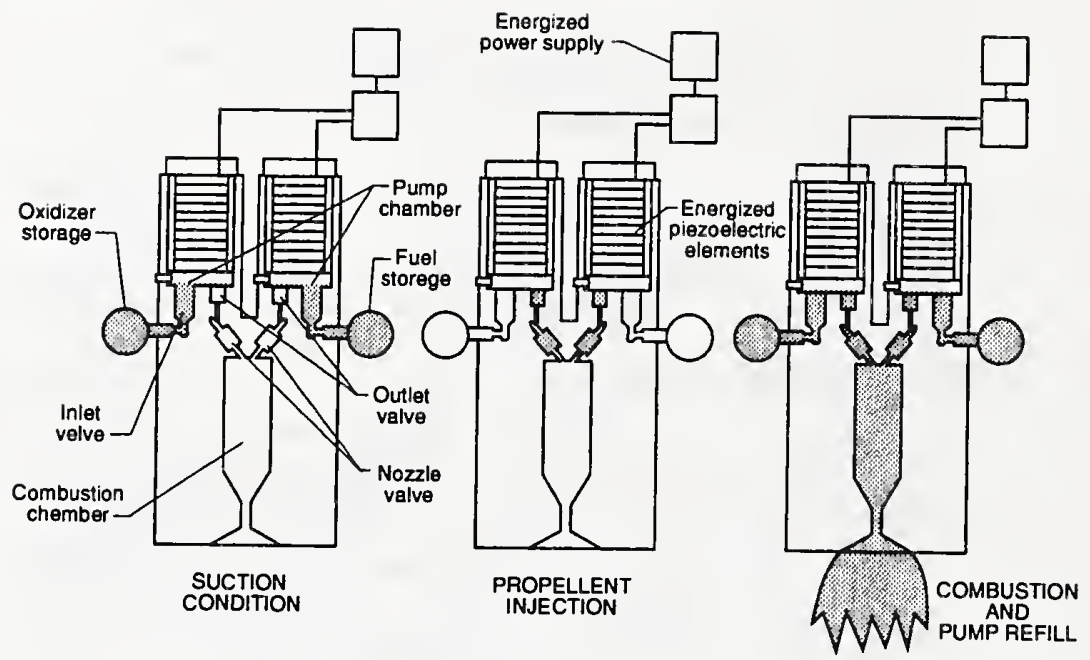

Fig. 1.6: Injector operating sequence used for piezoelectric vernier thruster system.

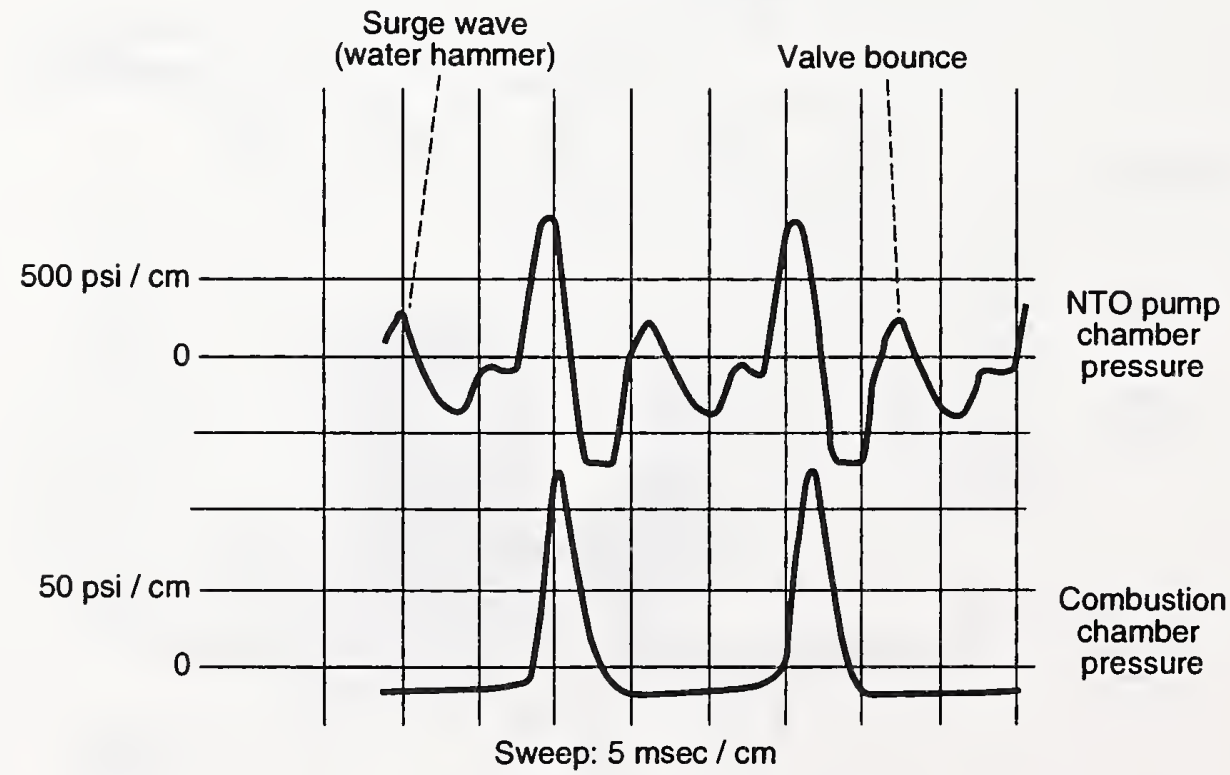

Fig. 1.7: Sample pressure traces from tests performed by Katchee on a piezoelectric vernier thruster system. 
Component Designations:
1) Valve body
2) Nozzle body
3) Nozzle member
4) Storage space
5) Valve seat
6) Valve stem
7) Closing piece
8) Connecting pipe section
9) Membrane
10) Drive space
11) Drive body
12) First thermally and electrically insulating body.

13) Second thermally and electrically insulating body.

14) Elastic element

15) Adjustment device

16) Casing

17) Flange connection

18) Pump nozzle

19) Bore

19a) Bore

20) Piezoelectric drive

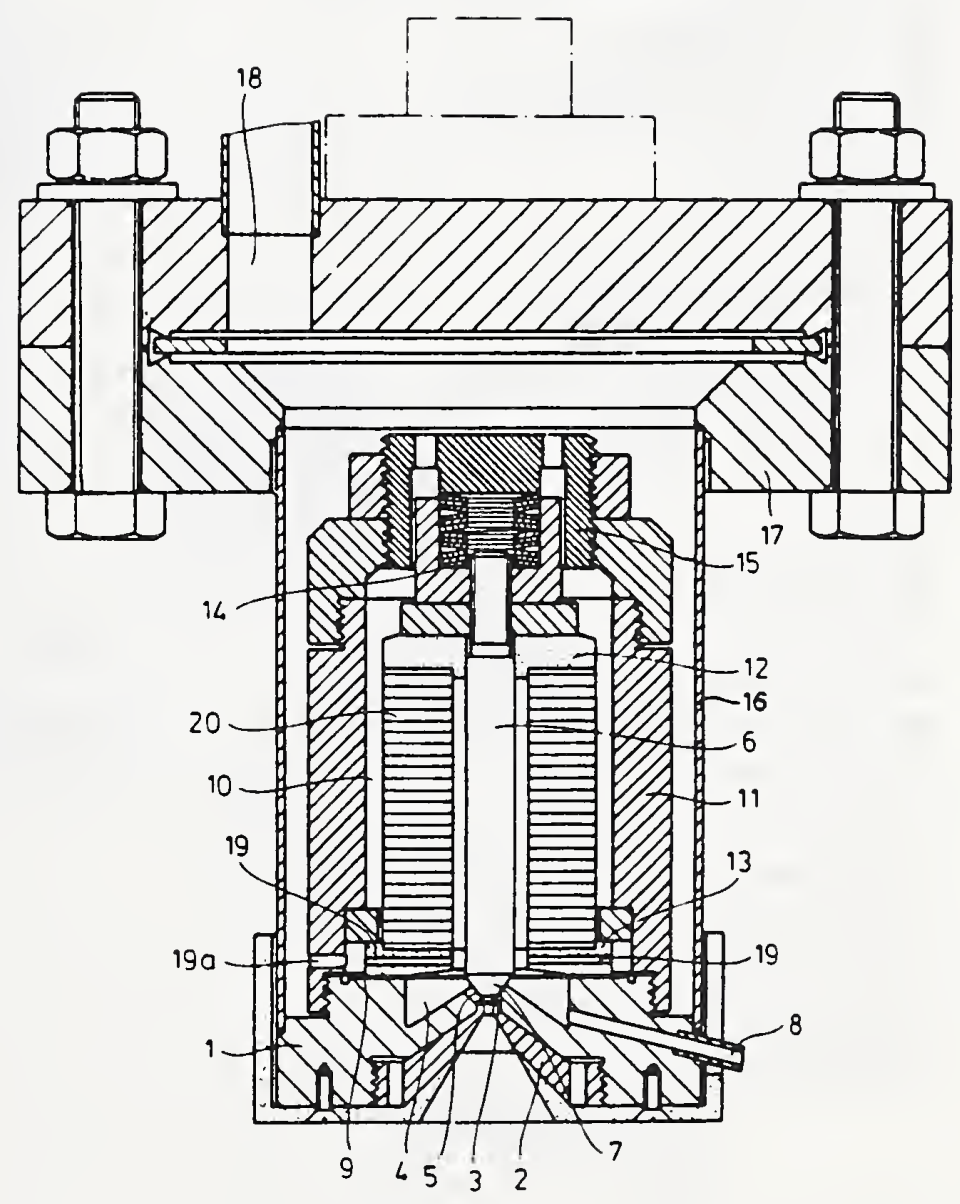

Fig. 1.8: Piezoelectric pulse valve developed by Weber et.al. for injection of trace elements into atomic beam spectrophotometers. 
Component Designations:

11) electrostrictive valve

12) hollow cylindrical body

13) external threads

14) orifice

16) outer cavity

17) metal seat

18) apertured adjusting nut

19) axial threaded nut

21) cylindrical stem

22) convex surface

23) internal screw threads

24) seal nut

26) radial tap

27) radially extending guide screw

28) spacer

29) longitudinal slot

31) circumferential groove

32) o-ring

33) enclosure

34) port

36) piezoelectric disks

37) thin copper disks

38) circular metal top plate

39) circular metal bottom plate

41) connecting tab

42) wire

43) insulated wire

44) passage

45) ground wire

46) registering passage

47) step washer

48) washer

49) washer

51) circular plug

52) metal tip

53) annular spring washer

54) flange

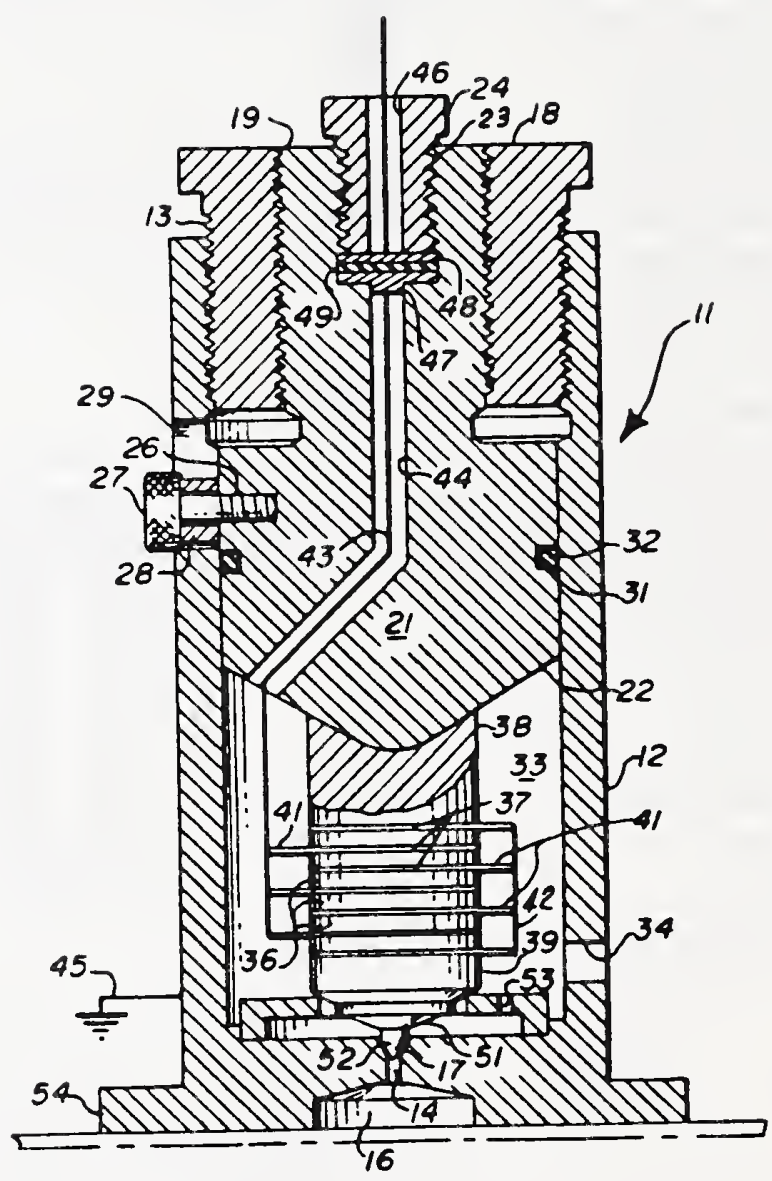

Fig. 1.9: Piezoelectric pulse valve from Kippenham for injection of deuterium gas into plasma field. 
Component Designations:

104) transducer

104a) transducer flange

105) electrostrictive detection device

106) horn

106a) injection path

106b) ball valve seat

106c) dispersion cup

107) electrostrictive device

107') electrostrictive elements

108) padding

109) nut

110) positive electrode

111) negative electrode

112) monitor electrode

121) lead wire for 110)

122) lead wire for 111)

125) lead wire for 112)

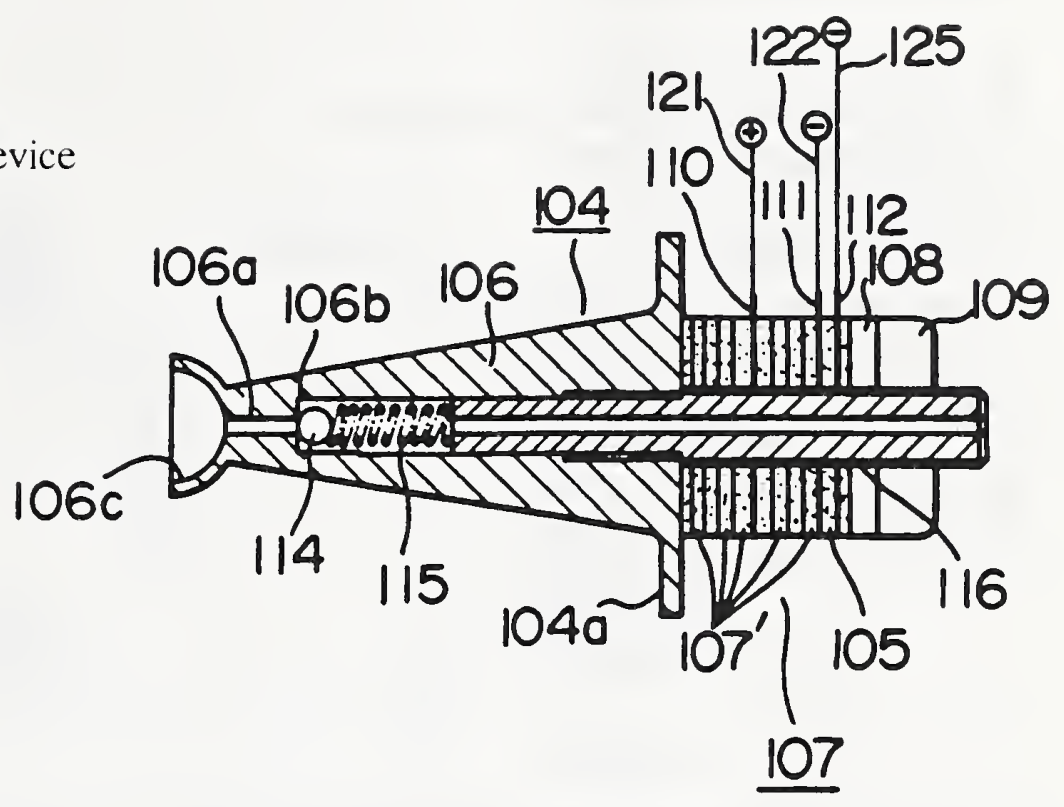

Fig. 1.10: Piezoelectric fuel injection valve from Yamauchi et.al.

Component Designations:

1) piezoelectric device

2) piezoelectric stack elements

3) mounting

4) housing

5) operating pin

6) operating lever

7) pivot

8) carrier

9) engine block

10) lever arm connection

11) actuating rod

12) valve

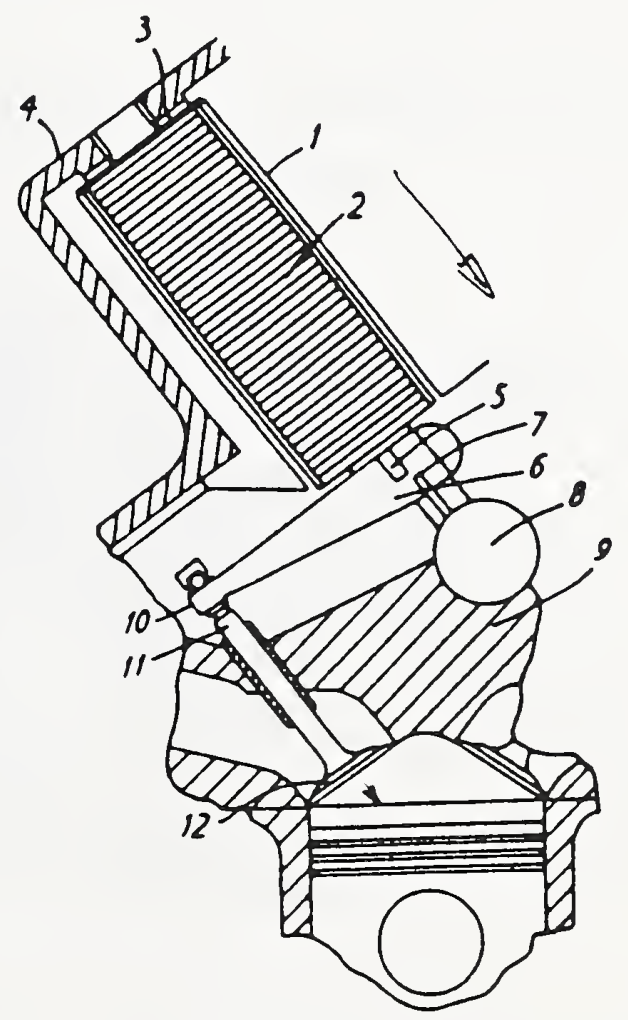

Fig. 1.11: Piezoelectric valve operating mechanism for internal combustion engines from Moloney. 
Component Designations:

10) flexure arm/support

11) bottom surface of actuator support

12) piezoelectric stack $\# 1$

13) piezoelectric stack \#2

14) hinge support

16) top surface of actuator support

17) milled hinge

18) pin

20) actuator element

22) support frame

23) milled hinges

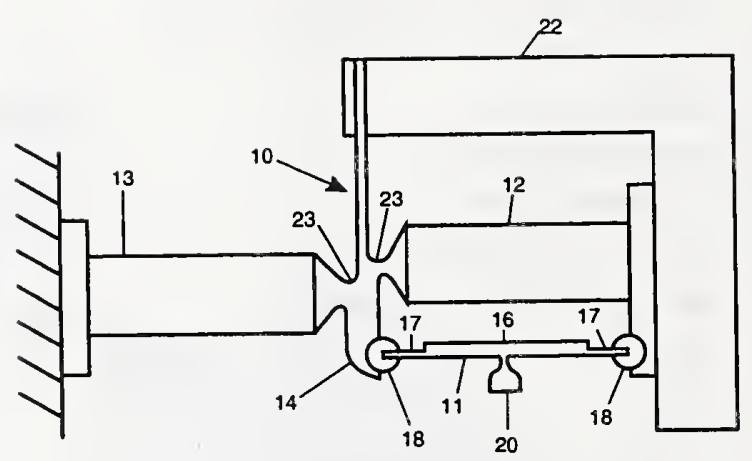

Fig. 1.12: Operating mechanism for high speed reciprocating machine parts (printers) from Knappe.

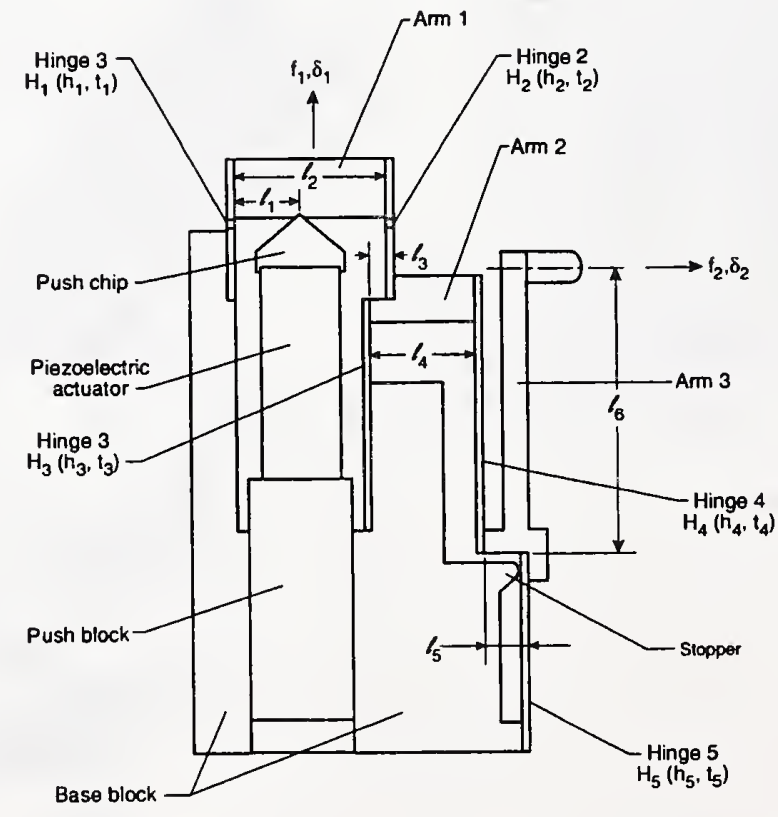

Fig. 1.13: Piezoelectric mechanical displacement amplifier used in the development of a piezoelectric relay from Mitsuhashi et.al. 


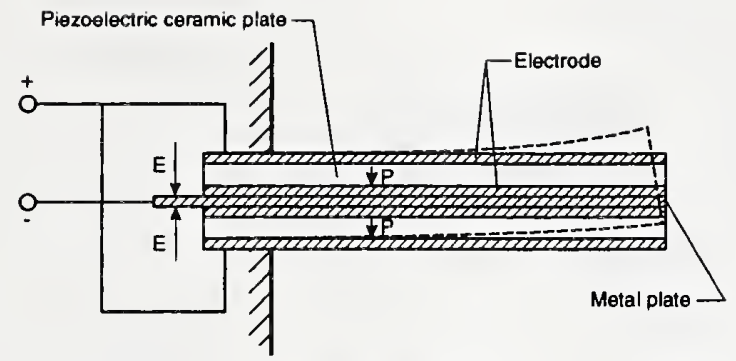

a) Parallel bimorph type

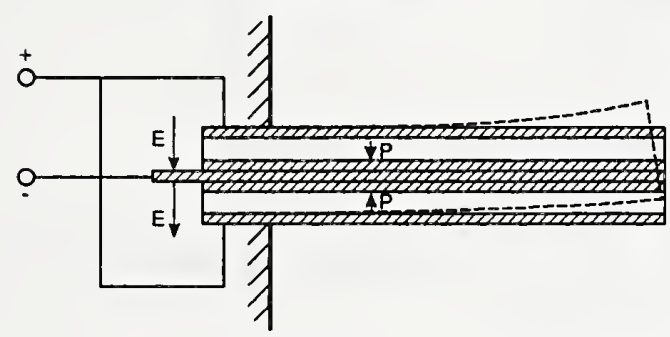

b) Series bimorph type

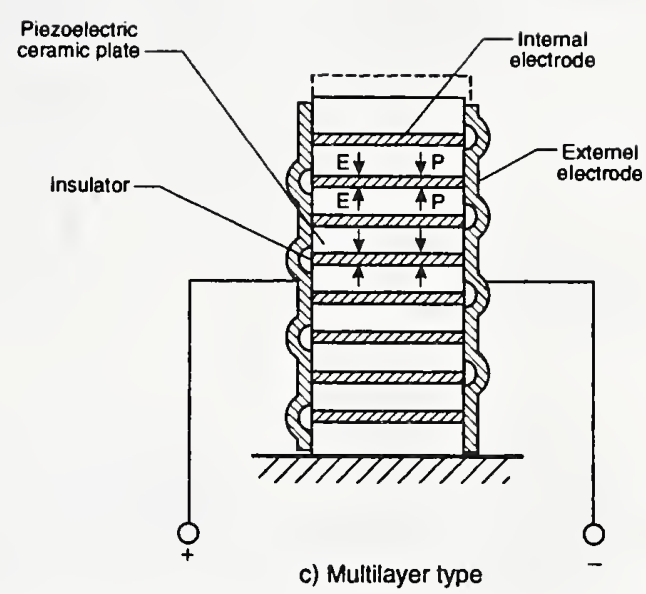

c) Multilayer type

Fig. 1.14: Principle piezoelectric actuator architectures (from Mitsuhashi, et.al.)

\begin{tabular}{|c|c|c|c|c|c|}
\hline hem & $\begin{array}{c}\text { Pushdown } \\
\text { type }\end{array}$ & $\begin{array}{c}\text { One-stege } \\
\text { lever type }\end{array}$ & $\begin{array}{c}\text { Two-stege } \\
\text { lever type }\end{array}$ & Compound type & $\begin{array}{c}\text { Spring deflection } \\
\text { type }\end{array}$ \\
\hline Shape & & Reletively simple & Complex & Complex & Reletively simple \\
\hline Structure & Simple & Good & Reletively good & Poor & Reletively good \\
\hline $\begin{array}{c}\text { Manufectur- } \\
\text { ebility }\end{array}$ & Good & $30-40$ & $50 \cdot 70$ & $50 \cdot 70$ & 30 - 50 \\
\hline $\begin{array}{c}\text { Mafnitying } \\
\text { factor (fimes) }\end{array}$ & $20-30$ & & & \\
\hline
\end{tabular}

Fig. 1.15: Characteristics of several piezoelectric displacement amplification mechanisms (from Mitsuhashi et.al.) 


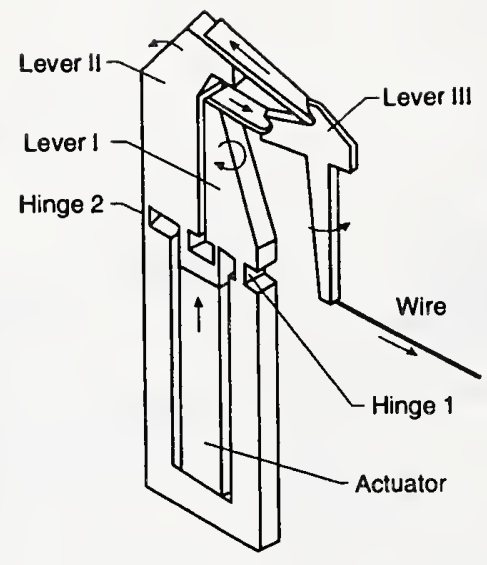

Fig. 1.16: Piezoelectric stack operated impact matric printer head element employing a differential two stage hinge-lever (from Takahashi).

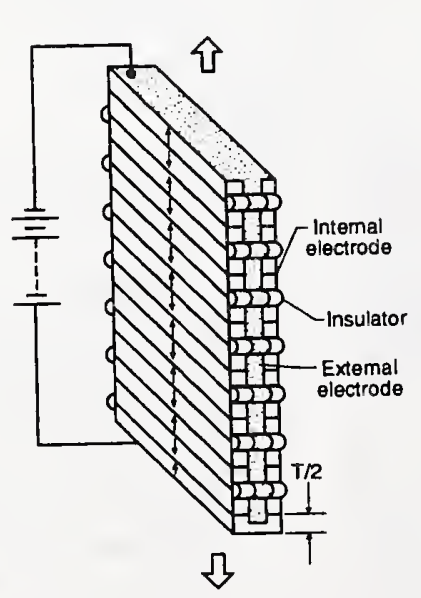

(a) Multilayer structure

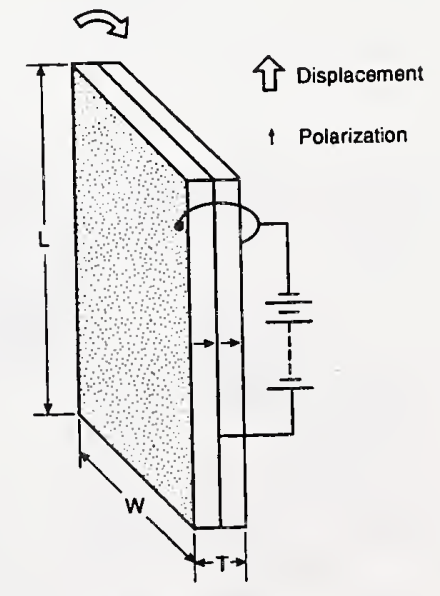

(b) Bimorph structure

Fig. 1.17: Architecture of piezoelectric stack and bimorph elements (from Takiahashi). 


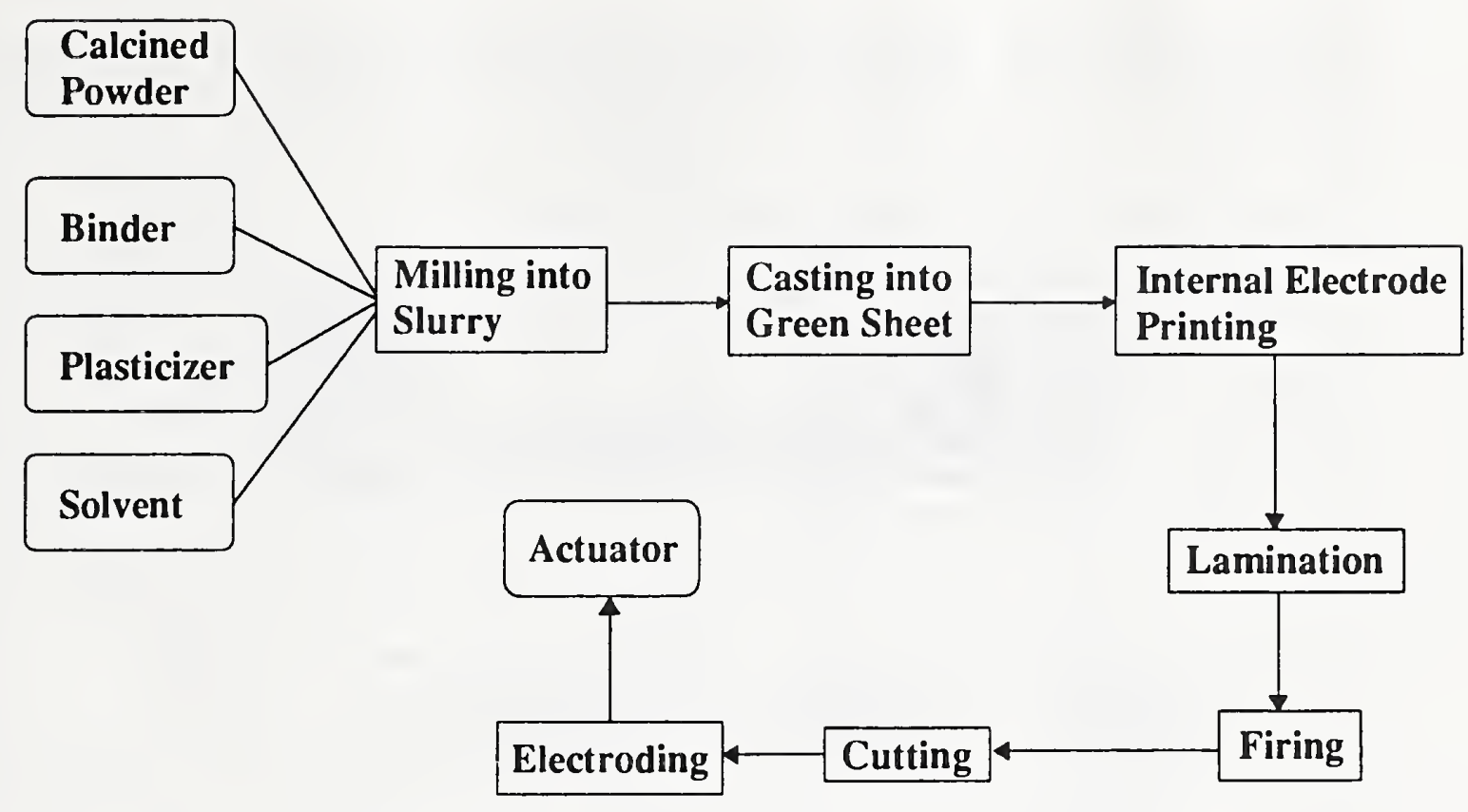

Fig. 1.18: Process flow chart for multilayer piezoelectric ceramic actuators made by the tape-casting method (from Takahashi).

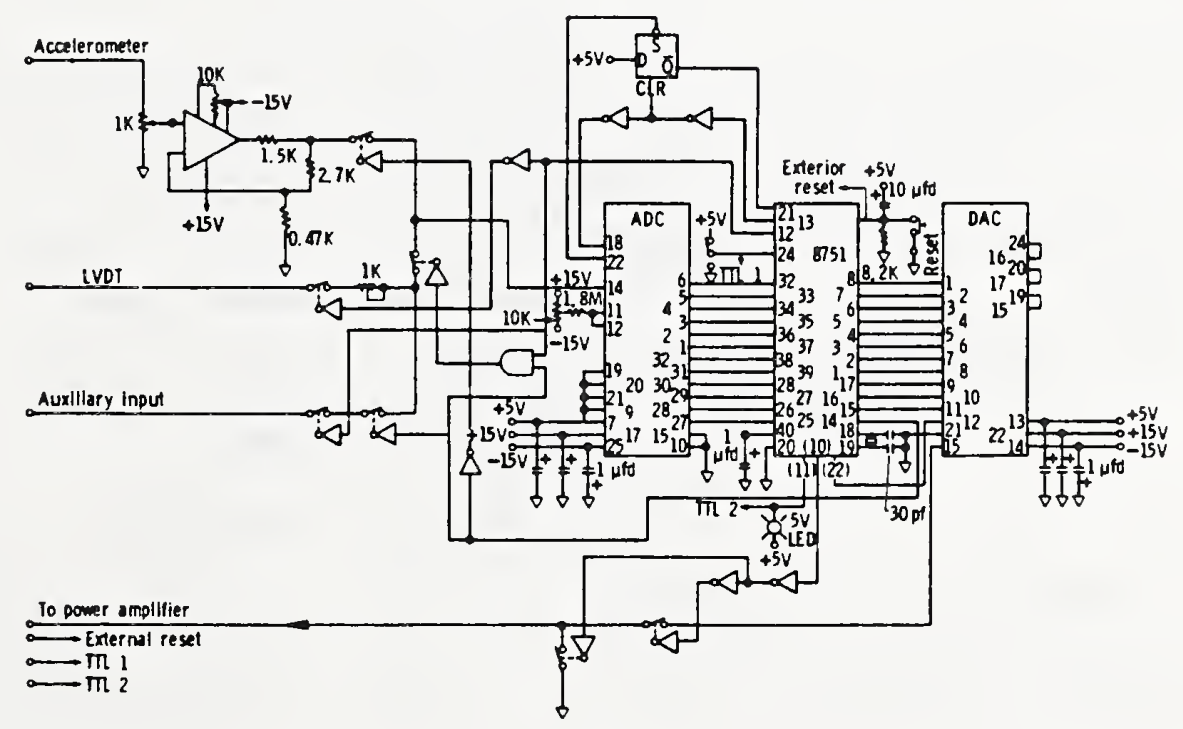

Fig. 1.19 Circuitry schematic of the digital onboard controller developed by Zimmerman et.al. for a harmonic proof-mass actuator. 

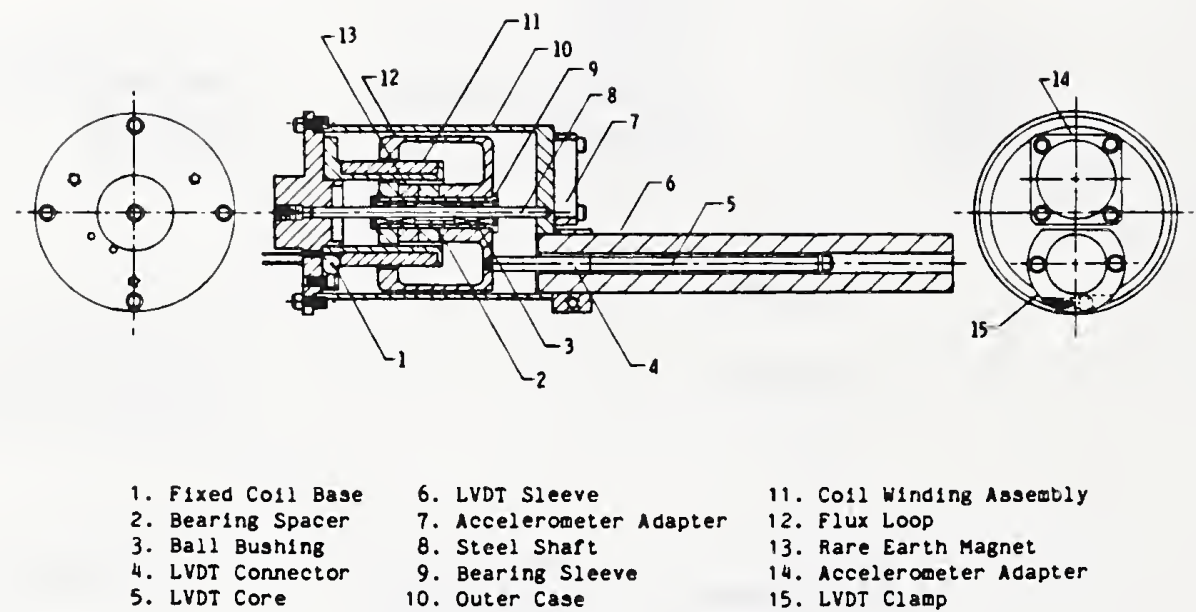

6. LVDT Sleeve

7. Accelerometer Adapter

8. Steel Shart

11. Cosl winding Assembly

Bearing Spac

4. LVDT Connector

9. Bearing Sleeve

10. Outer Case

12. Flux Loop

13. Rare Earth Magnet

14. Accelerometer Adapter

15. LVDT Clamp

Fig. 1.20: Schematic and major parts list for Zimmerman's proof-mass actuator.

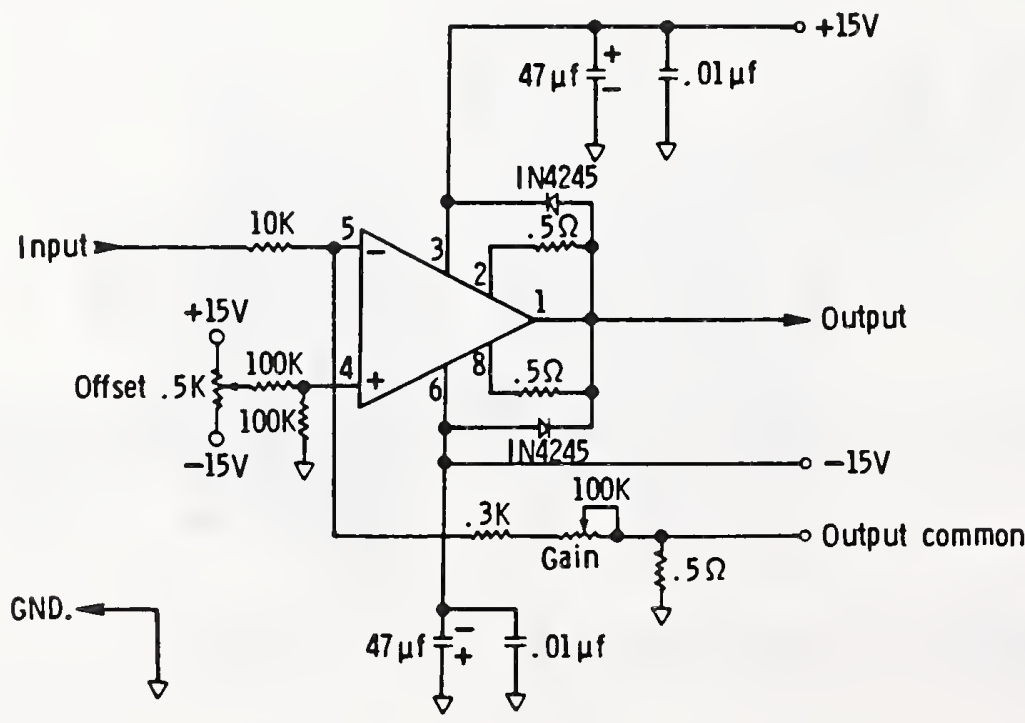

Fig. 1.21: Circuit schematic for Zimmerman's power amplifier used to drive the proof-mass actuator. 


\begin{tabular}{|c|c|c|c|}
\hline \multicolumn{2}{|c|}{ Category } & Bimorph Element & Multilayer (Stack) Element \\
\hline \multicolumn{2}{|c|}{ Displacement Mode } & Unstiffened strain & Stiffened strain \\
\hline \multicolumn{2}{|c|}{$\begin{array}{l}\text { External Dimensions } \\
(\mathrm{LxW} \mathrm{WH}), \mathrm{mm} .\end{array}$} & $\begin{array}{l}25 \times 10 \times 0.17 \\
\text { (two layers) }\end{array}$ & $3 \times 2 \times 9$ \\
\hline \multicolumn{2}{|c|}{ Thickness of lamination } & 170 um & $60 \mathrm{um}$ \\
\hline \multicolumn{2}{|c|}{ Number of laminations } & 2 & 128 \\
\hline \multicolumn{2}{|c|}{ Capacitance } & $140 \mathrm{nF}$ & $580 \mathrm{nF}$ \\
\hline \multicolumn{2}{|c|}{ Volume } & $85 \mathrm{~mm}^{3}$ & $54 \mathrm{~mm}^{3}$ \\
\hline $\begin{array}{c}\text { Output } \\
\text { (at } 60 \\
\text { vdc) }\end{array}$ & $\begin{array}{c}\text { Displacement: } \\
\text { Force: } \\
\text { Energy: }\end{array}$ & $\begin{array}{c}280 \mathrm{um} \\
18 \mathrm{~g} \\
250 \mathrm{erg} \\
\end{array}$ & $\begin{array}{l}7.8 \mathrm{um} \\
21,000 \mathrm{~g} \\
8,000 \mathrm{erg} \\
\end{array}$ \\
\hline \multicolumn{2}{|c|}{ Allowable Electric Field } & $400 \mathrm{~V} / \mathrm{mm}$ & $>2000 \mathrm{~V} / \mathrm{mm}$ \\
\hline \multicolumn{2}{|c|}{ Polarity } & yes & none \\
\hline \multicolumn{2}{|c|}{ Creep $(96 \mathrm{H})$} & $>30 \%$ & $<5 \%$ \\
\hline \multicolumn{2}{|c|}{ Shift Displacement $(96 \mathrm{H})$} & $>30 \%$ & $<2 \%$ \\
\hline
\end{tabular}

Table 1.2: Calculated actuator characteristics for a multilayer piezoelectric ceramic stack actuator and a bimorph actuator (from Takahashi).

\begin{tabular}{||l|l|l|l|l|l|l||}
\hline Structure & $\begin{array}{l}\text { Electr. } \\
\text { Energy } \\
\text { (UE) } \\
{\left[\mathrm{x} 10^{-8} \mathrm{~J}\right]}\end{array}$ & $\begin{array}{l}\text { Stored } \\
\text { Mech. } \\
\text { Energy } \\
\text { (UM) } \\
\text { [x10-8] }]\end{array}$ & $\begin{array}{l}\text { Electro- } \\
\text { mech. } \\
\text { coupling } \\
\text { factor } \\
\text { (UM/UE) } \\
\%\end{array}$ & $\begin{array}{l}\text { Induced } \\
\text { Displ. } \\
\text { (um) }\end{array}$ & $\begin{array}{l}\text { Clamping } \\
\text { Force } \\
\text { (newtons) }\end{array}$ & $\begin{array}{l}\text { Resonant } \\
\text { Freq. } \\
(\mathrm{kHz})\end{array}$ \\
\hline Stack & 1927 & 891 & 46 & 5 & 35 & 89 \\
\hline Bimorph & 1927 & 125 & 6.5 & 138 & 0.18 & 0.59 \\
\hline
\end{tabular}





\subsection{Design of a High Speed Intelligent Loading System (HSILS)}

\subsection{Concept Development}

At the inception of the HSILS project the question was posed as to whether a forcing function (thrust-time history) could be achieved which approximated an inverse Gaussian pulse, particularly one of very short duration. An example of such a pulse is shown in Fig. 2.1 along with its governing equation. The rate at which the pulse decays from its maxima, $\mathrm{F}_{\max }$, is determined by the shape coefficient, $\sigma$. None of the devices described in Chapter 1 , in their present state, is capable of reproducing the force-time history described in Fig. 2.1. If a reaction control system is to reproduce a pulse similar to that shown in Fig. 2.1, it must be capable of tracking rapid, pre-programmed or real-time generated command amplitude signals. Such a capability requires local computer control (or "intelligence") at the actuator in addition to a fast-reponse electro-mechanical thrust activation system capable of achieving amplitude control and making amplitude changes very rapidly.

At issue are several performance factors which are defined graphically in Fig. 2.2. These factors define the various command and response terms associated with a reaction control system in which a half square wave command pulse is issued. There is usually a lag time associated with both the rising and falling edges of the thrust pulse, relative to the rising and falling edges of the command signal. In a real reaction control system (as would be recorded by onboard accelerometers or force sensors) there will also generally be some "ringing" oscillations associated with the rising and falling edges of the thrust pulse as well as superimposed noise.

The rise lag ( $R L$ in Fig. 2.2) is defined as the elapsed time from the leading edge of the drive (or control) pulse to the initiation of measurable thrust. This is a measure of the electromechanical efficiency of the actuator. Rise lag time is associated with mechanical response times of, for example, electrostrictive elements (piezoelectric stacks); wave propagation through connecting elements of a displacement amplifier; the presence of various sources of friction and viscous damping; and reaction times for fuel constituents (if a bi-propellant is used instead of a compressed gas).

The response pulse width (RPW) is defined as the base-to-base time of the response thrust profile, which equals the elapsed time from thrust initiation to thrust termination for an actuator responding to the minimum amplitude half square wave command signal required to initiate measurable thrust. The RPW is a useful measure of the absolute shortest impulse that can be produced by a reaction control system.

If one views rise lag as electromechanical propagation delay, then one might expect the response pulse to terminate at a time interval equal to DPW (the drive pulse width) following initiation of measurable thrust from the actuator. In actual fact this proves not to be the case. The difference in elapsed time from initiation of measurable thrust to the point at which thrust commences a marked decrease minus the DPW constitutes the parameter known as fall lag. For inductive type systems (e.g. solenoid coils) this results from delays in 
the collapse of the magnetic field. It can also result from mechanical delays caused by having to overcome static friction in seals.

A final performance parameter is the amplitude control rate (ACR), which is a measure of the maximum thrust slew rate (or rate of thrust rise per unit time) to a unit change in command signal. Typically this would have units of N/s and could be estimated by dividing the peak thrust by the rise time (RT, in Fig. 2.2). In the case of a solenoid operated thruster, as described in Chapter 1, there are only two states that can be achieved: full-off or full-on, and thus the ACR rating is somewhat inappropriate. One could construct an array of axially aligned thrusters of this type and drive them in parallel through the output pins on a microcontroller such that each thruster could be discretely turned either on or off. In this manner, crude amplitude control could be achieved, and the ACR would simply be the unit thrust change divided by the rise time to reach that thrust level. This equivalent ACR will be used later in Chapter 4 to compare performance of solenoid and HSILS actuators.

\subsubsection{HSILS Overview}

Briefly, the NIST HSILS loading system incorporates a very high speed, electronically controllable valve system which is capable of continuously metering the flow of pressurized gas and/or pressurized propellants through an expansion nozzle to create thrust. The device may be envisioned in a simplified way as shown in Fig. 2.3, in which a valve core element seats directly against the throat of the expansion nozzle. Axial (vertical) displacement of the valve core, under the command of an embedded microcontroller, causes a gap to form which permits mass flow from the pressurized fuel container to the expansion nozzle. As long as the annular area determined by the gap between the valve core and the valve seat remains less than the nozzle throat area linear thrust control is possible. Maximum thrust is thus determined by the nozzle throat diameter.

Where the expansion of pressurized gas or of a monopropellant is the thrust-producing factor the high pressure valve seat is integral with the throat of the expansion nozzle (as shown in Fig. 2.4). If the combustion of hypergolic bipropellants is the thrust-producing factor the valve seat communicates with an injector tube. The injector tube communicates with a combustion chamber and is designed such that the separate flows of the two propellants impinge upon on another inside the combustion chamber in such a manner as to promote complete and uniform burning prior to expansion of the reactants through the exhaust nozzle.

The heart of the high speed valve is a monolithic (or "co-fired") piezoelectric (or electrostrictive) stack. A custom stack measuring $76 \mathrm{~mm}$ long by $9.5 \mathrm{~mm}$ square was produced specially for the project by Piezo Systems of Cambridge Massachusetts. This stack was capable of producing $0.2 \%$ strain when subjected to an electric potential of approximately $300 \mathrm{vdc}$ (Volts, direct current). This strain is essentially fully developed within 10 microseconds of the application of a step change in voltage to the stack and therefore allows for extremely rapid displacement control, provided an appropriate voltage-time history can be applied to the stack. Electrostrictive characteristics, including blocked force response, 
of this piezoelectric stack are presented in Fig. 2.5. A blocked force response chart shows the relationship between the maximum force level capable of being developed by the piezoelectric element between a pair of rigid reaction surfaces at a specified level of total expansion when the element is driven at a constant voltage. There exists a family of blocked force curves for any piezoelectric element with one curve for each unique drive voltage. The relationship between force and displacement at any given drive voltage is typically linear. However, the force (y-axis) intercept may not be linearly related to the drive voltage, hence (e.g. Fig. 2.5) two separate equations of state are required to characterize the stack.

The performance characteristics described above and in Fig. 2.5 can be considered representative of the best available today for commercial grade piezoelectric materials. However, even with a relatively long, hybrid stack $0.2 \%$ strain is insufficient for operation of an effective rocket engine feed line valve. To be practicable, a strain of approximately $1-2 \%$ would be required for direct axial operation of a thruster capable of producing a force amplitude sufficient for active control purposes.

Accordingly, the device employs a specially designed mechanical displacement amplifier which produces as its output a displacement which is opposite in direction to the expansion (or contraction) of the piezoelectric stack and larger than the absolute magnitude of the piezoelectric stack displacement. The amplifier consists of a stiff eccentric anvil (see Fig. 2.6) which is monolithically milled from the same base block, and is integral with, a support means. The anvil is connected to the support means by a finely milled hinge (see Appendix E, Fig. E.10) that is integral to both the anvil and the support means and comprises a structural element that provides negligible resistance to rotation about an axis perpendicular to the plane of the anvil. The hinge is also designed to provide stiff resistance to displacements and rotations perpendicular to its rotational axis. The anvil is designed to provide, as nearly as practicable, a rigid lever, the fulcrum of which is provided by the hinge.

The piezoelectric stack is provided with special low friction, high strength bearings at both ends which insure axial transmission of force as the stack expands under increasing voltage. One such bearing forms an interface with an adjustable, threaded nut which serves as a moveable reaction surface within a housing. The bearing means at the output end of the piezoelectric stack forms an interface with the short side of the lever/anvil of the displacement amplifier.

The output of the displacement amplifier is connected to a valve core by a similar low friction, high strength bearing such that as the piezoelectric stack expands under increasing applied voltage the valve core lifts off its corresponding valve seat and permits high pressure gas and/or propellant to flow. In order to achieve continuous control, however, the valve core must be capable of being returned to the closed position under positive control. This is achieved by use of a suitable adjustable force compression spring means which maintains the valve in a normally closed position. The spring force is designed to insure that the closing acceleration of the valve core is capable of matching the un-amplified contraction acceleration of the piezoelectric stack in such a manner as to maintain all of the bearing in a state of compression. 
The valve core is constrained to move in a linear fashion by various guides and seals which additionally serve to prevent buckling of the rod during the application of compressive loads and to damp out unwanted vibrations. The valve seal is achieved by means of a metal-tometal contact between the end of the valve core, which is tapered at an angle (typically $59^{\circ}$ inclusive), and which mates to the valve seat which is also tapered but with an angle (typically $60^{\circ}$ inclusive) that is slightly larger than that for the valve core (see Fig. 2.4).

In one form of the device, in which a cold gas thruster is to be provided, said valve seat is integral with the throat of an expansion nozzle. A chamber on the interior side of the valve seat is in communication with a high pressure reservoir of gas (e.g. nitrogen). The expansion of this gas through the nozzle as the valve core is raised from and lowered to the closed position creates thrust which is directly proportional to the displacement of the valve core, and therefore directly proportional to the control signal (voltage-time history) used to drive the piezoelectric stack. The actual response "speed" (delay time) between a step change in control voltage to the piezoelectric stack and the corresponding change in thrust level at the nozzle is determined by the response time of the piezoelectric stack and the propagation speed of the resulting stress wave to the valve tip. This response speed can be shown through structural dynamics calculations to be substantially better than for any of the aforementioned alternative loading systems.

In a second form of the device, in which a bi-propellant, pressure fed thruster is to be provided, the valve seats are located at one end of propellent delivery tubes which are in communication with injection ports within a combustion chamber. A chamber on the interior side of one valve seat is in communication with a reservoir of propellent (e.g. monomethyl hydrazine), while a chamber on the interior side of the second valve seat is in communication with a reservoir of oxidizer (e.g. nitrogen tetroxide). Both propellent and oxidizer reservoirs are pressurized by means of expansive bladders which are in communication with respective high pressure inert gas supplies. These expand the bladders as fuel and oxidizer are used, and thus permit fuel to be delivered independently of attitude. The expansion of the combustion product gases through the nozzle, which occurs when the valve cores are raised from and lowered to the closed position creates thrust which is directly proportional to the displacement of the valve core, and therefore directly proportional to the control signal (voltage-time history) used to drive the piezoelectric stack.

In this report, a prototype cold gas thruster version of HSILS was built and tested using compressed nitrogen as the "fuel".

\subsection{Hardware and Software Design}

\subsubsection{HSILS Mechanical Description (Operation)}

Because of the mechanical complexity of the HSILS, and because of the density of components contained in the figures associated with the following text, numbered callouts have been used to designate particular parts rather than actual text labels. 
Referring to Fig. 2.7, a housing, 24, is provided as a means for anchoring the device to the structure to be controlled or tested, and for providing internal reaction points for its moving parts. Housing 24 is machined from a solid block of a high strength, lightweight engineering material (such as aluminum alloy) or otherwise fabricated by such processes as centrifugal casting, injection molding or the like, as a monolithic unit containing the functional cavities which will be explained in detail below.

Mechanical action within housing 24 is initiated by sending a direct current voltage signal via electrical connectors 80 and 81 to piezoelectric stack 1 which resides inside cavity 34 and which is axially oriented within and parallel to cavity 34 . Integral bearing supports 2 and 82 are affixed permanently to both ends of the piezoelectric stack. These consist of machined blocks of a high strength material such as hardcoated aluminum alloy and contain a machined, tapered circular bearing hole to which are affixed spherical bearings 3 and 83 . Bearings 3 and 83 should be made of a tough, lightweight material with low friction characteristics such as a ruby-sapphire sphere. These spherical bearings are used to insure that all load is transmitted axially through the piezoelectric stack to the anvil-lever 4 and to allow for rotation of the anvil-lever 4 about its hinge 5 without the consequent development of significant resistance to such motion at bearing 3 .

The top bearing of the piezoelectric stack mates with a similar tapered circular bearing hole 90 in the base of a threaded nut 8 fabricated from a high strength material such as hardcoated aluminum alloy. The bottom bearing of the piezoelectric stack 3 mates with a similar tapered circular bearing hole 88 on the top surface of the short side of the anvil-lever 4 which comprises the moving part of displacement amplifier 6 . Threaded nut 8 is used to adjust the vertical position of the piezoelectric stack with respect to anvil-lever 4 so as to insure that it is in compression contact with anvil-lever 4 at all times during the operation of the device.

Displacement amplifier 6 is comprised of a stiff, anvil-shaped lever 4 , a hinge 5 and a support 6 which is also used to designate the overall amplifier. The amplifier 6 , for reasons which will be subsequently described in detail, is fabricated from a very high strength material having a low modulus of elasticity. The displacement amplifier 6 is bolted to housing 24 and rests within cavity 36 such that the plane which is perpendicular to the axis of rotation of and lies on the centerline through the thickness of the anvil-lever, also lies on the centerline through the thickness of housing 24. Furthermore, the bottom bearing 3 of the piezoelectric stack 1 , which contacts the short side of the anvil-lever 4 and the top bearing 83 of the piezoelectric stack are so positioned so as to orient the longitudinal axis of the piezoelectric stack in an initially perpendicular orientation with respect to the plane which comprises the top surface of anvil-lever 4.

A third spherical bearing 22 is provided at the end of the long side of anvil-lever 4 and is in compressive contact with a tapered circular bearing seat 87 which has been machined into the top face of an interior slot in core rod coupler 20, through which the long end of anvillever 4 passes. Core rod coupler 20 is fabricated from a high strength lightweight material such as hardcoated aluminum alloy and contains threaded holes 85 and 89 at its top and bottom to which are affixed guide rod 52 and valve core rod 19 . 
Valve core rod 19 is normally held in contact with valve seat 11 by means of compressive spring 23 which reacts against threaded rod 25 which is in turn screwed into a threaded borehole 35 on the centerline through the thickness of housing 24 . Threaded nut 25 is used to adjust the level of precompression exerted by the valve core rod 19 on valve seat 11 . Normally this level of precompression is that required to ensure that no leakage of high pressure gas and/or propellant occurs at the valve seat 11 . Guide rod 52 connects to threaded hole 85 on the top of core rod coupler 20 and passes through the center of compression spring 23 and into guide hole 84 , which is machined through the centerline of threaded nut 25. Guide hole 91 is machined from housing 24 and communicates with borehole 35 and pressure chamber 14. The purpose of guide holes 91 and 84 is to insure that only axial motion which is perpendicular to the plane of the top face of anvil-lever 4 is possible in the spring-loaded core rod assembly, which consists of guide rod 52, core rod coupler 20, and valve core rod 19.

Guide rod 52 and valve core rod 19 should be fabricated from a very high strength, high hardness material such as Vascomax 240 or similar high strength, hardened steel alloys.

In the embodiment of the device depicted in Fig. 2.7, where the latter is to be operated as a cold gas thruster, onboard high pressure gas reservoirs 10 are connected by high pressure fittings 29 and high pressure tubing 26 to form a single reservoir which is connected directly to pressure chamber 14 by means of fittings 33,15 , and high pressure tubing 13 . It is presumed that gas reservoirs 10 are charged prior to using the device by means of an external gas supply which is subsequently disconnected prior to use of the system, so that the device can be operated autonomously from any umbilicals.

Pressure chamber 14 is in communication with the high pressure gas supply via fitting 15 which is a threaded fitting of common availability capable of being sealed in such a manner as to prevent any loss of gas either through the threaded connection into housing 24 , or through the junction with supply tube 13 . Since pressure chamber 14 is also in communication with borehole 35 , which is unpressurized, via guide hole 91 a high pressure seal must be provided at this location which both permits axial motion of core rod 19 to take place while simultaneously preventing leakage of gas through guide hole 91 . This is accomplished by means of radial o-ring 18 which seals valve core rod 19 against plate 16 . Plate 16 is consequently sealed against housing 14 by means of face o-ring 18 . Both o-rings, in combination, achieve the necessary seal for pressure chamber 14 while permitting axial motion of valve core rod 19. Pressure chamber 14 is furthermore in communication with expansion nozzle 12 . The throat 11 of expansion nozzle 12 , as was previously described, forms the high pressure valve seat for valve core rod 19. One possible method of fabricating the housing is to bore pressure chamber 14 from one side of housing 24 . For this embodiment of the device, expansion nozzle 12 may be fabricated separately and subsequently bolted to housing 24 by means of fasteners 9 . Sealing of the expansion nozzle assembly 12 to housing 24 may be achieved by means of a radial o-ring 39, as shown in Fig. 2.10 .

Figs. 2.8 and 2.9 illustrate side and top views of the cold gas thruster embodiment of the device which show, in addition to those features described in Fig. 2.7, one possible means 
for mounting an onboard microcontroller subsystem 30 and an energy storage and amplification subsystem 32. These are affixed to opposing sides of gas reservoirs 10 by means of special brackets 31 which are connected to housing 24 by means of fasteners 40 . It is further illustrated in Figs. 2.8 and 2.9 that boreholes 24 and 35 for the piezoelectric stack and for the valve core assembly, respectively, are machined in such a manner as to lie on the plane which passes through the centerline of the thickness of housing 24. Bracket 21 shown in Fig. 2.9 is provided with threaded holes which may be used to mount the device on the structure to be controlled and/or tested.

Figure 2.10 shows an extracted assembly of the internal working parts of the device, while Fig. 2.11 shows a detailed cutaway of pressure chamber 14 and its associated interfaces. During operation of the device a positive direct current voltage will cause piezoelectric stack 1 to expand. Since the stack 1 is connected to a rigid internal reaction surface at bearing seat 90 , all expansion occurs at the lower end and is transferred via bearing 3 to tapered bearing seat 88 which is machined on the short side of anvil-lever 4 . The vertical displacement of piezoelectric stack 1 therefore causes bearing seat 88 on anvil-lever 4 to move downward and for anvil-lever 4 to rotate about hinge 5 . Consequently, and as will be explained in detail below, bearing 22 on the long side of anvil-lever 4 is caused to move upward, which is precisely the direction needed in order to unseat valve core tip 48 from valve seat 11 and initiate loading as gas is expanded through nozzle 12 . This inversion of displacement direction is required, since the piezoelectric stack 1 is unable to effectively transmit loads in tension. Furthermore, a positive return mechanism must be available to close valve seat 11 for the same reason. This is accomplished by means of precompression spring 23 which is chosen so that the precompression force satisfies two criteria: First, it must be capable of sealing valve seat 11 so that no gas and/or propellant is permitted to escape through expansion nozzle 12 when the piezoelectric stack is in the uncharged state. Secondly, the precompression force must be capable of accelerating anvil-lever 4 and the valve core rod assembly $(52,20$, and 19$)$ downward towards a closed valve position in such a manner as to always exceed the contracting acceleration of piezoelectric stack 1 as the voltage signal which drives the stack is diminished. This is required in order to maintain all bearings (83,3, and 22 ) in a state of continual compression; otherwise the possibility of separation occurs leading to subsequent shock loading and noise in the "intelligent" impulse.

Figure 2.11 shows a detailed view of pressure chamber 14 . In the preferred embodiment of the device this chamber is milled from housing 24 as a circular borehole. Radial o-ring 39 and backup ring 47 (optional) provide for a high pressure static seal between nozzle 12 and the circular wall of chamber 14. Nozzle 12 is bolted to housing 24 by fasteners 9 which are sized to resist the resultant force acting to expel the nozzle from the housing due to the high internal pressure inside pressure chamber 14. Plate 16 contains two sets of o-ring seals which prevent gas from escaping via borehole 91, through which the valve core rod enters chamber 14 . Face o-ring seal 18 is precompressed against housing 24 by plate 16 by means of fasteners 94 and prevents escape of gas around plate 16 and into borehole 91. O-ring seal 17 and optional backup rings 51 prevent escape of gas through borehole 95 in plate 16, through which the valve core rod passes. Seal 17 additionally serves as a viscous damper for valve core rod 19 , which serves to minimize elastic rebound when the valve core rod tip 48 closes with valve seat 11 . 
During normal operation of the device, upward motion of valve core rod 19 will permit high pressure gas to expand through nozzle 12 and thus create thrust 50. The high pressure gas and/or propellant feed supply 49 to chamber 14 is delivered through fitting 15 and gas supply tubing 13 , both of which must have significantly larger internal diameters than the throat diameter 103 of the expansion nozzle 12, as shown in Fig. 2.12. This ensures that fully developed flow is maintained at all times when the valve is open.

Referring now to Fig. 2.12, which is a general detail of the valve core tip and valve seat, valve core rod mating surface 48 is precision ground to have a slope 99 of 29.5 degrees, and thus an included angle of 59 . Core rod tip 100 is precision ground to a flatter angle 101 of approximately $30^{\circ}$ from horizontal $\left(120^{\circ}\right.$ included angle) so as not to come into contact with the valve seat. Valve seat 11 is machined with a tapered angle 98 of $30^{\circ}$, or a $60^{\circ}$ included angle. Since angle 98 is slightly larger than angle 99 , initial sealing of the valve occurs at the expansion nozzle throat 103 .

Figure 2.13 presents a detailed side view of the displacement amplifier which is used to multiply the movement from the piezoelectric stack to a level useful for practical valve control. As previously described, this consists of a rigid anvil-lever 4, a hinge 5, and a support 6. During normal operation of the device, expansion of the piezoelectric stack in response to a controlled direct current signal will in turn exert force 88 on the tapered circular bearing support 88 on the short side of the anvil lever, whose fulcrum is approximately given by hinge 5 . In turn anvil-lever 4 will rotate clockwise about hinge 5 and cause bearing support 86 on the long side of anvil-lever 4 to be forced upward, thereby generating force 105 as it reacts against precompression spring 23 (see Fig. 2.7). The upward displacement at bearing support 86 will be, to within four significant figures, equal to the expansion of the piezoelectric stack times the ratio of length 52 divided by length 54 .

The tapered shape of anvil-hinge 4 is necessary in order to minimize both the mass of the lever (i.e., in order to reduce inertially induced forces and moments as the piezoelectric stack expands) as well as to minimize flexural deformations relative to the un-deformed top surface of the lever due to the action of applied forces 105 and 104. Hinge 5 is designed to be as thin as possible in order to minimize rotational resistance about an axis perpendicular to the principal plane of the amplifier. The height of the hinge is selected to be as tall as possible while avoiding the possibility of buckling under the combined compressive loads 104 and 105. The hinge width 56 is selected to prevent both bearing failure of the hinge and to inhibit the likelihood of the anvil-lever resonating in a torsional mode. These design criteria lead to the requirement for the amplifier to be fabricated from a very high strength, low modulus material with a relatively long linear elastic stress-strain curve such as titanium alloy. To minimize stress concentration and to alleviate the likelihood of fatigue cracking, hinge 5 is machined or otherwise fabricated with curved interfacing radii 58 between anvil-lever 4 and support 6 . Note that hinge width 56 (and also the width of the anvil-lever) is less than the width of the support 55 so that when support 6 is affixed to housing 24 by means of fasteners 103 there will be no interference with the housing wall as the anvil-lever rotates. The amplification ratio of the anvil-lever is equal to length 52 divided by length 54 . 
Figure 2.14 refers to the second major embodiment of the device which is a pressure-fed bipropellent thruster of a type that can be used for very high precision attitude control of spacecraft. There are several fundamental differences between the operation of the device shown in Fig. 2.14 and that for the cold gas thruster described in Figs. 2.7, 2.8 and 2.9. The primary difference is that the propellent medium consists of two liquids (an oxidizer 111 and a fuel 110), which are stored inside non-reactive chambers 113 and 112, respectively. Chambers 113 and 112 are in turn pressurized by means of high pressure inert gas sources 64 and 61, which are in turn connected by means of delivery tubes 65 and 62 to the respective chambers. Delivery tubes 65 and 62 are further connected to expansive bladders 66 and 63, which expand and pressurize chambers 113 and 112 so as to occupy the volume of space vacant of oxidizer or fuel and to apply uniform pressure to the remaining oxidizer or fuel.

Acting under the influence of the high internal pressure from pressure vessels 64 and 61 , oxidizer and fuel are forced to flow through delivery tubes 68 and 67, respectively, which communicate with valve chambers 114 and 115, respectively. Items 64, 65, 66, 111, 113, and 68 comprise the oxidizer pressure-fed delivery system and are defined as a functional unit by 76 . Items $61,62,63,110,112$, and 67 comprise the fuel pressure-fed delivery system and are defined as a functional unit by 75 .

Functional unit 74 is comprised of all of the basic components described for the high speed intelligent valve system in Figs 2.7 through 2.13 less the cold gas supply system and the expansion nozzle. Unit 74 provides for highly responsive monitoring and metering of oxidizer from valve core chamber 114 through valve seat 116 . Unlike the cold gas thruster embodiment of the device, valve seat 116 is in communication with delivery tube 70 which is in communication with combustion chamber 71. A supplementary nozzle 118 may be used to direct and disperse the flow of oxidizer into combustion chamber 71 .

Functional unit 73 is comprised of all of the basic components described for the high speed intelligent valve system in Figs 2.7 through 2.13 less the cold gas supply system and the expansion nozzle. Unit 74 provides for highly responsive monitoring and metering of fuel from valve core chamber 115 through valve seat 117 . Unlike the cold gas thruster embodiment of the device, valve seat 117 is in communication with delivery tube 69 which is in communication with combustion chamber 71. A supplementary nozzle 119 may be used to direct and disperse the flow of fuel into combustion chamber 71.

A typical oxidizer 111 for use in the device may be nitrogen tetroxide whereas a typical fuel 110 may be mono methyl hydrazine, although any oxidizer and fuel combination which is hypergolic in nature may be utilized. The impingement pattern of nozzles 118 and 119 may be optimized to produce uniform and complete burning of the constituents within combustion chamber 71 . The combustion products are then expanded through nozzle 72 to produce thrust. It may be appreciated that, due to the ability to place valve system 74 and valve system 73 under separate microprocessor control, the mix ratio of fuel to oxidizer, as well as the flow rates to combustion chamber 72 , can be varied at extremely rapid rates so as to be able to create, on demand, both very small, very rapid control forces, and large, rapid control forces, as determined to be necessary depending on the nature of the dynamic 
disturbing force which must be damped; an attitude control maneuver which must be initiated; or a pointing requirement which must be maintained with a high degree of precision. The reaction control system embodied in Fig. 2.14 makes possible extremely rapid control response, as well as very high precision in both small and large applied forces.

\subsubsection{Onboard Microcontroller Subsystem Functional Overview}

The overall problem is to provide a rocket motor with a programmable thrust vs. time profile. The thrust is varied by controlling the position of a fuel valve. The actual burn time is very short: less than one second and the valve must be able to fully open or close within 500 microseconds. To achieve this response the valve is actuated by a piezoelectric transducer which converts voltage (0-300v) into mechanical displacement. A position sensor can be used to provide position data logging or feedback for closed loop control. Fig. 2.15 provides a control system block diagram for the control system developed for the HSILS by Cytek, Inc., North Andover, MA.

The microcontroller will be based on an Intel $8751 \mathrm{H}-12$ microprocessor. This device has 4 Kbytes of internal EPROM program memory, 128 bytes of internal data memory, an asynchronous serial port, two counter/timers, I/O and interrupt lines. Additional components include:

- 32 Kbytes of battery backed RAM to be used for profile and data logging

- A 10 bit Tracking Analog to Digital (A/D) Converter to acquire valve position data. Maximum conversion rate is $500 \mathrm{~K}$ samples/sec.

- A 10 bit Digital to Analog (D/A) Converter to generate the position signal for the Power Amplifier.

- Signal conditioning components for discrete input and output lines.

I/O Capabilities:

Input:

1 Analog strain gage input. +/- 5 volt excitation voltage, input range adjustable $0-50$ millivolts to 0-200 millivolts. Measurement accuracy of $1 \%$.

1 Asynchronous communications port (this is also an output) conforming to the RS232 electrical standard and operating at $9600 \mathrm{bits} / \mathrm{sec}$.

4 Discrete inputs. An input of 0-.7 volts will be considered a logical 0 . Inputs greater than 2 volts will be considered a logical 1 . Voltages greater than 0.7 but less than 2 volts will be undefined. The input impedance will be $100 \mathrm{~K}$ ohms. The maximum permissible input range is $+/-35$ volts.

2 Interrupt inputs: The electrical specifications are the same as the Discrete Inputs. 


\section{Output:}

1 Analog output: The voltage range will be $0-5$ volts with an output impedance of 1,000 ohms. The accuracy and settling time (to rated accuracy) will be $1 \%$ and 2 microseconds, respectively.

4 Discrete Outputs: These are of the open collector type and can sink a maximum of 20 milliamperes. The maximum applied voltage range is $0-35$ volts.

The microcontroller employs printed circuit (PC) board construction with design emphasis on compactness and shock resistance. Communications between the microcontroller and the host PC take place over the serial link using a blocked asynchronous protocol as shown in Fig. 2.16. The parameters are 9600 bits/second; 8 bits; no parity; and 1 stop bit. The protocol requires that each packet be acknowledged before the next can be sent. The PC acts as master, initiating all transactions. ACK $(06 \mathrm{H})$ and NAK $(15 \mathrm{H})$ characters are used for positive and negative (error) acknowledgement, respectively.

\subsubsection{Microcontroller Hardware Description}

The microcontroller unit, shown in Fig. 2.17, uses an Intel 80C31 CMOS microcontroller as the computational unit. The clock rate is set to $11.059 \mathrm{MHz}$ to facilitate the generation of standard asynchronous baud rates using an internal timer. The CPU design is conventional with program and main data memory residing outside the microcontroller. The data memory, a $32 \mathrm{~K}$ x 8 CMOS static RAM device, is mounted on a Dallas Semiconductor DS1213C "SmartSocket" battery backup unit. Microcontroller ports 0 and 2 provide the data bus interfaces.

Port 1 of the microcontroller is used for discrete $\mathrm{I} / \mathrm{O}$. Each discrete output is buffered using an invertor and open collector transistor. The invertor ensures that the transistor will be in the "off" state at startup. Bits 0-3 are used for input and 4-7 for output. Port 3 is used for asynchronous serial I/O, external memory control, and miscellaneous I/O.

The analog input section has two inputs. The first, used to measure the output of the power amplifier, is single ended and unconditioned. The second input is for use with a bridge type strain gage sensor and uses a high speed instrumentation amplifier. A 5 volt excitation supply is also included. A multiplexer allows software selection of the input source. A TL020 half-flash, 8 bit, A/D converter converts a $0-2.5$ volt input in 1.2 microseconds. A separate overflow bit indicates the validity of the reading. An AD 75258 bit D/A converter provides a $0-2.5$ volt output to control the driver amplifier.

Complete schematics and component lists for the microcontroller subsystem are provided in Appendix $\mathrm{C}$ of this report. 


\subsubsection{Onboard Programmable Pulse Power}

The power amplifier has the following characteristics:

- Type: single ended, Class B

- Input Voltage: 0-5 V

- Output Voltage: 0-300 V

- Voltage Gain: 50

- Power Handling Capability, 2 Second Interval: 15 mJ.

- Voltage Switching Rate: 1 volt/microsecond

- Frequency Response: 0-100 kHz@ +/-1dB

- Overshoot: 5\% Maximum with a 20 microsecond settling time in response to a $50 \%$ full scale input step.

Like the microcontroller, the power amplifier was constructed using printed circuit technology except for the power transistors which are mounted on heat sinks. The power pack consists of a $400 \mathrm{~V} 25 \mathrm{~mA}$ power supply which charges a $150 \mathrm{uF}$ capacitor. The power pack is disconnected from the power supply once the voltage falls below $300 \mathrm{~V}$. Since the available energy stored in the $100 \mathrm{~V}$ discharge range of the capacitor is $15 \mathrm{~mJ}$, the power amplifier cannot be overloaded. A safety interlock completely discharges the capacitor when the main power is disconnected of the power amplifier cover is opened. It should be noted that the energy stored in such a system supplies sufficient voltage and current to cause a lethal shock. Anyone attempting to re-create or expand upon the research described in this report should thus take appropriate safety precautions.

The driver amplifier must operate under some fairly severe constraints:

- The load is an essentially pure 25 uF capacitance.

- The load must be drive between $0-300 \mathrm{~V}$ at a switching rate of $1 \mathrm{volt} / \mathrm{microsecond}$

- Frequency response is to be $0-100 \mathrm{kHz}$ with a maximum overshoot of $5 \%$.

As a result, the amplifier must be able to handle extremely high peak power levels ... as much as $8 \mathrm{~kW}$. Also, the use of feedback to maintain DC and AC stability must allow for the very low frequency "pole" introduced by the load.

To meet these requirements, the driver amplifier, shown in Fig. 2.18, is divided into two stages. The first uses conventional op-amp topology to provide both voltage and current gain. This stage is switching rate limited at $1 \mathrm{volt} / \mathrm{microsecond}$. This controls the maximum current into the stack $(25 \mathrm{~A})$. The primary feedback loop is within this stage. The second stage is a class $\mathrm{AB}$ voltage follower, i.e. it has a voltage gain of one and a current gain of at least 30. This stage also provides isolation between the feedback loop and the load.

The power supply section is comprised of a conventional low voltage supply driving the microcontroller and front end section of the driver amplifier and a high voltage supply for the load. Since a $300 \mathrm{~V}, 25$ A supply would be impractical, the high voltage supply is sized to directly provide the bias current requirements of the driver amplifier and the time to 
charge a capacitor bank to $350 \mathrm{~V}$. These capacitors supply the stack charging current. Complete schematics for the pulse power supply are provided in Appendix $\mathrm{C}$ of this report.

\subsubsection{HSILS Driver Software}

The software, both onboard the microcontroller as well as the PC interface code, was written in " $\mathrm{C}$ " using the Franklin 8051 compiler. A modular design to the code was adopted to permit future modification and flexibility. The program presently contains the following components:

\section{Initialization}

The initialization module is responsible for ensuring that all outputs are in a known state and initializing the internal clock and serial port.

\section{Serial I/O drivers}

The Serial I/O drivers provide interrupt driven buffering for incoming characters. This is necessary to guarantee proper operation at $9600 \mathrm{bits} / \mathrm{second}$. The communication parameters are: 9600 bits/second; 8 bits; no parity; and one stop bit. The only entry points to the Serial $\mathrm{I} / \mathrm{O}$ drivers are getchar and putchar.

\section{Command Dispatcher}

The command dispatcher simply reads a command from the communications processor and calls the appropriate execution module. Adding a new command is accomplished by creating a new reference in the command table described below.

\section{Command Execution Modules}

The microcontroller software (See Appendix D) uses standard ASCII codes and can be used with any standard communications program that supports direct (non-modem) connections. The initial version of this program contains the following executable commands.

\section{$\underline{\text { Reset }}$}

Parameters: None

Description: Returns system to power on state. Resets any outputs but does not clear the profile memory.

\section{$\underline{\text { Load Profile }}$}

\section{Parameters: None}

Description: Loads the stack actuation profile. When the load profile command is received, the controller waits for the user to enter time and voltage 
pairs as follows:

time,voltage

where the time is in microseconds from start and voltage is a stack voltage from 0 to $300 \mathrm{~V}$. Up to 1024 points may be entered. Load profile is ended when the line:

\section{End Profile}

is received. The last point must contain a zero voltage value.

\section{$\underline{\text { Start Run }}$}

Parameters: None

Description: Begins execution of downloaded profile. After the last point, the output is returned to 0 and a prompt is returned to the host.

\section{Set Discrete Outputs}

Parameters: $\quad$ New value to output (0-15)

Description: Writes the lower 4 bits of the parameter to the discrete outputs. A "1" places the output in the "low" state.

\section{Get Discrete Status}

Parameters: None

Description: Returns a number from $0-15$ reflecting the current state of the discrete input lines. A 1 bit value indicates the input is low.

\subsection{RCS Control Thruster}

A "control" experiment (cold gas thruster) was constructed using a traditional solenoid valve in order to provide first hand data for comparison with the performance of the HSILS actuator. This device, shown in Fig. 2.19, consisted of two interconnected stainless steel pressure vessels (service rated at $35 \mathrm{MPa}$; STP volume of $150 \mathrm{cc}$ each); a recharge port; a $6 \mathrm{~mm}$ stainless steel delivery pipe connecting the pressure vessels to the control valve; a Honeywell/Skinner B2LX94N solenoid valve; and an expansion nozzle.

The solenoid valve had the following specifications:

- Operating Voltage: $24 \mathrm{vdc}$

- Operating Pressure 2.76 - 6.9 MPa

- Orifice size: $0.794 \mathrm{~mm}$;

- Coil: $2440+/-1 \%$ turns; \#33 awg wire 
$86.6+/-8 \%$ ohms at $25 \mathrm{C}$

- Return spring: Part No. B04005; k = 1.384 n/mm force $=2 \mathrm{n}$ preload; $3.3 \mathrm{n}$ in full open state.

- Core Spec: Carpenter Steel \#430FR

- Valve Seat Material: Teflon

Operation of this valve was accomplished using the same programmable pulse power unit developed for HSILS with the notable exception that the peak voltage was limited to $40 \mathrm{vdc}$ to prevent failure of the $24 \mathrm{vdc}$ rated solenoid coil. All other aspects of the experimental program, including sensors, data collection and data reduction procedures were identical to those used for the HSILS tests.

\subsection{Analytical Modeling}

\subsubsection{Force, Duration, and Gas Storage Requirements}

In order to proceed from the conceptual HSILS unit shown in Figs. 2.7 through 2.13 to the construction of a practical experimental prototype a number of subsystem elements had to be sized and designed. This proved to be an iterative process since each element in the electro-mechanical linkage affected the design of all the other components (e.g. selection of a nozzle throat diameter affected the sizing of the return spring, which in turn affected the dynamic behavior of the unit). To remedy this a set of performance criteria were identified and an interactive computer graphics program, THRUSTER (see Appendix A for program listing), was developed which permitted parametric analysis of the system. The performance criteria selected for the bench test HSILS unit were as follows:

- Capable of generating inverse gaussian impulse.

- Peak impulse thrust $=44 \mathrm{~N}$.

- Maximum impulse duration $=0.020 \mathrm{~s}$.

- Onboard power and gas storage to meet, but not significantly exceed the above specifications in an effort to reduce mass to less than $5 \mathrm{~kg}$ for the entire HSILS unit.

The specific elements of the parametric analysis (under user control) were:

- Initial gas storage pressure (MPa)

- Pressure vessel inside diameter (i.e. STP volume, cc)

- Room temperature (oC)

- Nozzle throat diameter $(\mathrm{mm})$

- Displacement amplifier magnification factor

- Integration time step (seconds)

- Return spring stiffness $(\mathrm{N} / \mathrm{mm})$

- Inverse gaussian pulse shape parameter, $\sigma$

Given these input data the ideal inverse gaussian impulse force as a function of time can be calculated as: 


$$
F_{\text {theo }}=\frac{\left(F_{\text {imp }} \sqrt{4 \pi\left(\frac{\sigma^{2}}{6}\right)^{3}}\right) \sigma}{\sqrt{4 \pi t^{3}}}\left(e^{\left.\frac{-0^{2}}{4 t}\right)}\right.
$$

where:

$$
\begin{aligned}
& \mathrm{F}_{\text {theo }}=\text { theoretical impulse force at time } \mathrm{t} \text { (newtons) } \\
& \mathrm{F}_{\mathrm{imp}}=\text { specified peak impulse force (newtons) } \\
& \mathrm{t} \quad=\text { elapsed time (seconds) } \\
& \sigma \quad=\text { shape constant for inverse gaussian pulse }
\end{aligned}
$$

For the particular case of a cold gas thruster nozzle flow can be modeled by one-dimensional isentropic expansion relations. Sutton (Sutton, 1986) provides the following relationship for thrust:

$$
F=P_{\mathrm{c}} A_{t} C_{f}
$$

where:

$\mathrm{F} \quad=\quad$ Actual thrust (newtons)

$\mathrm{P}_{\mathrm{c}} \quad=\quad$ Chamber pressure $(\mathrm{Pa})$

$\mathrm{A}_{\mathrm{t}}=$ Nozzle throat area $\left(\mathrm{m}^{2}\right)$

$\mathrm{C}_{\mathrm{f}}=$ Thrust coefficient, defined as:

$$
C_{f}=\sqrt{\frac{2 \gamma^{2}}{\gamma-1}\left(\frac{2}{\gamma+1}\right)^{\frac{(\gamma+1)}{(\gamma-1)}}\left[1-\left(\frac{P_{e}}{P_{c}}\right)^{\left[\frac{\gamma-1}{\gamma}\right]}\right]}+\frac{P_{e}-P_{a}}{P_{c}}\left(\frac{A_{e}}{A_{t}}\right)
$$

where:

$\gamma=$ Specific heat ratio of the compressed gas

$\mathrm{P}_{\mathrm{e}} \quad=\quad$ Nozzle exit pressure $(\mathrm{Pa})$

$\mathrm{P}_{\mathrm{a}}=$ Ambient pressure $(\mathrm{Pa})$

$\mathrm{A}_{\mathrm{e}}=$ Nozzle exit area $\left(\mathrm{m}^{2}\right)$ 
For laboratory tests at STP $\mathrm{P}_{\mathrm{e}}=\mathrm{P}_{\mathrm{a}}=1$ bar; in space both terms would be effectively zero. Useful constants for various gases that might be used in a cold gas thruster are as follows:

Table 2.1: Gas Constants

\begin{tabular}{||l|c|c|c|c|c|c|}
\hline Gas & $\begin{array}{c}\text { Specific } \\
\text { Heat Ratio, } \\
\gamma\end{array}$ & $\begin{array}{c}\text { Molecular } \\
\text { Weight }\end{array}$ & $\begin{array}{c}\mathrm{C}_{\mathrm{f}} \\
{\left[\mathrm{P}_{\mathrm{a}}=1\right.} \\
\mathrm{bar}]\end{array}$ & $\begin{array}{c}\mathrm{C}_{\mathrm{f}} \\
{\left[\mathrm{P}_{\mathrm{a}}=0\right]}\end{array}$ & $\begin{array}{c}\mathrm{I}_{\mathrm{sp}} \\
(\mathrm{seconds}) \\
{\left[\mathrm{P}_{\mathrm{a}}=1 \text { bar }\right]}\end{array}$ & $\begin{array}{c}\mathrm{I}_{\mathrm{sp}} \\
(\mathrm{seconds}) \\
{\left[\mathrm{P}_{\mathrm{a}}=0\right]}\end{array}$ \\
\hline $\begin{array}{l}\text { Hydrogen } \\
\left(\mathrm{H}_{2}\right)\end{array}$ & 1.410 & 2.015 & 1.626 & 1.800 & 267 & 296 \\
\hline $\begin{array}{l}\text { Nitrogen } \\
\left(\mathrm{N}_{2}\right)\end{array}$ & 1.404 & 28.016 & 1.629 & 1.807 & 72 & 80 \\
\hline $\begin{array}{l}\text { Helium } \\
(\mathrm{He})\end{array}$ & 1.659 & 4.003 & 1.544 & 1.627 & 170 & 179 \\
\hline
\end{tabular}

As the valve core lifts away from the nozzle throat, as shown in Fig. 2.20, pressurized gas escapes producing thrust as defined by eq (2). The effective throat area is given by:

$$
A_{t}=2 \pi\left(\frac{d_{t h}}{2}-\frac{\delta_{c}}{4} \cos \theta\right) \delta_{c} \sin \theta
$$

where:

$\gamma=$ Valve core displacement $(\mathrm{mm})$

$\mathrm{d}_{\mathrm{th}}=$ Nozzle throat diameter $(\mathrm{mm})$

$\theta=$ Valve core half cone angle (degrees)

For a 60-degree valve core cone angle, typical of high pressure valve seats, the effective throat area reduces to:

$$
A_{t}=\frac{\pi d_{t h} \delta_{c}}{2}
$$

For a low pressure elastomeric pad seat $(180$-degree cone angle $=$ flat interface $)$ the equation for effective throat area is given by: 


$$
A_{t}=\pi d_{t h} \delta_{c}
$$

In any event, the maximum effective throat area is controlled by the nozzle throat area given by:

$$
A_{t}=\frac{\pi d_{t h}^{2}}{4}
$$

We may now substitute the expression for effective throat area into eq (2) to determine the required core displacement at time $t$ (seconds) as:

$$
\delta_{c}=\frac{F}{P_{c} \pi d_{t h} C_{f}}
$$

Since there is a limiting state for $\delta_{c}$ the real time value for $F$ (actual thrust) must be recalculated as:

$$
F=P_{\mathrm{c}} \pi d_{t h} C_{f} \delta_{\mathrm{c}}
$$

As the analysis progresses through time it is possible to determine the maximum core displacement. The NIST piezoelectric stack was proven to be capable of achieving a maximum axial displacement of $0.0686 \mathrm{~mm}$ at $225 \mathrm{vdc}$ drive voltage. Knowing this mechanical limitation, the required displacement amplification ratio is given by:

$$
R_{a}=\frac{\delta_{c-\max }}{0.0686}
$$

If the required amplification factor is greater than that specified program THRUSTER advises the user that the amplification factor must be adjusted and the analysis to this point is rerun. The required piezoelectric stack displacement at any given time is then defined as:

$$
\delta_{\text {stak }}=\frac{\delta_{\mathrm{c}}}{R_{a}}
$$


Given a spring preload force, amplification factor, and required stack displacement, the required drive voltage from the pulse power system can be calculated using the block force piezoelectric equations from Fig. 2.5 as:

$$
V_{\text {drive }}=\left(\frac{F_{\text {preload }} R_{a}-65669 \frac{\delta_{c}}{R_{a}}}{159.86}\right)^{1.517}
$$

This completes one differential time step in the parametric HSILS analysis. At this point a finite amount of gas molecules have been expelled through the nozzle at a weight flow rate (expressed in units of newtons/second) given by Sutton (Sutton, 1986) as:

$$
\dot{w}=\frac{F_{\text {thrust }}}{I_{s p}}
$$

Given that the initial weight of gas contained in the pressure vessel can be calculated from the ideal gas equation as:

$$
w_{0}=\frac{P_{0} V_{\text {rank }} M}{R_{\text {const }} T_{a b s}}
$$

where:

$\mathrm{V}_{\text {tank }}=$ Pressure vessel volume, given by $(4 / 3) \pi(D / 2)^{3}$

$\mathrm{M}=$ Molecular weight of the propulsive gas

$\mathrm{R}_{\text {con }}=$ Universal gas constant

$\mathrm{T}_{\mathrm{abs}}=$ Absolute temperature

it is then possible to determine the internal pressure, $\mathrm{P}_{c}$, at any time $\mathrm{t}$ as:

$$
P_{c}=P_{0}-\frac{1}{w_{0}} \int \dot{w} d t
$$

where:

$\mathrm{P}_{0} \quad=$ initial internal tank pressure $(\mathrm{MPa})$ 
and the bounds on the integral are from zero to time t. This then provides the initial values for the next numerical time step calculations. For small time steps (on the order of 0.0001 second) it is possible to accurately determine both the instantaneous velocity and acceleration of the valve core. This permits a determination of the required return spring force needed to insure that, as the piezoelectric stack contracts as voltage is reduced in a voltage-time history, there is no "lift off" at any of the spherical sapphire bearings which form the hinge contact points in the mechanism.

The above equations do not model the transient dynamic effects associated with the various stiffnesses, masses, and damping properties of the HSILS components. Rather it is assumed for the purposes of initial component sizing that motion transmission is instantaneous and that all components are perfectly rigid and massless (except for the calculation of return spring stiffness). Transient structural response is discussed in Section 2.4.3 below.

\subsubsection{Typical Limiting Design Conditions}

Figs. 2.21 and 2.22 show the effect of the nozzle throat diameter on the ability of the HSILS to track an inverse gaussian pulse whose characteristics are given in the inset boxes on these figures. In viewing these figures the reader should keep in mind that as time increases from initiation of the pulse the chamber pressure, $\mathrm{P}_{c}$, in the onboard gas storage vessel is decreasing in a non-linear fashion. The HSILS unit compensates for this by increasing the valve core displacement so as to achieve the desired thrust (force) level at any given point along the pre-defined pulse (which in the actual unit is downloaded from memory to the digital to analog converter and then amplified via the pulse power unit). Peak thrust is determined, as defined above in eq (2), by the internal chamber pressure, the thrust coefficient (which is a function of the gas used, and the nozzle throat area, which is effectively defined by the throat diameter, $\mathrm{d}_{\mathrm{th}}$.

In Fig. 2.21 it can be seen that for nozzle diameters less than approximately $1 \mathrm{~mm}$ the unit cannot achieve the desired peak thrust, as evidenced by a "flat top" profile. Actually, the maximum thrust plateaus in this case are sloped with gradually decreasing maximum thrust level with increasing time. This is a result of decreasing chamber pressure with time in the face of a full-open valve. An alternative means of viewing the effects of nozzle throat diameter is shown in Fig. 2.22 which plots the HSILS valve core displacement with time for the same problem shown in Fig. 2.21. Here it can be seen that beyond a throat diameter of $1 \mathrm{~mm}$, the peak valve core displacement needed to achieve the desired peak thrust is decreased with increasing throat diameter. Conversely, for throat diameters less than $1 \mathrm{~mm}$, the maximum nozzle throat area is achieved at lower valve core displacements, as evidenced by the curves with truncated tops. For design purposes the throat diameter should be selected to insure that the peak desired thrust is capable of being attained without truncation and that the required valve core displacement to achieve this can be delivered by the piezoelectric stack displacement amplifier. For this example, the amplification ratio was set at 12 . 
Figures 2.23 and 2.24 show the effects of the volume of the onboard gas storage vessel (as reflected by the inside diameter, $\mathrm{D}_{\text {tank }}$, of a spherical tank) on the thrust tracking ability of the HSILS unit. The philosophy here is to design the minimum size onboard gas storage system so as to achieve a desired maximum pulse (or pulse series) capability between periods of recharge. Although the HSILS unit is intended for remote operation, it will require a relatively small umbilical to supply recharge power to the pulse power unit and to provide high pressure gas to the local "accumulator" storage vessel(s).

With each firing of the unit thrust is created by the expulsion of a finite number of gas molecules stored in the accumulator tank. If the volume of this tank is insufficient the HSILS unit will be unable to track the desired impulse which is downloaded from the onboard microprocessor. Fig. 2.23 shows the gradual degradation of the ability of the HSILS unit to track the desired pulse (shown for $D_{\text {tank }}=89 \mathrm{~mm}$ ) with decreasing storage vessel diameter. During this time it can be seen in Fig. 2.24 that the onboard microcontroller will try and compensate for reduced internal pressure by increasing the valve core displacement. For tank diameters of less than $89 \mathrm{~mm}$ in this example the processor eventually commands a full-open condition (given by a valve core displacement of $0.3 \mathrm{~mm}$ in this case), after which no further compensation can be made and the tracking ability is lost, as shown in Fig. 2.23.

On the basis of analyses using THRUSTER the following design parameters were set for the laboratory demonstration HSILS unit:

- Onboard gas storage tank volume $(@ S T P)=0.6$ liters, which corresponds to $\mathrm{D}_{\operatorname{tank}}$ $=105 \mathrm{~mm}$. In the actual unit this was provided by four $150 \mathrm{cc}$ high pressure stainless sample cylinders.

- Service pressure $=34.5 \mathrm{MPa}$

- Nozzle throat diameter, $\mathrm{d}_{\mathrm{th}}=1.194 \mathrm{~mm}$

- Amplification ratio, $\mathrm{R}_{\mathrm{a}}=12$

- Return spring stiffness $=11.74 \mathrm{~N} / \mathrm{mm}$

Further specific mechanical details on the HSILS prototype are presented in Appendix E.

\subsubsection{Dynamic Simulation of HSILS}

The simulations described above, while being useful for initial design purposes, do not include the effects of transient structural response on the internal mechanism. This internal dynamic response ultimately will manifest itself at the valve core tip and subsequently will have an effect on thrust. In addition to assessing the impact of these vibrations a dynamic structural model is also useful for later identification of actuator characteristics. Of these characteristics, damping ratio is the most difficult to quantify a priori.

In this section a one-degree-of-freedom equivalent structural model for the HSILS is presented. This model was implemented in the interactive computer graphics program HDYN described in Appendix B. HDYN permits real time display of analytically predicted and experimentally observed impulse response of the HSILS and allows for interactive 
manipulation of the model parameters, including response amplitude, time shift, mass, stiffness, and damping.

Fig. 2.25 shows a simplified model of the internal mechanism of the HSILS (see Figs. 2.7 and 2.10 for reference to the actual hardware). The displacement amplifier (shown previously in Fig. 2.3) was determined (via finite element analyses) to have the dynamic characteristics presented in Table 2.2 for two different cross-sectional widths. An amplifier width of $10 \mathrm{~mm}$ was selected for the final design.

Table 2.2: Displacement Amplifier Modes and Frequencies

\begin{tabular}{||l|l|l||}
\hline $\begin{array}{l}\text { Mode } \\
\text { Number }\end{array}$ & $\begin{array}{l}\text { Frequency } \\
\text { (hertz) } \\
\text { thickness = 5 mm }\end{array}$ & $\begin{array}{l}\text { Frequency } \\
\text { (hertz) } \\
\text { thickness = 10 mm }\end{array}$ \\
\hline 1 & 598 & 598 \\
\hline 2 & 1160 & 1855 \\
\hline 3 & 5220 & 7673 \\
\hline 4 & 7670 & 9215 \\
\hline 5 & 19085 & 19085 \\
\hline 6 & 20493 & 29379 \\
\hline 7 & 33789 & 37303 \\
\hline 6 & 34185 & 52565 \\
\hline 6 & 51828 & 72016 \\
\hline 10 & 54843 & 73428 \\
\hline
\end{tabular}

In the above data the first mode of vibration is the desired rocking motion about the milled hinge z-axis; modes 2 through 4 are sway and torsional rotations about the $\mathrm{x}$ and $\mathrm{y}$ axes. Mode 5 is the first true flexural response of the amplifier. The anvil shape of the amplifier was specifically selected to achieve high bending stiffness (e.g. $598 \mathrm{~Hz}$ in rocking versus $19085 \mathrm{~Hz}$ in flexure). For this reason the amplifier may be assumed for analytical modeling purposes to be essentially rigid (but not massless). Energy losses (damping) as a result of flexural strains at the milled hinge can be shown to be approximately $1 \%$ for the design described in Appendix $\mathrm{E}$ and are therefore omitted from the model. Calculated properties for the displacement amplifier are as follows:

$$
\begin{aligned}
& \mathrm{t}_{\text {anvil }}=\text { Cross section thickness of amplifier }=10 \mathrm{~mm} \\
& \mathrm{~A}_{\text {anvil }}=\text { Cross Sectional Area }=780 \mathrm{~mm}^{2} \\
& \mathrm{I}_{\mathrm{x}}=86073 \mathrm{~mm}^{2} \\
& \mathrm{I}_{\mathrm{y}}=738519 \mathrm{~mm}^{2}
\end{aligned}
$$




$$
\begin{aligned}
& \mathrm{I}_{\mathrm{xy}}=196162 \mathrm{~mm}^{2} \\
& \mathrm{I}_{0} \quad=\mathrm{I}_{\mathrm{z}}=\rho\left(\mathrm{I}_{\mathrm{x}}+\mathrm{I}_{\mathrm{y}}\right) \mathrm{t}_{\text {anvil }}=37189 \mathrm{~g}-\mathrm{mm}^{2}\left(0.00033425 \mathrm{lb}-\mathrm{sec}^{2}\right)
\end{aligned}
$$

The anvil was fabricated from $6 \mathrm{AL}-4 \mathrm{~V}$ ( $6 \%$ aluminum; $4 \%$ vanadium; balance titanium) titanium alloy with a mass density of $4.51 \mathrm{~g} / \mathrm{cc}$; yield strength $(0.2 \%$ offset $) 828 \mathrm{MPa}$; and tensile strength $897 \mathrm{MPa}$. The following values apply to the anvil mass, $\mathrm{M}_{2}$; the valve core mass, $\mathrm{M}_{1}$; the return spring stiffness, $\mathrm{K}_{1}$; and anvil lever arms a,b, and $\mathrm{c}$.

$$
\begin{array}{ll}
\mathrm{M}_{1} & =3.8 \mathrm{~g}(0.00837 \mathrm{lb}) \\
\mathrm{M}_{2} & =35.8 \mathrm{~g}(0.078854 \mathrm{lb}) \\
\mathrm{K}_{1} & =11.738 \mathrm{~N} / \mathrm{mm}(67 \mathrm{lb} / \mathrm{inch}) \\
\mathrm{a} & =\text { long lever side }=61 \mathrm{~mm}(2.4 \mathrm{inch}) \\
\mathrm{b} \quad=\text { hinge to center of mass of anvil }=23.243 \mathrm{~mm}(0.91508 \mathrm{inch}) \\
\mathrm{c} \quad=\text { short lever side }=5.08 \mathrm{~mm}(0.2 \text { inch })
\end{array}
$$

From Fig. 2.25 equations can be written for the resisting forces to the piezoelectric stack driving force, $\mathrm{P}(\mathrm{t})$. These resisting forces are given as:

$$
\begin{aligned}
& F_{K I}=K_{1}\left(\frac{a}{c}\right) y(t) \\
& F_{M I}=M_{1}\left(\frac{a}{c}\right) \ddot{y}(t) \\
& F_{C I}=C_{1}\left(\frac{a}{c}\right) \dot{y}(t) \\
& F_{M 2}=M_{2}\left(\frac{b}{c}\right) \ddot{y}(t) \\
& M_{I}=I_{0} \ddot{\theta} \approx I_{0}\left(\frac{\ddot{y}}{c}\right) \\
& P(t)=\text { piezoelectricforcingfunction }
\end{aligned}
$$

Following the virtual displacements shown in Fig. 2.25 the virtual work equation can be written as:

$$
\delta W=-F_{K 1}\left(\frac{a}{c}\right) \delta y-F_{M 1}\left(\frac{a}{c}\right) \delta y-F_{C 1}\left(\frac{a}{c}\right) \delta y-F_{M 2}\left(\frac{b}{c}\right) \delta y-M_{I}\left(\frac{\delta y}{c}\right)+P(t) \delta y
$$

Since the virtual work must be zero, Eq. 17 can be solved and re-arranged in generalized coordinates for the equivalent single degree-of-freedom problem as follows: 


$$
\begin{aligned}
& M^{\star} \ddot{y}+C^{\star} \dot{y}+K^{\star} y=P(t) \\
& \text { where: } \\
& M^{\star}=M_{1}\left(\frac{a}{c}\right)^{2}+M_{2}\left(\frac{b}{c}\right)^{2}+I_{0}\left(\frac{1}{c}\right)^{2} \\
& C^{\star}=C_{1}\left(\frac{a}{c}\right)^{2} \\
& K^{\star}=K_{1}\left(\frac{a}{c}\right)^{2}
\end{aligned}
$$

The forcing function, $\mathrm{P}(\mathrm{t})$ in Eq. 18 is simply the piezoelectric stack equilibrium equation in the face of an applied voltage and existing instantaneous displacement, given as:

$$
\begin{aligned}
& P(t)=-37500 y(t)+35.94 E(t)^{0.6597} \\
& \text { where: }
\end{aligned}
$$

$E(t)=$ InstantaneousDrivePulseVoltage

The instantaneous valve core displacement (which will be directly proportional to output thrust provided the gas accumulator pressure remains constant) is then given by:

$$
Y^{\star}=\left(\frac{a}{c}\right) y(t)
$$

This value can then be substituted into Eq. 9 to obtain an estimate of the actual HSILS thrust. For short pulse widths (as typically achieved using the HSILS prototype unit during laboratory tests) the assumption of nearly constant accumulator pressure is valid.

Sample analysis runs using HDYN are shown in Figs. 2.26 through 2.30 to illustrate the type of behavior that were anticipated of the device. The predicted thrust response shown in these figures is based on the material and geometric properties described above for the prototype laboratory demonstration unit. Fig. 2.28 shows the response of the HSILS unit to a $0.001 \mathrm{~s} \times 200 \mathrm{~V}$ half square wave pulse for various values of the damping coefficient $\mathrm{C}^{*}$ as a percentage of critical damping, defined by:

Laboratory tests on the prototype HSILS unit showed that at a core rod velocity of approximately 0.0254 meters/second a viscous damping force of $2.94 \mathrm{~N}$ was developed. This leads to an experimental damping coefficient for the system of $115.9 \mathrm{~N}-\mathrm{s} / \mathrm{m}$. This value 


$$
C_{\text {critical }}=\frac{2 M^{\star} \omega}{\left(\frac{c}{a}\right)^{2}}=\frac{2 \sqrt{M^{\star} K^{\star}}}{\left(\frac{c}{a}\right)^{2}}=30 N-s / m
$$

where:

$$
\begin{aligned}
\omega & =\text { naturalfrequency (radians } / \text { s) } \\
M^{*} & =2.759 \mathrm{~N}-s^{2} / \text { meter } \\
K^{*} & =1690296 \mathrm{~N} / \mathrm{m}
\end{aligned}
$$

indicates a heavily overdamped system with a damping ratio of $115.9 / 30=3.88$, or $388 \%$ of critical. Viscous damping in the HSILS prototype was developed via friction between the valve core rod and the o-ring seals (both primary and backup rings) and guide slots through which it passes (see Fig. 2.11) to reach the high pressure gas chamber where it subsequently serves as the seal to the expansion nozzle. Since the experimentally measured damping coefficient was only able to be determined approximately, a sensitivity study was performed using HDYN (Appendix B).

Figs. 2.26 and 2.27 show the predicted response of the HSILS prototype to various drive voltage pulses of increasing duration (but identical peak voltage) with damping ratios of $388 \%$ and $50 \%$ of critical, respectively. Figure 2.28 shows the effect of damping, for a 200 $\mathrm{V}$ amplitude drive pulse with a nominal pulse-width of $0.001 \mathrm{~s}$, for a larger range of damping ratios. These figures indicate that for the highly overdamped case the peak response amplitudes are smaller than for the $50 \%$ damping case and the response tends to better reproduce the drive pulse shape. For shorter drive pulse widths the effect of overdamping can be seen as a rounding of the edges in the response pulse. In general, the "ringing" associated with the rising and falling edges of the pulse (as exhibited in Figs. 2.27 and 2.28) is effectively eliminated for the overdamped system. It is particularly important that this type of behavior, especially on the falling edge, be exhibited by the HSILS unit. The reason is that underdamped behavior would lead to multiple impacts (and subsequent rebound impulses) at the expansion nozzle throat as the valve core rod overshoots the full closure displacement. Aside from detracting from the ability to accurately track a voltage-time history, this also leads to impact induced fatigue, and eventual spalling, of the polished nozzle seat metal and subsequent leakage of high pressure gas.

Figures 2.29 and 2.30 show predicted HSILS response to a series of $0.001 \mathrm{~s}$ drive pulses at varying drive voltage amplitudes. These show good tracking of the drive pulse for the overdamped system and deteriorated performance at reduced damping ratios. The frequency of oscillation for the underdamped cases is approximately $124 \mathrm{~Hz}$, as calculated from the generalized mass and stiffness for the system defined in Eq. 18. 


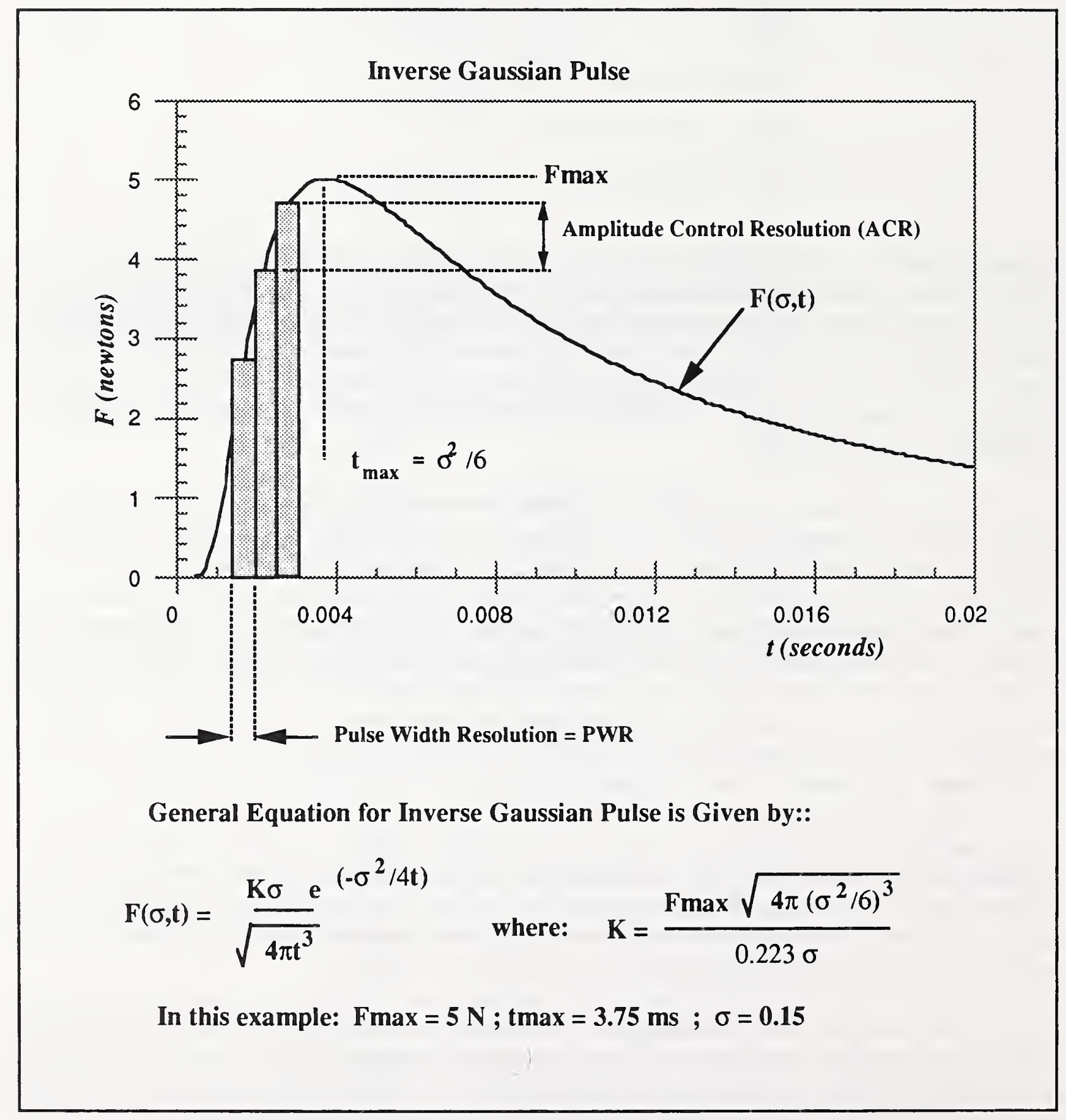

Fig. 2.1: Inverse gaussian pulse and associated variable definitions. 


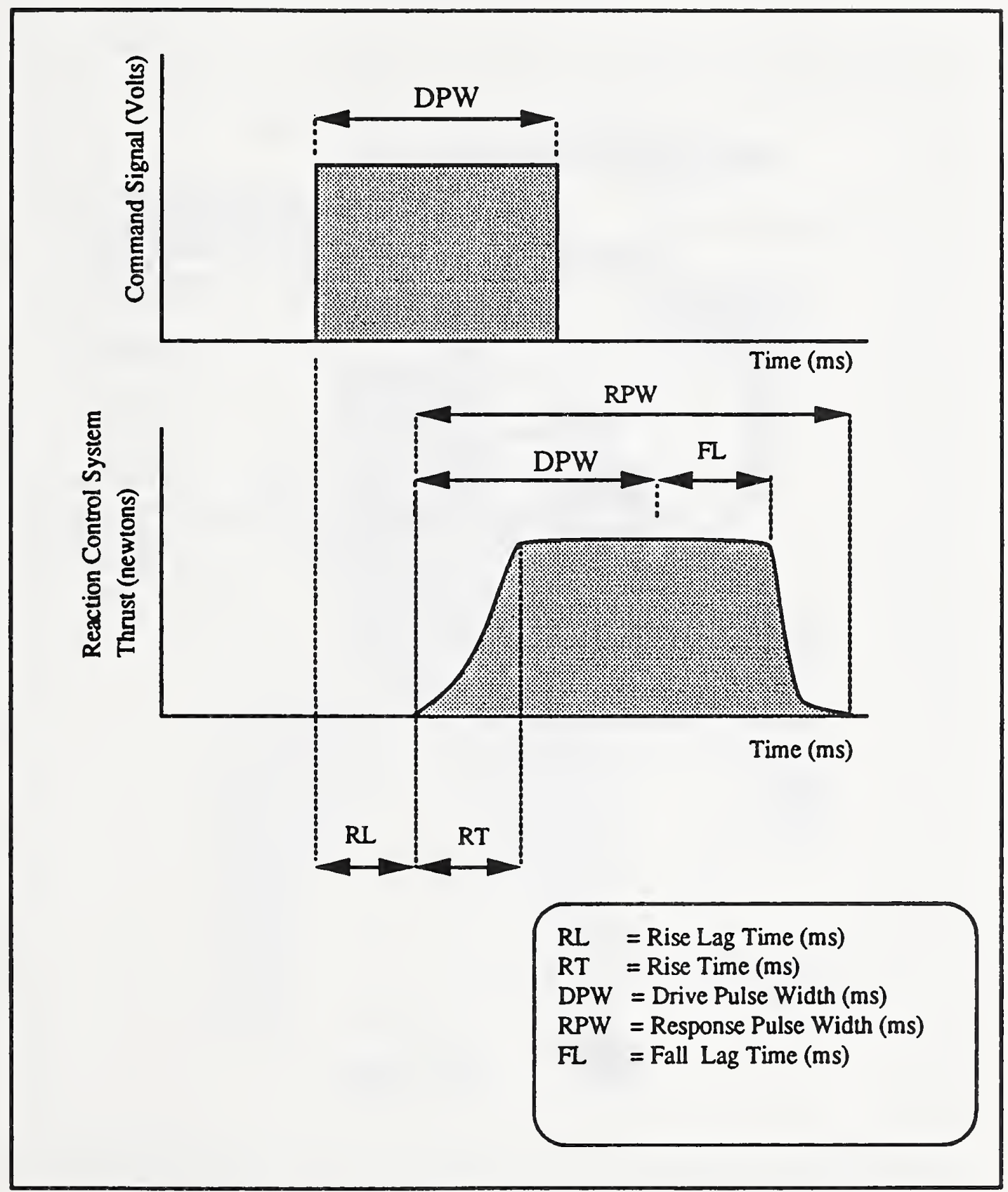

Fig. 2.2: Command and response transient performance definitions 


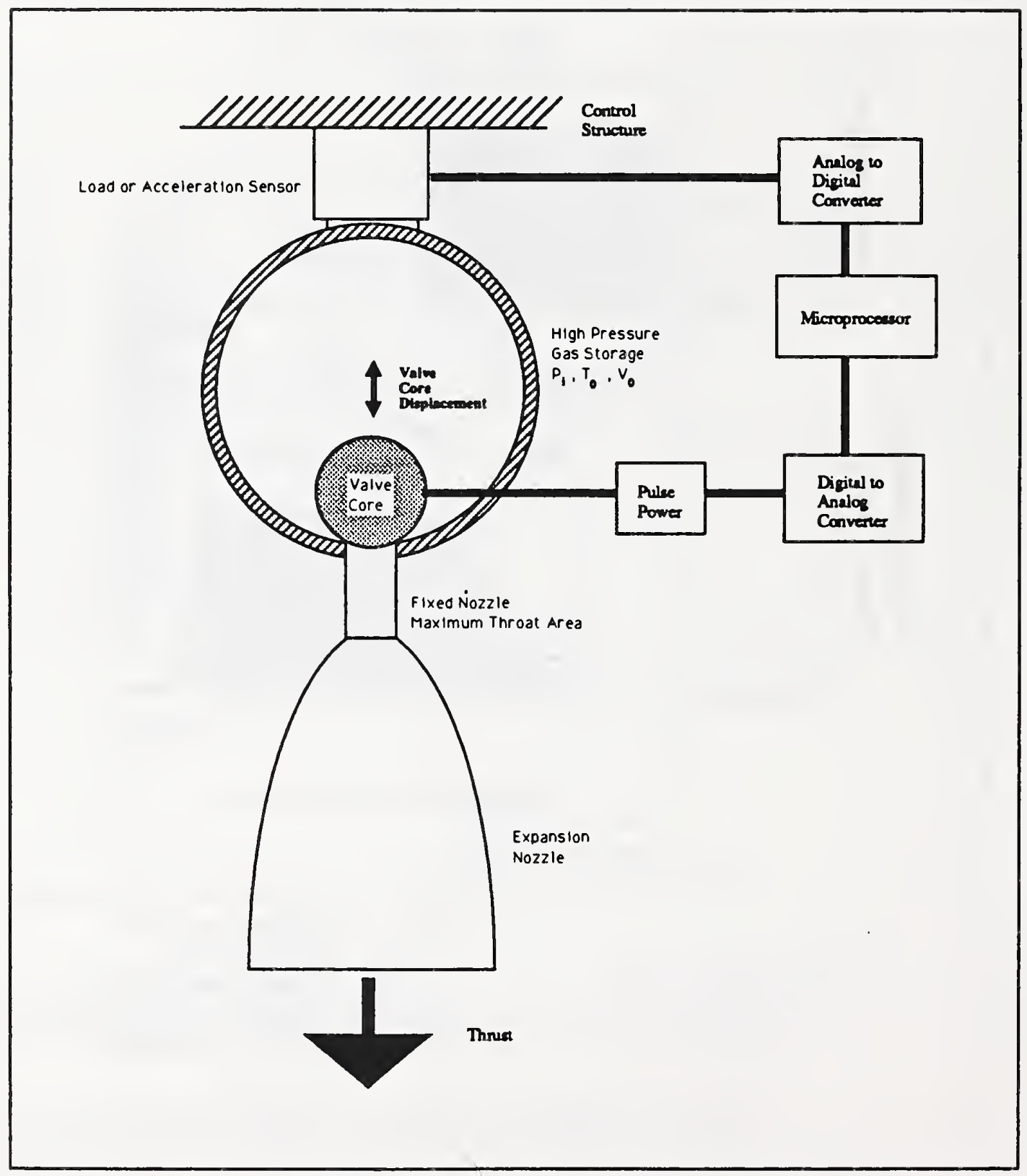

Fig. 2.3: HSILS variable amplitude control concept. 


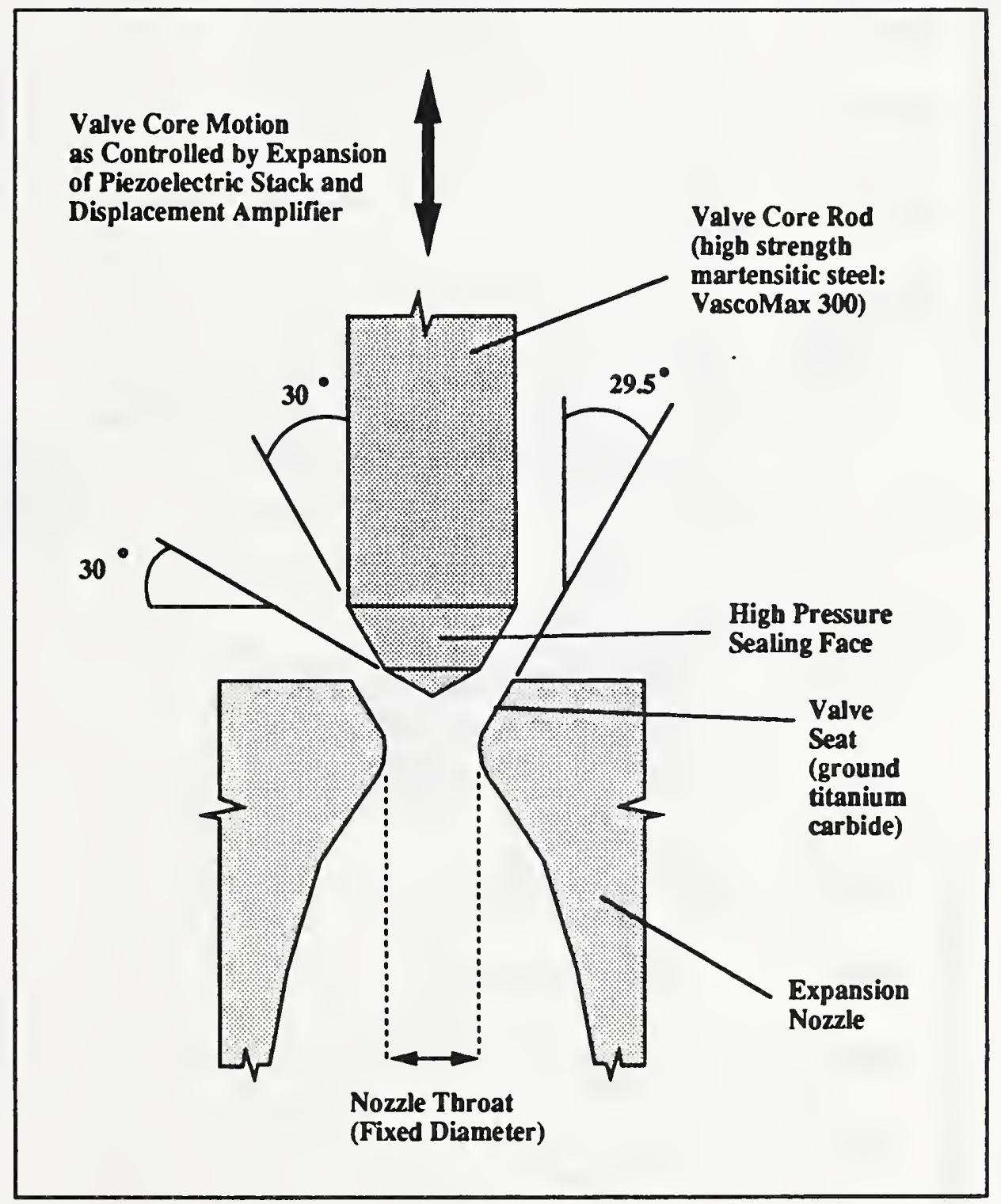

Fig. 2.4: High pressure variable mass flow rate valve seat. 

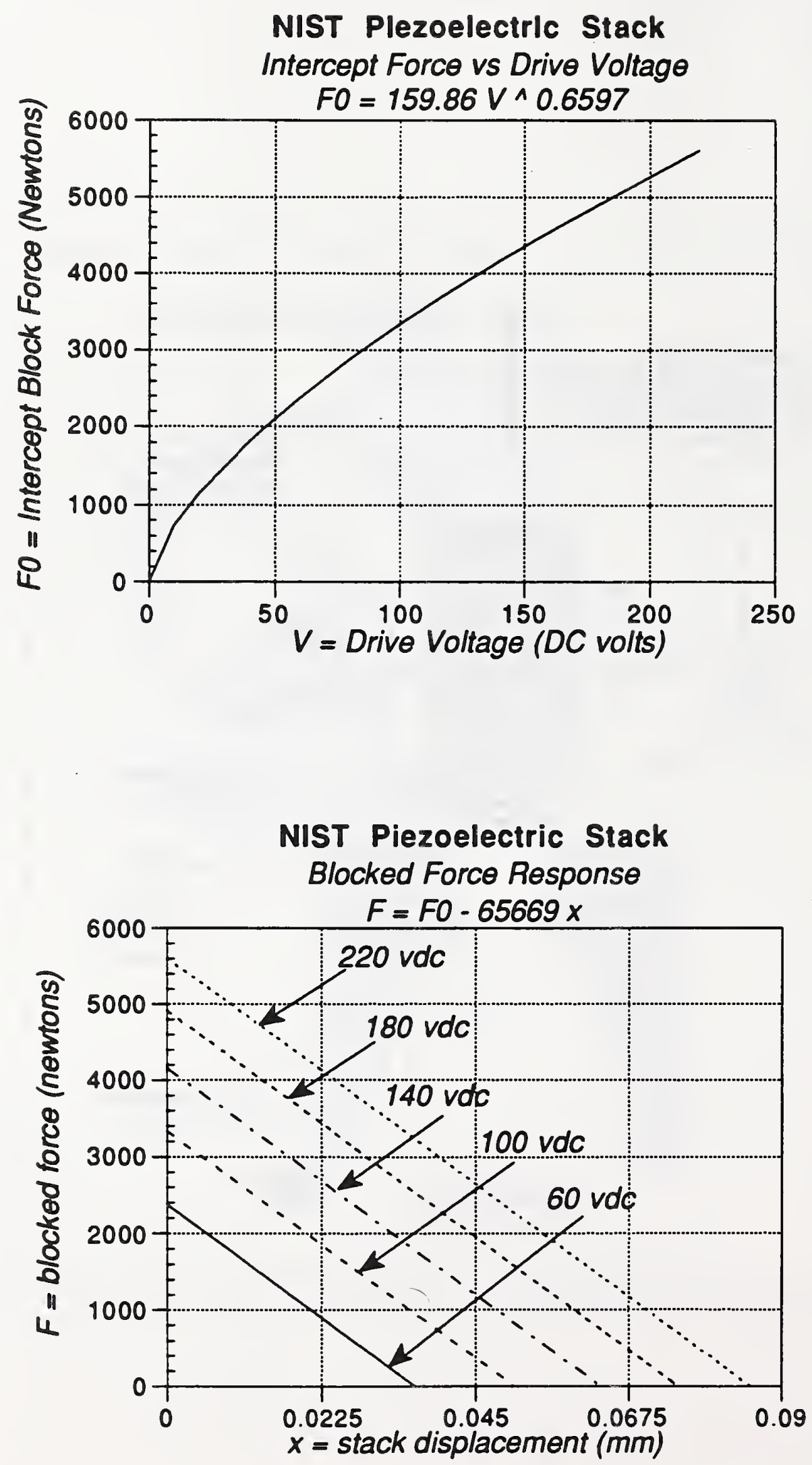

Fig. 2.5: NIST piezoelectric custom stack characteristics. 


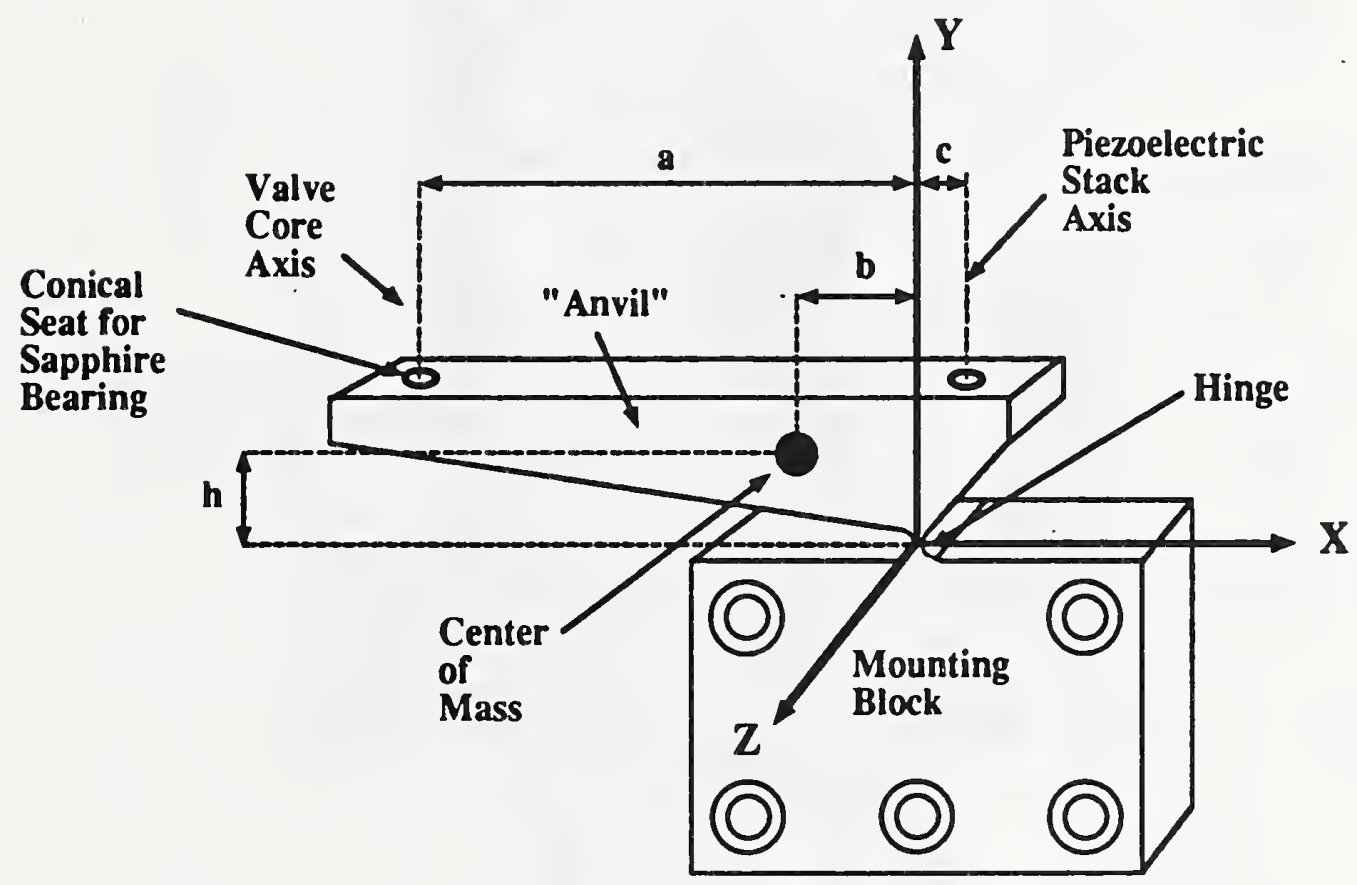

Fig. 2.6: HSILS Mechanical displacement amplifier. 


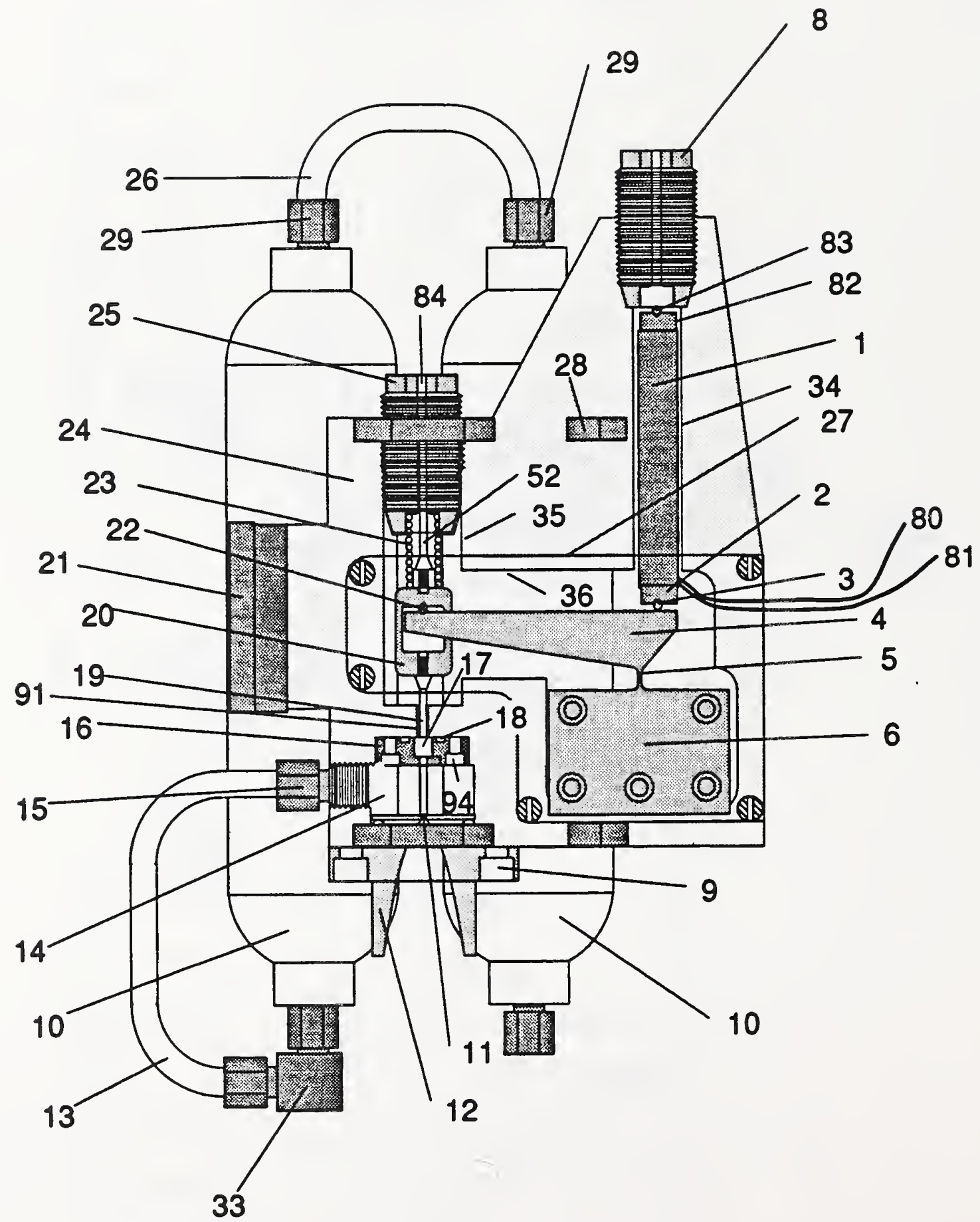

Fig. 2.7: Side view of HSILS showing all internal moving components (descriptions of numbered features are provided in the text). 


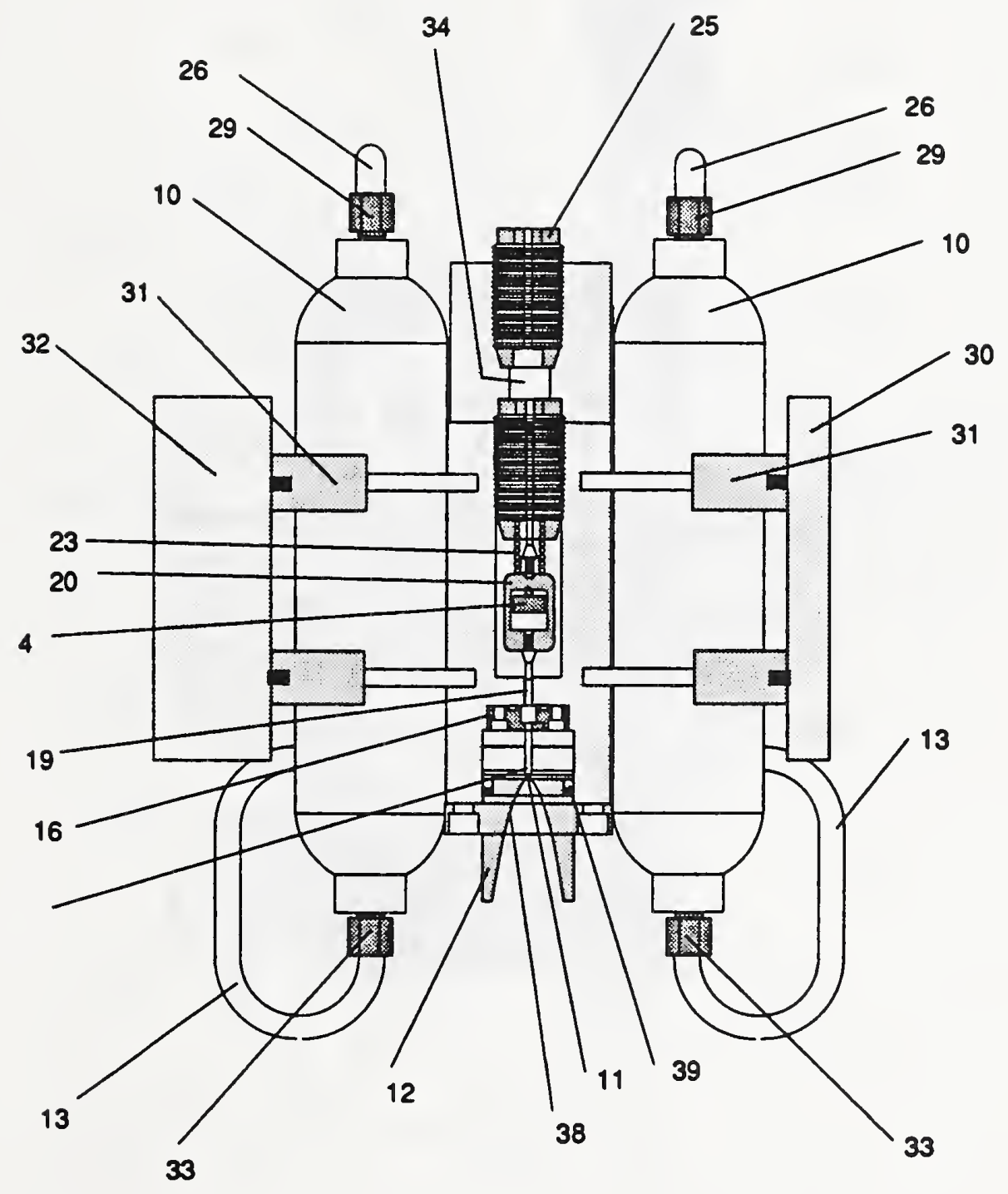

Fig. 2.8: End view of HSILS showing internal moving components (descriptions of numbered features are provided in the text). 


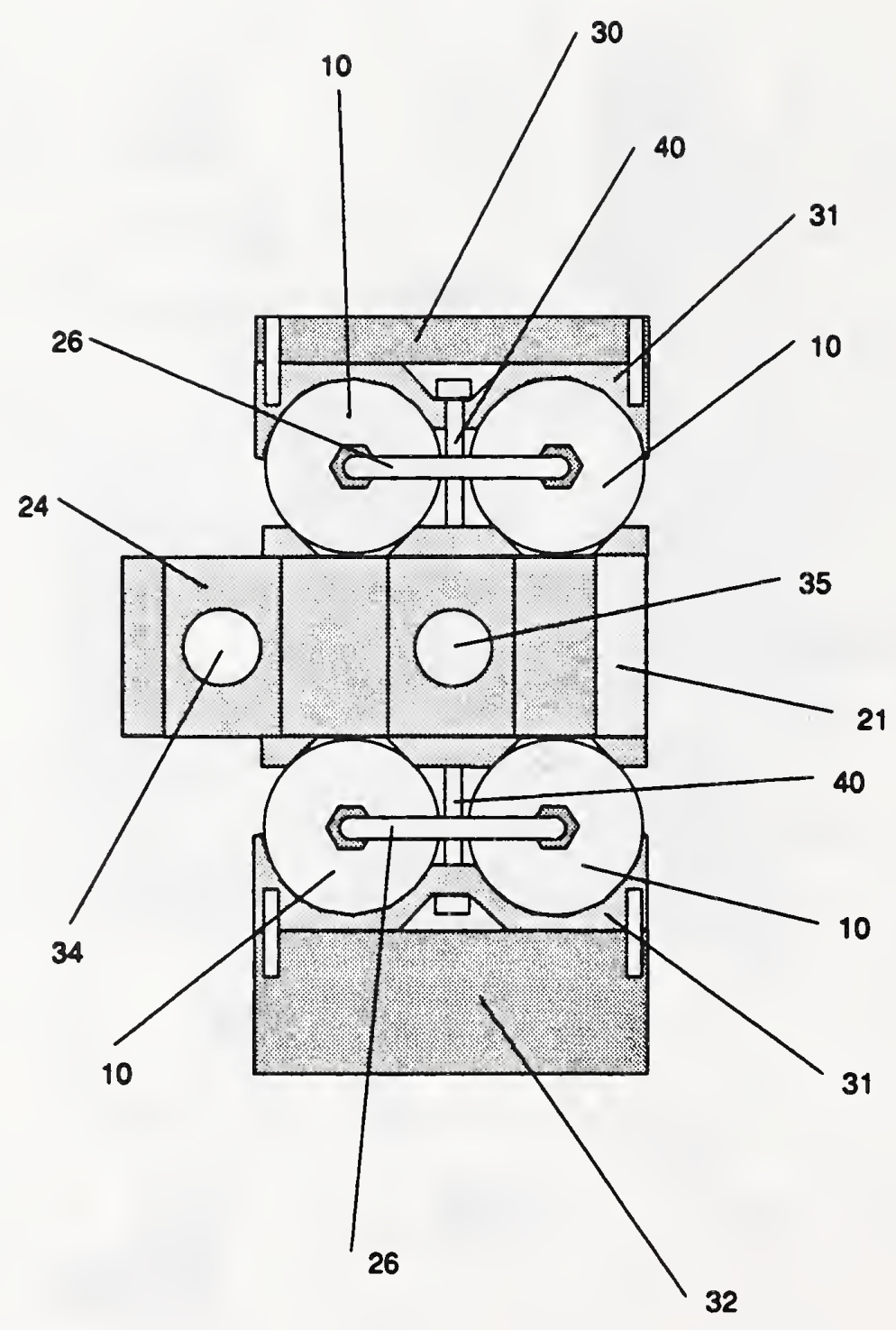

Fig. 2.9: Top view of HSILS showing gas accumulators, onboard pulse power and microcontroller subsystems and primary axes of piezoelectric stack and valve core rod (descriptions of numbered features are provided in the text). 


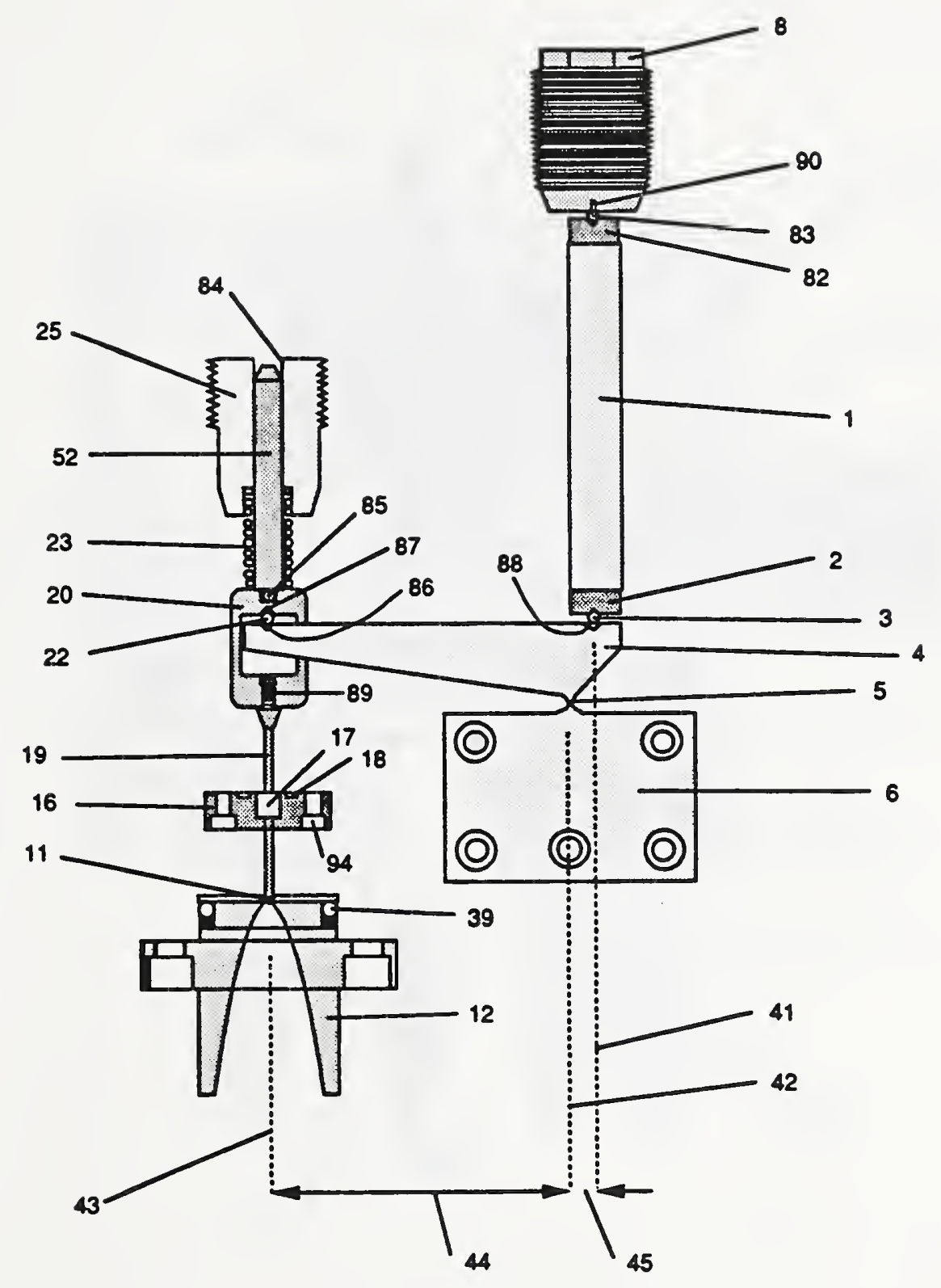

Fig. 2.10: Side view of HSILS showing all internal moving components, extracted from the housing and peripheral subsystems (descriptions of numbered features are provided in the text). 


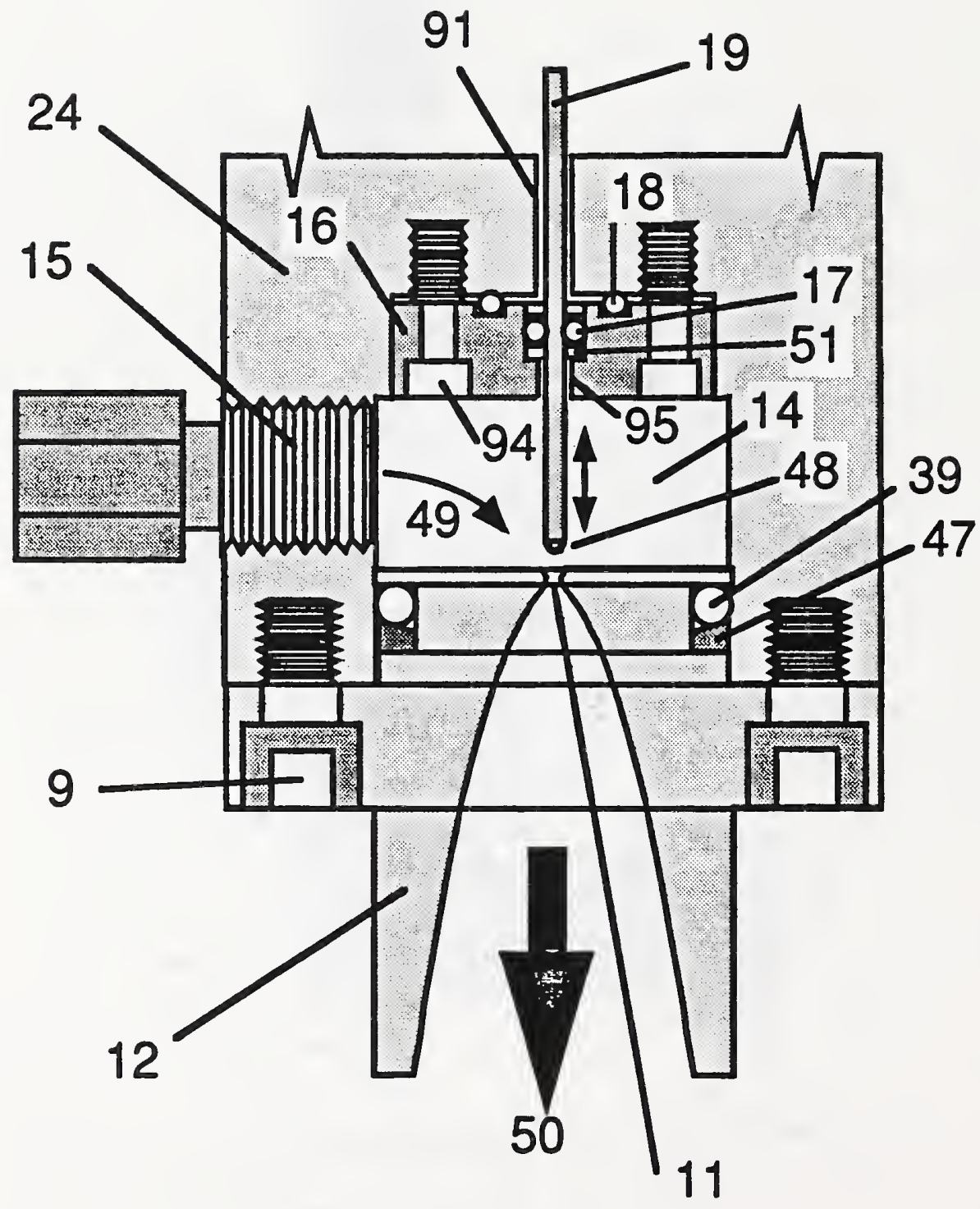

Fig. 2.11: Detail of the high pressure valve seat cavity of the HSILS unit showing valve core rod and nozzle throat seat; high pressure seals and backup rings for the valve core rod; and high volume high pressure feed line from the gas accumulators (detailed descriptions of numbered features are provided in the text). 


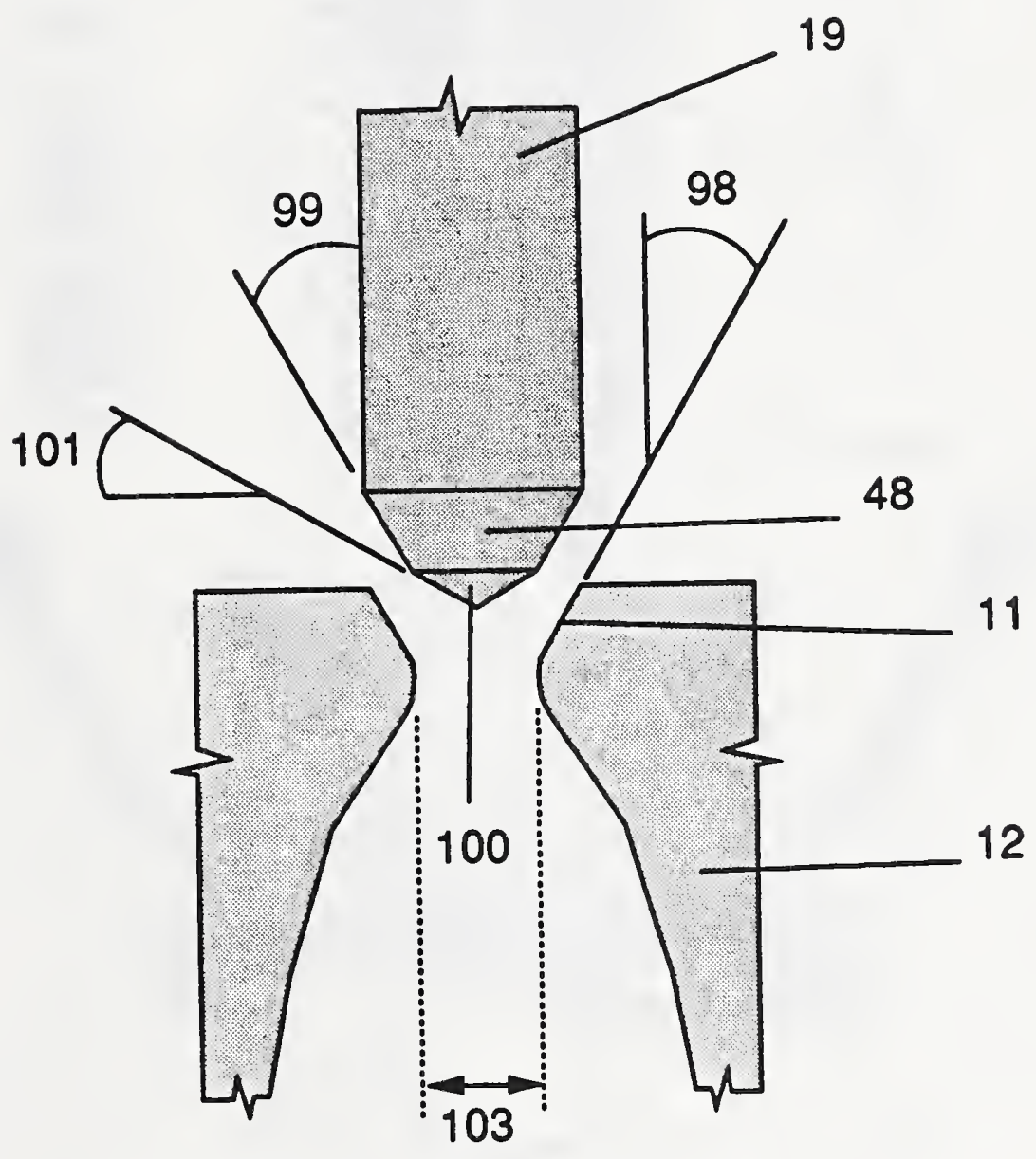

Fig. 2.12: Detailed view of the valve core rod and combination valve-seat/nozzle throat detal for the HSILS prototype (descriptions of numbered features are provided in the text). 


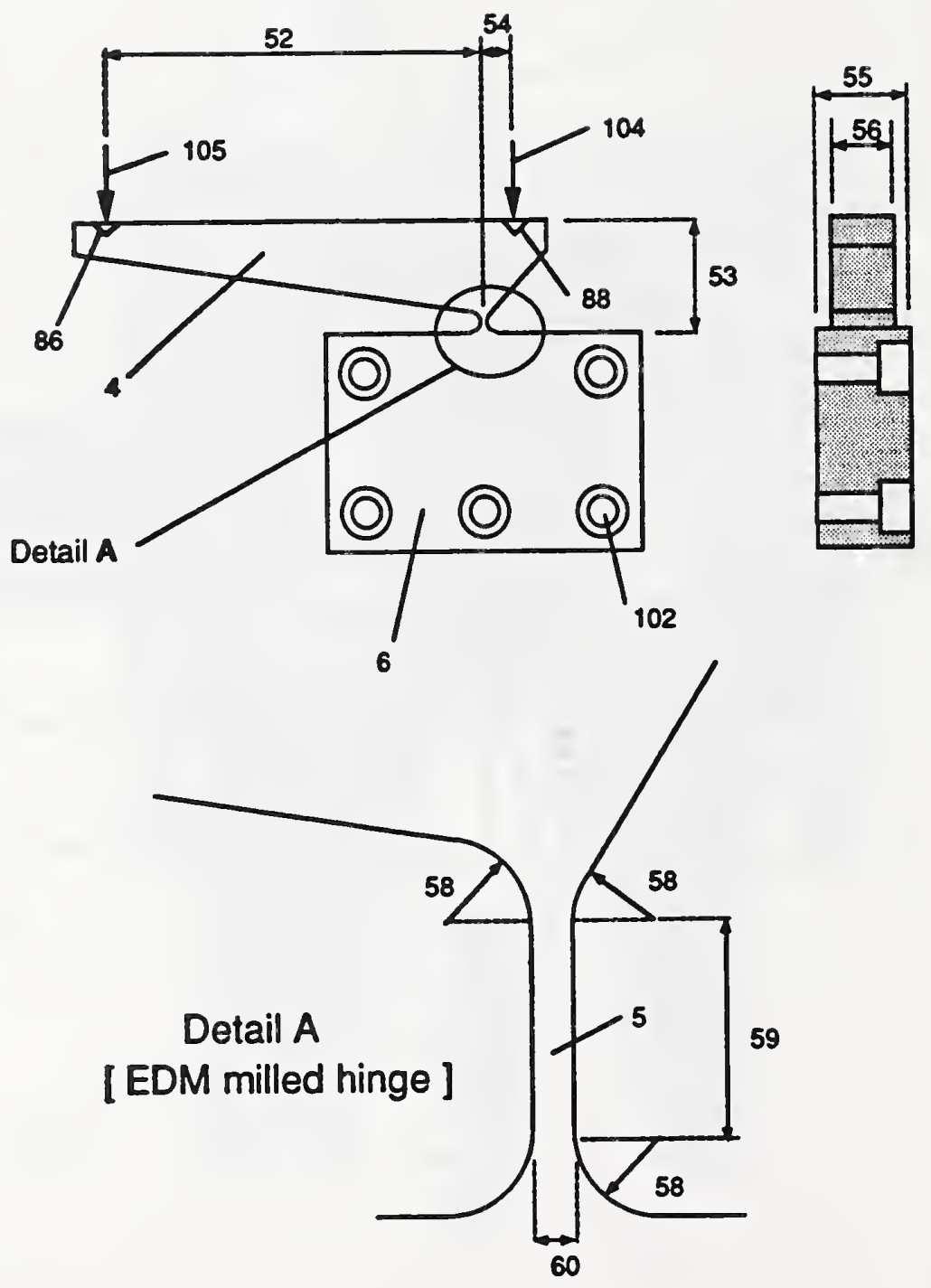

Fig. 2.13: Detail of HSILS displacement amplifier including EDM-milled hinge and conical seats for sapphire pivot bearings (descriptions of numbered features are provided in the text). 


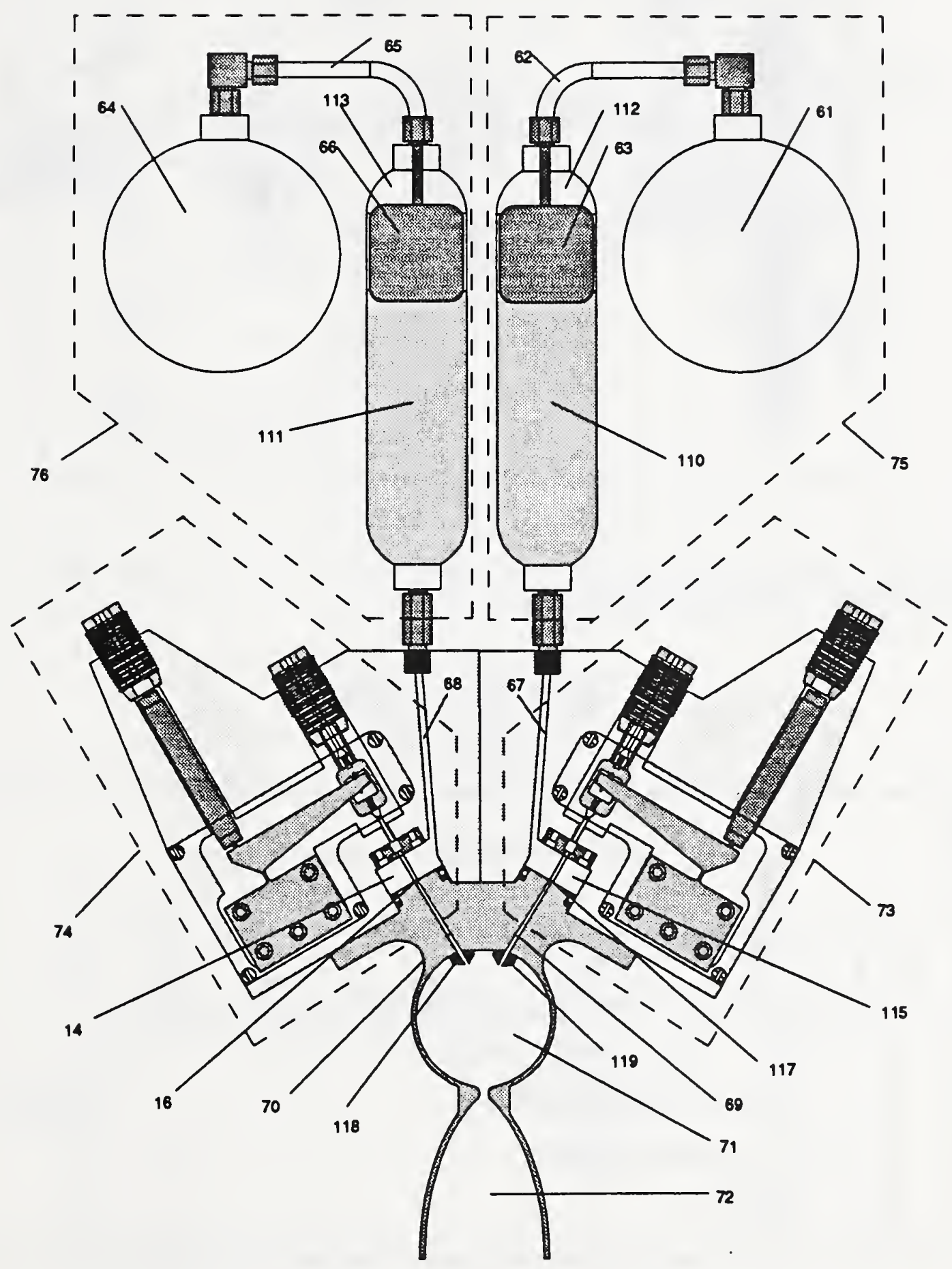

Fig. 2.14: Conceptual drawing of an HSILS-based variable fuel/oxydizer mixing ratio, variable thrust bi-propellant reaction control system for use in spacecraft control (descriptions of numbered features are provided in the text). 


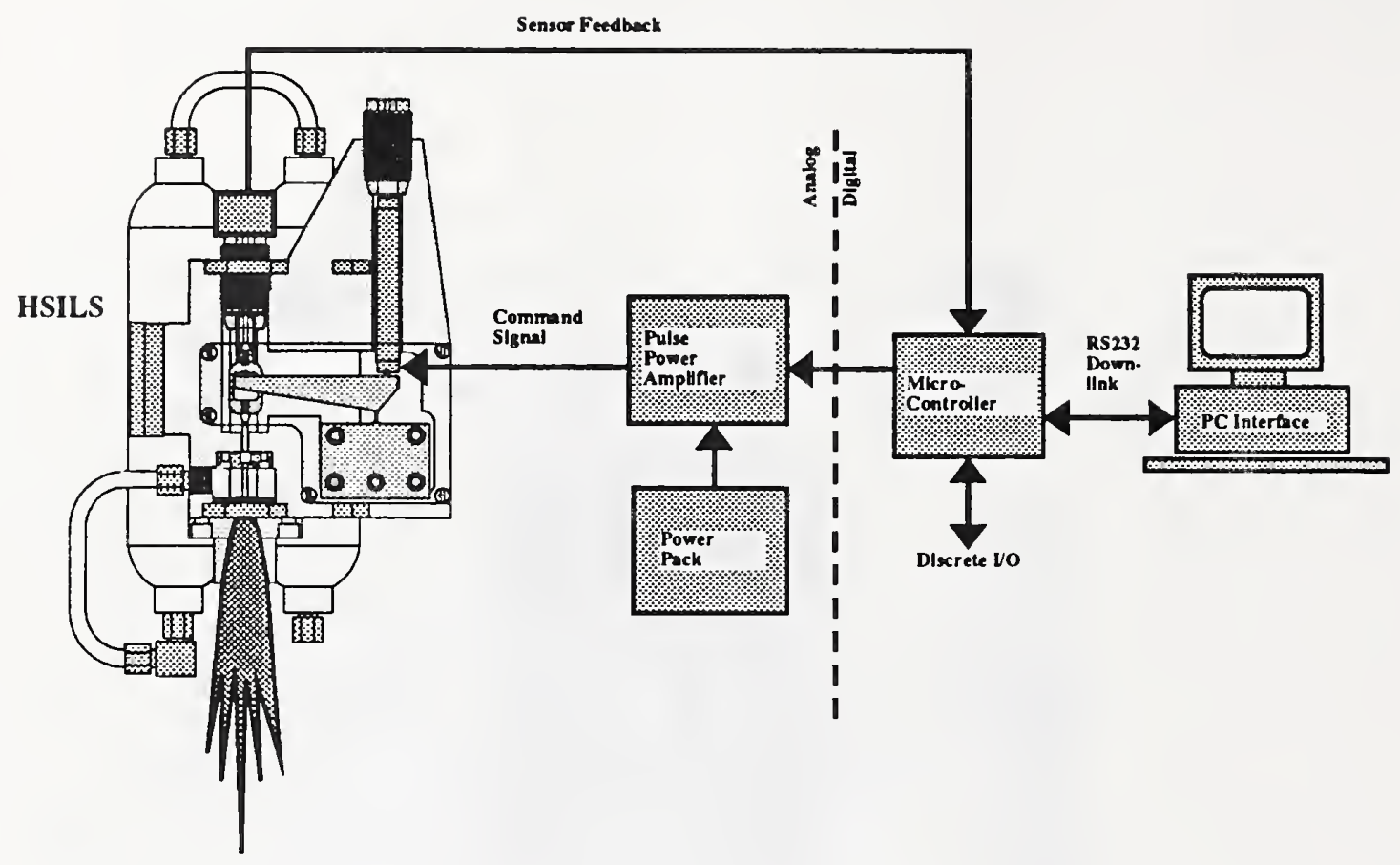

Fig. 2.15: HSILS control system block diagram.

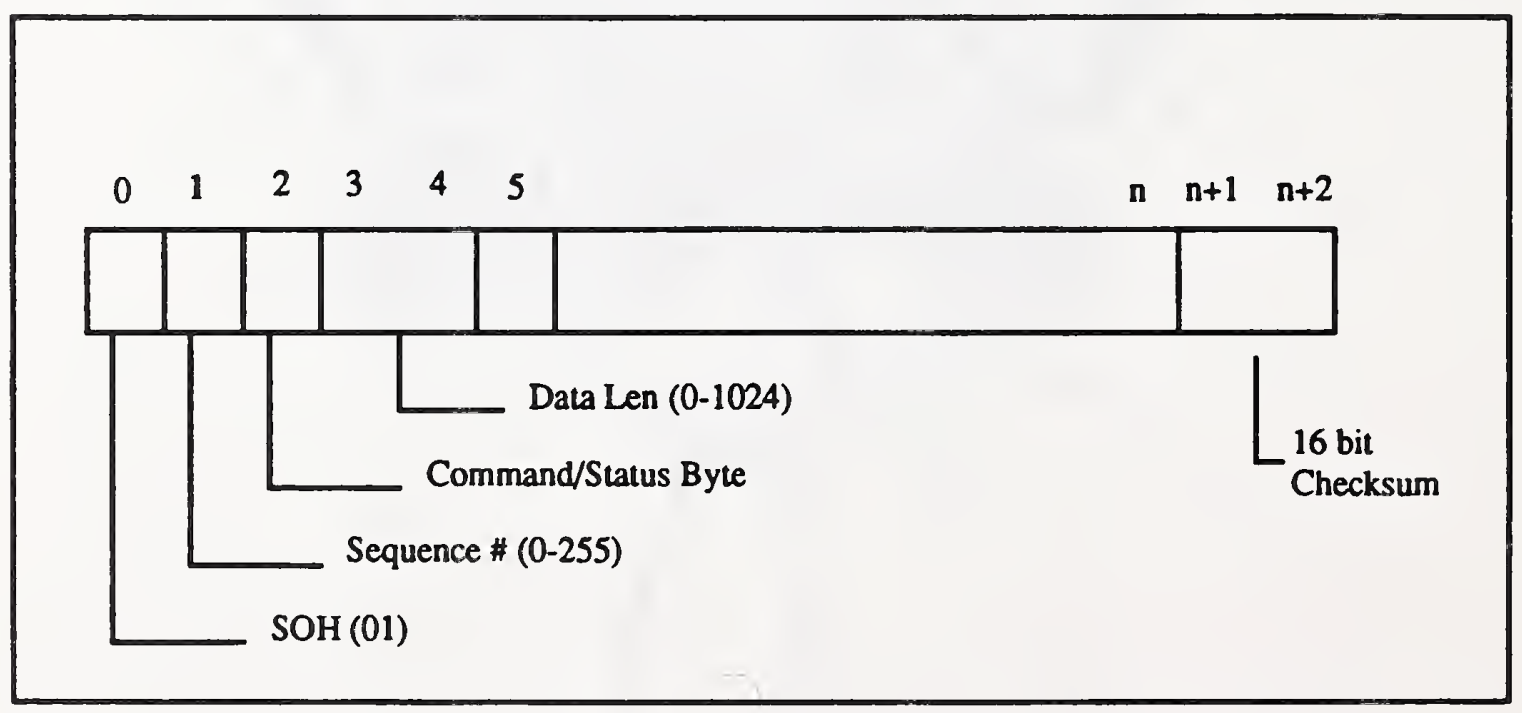

Fig. 2.16: Data packet format for PC-host to onboard microcontroller uplink/downlink communications. 


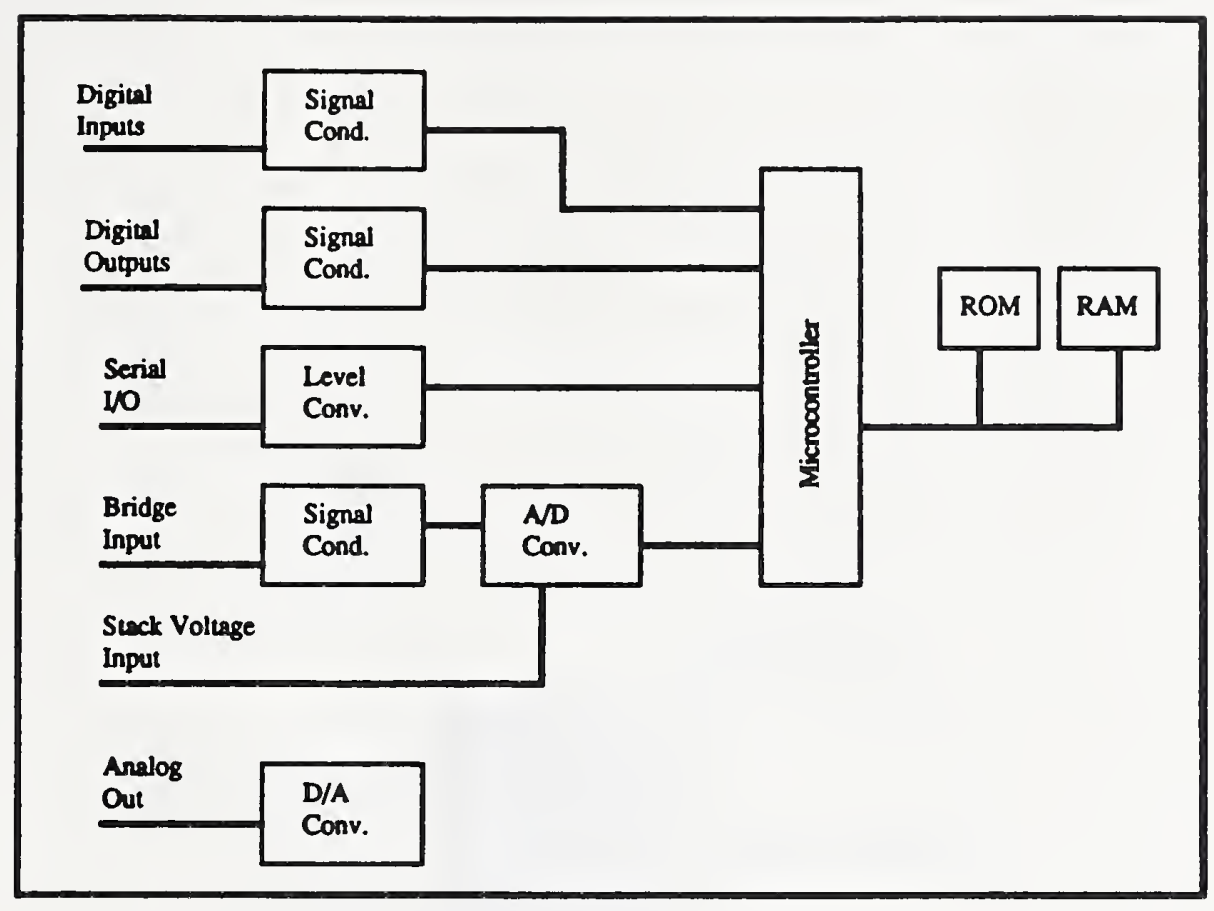

Fig. 2.17: HSILS microcontroller block diagram (see Appendix C for complete schematics).

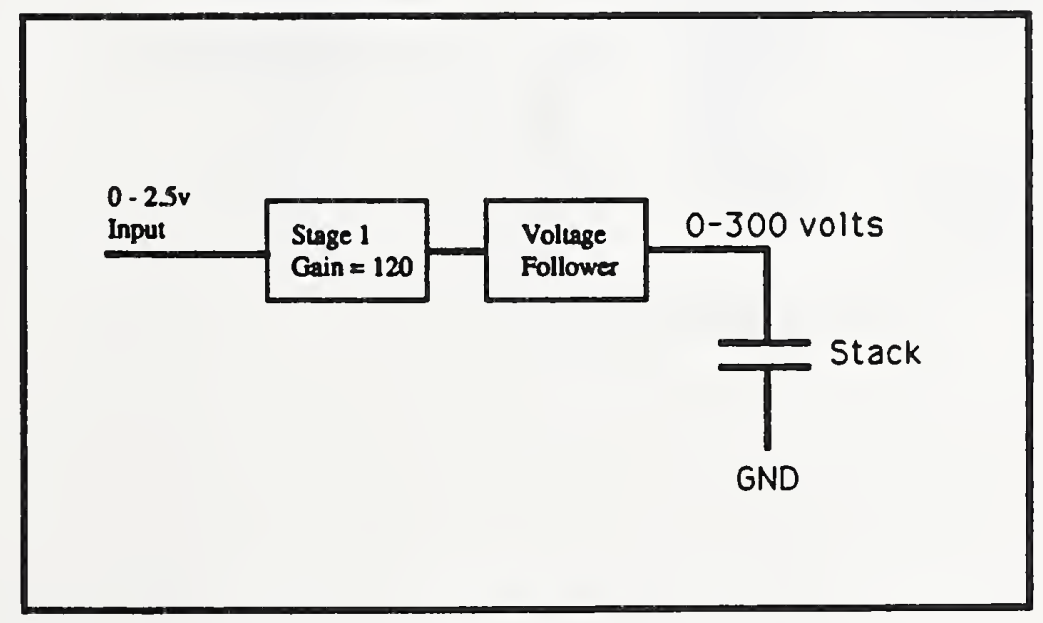

Fig. 2.18: HSILS pulse power amplifier block diagram. 


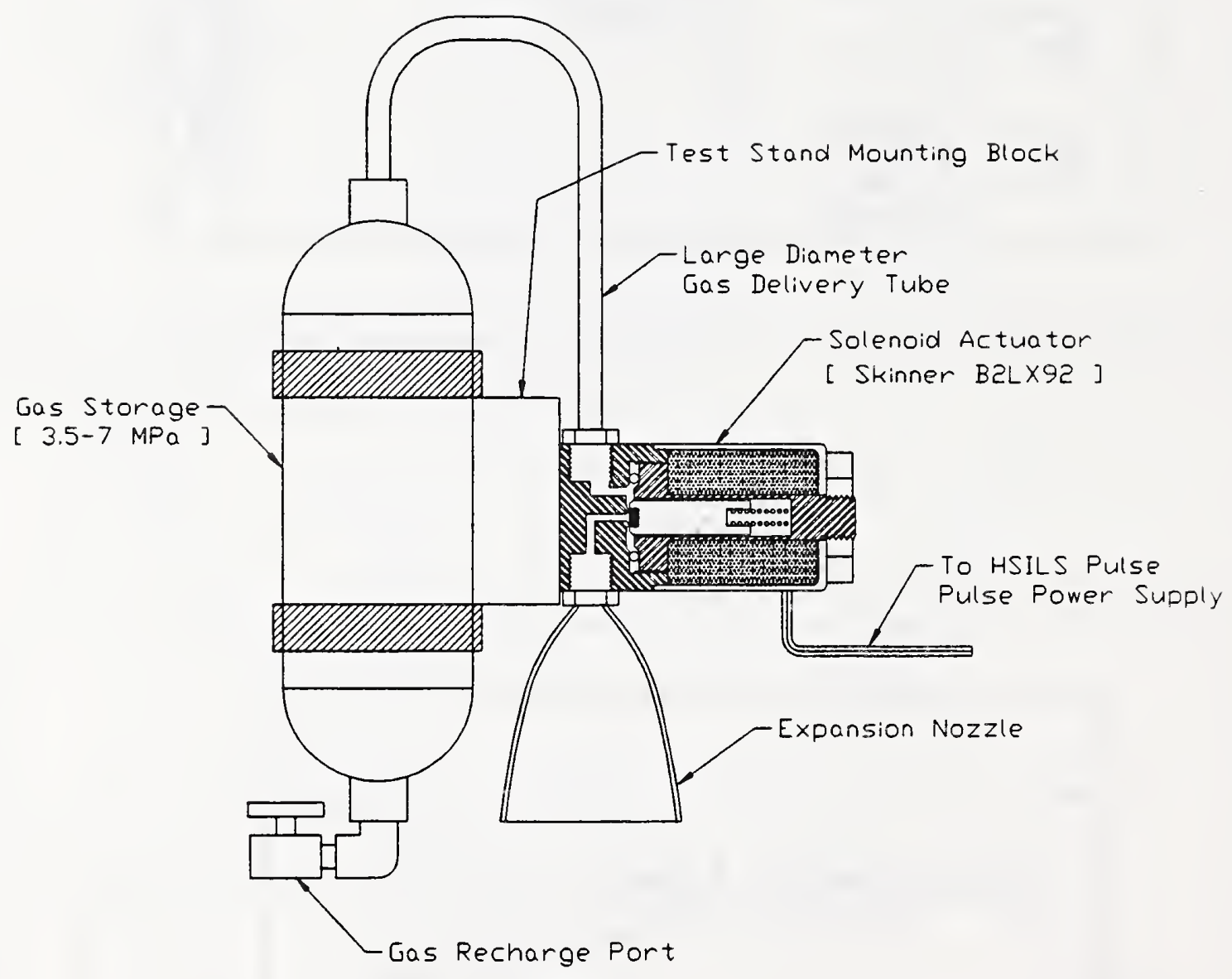

Fig. 2.19: Solenoid operated reaction control system (RCS) test bench. 


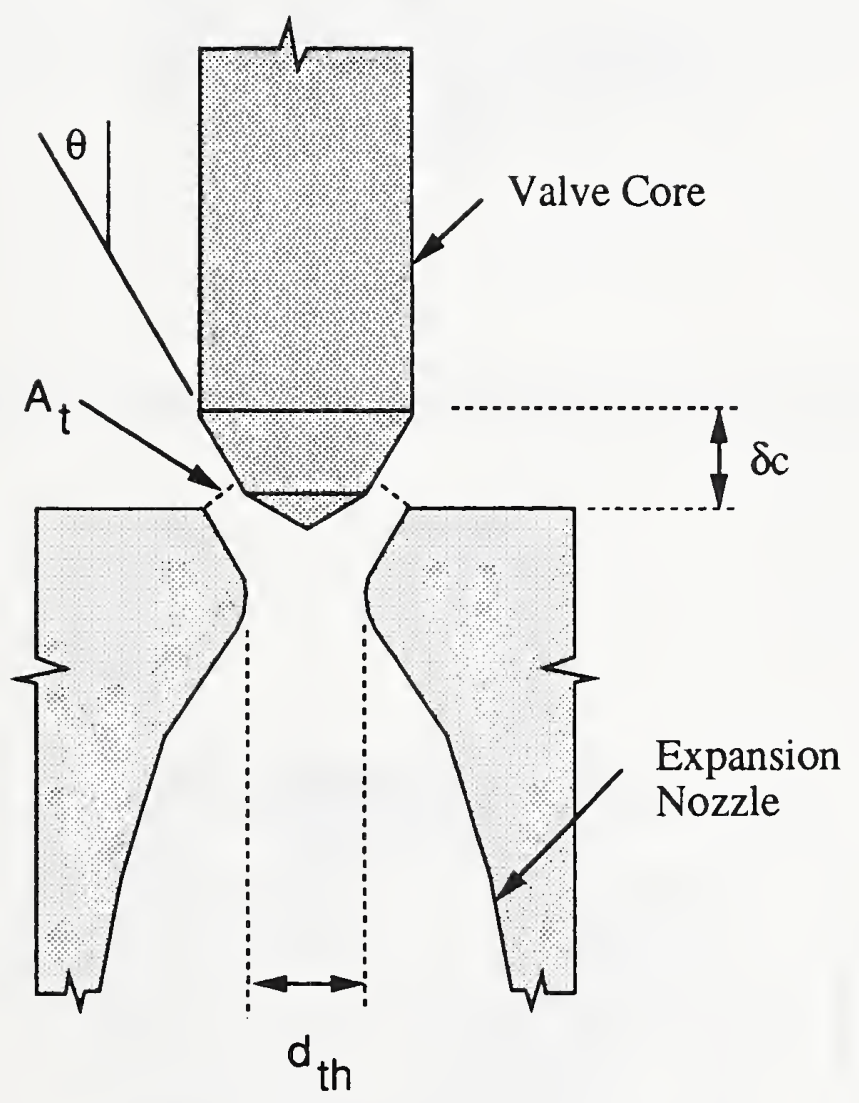

Fig. 2.20: Determination of effective nozzle throat area for HSILS prototype. 


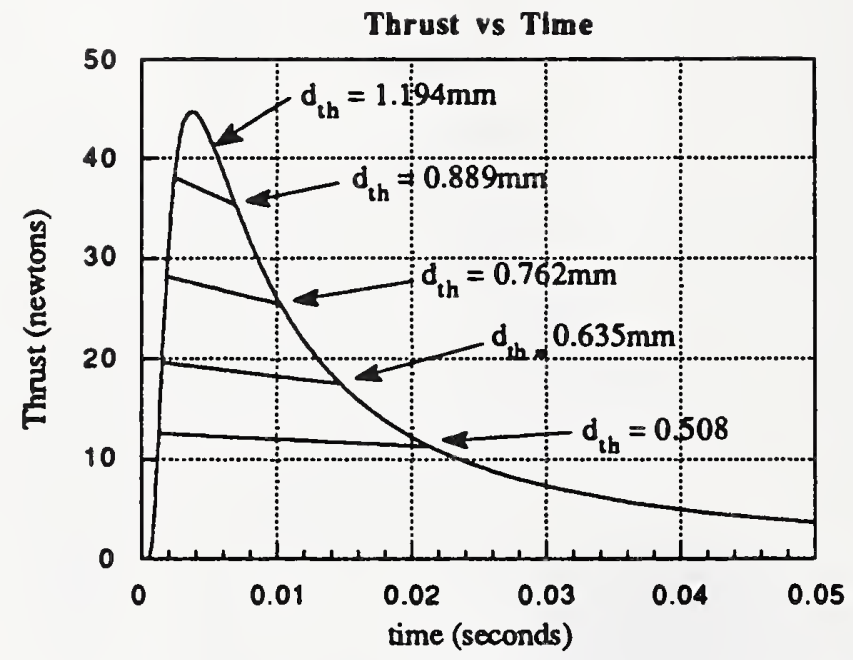

Fig. 2.21: Effect of nozzle throat diameter: thrust versus time simulation.

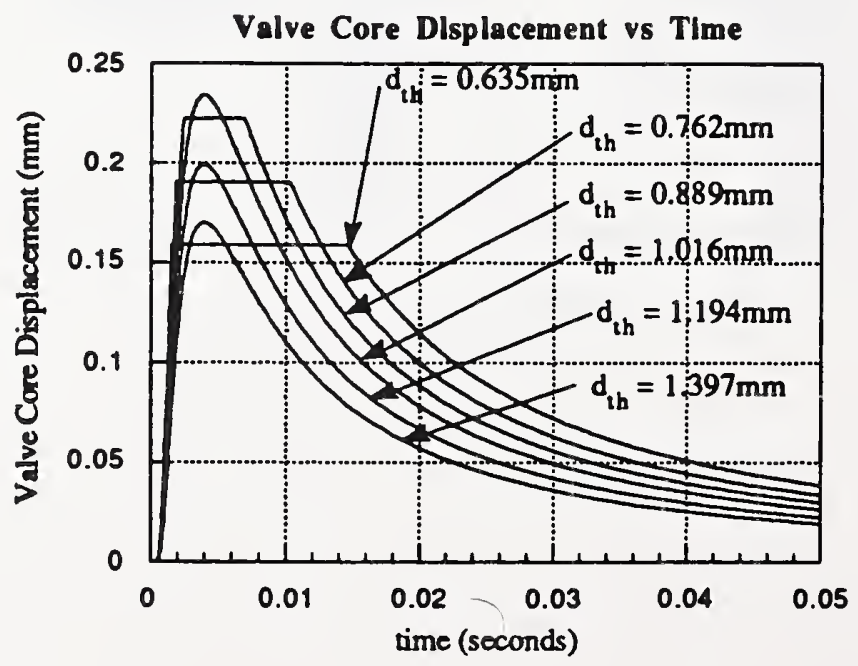

Fig. 2.22: Effect of nozzle throat diameter: core displacement versus time simulation. 


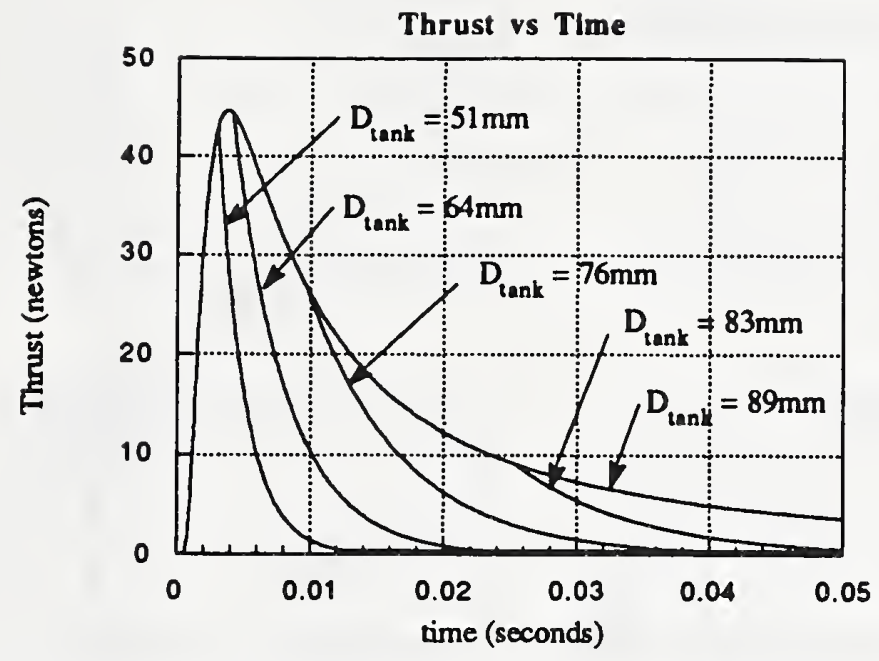

Fig. 2.23: Effect of pressure vessel volume: thrust versus time simulation.

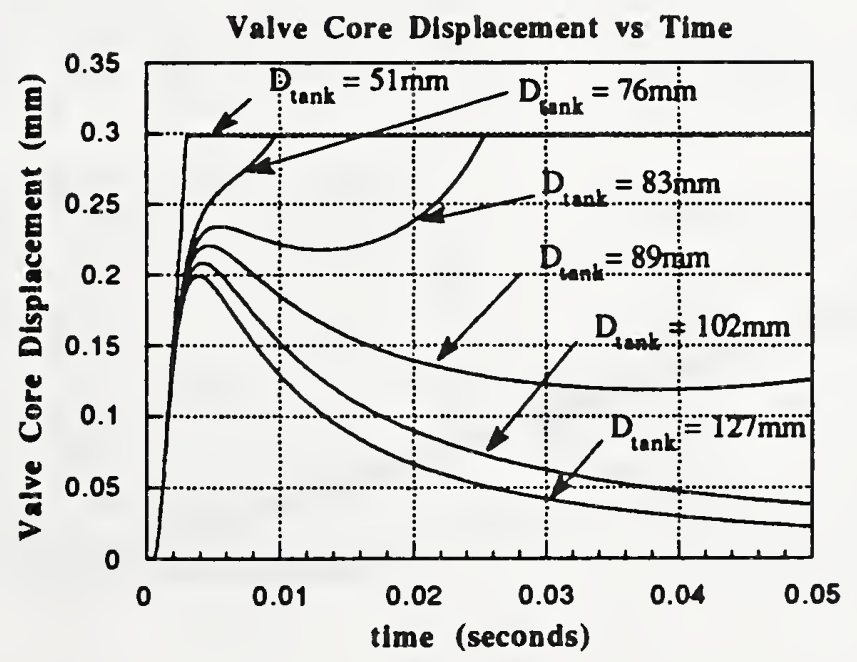

Fig. 2.24: Effect of pressure vessel volume: core displacement versus time. 

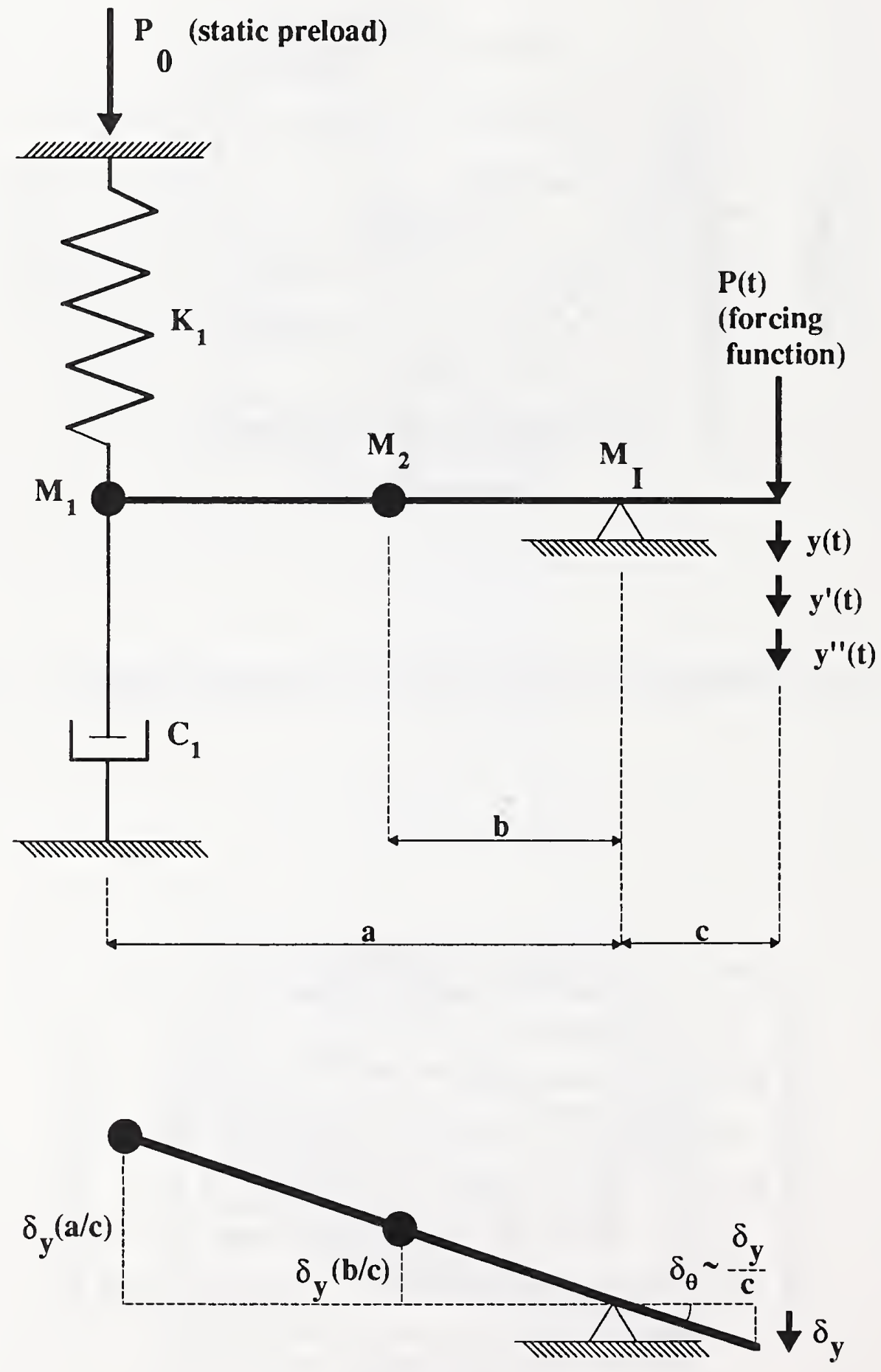

Fig. 2.25: Single degree of freedom model used for HSILS dynamic simulations. 

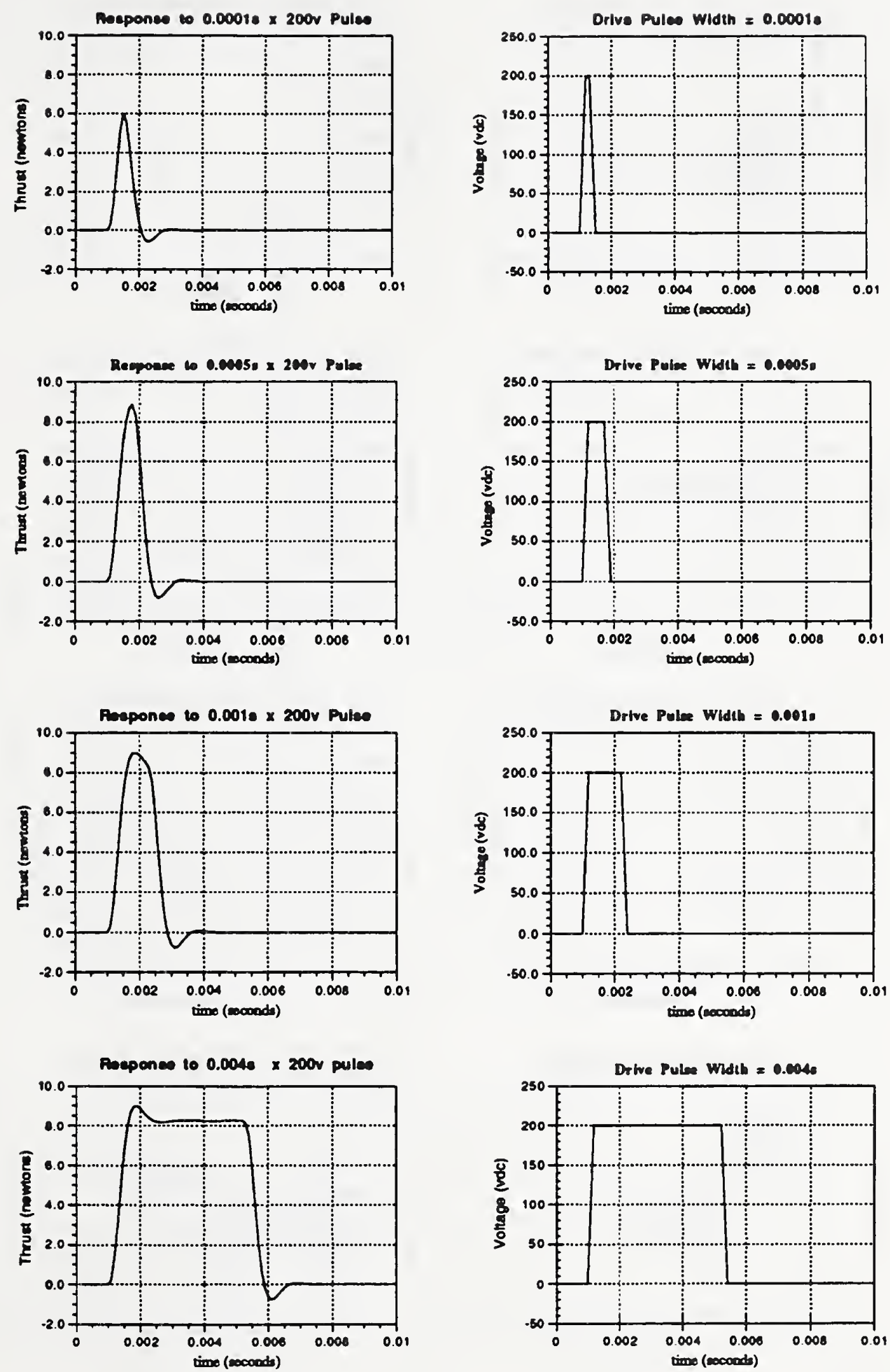

Fig. 2.26: HDYN-predicted HSILS response to various half square wave drive pulses assuming $388 \%$ of critical damping due to internal high pressure seals. HSILS predicted thrust versus time is plotted in the left column; drive pulse voltage-time histories are plotted on the right. 

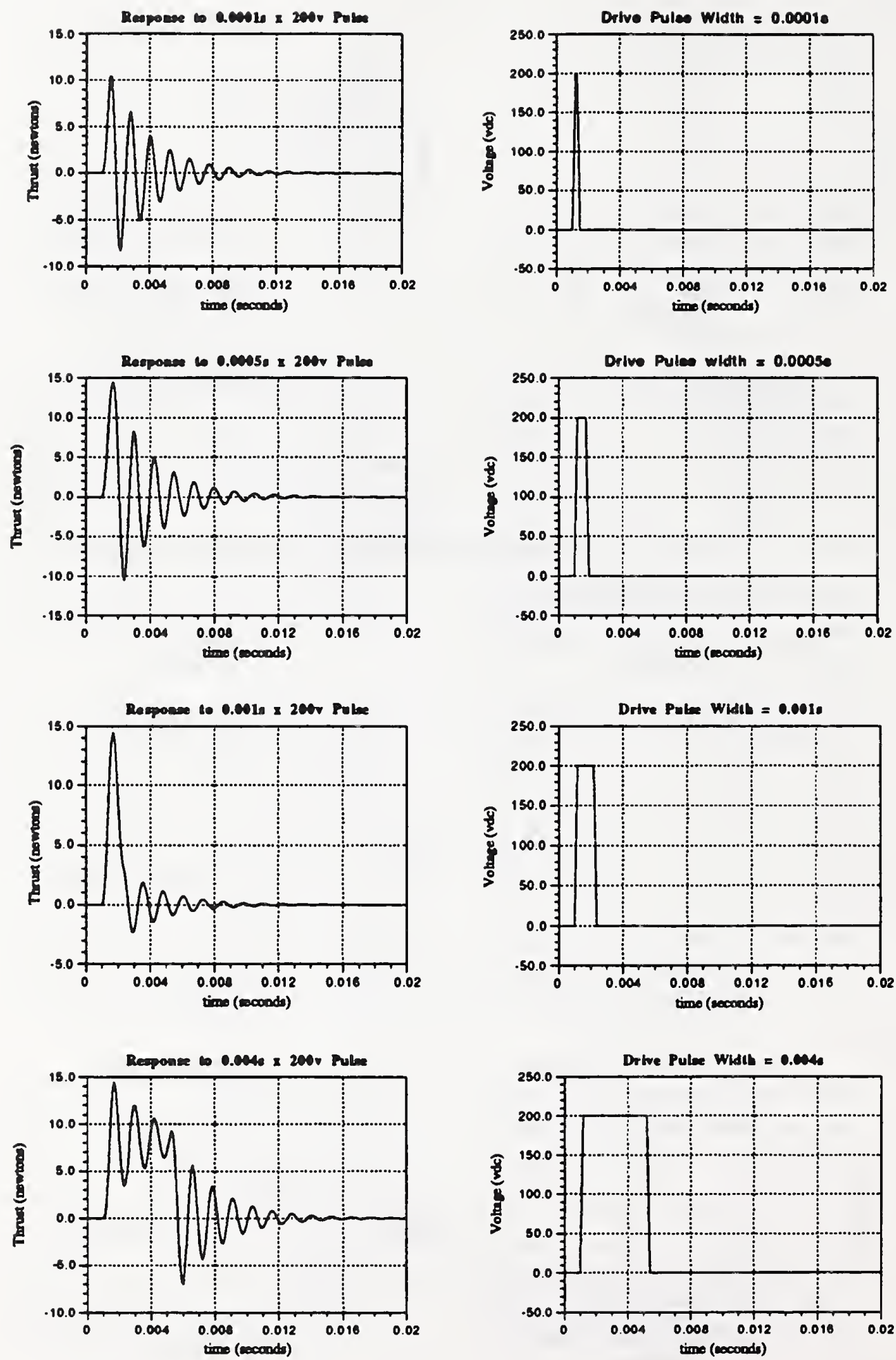

Fig. 2.27: HDYN-predicted HSILS response to various half square wave drive pulses assuming $50 \%$ of critical damping due to internal high pressure seals. HSILS predicted thrust versus time is plotted in the left column; drive pulse voltage-time histories are plotted on the right. 

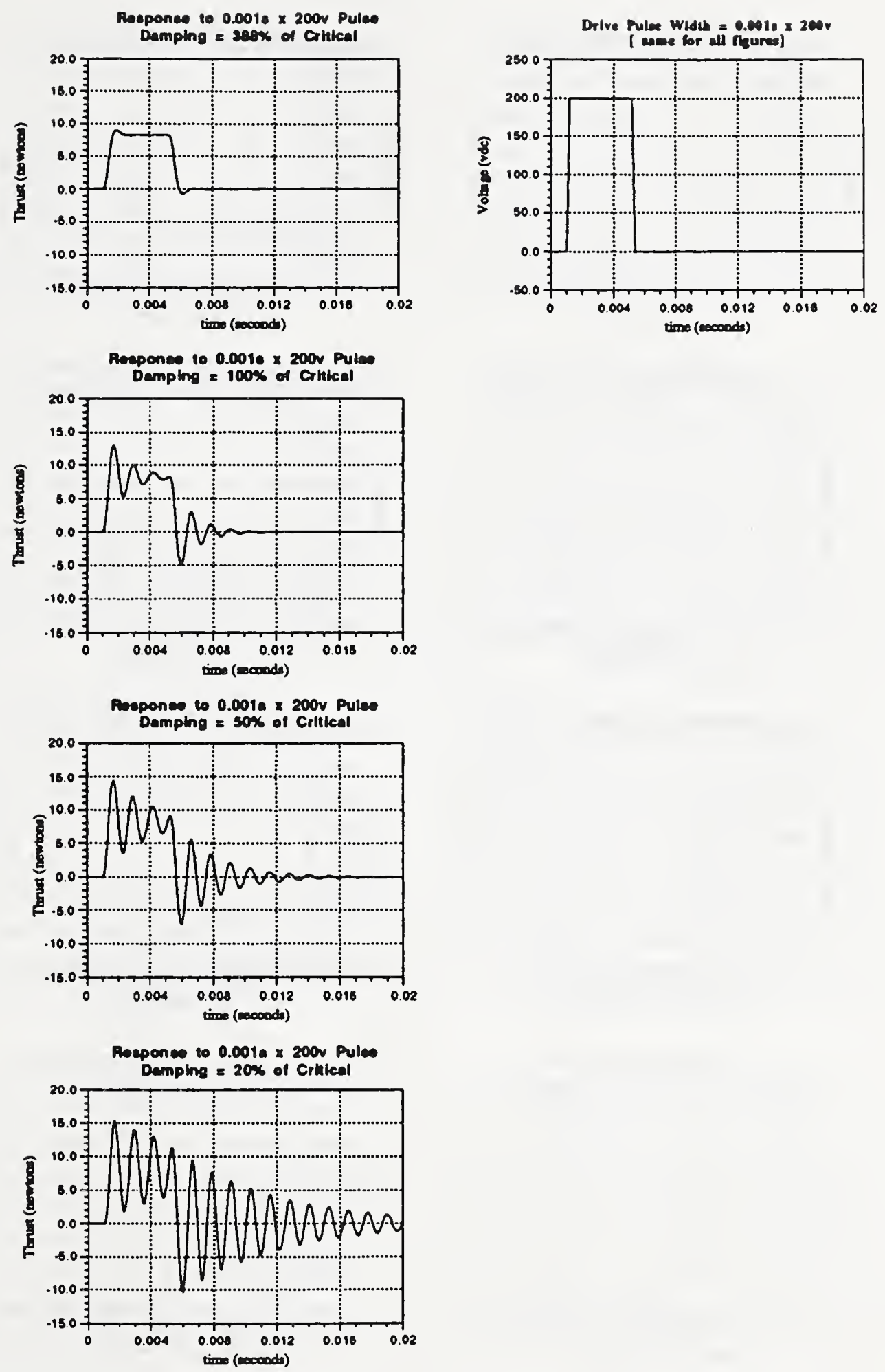

Fig. 2.28: HDYN-predicted HSILS response to various half square wave drive pulses for varying levels of viscous damping due to internal high pressure seals. HSILS predicted thrust versus time is plotted in the left column; drive pulse voltage-time history (common to all responses) is plotted on the right. 

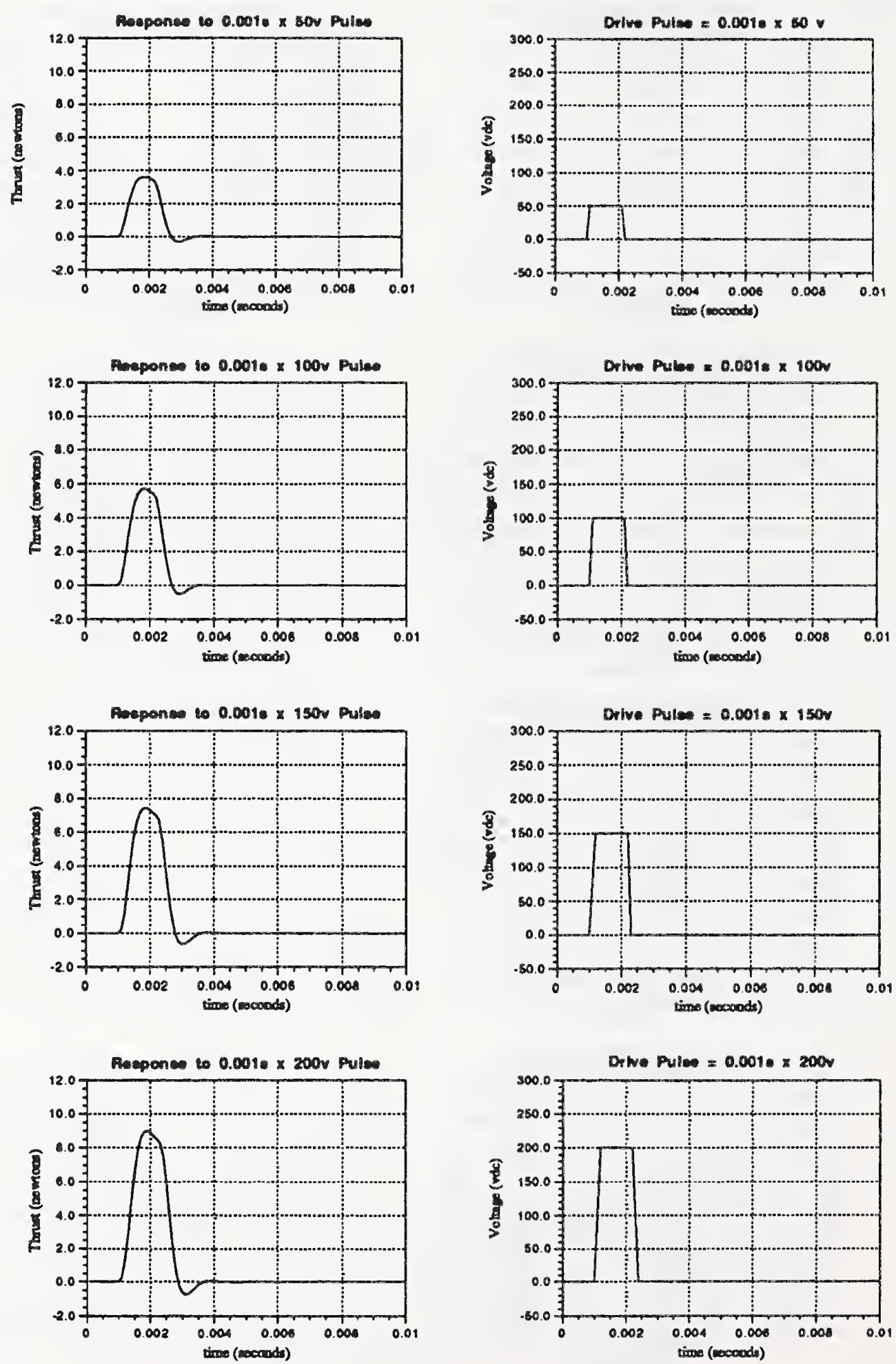

Fig. 2.29: HDYN-predicted HSILS response to various half square wave drive pulses of differing amplitude for $388 \%$ of critical damping due to internal high pressure seals. HSILS predicted thrust versus time is plotted in the left column; drive pulse voltage-time histories are plotted on the right. 

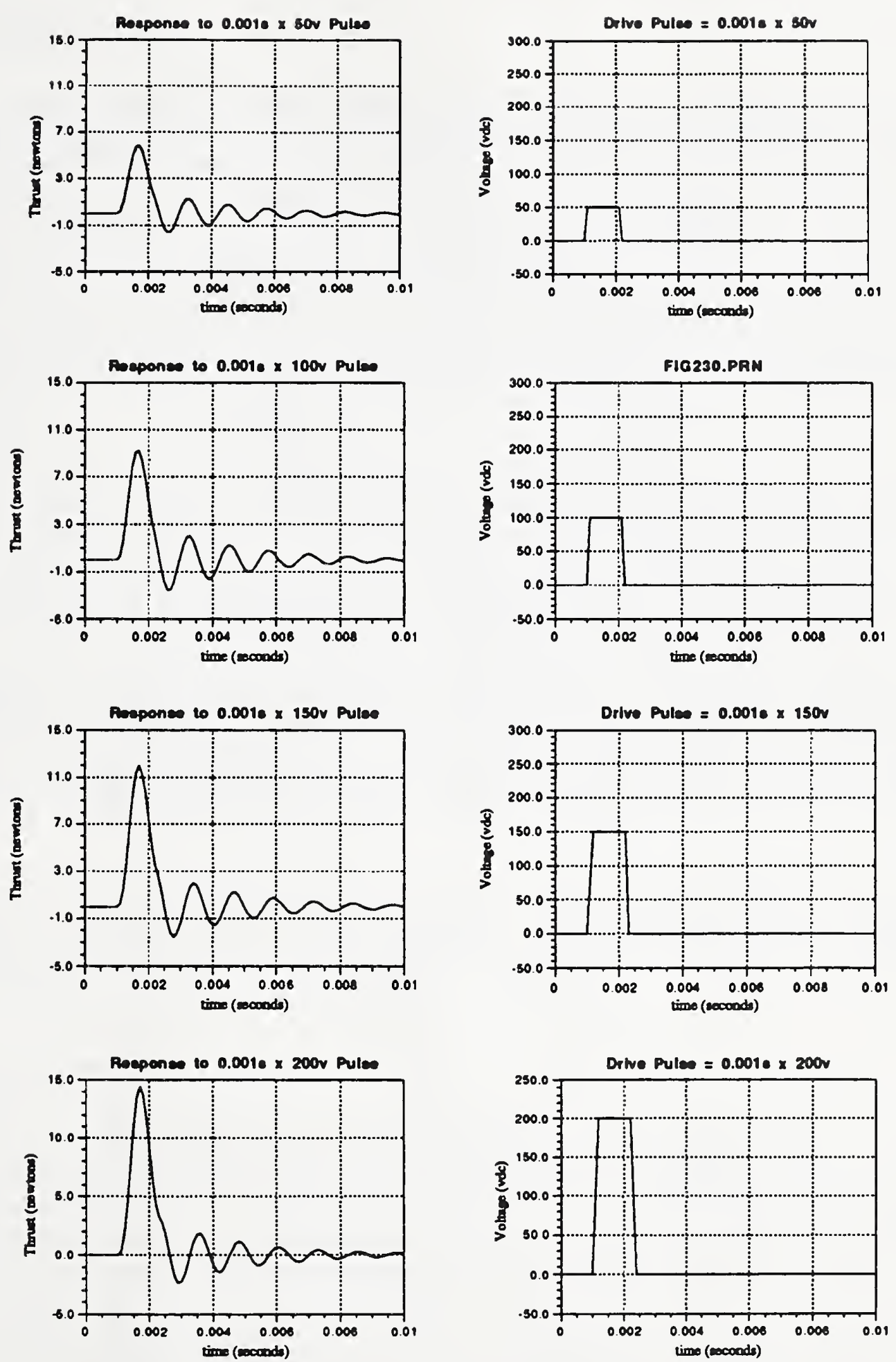

Fig. 2.30: HDYN-predicted HSILS response to various half square wave drive pulses of differing amplitude for $50 \%$ of critical damping due to internal high pressure seals. HSILS predicted thrust versus time is plotted in the left column; drive pulse voltage-time histories are plotted on the right. 


\subsection{Experimental Testing}

A laboratory prototype HSILS unit, shown in Figs. 3.1 through 3.4, was constructed in order to test the feasibility of the concept and to determine some of its operating characteristics and limitations. The hardware was fabricated in accordance with the shop drawings provided in Appendix D. Operational principles for the prototype were described in Chapter 2. The device shown in Fig. 3.1 comprises the entire HSILS unit, which can be operated in stand-alone mode once the compressed gas and capacitor storage banks are charged. No great efforts were undertaken to minimize space and weight. Hence, the large box to the left of the thruster unit was used to house the onboard microcontroller, capacitor discharge banks, and power amplifiers. The smaller boxes comprised signal conditioning and power supplies for acoustic and pressure sensors used to measure pulse width and thrust.

Fig. 3.2 shows a side view of the HSILS unit including a $41.4 \mathrm{MPa}$ dry nitrogen charging line connected to the onboard gas accumulator bank. Once the accumulators were charged this line could be disconnected and several tests conducted before recharging became necessary. The high voltage $(0-300 \mathrm{~V})$ output of the pulse power supply was connected to the piezoelectric stack via a jacketed BNC type connecter, shown at mid-height on the left of the unit. Fig. 3.3 shows a top view of the exhaust nozzle and the feed lines for the gas accumulators. The nozzle was designed for easy removal and access to the replaceable throat seat shown in Fig. E.18 in Appendix E. Fig. 3.4 shows a view of the internal working components of the HSILS including the titanium displacement amplifier, the piezoelectric stack and its associated sapphire spherical end bearings, and the connector/pivot mechanism which links the displacement amplifier to the valve core rod and its associated spring return system.

Fig. 3.5 shows a view of the solenoid operated reaction control system (RCS) which was used as a "control" reference with which to compare the performance of the HSILS unit. Operating pressures for this unit were limited to approximately 5.5 MPa. This device was described earlier in Chapter 2 (see Fig. 2.19).

\subsection{Onboard Sensors}

It was initially thought that a responsive load cell could be used to measure the thrust output of both the HSILS and RCS (solenoid reaction control system) systems. However, and as was subsequently ascertained independently by Hallauer and Smith (Hallauer and Smith, 1990), this led to unwanted high-level noise in the response signal which represented the vibration of the structural system consisting of the force actuator and the load cell. It was shown that this effect became worse as efforts were made to make the load cell more sensitive (and therefore more flexible). Hallauer and Smith ultimately made use of dynamic piezoelectric based load cells which were by nature quite stiff. However, at the time of testing at NIST piezoelectric cells were not available and alternative methods were developed for determining the minimum pulse width resolution and amplitude (thrust) reponse of the two candidate actuators. 


\subsubsection{Acoustic}

The first sensor to be used consisted of a commonly available PC Mount condenser microphone element. The actual unit was manufactured by Tandy Corp. Cat. No. 270-090 and had a 2.0 to $10 \mathrm{~V}$ operating range; $1.0 \mathrm{~mA}$ maximum current drain; $40 \mathrm{~dB}$ minimum signal to noise ratio; $-65+/-4 \mathrm{~dB}$ sensitivity over the range of $20 \mathrm{~Hz}$ to $20 \mathrm{kHz}$; and an output impedance of $1 \mathrm{k}$ ohms. This element was placed at the exhaust lip of the actuator nozzle as shown in Figs. 3.6 and 3.7 for the HSILS and RCS units, respectively. This meant that there was an inherent delay from the time the valve core first lifted off the seat until the sensor detected perceptible thrust of approximately 75 microseconds, owing to the propagation speed of sound in air. This was included in the rise-lag times recorded in the data tables described below.

\subsubsection{Static Pressure}

While the acoustic sensor provided an accurate means for determining pulse width, it was incapable of providing quantitative thrust measurement data (qualitatively, the noise amplitude did appear to be proportional to thrust but there was no means of calibrating this). Given the low levels of anticipated thrust an approach was developed which employed a vented chamber that was attached to the end of the nozzle as shown in Figs. 3.8 and 3.9 for the HSILS and RCS (solenoid) thruster units, respectively. A Keller-PSI PAA-9, 10 bar semiconductor absolute diaphram pressure transducer was mounted on the face of the vented chamber opposite the actuator nozzle. Thrust was then measured indirectly by means of equivalent static exhaust pressure.

\subsection{Pulse Width Tests}

Pulse width tests for each type of actuator were conducted using the following procedure:

1) The acoustic sensor (or pressure sensor in the case of the second set of RCS tests) was positioned and the gas accumulator and power capacitors were charged.

2) A specific drive pulse of the form "P XXX YYY" was entered at a remote personal computer which was connected to the onboard microprocessor via a communications cable. This in turn, caused the onboard microcontroller to execute a power discharge to the actuator in the form of a half square wave of width "XXX" seconds and having a peak (plateau) amplitude of "YYY" volts, DC. The drive pulses had typical rising and falling slopes (switching rates) of $1 \mathrm{~V} /$ microsecond. Further information on the pulse downloading operation is presented in Appendix F.

3) A two channel digital signal analyzer acquired data from the acoustic sensor and also recorded the drive pulse at a rate of $100000 \mathrm{kHz}$ beginning 50 microseconds prior to the rising edge of the drive pulse. These records were stored on disk for further processing.

4) The response of the actuator was examined using the parameters previously defined in Fig. 2.2. These included: drive pulse width; drive pulse amplitude; response rise lag; response pulse width; and response fall lag. 


\subsubsection{RCS Tests}

Tables 3.1 and 3.2 present a sample of pulse width response data for the RCS (solenoid) actuator for drive pulse widths beginning at 0.1314 seconds and decreasing to $3.5 \mathrm{~ms}$. From these it may be observed that the correlation between the drive and response pulse widths begins to degrade for shorter pulse widths. That is to say, for example, that a $0.0036 \mathrm{~s}$ drive pulse produces a $0.0301 \mathrm{~s}$ response, not a $0.0036 \mathrm{~s}$ response (as shown in Fig. 3.11, third row from the top). This may be interpreted as approaching the minimum "full-on" pulse width, which comprises the time to energize the inductive solenoid coil, for the magnetic core to lift off and compress the return spring, and for the field to collapse and the compression spring to return the core to its closed position. At some point a drive pulse becomes short enough to produce a "ballistic" trajectory from the valve core: that is, the energy is insufficient to pull the valve core away from the exhaust orifice to its fully retracted position, but it is sufficient to just cause lift off. This type of response can be seen in Fig. 3.11, bottom row and can be considered the minimum achievable pulse from the RCS actuator. Tests shown in Figs. 3.10 and 3.11 were conducted with a nominal drive pulse amplitude of $20 \mathrm{~V}$ and $39 \mathrm{~V}$, respectively. The response characteristics that result from these different amplitudes are discussed in Chapter 4 below.

\subsubsection{HSILS Tests}

Fig. 3.12 presents the results of 16 representative tests of the HSILS prototype for drive pulse widths beginning at $0.01026 \mathrm{~s}$ and decreasing to $0.00025 \mathrm{~s}$ (250 microseconds). Complete tabular listings of pertinent data for these tests are contained in Table 3.3. Note in these figures the compressed time scale. Most of the responses are less than $3 \mathrm{~ms}$ and the limiting pulse less than $1 \mathrm{~ms}$. As a result the nature of the acoustic noise that is superimposed on the signal is more evident than for the RCS tests. It has been determined from frequency analysis that the noise has a strong dominant frequency of approximately 4 $\mathrm{kHz}$. This corresponds quite closely to the characteristic resonant frequency of the expansion nozzle. Since the nozzle continues to vibrate for a small period of time after ceasation of the delivery of gas there is to be expected a resonant decay (centered about the $\mathrm{X}$-axis) at the tail end of each pulse. This is seen in most of the shorter HSILS response pulse records. In all such cases there is a dramatic reduction in overall amplitude at the point at which the valve closes. This point corresponds to the termination of thrust.

There is a limiting drive pulse amplitude, below which measureable thrust is not produced by the HSILS. This threshold can be seen in the last two rows of Fig. 3.12d for drive pulse amplitudes of 85 and 44 volts, respectively. The limiting drive voltage appears, for the current HSILS configuration, to be approximately 85 volts. That such a threshold drive voltage exists can be understood by considering the blocked force diagram for the piezoelectric stack presented earlier in Fig. 2.5. The stack must initially generate a force necessary to cause the valve core to lift off the valve seat by an amount sufficient to create measureable thrust. However, such motion is prevented by the return spring at the end of the displacement amplifier. The force necessary for lift off is therefore the return spring precompression times the amplification factor for the displacement amplifier, which in the case of the HSILS prototype unit was 12 . Since experimental data indicated that an 85 volt amplitude was required to initiate measureable thrust, using the stack equations given in Fig. 
2.5 one can back calculate that the valve core displacement at that time was $0.007 \mathrm{~mm}$.

Further discussion on limiting pulse widths for both the HSILS and RCS actuators is presented in Chapter 4.

\subsection{Amplitude Control Tests}

The ability to "intelligently" create an output thrust profile from an active control system implicitly requires the ability to vary the thrust amplitude. Thus far we have addressed the response speed or reaction time of two actuator systems. This will, ultimately, determine the time-domain precision with which one can create an "intelligent" pulse. A subsequent series of tests were conducted on both the HSILS and RCS units to determine their steady state response to various amplitude control voltages. The test protocol was as follows:

1) The Keller absolute pressure sensor was positioned as previously described in Figs. 3.8 and 3.9 and the gas accumulator and power capacitors were charged.

2) A continuous DC voltage was applied to the respective actuators for a period of approximately 0.5 second (corresponding to the previous nomenclature of "P 500000 YYY", in which YYY was the drive pulse amplitude).

3) A two channel digital signal analyzer acquired data from the acoustic sensor and also recorded the drive pulse at a rate of $100000 \mathrm{kHz}$ beginning 50 microseconds prior to the rising edge of the drive pulse. These records were stored on disk for further processing.

4) The mean thrust was determined from the average output signal after attaining steady state (valve open) response. This value, and the drive voltage amplitude, were then recorded.

\subsubsection{RCS Tests}

Table 3.4 contains the experimental data for this series of tests. Fig. 3.13 shows the amplitude response characteristics for the RCS (solenoid) actuator. This clearly indicates the presence of a threshold drive voltage of approximately $17 \mathrm{~V}$. After this threshold has been reached the level of thrust is shown to be constant with increasing voltage. This type of performance, as previously discussed in Chapter 1, is the primary impediment to using solenoid based actuators for intelligent control. Other limitations, in the form of rise and fall lag times and minimum pulse width are discussed in detail in Chapter 4.

\subsubsection{HSHS Tests}

Table 3.5 contains the experimental data resulting from this test series. Fig. 3.14 shows the amplitude response characteristics for the HSILS prototype. This indicates linear amplitude response with increasing drive voltage. There is, as was discussed above, a threshold drive voltage of approximately 85 volts which corresponds to the drive voltage necessary to create stack compressive forces which can overcome the amplified valve core return spring force. There is some scatter to the data beyond a drive voltage of approximately 180 volts, although the trend (increasing thrust with increasing drive voltage) is still preserved. It is the author's belief that the scatter was a product of turbulence within the static pressure 
sensing attachment at higher gas flow rates and that, given more sophisticated means for measuring actual thrust, such variability could be eliminated. A regression equation relating output thrust to drive voltage is presented in Fig. 3.14. The manufacturer's maximum recommended drive voltage for the piezoelectric stack used in these tests was $300 \mathrm{~V}$. However, for reasons of conservatism, the amplitude tests were limited to drive voltages less than 240 volts. At higher voltages there exists the potential for shorting (arc over) between the stack elements and the subsequent loss of either a stack block sub-assembly or the entire stack.

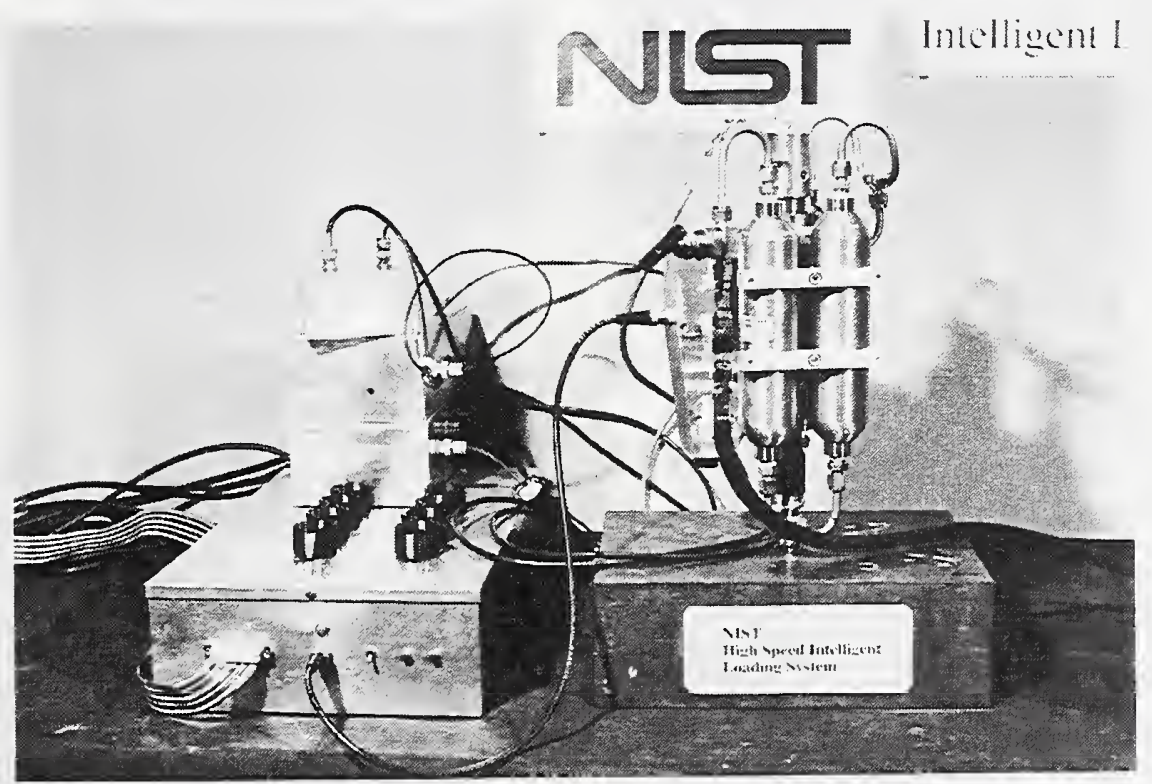

Fig. 3.1: HSILS microcontroller and pulse power subsystems (left) and HSILS cold gas thruster unit with attached high pressure accumulators (right). 


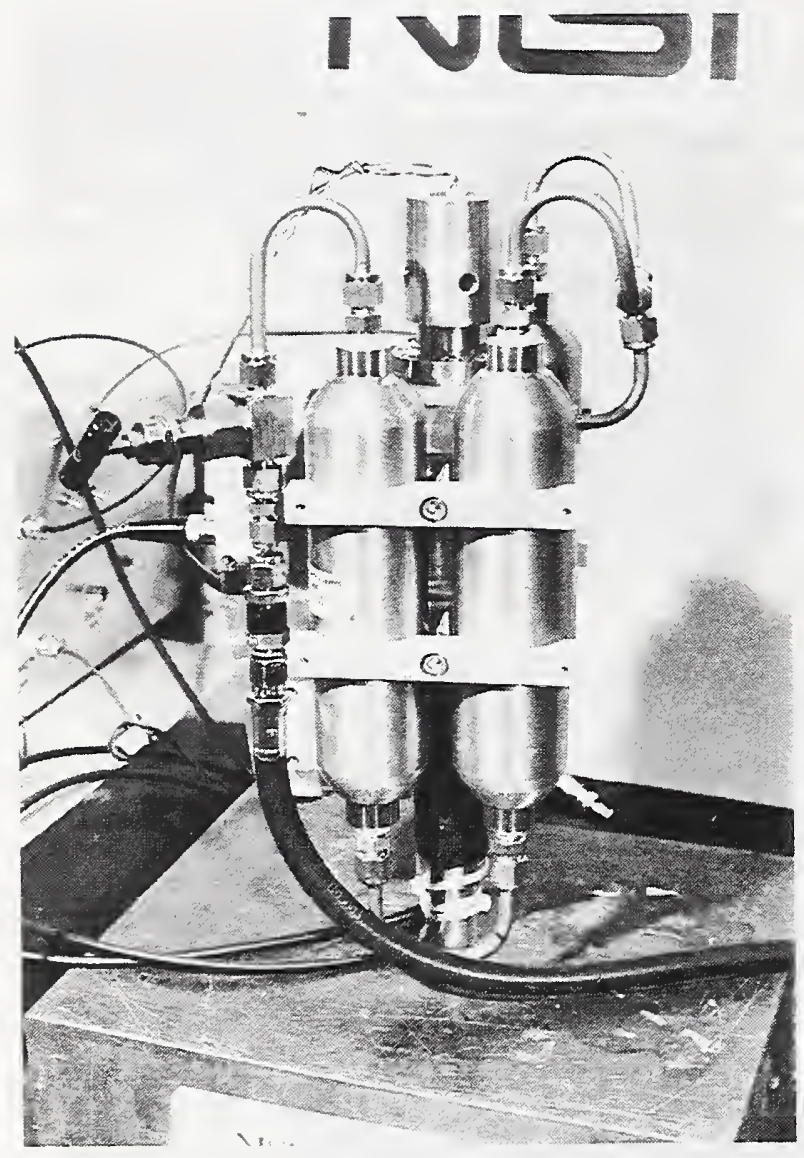

Fig. 3.2: (LEFT) Close-up side view of HSILS thruster unit. Visible from left are a) BNC high voltage connector from pulse power unit; b) high pressure umbilical charging line and onboard shutoff valve; c) high pressure onboard gas accumulators; and d) equivalent static thrust sensor unit mounted on top of the HSILS nozzle (top).

Fig. 3.3: (RIGHT) Close-up side view of HSILS thruster unit. Visible from left are a) BNC high voltage connector from pulse power unit; b) high pressure umbilical charging line and onboard shutoff valve; c) high pressure onboard gas accumulators; and d) equivalent static thrust sensor unit mounted on top of the HSILS nozzle (top).

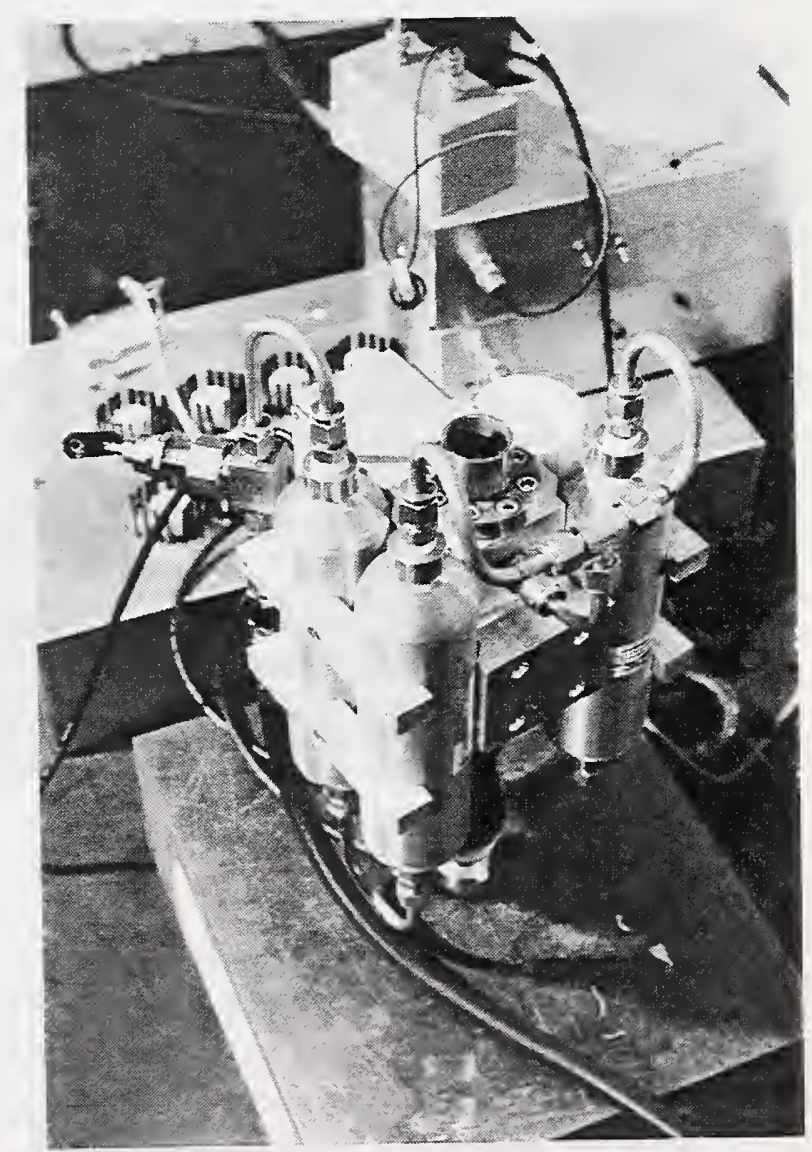




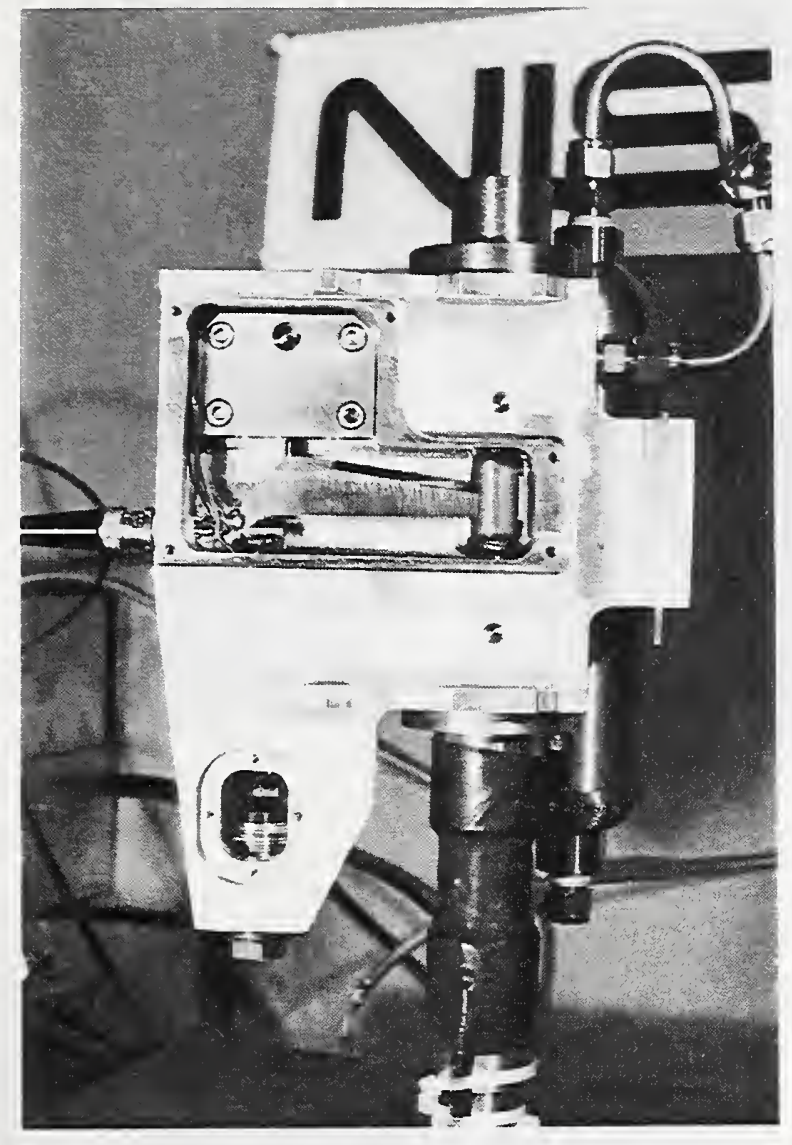

Fig. 3.4: (LEFT) Close-up side view of HSILS thruster unit with gas accumulators and cover plates removed. BNC high voltage connector from pulse power unit is visible at left. Lower port (with cover removed) allows access to piezoelectric stack adjustment screw and lower sapphire spherical pivot. Upper port shows upper piezoelectric stack connection to the short side of of the titanium displacement amplifier (and its associated sapphire pivot) and the right hand connection of the displacement amplifier to the valve core rod and its preload return spring.

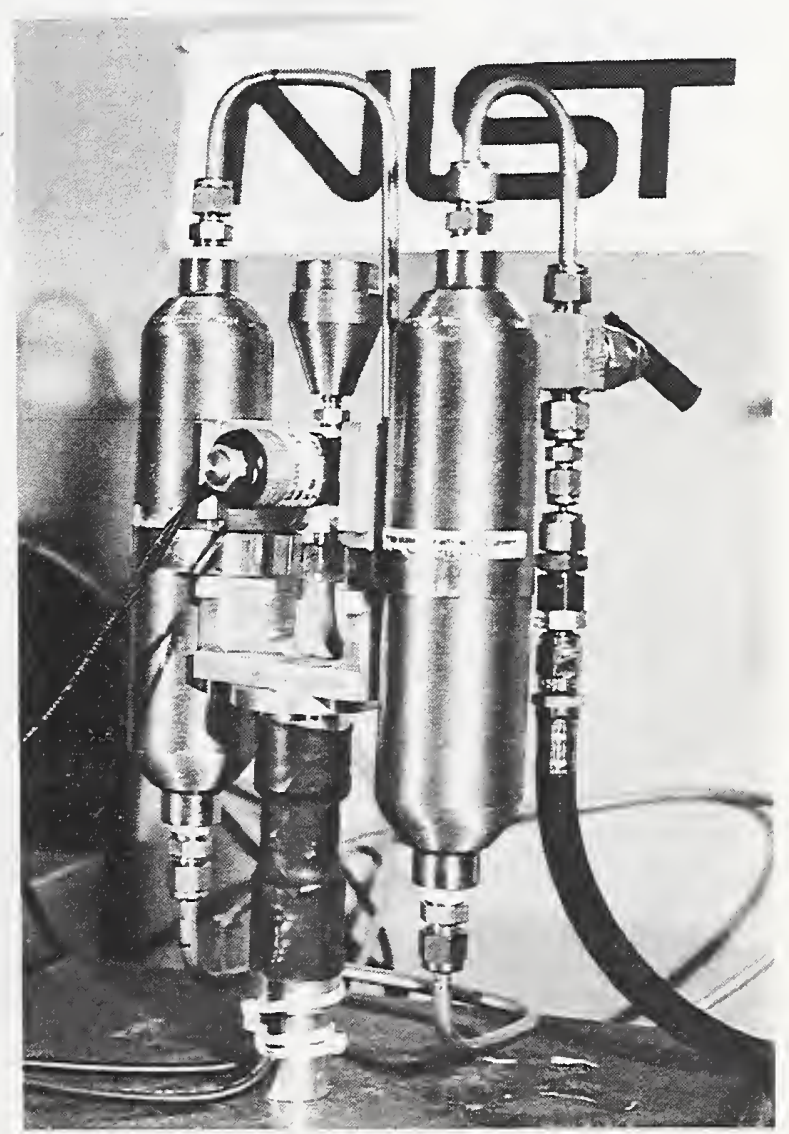




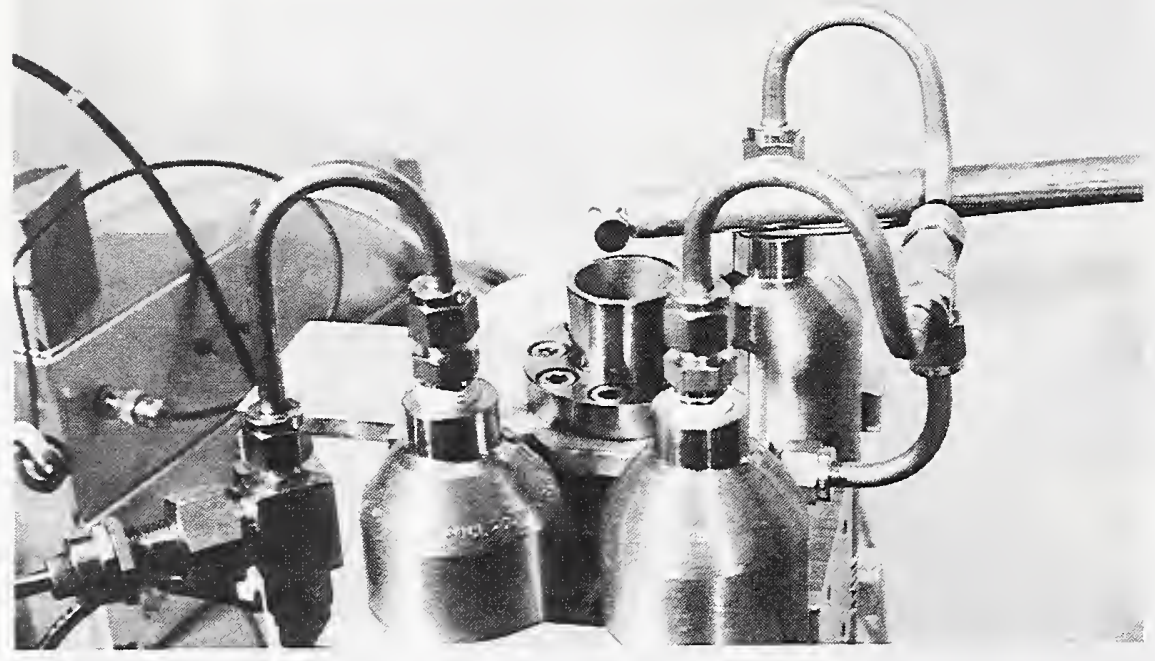

Fig. 3.6: (ABOVE) Close-up side view of HSILS thruster unit with acoustic sensor ready for pulse width resolution tests.

Fig. 3.7: (RIGHT) Close-up side view of solenoid-based RCS unit with acoustic sensor ready for pulse width resolution tests.

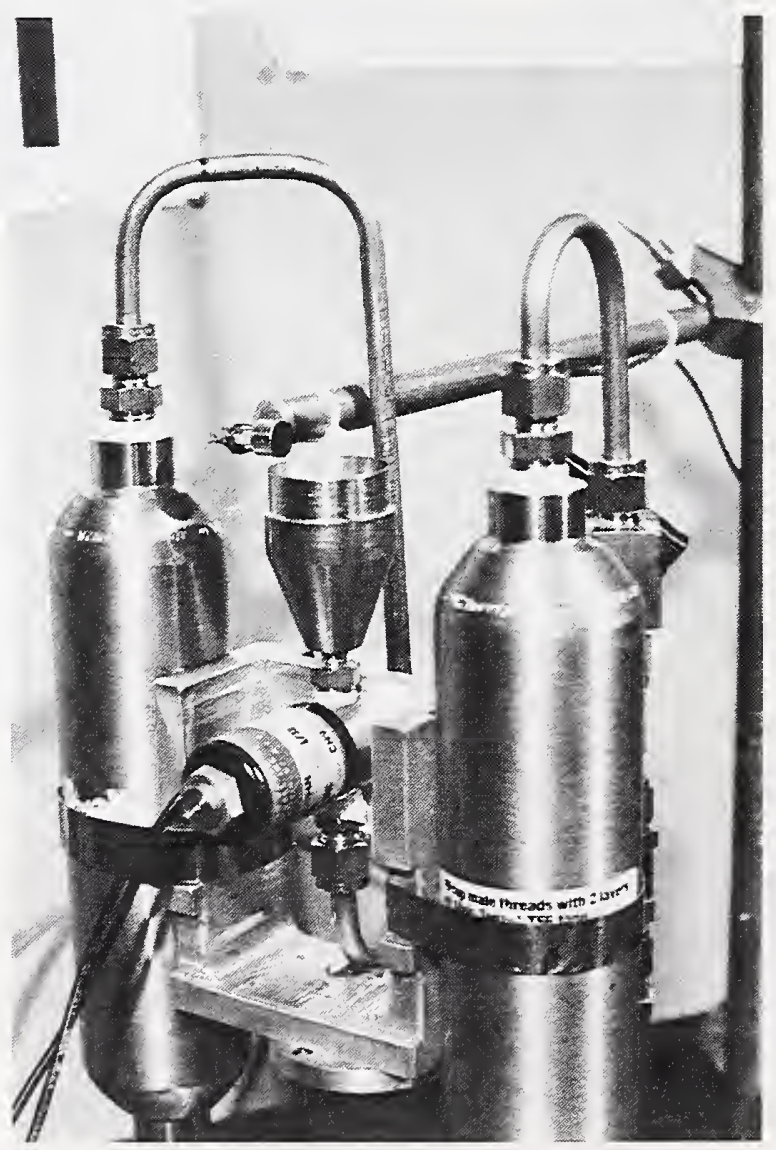




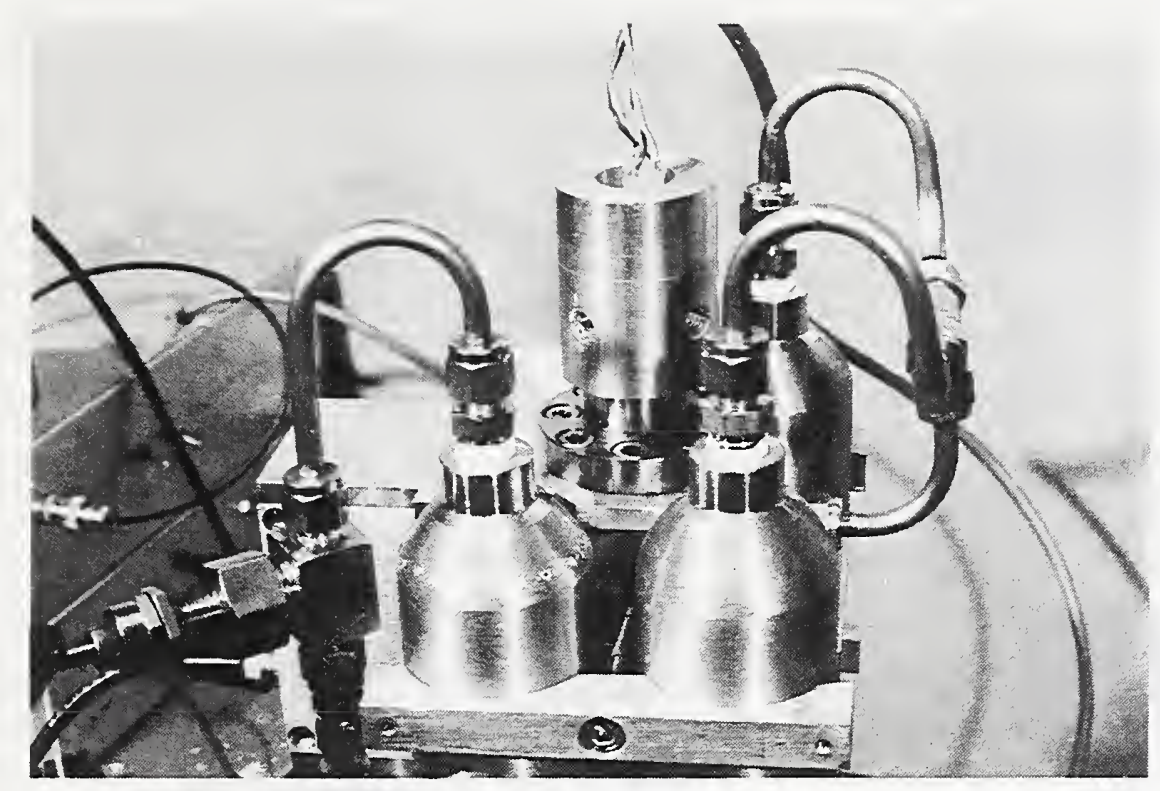

Fig. 3.8: (ABOVE) Close-up side view of HSILS thruster unit with pressure sensor cavity ready for amplitude control tests.

Fig. 3.9: (RIGHT) Close-up side view of solenoid-based RCS unit with pressure sensor cavity ready for amplitude control tests.

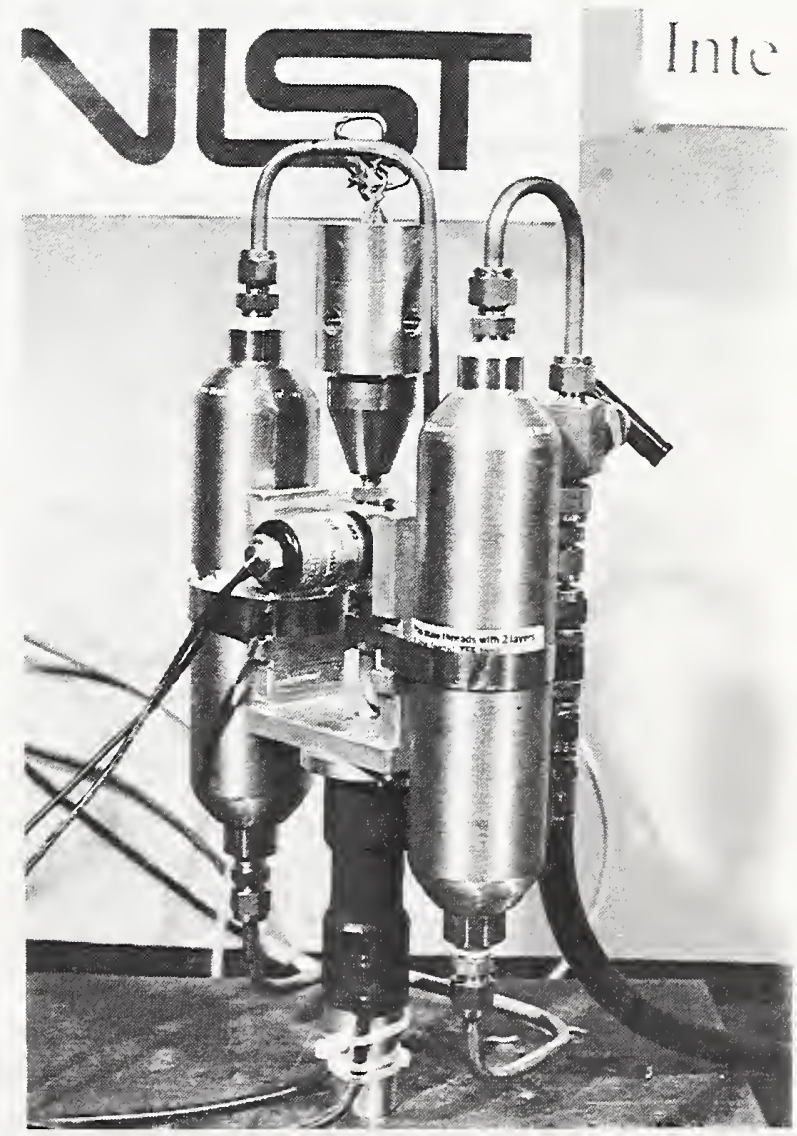



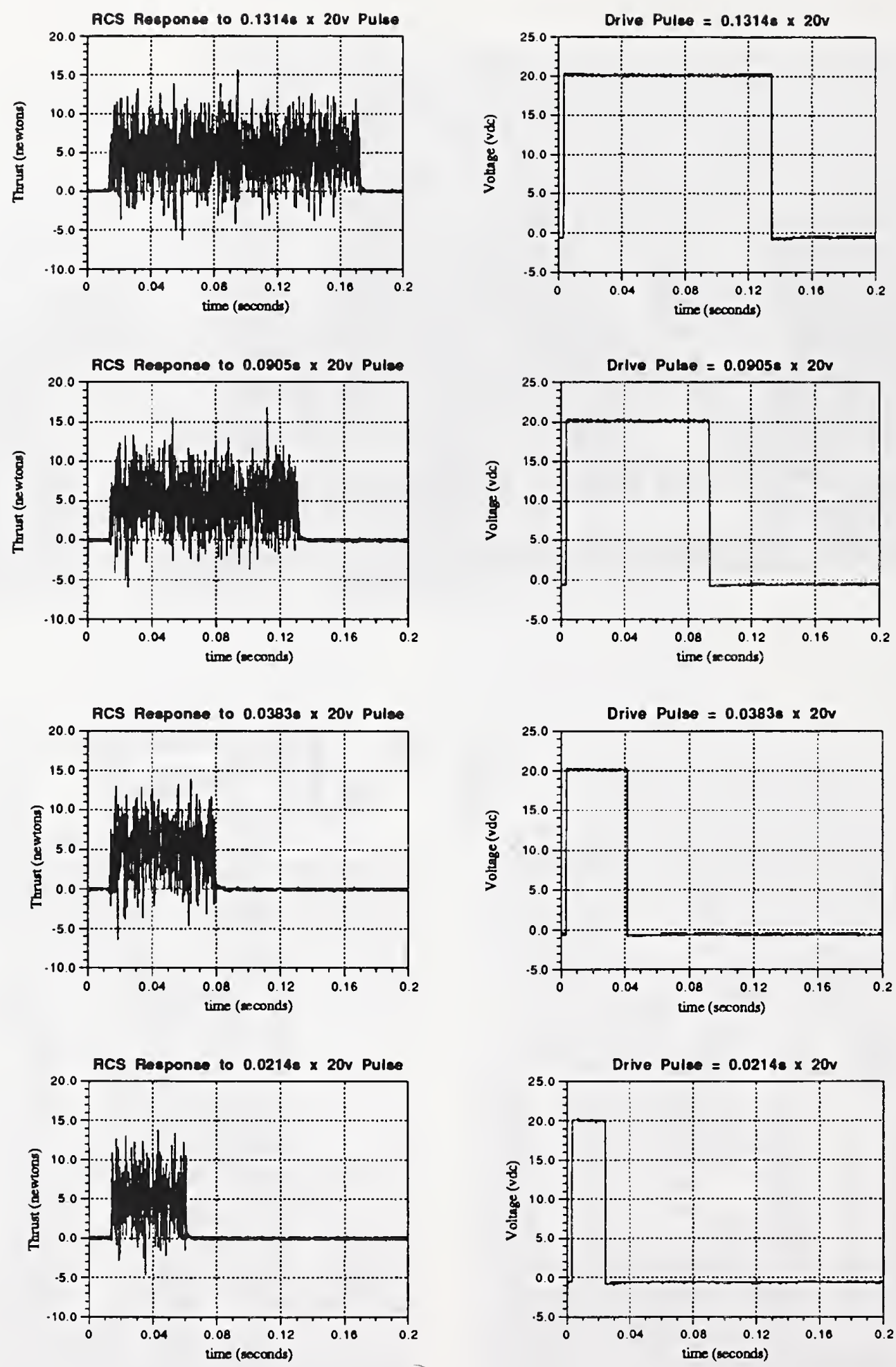

Fig. 3.10a: Pulse width response of solenoid-based RCS actuator to various half square wave drive pulses of decreasing duration (top to bottom). Thrust was measured indirectly by means of an attached pressure sensing cavity. Response thrust versus time is plotted in the left hand column; drive voltage-time history is plotted at right for each test. Nominal drive amplitude is $21 \mathrm{~V}$. 

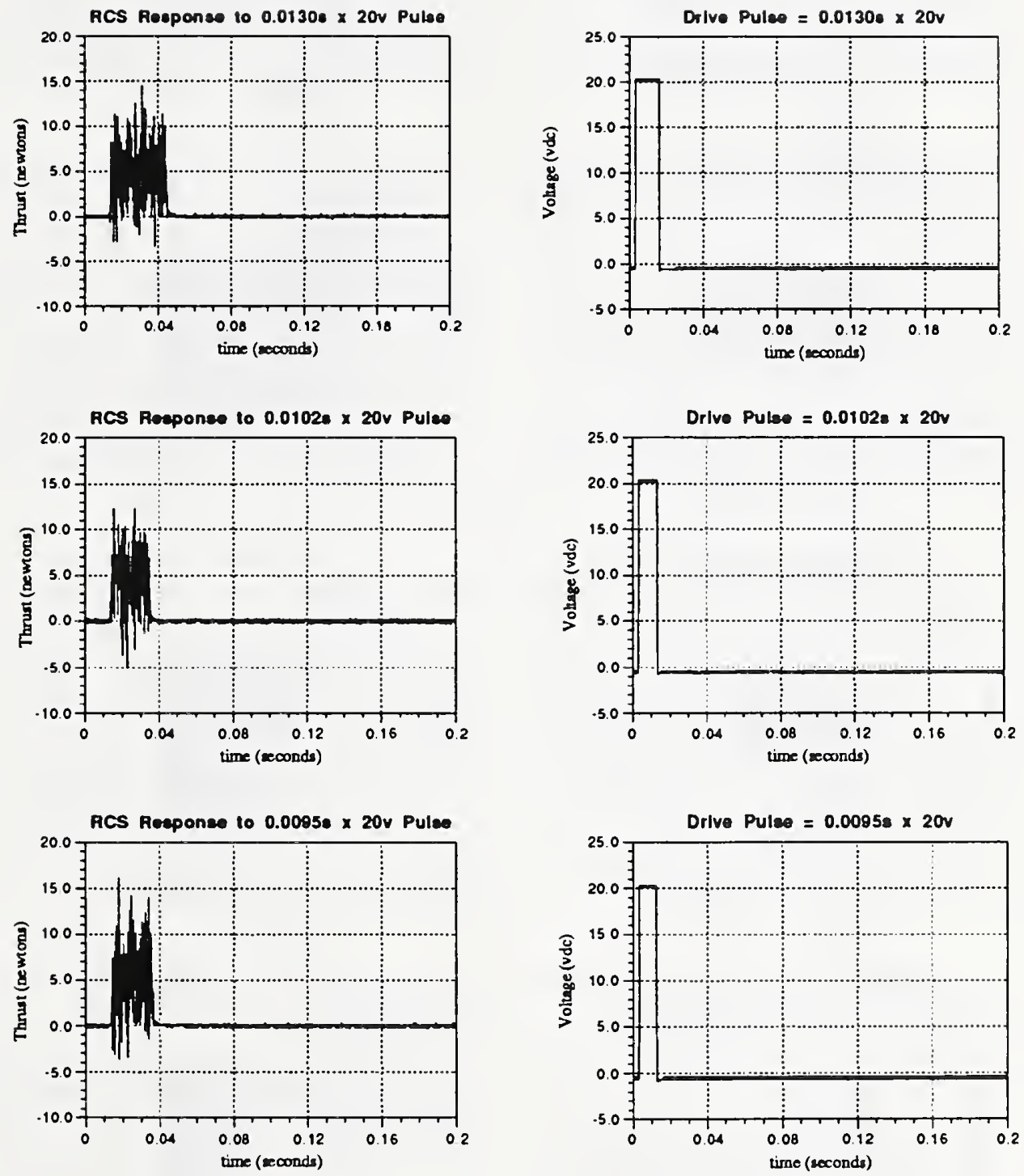

Fig. 3.10b: Pulse width response of solenoid-based RCS actuator to various half square wave drive pulses of decreasing duration (top to bottom). Thrust was measured indirectly by means of an attached pressure sensing cavity. Response thrust versus time is plotted in the left hand column; drive voltage-time history is plotted at right for each test. Nominal drive amplitude is $21 \mathrm{~V}$. (continued from Fig. 3.10a). 

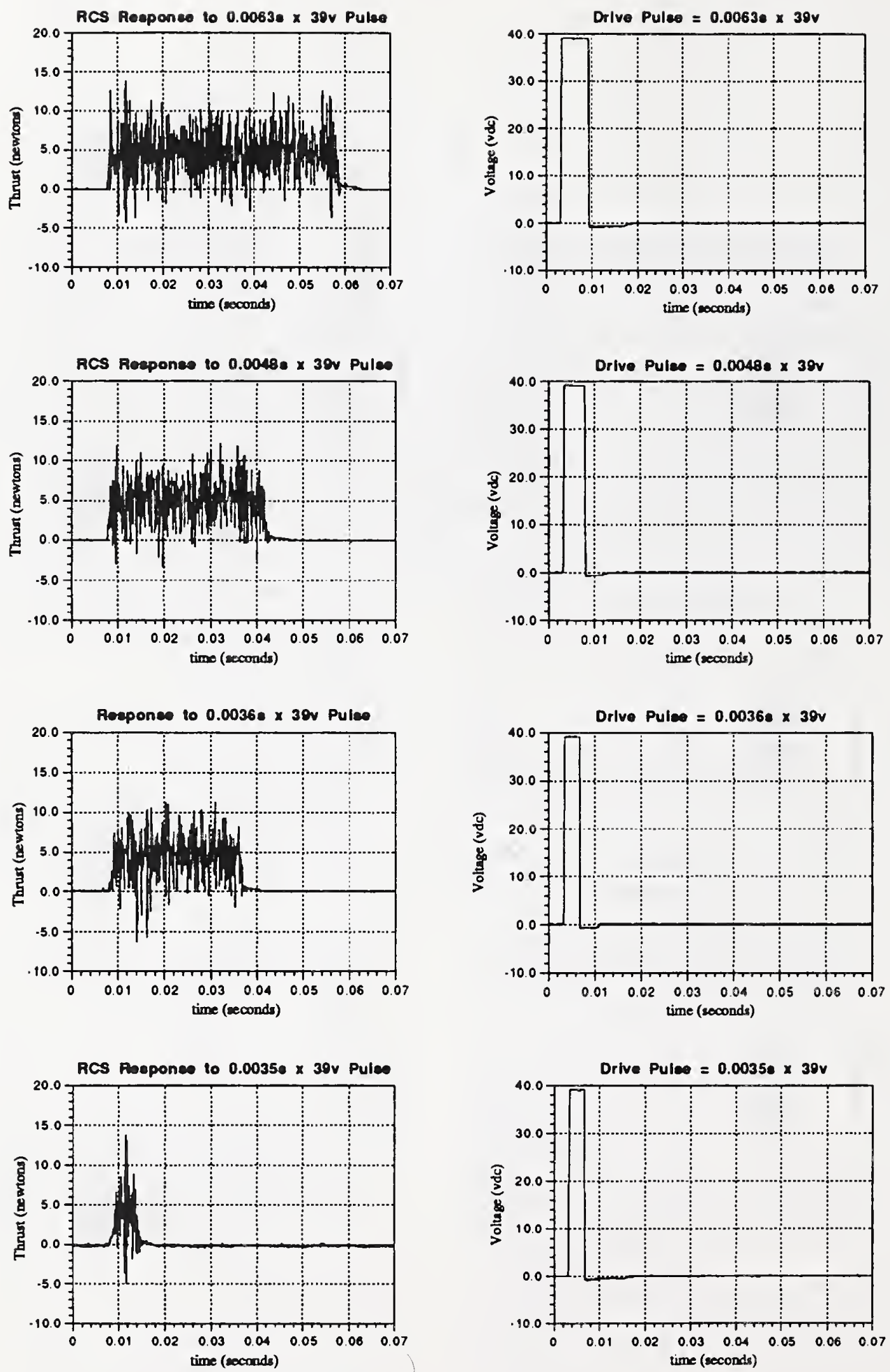

Fig. 3.11: Pulse width response of solenoid-based RCS actuator to various half square wave drive pulses of decreasing duration (top to bottom). Thrust was measured indirectly by means of an attached pressure sensing cavity. Response thrust versus time is plotted in the left hand column; drive voltage-time history is plotted at right for each test. Tests are similar to those shown in Fig. 3.10 with the exception of having a nominal drive amplitude of $39 \mathrm{~V}$. 

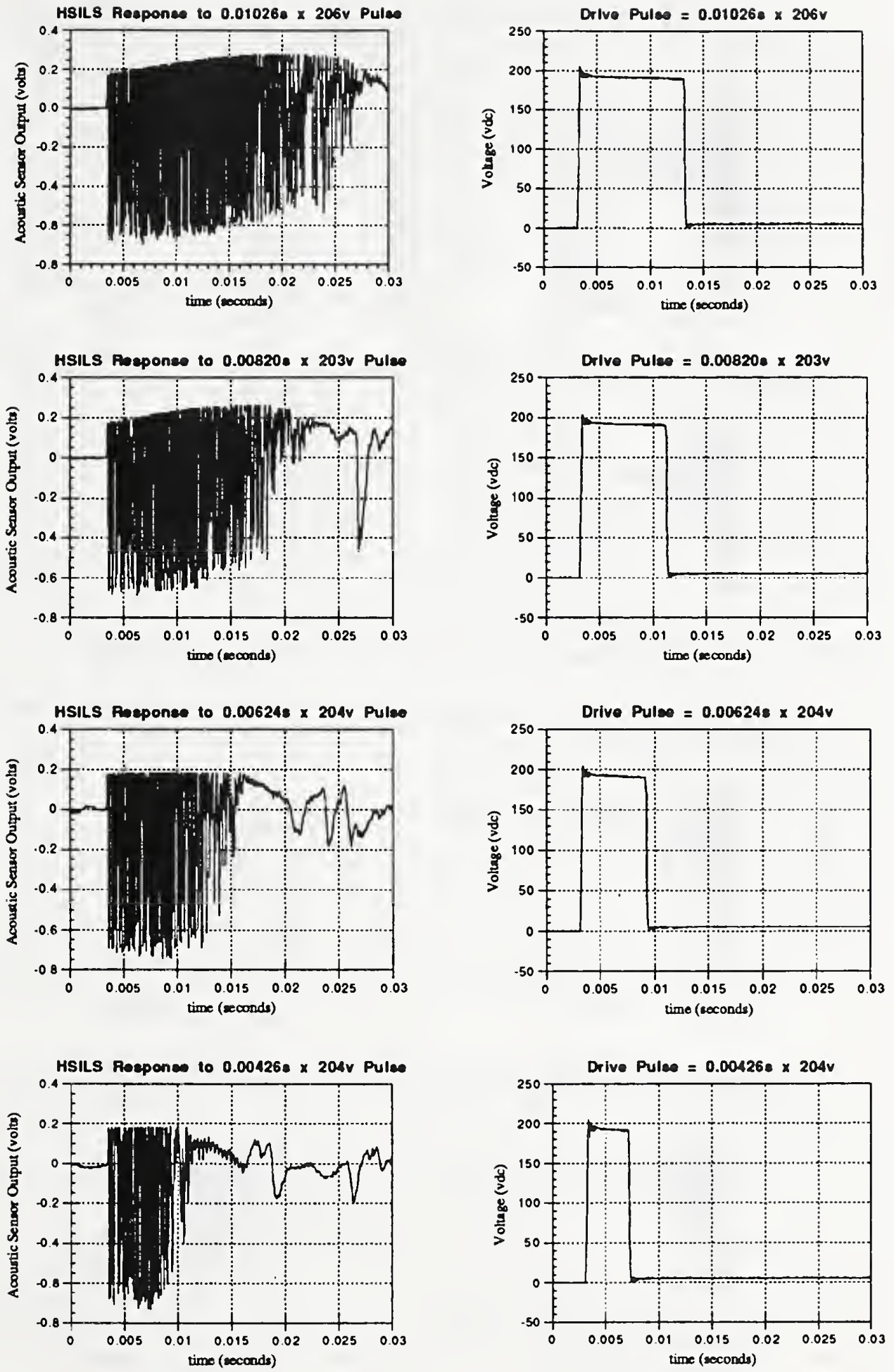

Fig. 3.12a: Pulse width response of HSILS actuator to various half square wave drive pulses of decreasing duration ( $10.2 \mathrm{~ms}$ top to $4.3 \mathrm{~ms}$ bottom). Pulse width was measured using an acoustic microphone. Acoustic sensor response versus time is plotted in the left hand column; drive voltage-time history is plotted at right for each test. 
HSILS Reepones to $0.00222 \times 205 y$ Puleo

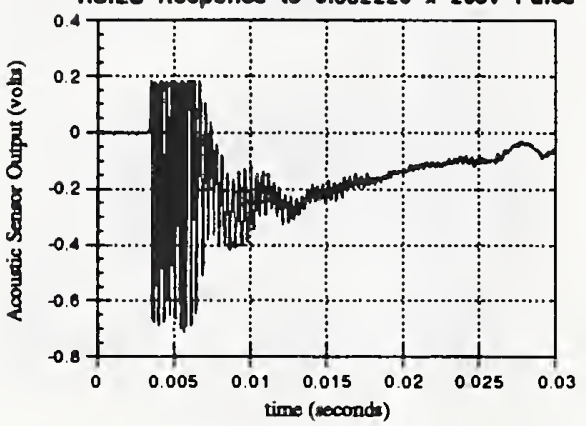

HSILS Paeponee to $0.00130 \mathrm{~s} \times 204 \mathrm{v}$ Pulse
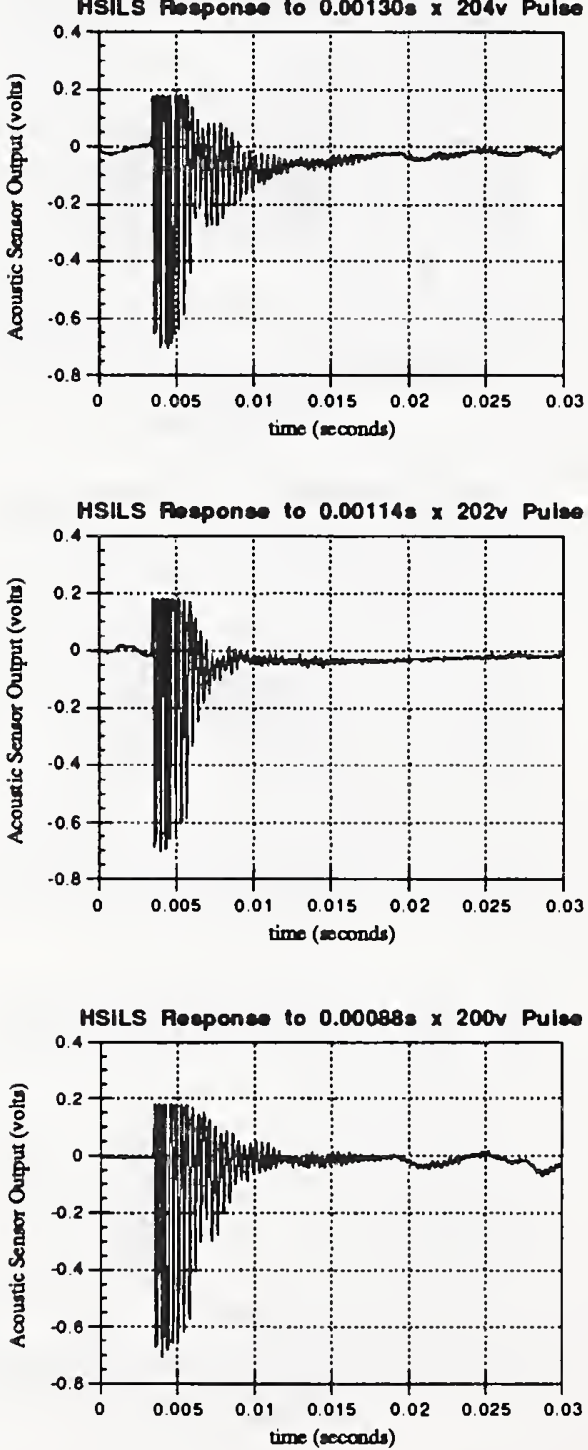
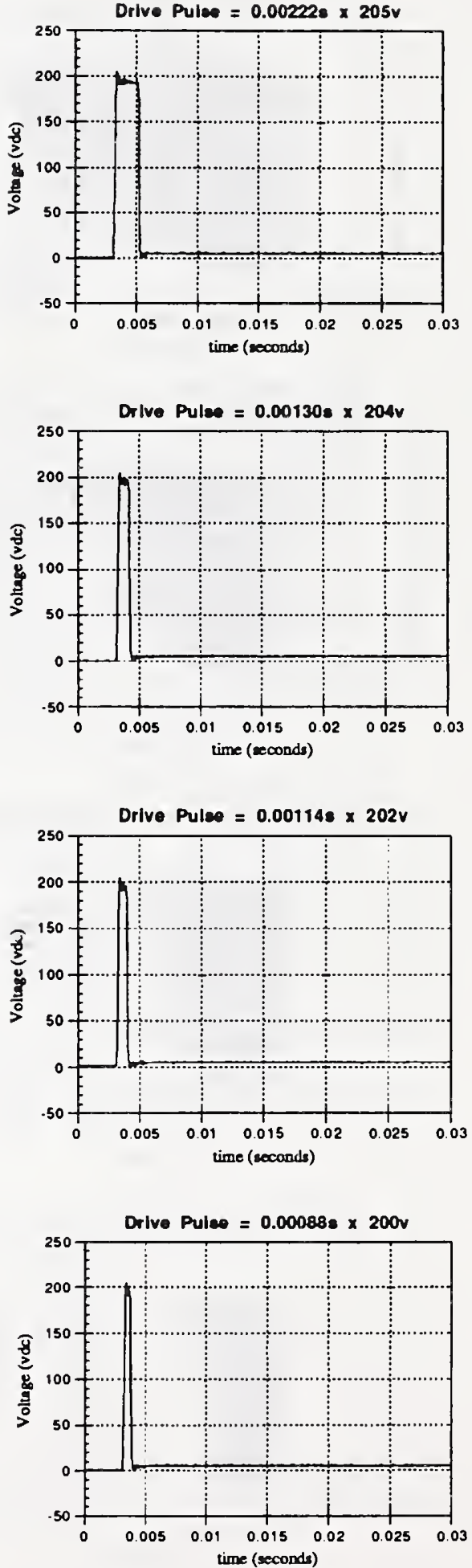

Fig. 3.12b: Pulse width response of HSILS actuator to various half square wave drive pulses of decreasing duration $(2.2 \mathrm{~ms}$ top to $0.8 \mathrm{~ms}$ bottom). Pulse width was measured using an acoustic microphone. Acoustic sensor response versus time is plotted in the left hand column; drive voltage-time history is plotted at right for each test. (continued from Fig. 3.12a). 

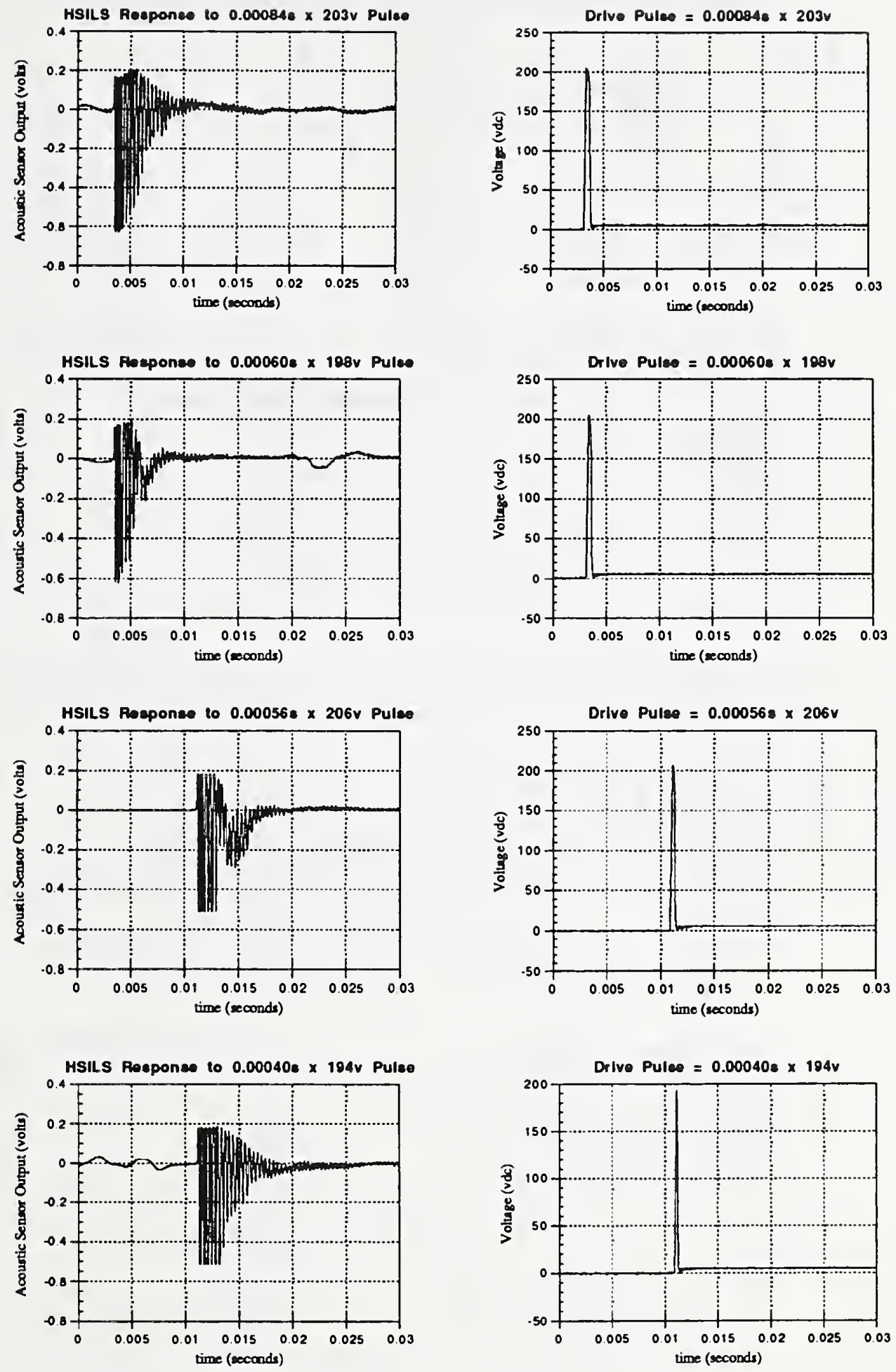

Fig. 3.12c Pulse width response of HSILS actuator to various half square wave drive pulses of decreasing duration ( $0.8 \mathrm{~ms}$ top to $0.4 \mathrm{~ms}$ bottom). Pulse width was measured using an acoustic microphone. Acoustic sensor response versus time is plotted in the left hand column; drive voltage-time history is plotted at right for each test. (continued from Fig. 3.12b). 

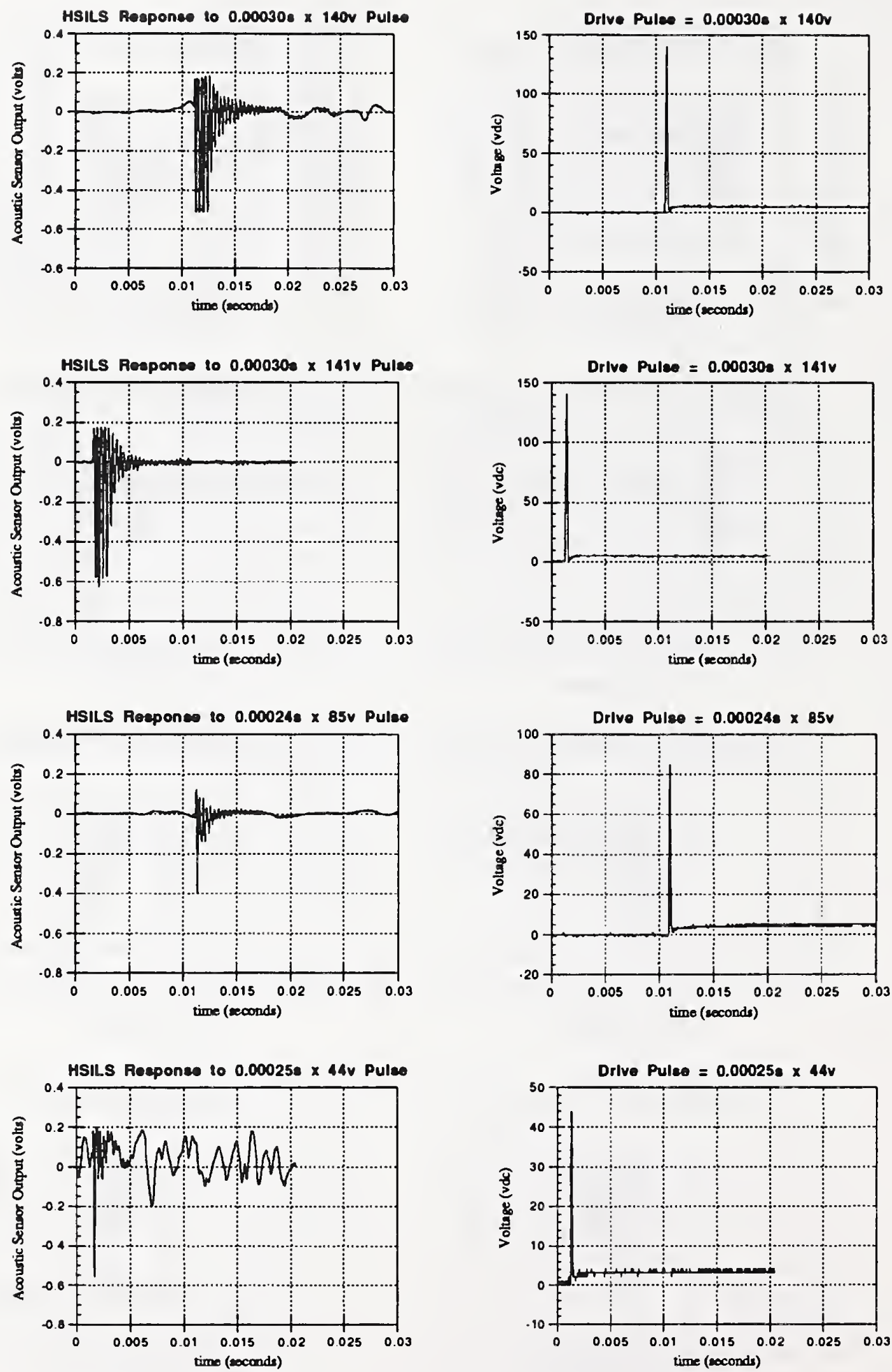

Fig. 3.12d Pulse width response of HSILS actuator to various half square wave drive pulses of decreasing duration ( $0.3 \mathrm{~ms}$ top to $0.2 \mathrm{~ms}$ bottom). Pulse width was measured using an acoustic microphone. Acoustic sensor response versus time is plotted in the left hand column; drive voltage-time history is plotted at right for each test. (continued from Fig. 3.12c). 


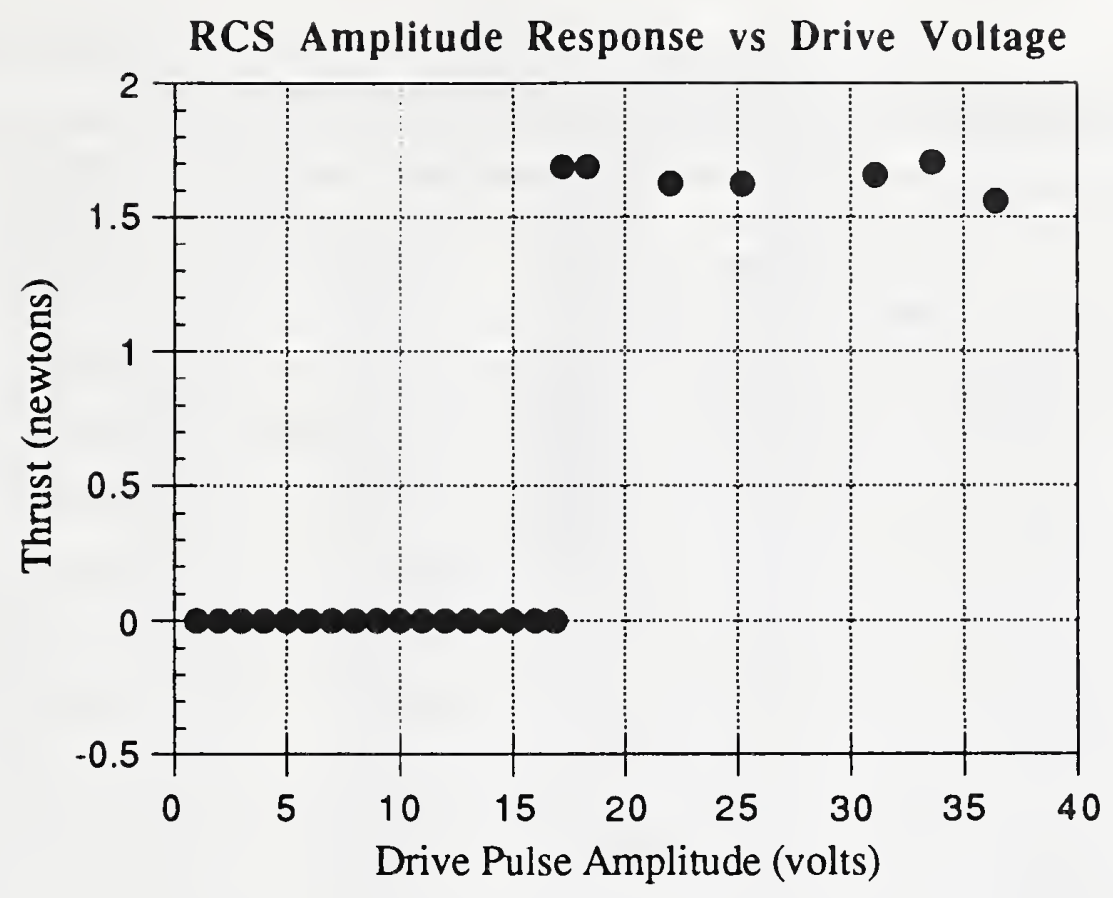

Fig. 3.13: Amplitude (thrust) response characteristics for solenoid-based RCS actuator.

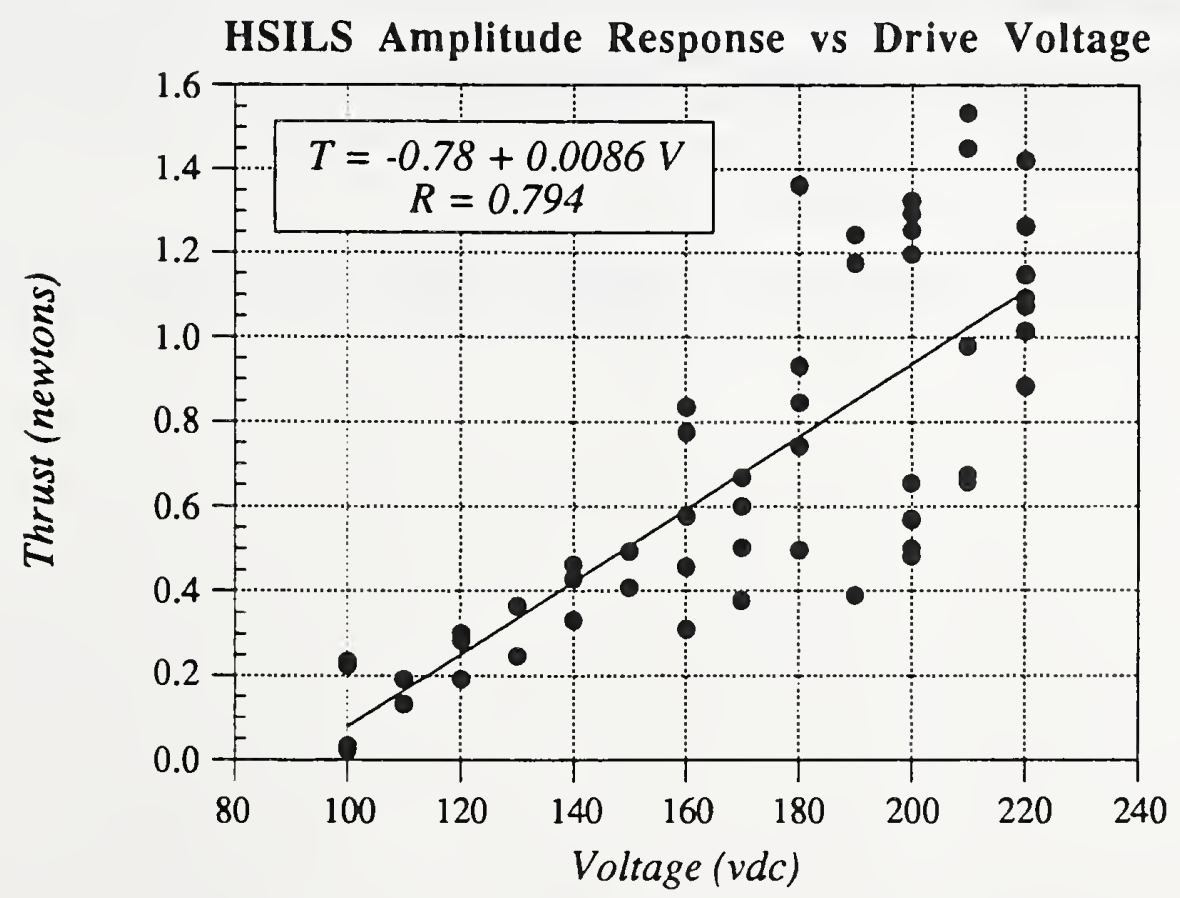

Fig. 3.14: Amplitude (thrust) response characteristics for HSILS prototype. 
Table 3.1: Acoustic Sensor Data for RCS Pulse Width Resolution Tests

\begin{tabular}{|c|c|c|c|c|c|c|c|}
\hline $\begin{array}{l}\text { Nominal } \\
\text { Pulse } \\
\text { Description }\end{array}$ & $\begin{array}{l}\text { Drive } \\
\text { Pulse } \\
\text { Width } \\
\text { (sec.) }\end{array}$ & $\begin{array}{l}\text { Peak } \\
\text { Drive } \\
\text { Ampl. } \\
\text { (volts) }\end{array}$ & $\begin{array}{l}\text { Active } \\
\text { Energy } \\
\text { Xfer } \\
\text { (joules) }\end{array}$ & $\begin{array}{l}\text { Response } \\
\text { Rise } \\
\text { Lag } \\
\text { (sec.) }\end{array}$ & $\begin{array}{l}\text { Response } \\
\text { Pulse } \\
\text { Width } \\
\text { (sec.) }\end{array}$ & $\begin{array}{l}\text { Response } \\
\text { Fall } \\
\text { Lag } \\
\text { (sec.) }\end{array}$ & $\begin{array}{l}\text { Data } \\
\text { File } \\
\text { Name }\end{array}$ \\
\hline P $13400 \times 21$ & 0.0134 & 21 & 0.0682 & 0.0076 & 0.1616 & 0.1482 & rcs24.wq1 \\
\hline P $129300 \times 21$ & 0.1293 & 21 & 0.6584 & 0.0061 & 0.1906 & 0.0613 & rcs25.wq1 \\
\hline P $55900 \times 21$ & 0.0559 & 21 & 0.2846 & 0.0080 & 0.1132 & 0.0573 & rcs26.wq1 \\
\hline P $13100 \times 21$ & 0.0131 & 21 & 0.0667 & 0.0072 & 0.0682 & 0.0551 & $\mathrm{rcs} 28 . w q 1$ \\
\hline P $7000 \times 21$ & 0.007 & 21 & 0.0356 & 0.0074 & 0.0431 & 0.0361 & $\operatorname{rcs} 29 . w q 1$ \\
\hline P $7000 \times 21$ & 0.0071 & 21 & 0.0361 & 0.0076 & 0.0524 & 0.0453 & $\mathrm{rcs} 211 . w q 1$ \\
\hline P $10700 \times 20$ & 0.01055 & 20 & 0.0446 & 0.00825 & 0.11035 & 0.0998 & qs23.prn \\
\hline P $8200 \times 20$ & 0.00805 & 20 & 0.0341 & 0.0079 & 0.0991 & 0.09105 & qs25.prn \\
\hline$P 13400 \times 20$ & 0.01325 & 20 & 0.0563 & 0.0081 & 0.1617 & 0.1485 & qs27.prn \\
\hline P $130500 \times 20$ & 0.1292 & 20 & 0.2740 & 0.0072 & 0.1879 & 0.0587 & qs29.prn \\
\hline$P 56200 \times 20$ & 0.0557 & 20 & 0.1183 & 0.007 & 0.1135 & 0.0578 & qs211.prn \\
\hline P $23700 \times 20$ & 0.0234 & 20 & 0.0497 & 0.0069 & 0.0827 & 0.0593 & qs213.prn \\
\hline
\end{tabular}

* For example P $400 \times 200=$ nominal half square wave pulse having a pulse width of 400 microseconds and a peak amplitude of 200 volts DC. The actual rising and falling slopes are limited to 1 volt/microsecond. 
Table 3.2: Static Pressure Sensor Data for RCS Pulse Width Resolution Tests

\begin{tabular}{|c|c|c|c|c|c|c|c|}
\hline $\begin{array}{l}\text { Nominal } \\
\text { Pulse } \\
\text { Description }\end{array}$ & $\begin{array}{l}\text { Drive } \\
\text { Pulse } \\
\text { Width } \\
\text { (sec.) }\end{array}$ & $\begin{array}{l}\text { Peak } \\
\text { Drive } \\
\text { Ampl. } \\
\text { (volts) }\end{array}$ & $\begin{array}{l}\text { Active } \\
\text { Energy } \\
\text { Xfer } \\
\text { (joules) }\end{array}$ & $\begin{array}{l}\text { Response } \\
\text { Rise } \\
\text { Lag } \\
\text { (sec.) }\end{array}$ & $\begin{array}{l}\text { Response } \\
\text { Pulse } \\
\text { Width } \\
\text { (sec.) }\end{array}$ & $\begin{array}{l}\text { Response } \\
\text { Fall } \\
\text { Lag } \\
\text { (sec.) }\end{array}$ & $\begin{array}{l}\text { Data } \\
\text { File } \\
\text { Name }\end{array}$ \\
\hline P $132000 \times 20$ & 0.1314 & 20 & 0.3090 & 0.0107 & 0.1588 & 0.0274 & qs31.prn \\
\hline P $90500 \times 20$ & 0.0005 & 20 & 0.2116 & 0.011 & 0.1179 & 0.0274 & qs33.prn \\
\hline P $38300 \times 20$ & 0.0383 & 20 & 0.0898 & 0.0106 & 0.0898 & 0.0275 & qs35.prn \\
\hline P $21400 \times 20$ & 0.0214 & 20 & 0.0502 & 0.0108 & 0.047 & 0.0256 & qs37.prn \\
\hline P $13000 \times 20$ & 0.0130 & 20 & 0.0307 & 0.0109 & 0.0307 & 0.0177 & qs39.prn \\
\hline P $10200 \times 20$ & 0.0102 & 20 & 0.0239 & 0.0110 & 0.0208 & 0.0106 & qs311.prn \\
\hline P $9500 \times 20$ & 0.0095 & 20 & 0.0221 & 0.0110 & 0.022 & 0.0125 & qs313.prn \\
\hline P $3500 \times 39$ & 0.0035 & 39 & 0.0296 & 0.0048 & 0.0073 & 0.0038 & qs41.prn \\
\hline P $3750 \times 39$ & 0.00357 & 39 & 0.0208 & 0.0046 & 0.0097 & 0.00613 & qs43.prn \\
\hline P $4800 \times 39$ & 0.0048 & 39 & 0.0409 & 0.0045 & 0.0346 & 0.0298 & qs45.prn \\
\hline P $6300 \times 39$ & 0.0063 & 39 & 0.0533 & 0.0046 & 0.0511 & 0.0448 & qs47.prn \\
\hline P $17000 \times 39$ & 0.017 & 39 & 0.1325 & 0.0046 & 0.0594 & 0.0424 & qs49.prn \\
\hline P $41200 \times 39$ & 0.0412 & 39 & 0.2832 & 0.0047 & 0.0831 & 0.0419 & qs411.prn \\
\hline P $3600 \times 39$ & 0.0036 & 39 & 0.0296 & 0.0047 & 0.0301 & 0.0265 & qs415.prn \\
\hline
\end{tabular}

* For example $\mathrm{P} 400 \times 200=$ nominal half square wave pulse having a pulse width of 400 microseconds and a peak amplitude of 200 volts DC. The actual rising and falling slopes are limited to 1 volt/microsecond.

The bold data entry represents the minimum repeatable pulse width control exhibited by the RCS (solenoid valve) prototype during the laboratory tests reported herein. 
Table 3.3: Acoustic Sensor Data for HSIS Pulse Width Resolution Tests

\begin{tabular}{|c|c|c|c|c|c|c|c|}
\hline $\begin{array}{l}\text { Nominal } \\
\text { Pulse } \\
\text { Description }\end{array}$ & $\begin{array}{l}\text { Drive } \\
\text { Pulse } \\
\text { Width } \\
\text { (sec.) }\end{array}$ & $\begin{array}{l}\text { Peak } \\
\text { Drive } \\
\text { Ampl. } \\
\text { (volts) }\end{array}$ & $\begin{array}{l}\text { Active } \\
\text { Energy } \\
\text { Xfer } \\
\text { (joules) }\end{array}$ & $\begin{array}{l}\text { Response } \\
\text { Rise } \\
\text { Lag } \\
\text { (sec.) }\end{array}$ & $\begin{array}{l}\text { Response } \\
\text { Pulse } \\
\text { Width } \\
\text { (sec.) }\end{array}$ & $\begin{array}{l}\text { Response } \\
\text { Fall } \\
\text { Lag } \\
\text { (sec.) }\end{array}$ & $\begin{array}{l}\text { Data } \\
\text { File } \\
\text { Name }\end{array}$ \\
\hline$P 300 \times 200$ & 0.00060 & 206 & 0.5729 & 0.00030 & 0.00088 & 0.00022 & qh11.prn \\
\hline$P 400 \times 200$ & 0.00060 & 203 & 0.5563 & 0.00026 & 0.0015 & 0.00088 & qh13.prn \\
\hline$P 350 \times 200$ & 0.00056 & 206 & 0.5729 & 0.00028 & 0.00182 & 0.00126 & qh19.prn \\
\hline$P 400 \times 200$ & 0.00048 & 205 & 0.4977 & 0.00028 & 0.00214 & 0.00166 & qh17.prn \\
\hline$P 250 \times 200$ & 0.00044 & 192 & 0.5081 & 0.00026 & 0.00212 & 0.00166 & qh19.prn \\
\hline $\mathrm{P} 200 \times 200$ & 0.00040 & 194 & 0.5081 & 0.00028 & 0.00206 & 0.00166 & qh111.prn \\
\hline P $175 \times 150$ & 0.00030 & 140 & 0.2646 & 0.00039 & 0.00124 & 0.00093 & qh113.prn \\
\hline$P 100 \times 100$ & 0.00024 & 85 & 0.0975 & 0.00030 & 0.00034 & 0.00083 & qh115.prn \\
\hline P $400 \times 200$ & 0.00060 & 198 & 0.5293 & 0.00028 & 0.00148 & 0.00088 & qh21.prn \\
\hline P $800 \times 200$ & 0.00084 & 203 & 0.5563 & 0.00028 & 0.00308 & 0.00224 & qh23.prn \\
\hline$P 600 \times 200$ & 0.0008 & 200 & 0.54 & 0.00023 & 0.000242 & 0.00154 & qh25.prn \\
\hline$P 800 \times 200$ & 0.00114 & 202 & 0.5508 & 0.00028 & 0.00226 & 0.00112 & qh27.prn \\
\hline P $1000 \times 200$ & 0.00130 & 204 & 0.5618 & 0.00028 & 0.00208 & 0.00078 & qh29.prn \\
\hline$P 2000 \times 200$ & 0.00222 & 205 & 0.5673 & 0.00028 & 0.00310 & 0.00088 & qh211.prn \\
\hline$P 1000 \times 200$ & 0.00426 & 204 & 0.5618 & 0.00026 & 0.00562 & 0.00136 & qh213.prn \\
\hline$P 6000 \times 200$ & 0.00624 & 204 & 0.5618 & 0.00026 & 0.00884 & 0.00260 & qh215.prn \\
\hline$P \quad 8000 \times 200$ & 0.0082 & 203 & 0.5563 & 0.00026 & 0.01496 & 0.00676 & qh217.prn \\
\hline$P 10000 \times 200$ & 0.01026 & 206 & 0.5729 & 0.00028 & 0.02046 & 0.0102 & qh219.prn \\
\hline$P 150 \times 150$ & 0.00032 & 139 & 0.2608 & 0.00042 & 0.00125 & 0.00093 & qh31.prn \\
\hline P $150 \times 150$ & 0.00033 & 140 & 0.2646 & 0.00037 & 0.00103 & 0.0007 & qh33.prn \\
\hline P $75 \times 75$ & 0.00025 & 46 & 0.0286 & 0.00039 & 0.00107 & 0.00082 & qh37.prn \\
\hline P $125 \times 125$ & 0.00028 & 107 & 0.1546 & 0.00039 & 0.00101 & 0.0007 & qh39.prn \\
\hline P $70 \times 70$ & 0.00024 & 45 & 0.0273 & 0.00039 & 0.00107 & 0.00093 & qh311.prn \\
\hline $\mathrm{P} 100 \times 100$ & 0.00033 & 86 & 0.0998 & 0.00030 & 0.00103 & 0.00070 & qh313.prn \\
\hline $\mathrm{P} 70 \times 70$ & 0.00025 & 44 & 0.0261 & 0.00025 & 0.00029 & 0.000040 & qh315.prn \\
\hline$P 70 \times 70$ & 0.00025 & 43 & 0.0249 & 0.00022 & 0.00041 & 0.00013 & qh317.prn \\
\hline $\mathrm{P} 150 \times 150$ & 0.00032 & 140 & 0.260 & 0.00032 & 0.00103 & 0.00071 & qh41.prn \\
\hline $\mathrm{P} 100 \times 100$ & 0.00030 & 89 & 0.1066 & 0.00038 & 0.00102 & 0.00072 & qh45.prn \\
\hline
\end{tabular}




\begin{tabular}{||l|l|l|l|l|l|l|l||}
\hline $\begin{array}{l}\text { Nominal } \\
\text { Pulse } \\
\text { Description }\end{array}$ & $\begin{array}{l}\text { Drive } \\
\text { Pulse } \\
\text { Width } \\
\text { (sec.) }\end{array}$ & $\begin{array}{l}\text { Peak } \\
\text { Drive } \\
\text { Ampl. } \\
\text { (volts) }\end{array}$ & $\begin{array}{l}\text { Active } \\
\text { Energy } \\
\text { Xfer } \\
\text { (joules) }\end{array}$ & $\begin{array}{l}\text { Response } \\
\text { Rise } \\
\text { Lag } \\
\text { (sec.) }\end{array}$ & $\begin{array}{l}\text { Response } \\
\text { Pulse } \\
\text { Width } \\
\text { (sec. })\end{array}$ & $\begin{array}{l}\text { Response } \\
\text { Fall } \\
\text { Lag } \\
\text { (sec. })\end{array}$ & $\begin{array}{l}\text { Data } \\
\text { File } \\
\text { Name }\end{array}$ \\
\hline P 70 70 & 0.00023 & 46 & 0.0286 & 0.00039 & 0.00074 & 0.00051 & qh47.prn \\
\hline P $120 \times 120$ & 0.00033 & 107 & 0.1535 & 0.00038 & 0.00125 & 0.00092 & qh49.prn \\
\hline P $70 \times 70$ & 0.00023 & 45 & 0.0273 & 0.00039 & 0.00124 & 0.00101 & qh411.prn \\
\hline P $90 \times 90$ & 0.00027 & 86 & 0.0992 & 0.00040 & 0.00126 & 0.00099 & qh413.prn \\
\hline P $50 \times 50$ & 0.00025 & 44 & 0.0259 & 0.00025 & 0.00029 & 0.000040 & qh415.prn \\
\hline P $50 \times 50$ & 0.00021 & 44 & 0.0247 & 0.00023 & 0.00030 & 0.000090 & qh417.prn \\
\hline P $150 \times 150$ & $\mathbf{0 . 0 0 0 3 0}$ & $\mathbf{1 4 1}$ & $\mathbf{0 . 2 6 5 1}$ & $\mathbf{0 . 0 0 0 3 7}$ & $\mathbf{0 . 0 0 0 9 8}$ & $\mathbf{0 . 0 0 0 6 8}$ & qh43.prn \\
\hline
\end{tabular}

*For example P $400 \times 200=$ nominal half square wave pulse having a pulse width of 400 microseconds and a peak amplitude of 200 volts DC. The actual rising and falling slopes are limited to 1 volt/microsecond.

The bold data entry at the bottom of the table represents the minimum repeatable pulse width control exhibited by the HSILS prototype during the laboratory tests reported herein.

Table 3.4: Static Pressure Sensor Data for RCS (Solenoid) Amplitude Tests

\begin{tabular}{|c|c|c||c|c|c||c|c|c||}
\hline \begin{tabular}{|} 
Test \\
No.
\end{tabular} & $\begin{array}{c}\text { Drive } \\
\text { Pulse } \\
\text { Ampl. } \\
\text { (volts) }\end{array}$ & $\begin{array}{c}\text { Thrust } \\
\text { (newtons) }\end{array}$ & $\begin{array}{c}\text { Test } \\
\text { No. }\end{array}$ & $\begin{array}{c}\text { Drive } \\
\text { Pulse } \\
\text { Ampl. } \\
\text { (volts) }\end{array}$ & $\begin{array}{c}\text { Thrust } \\
\text { (newtons) }\end{array}$ & $\begin{array}{c}\text { Test } \\
\text { No. }\end{array}$ & $\begin{array}{c}\text { Drive } \\
\text { Pulse } \\
\text { Ampl. } \\
\text { (volts) }\end{array}$ & $\begin{array}{c}\text { Thrust } \\
\text { (newtons) }\end{array}$ \\
\hline 4 & 3 & 0 & 9 & 8 & 0 & 17 & 10 & 0 \\
\hline 2 & 1 & 0 & 16 & 9 & 0 & 18 & 16.9 & 0 \\
\hline 3 & 2 & 0 & 11 & 10 & 0 & 18 & 17.2 & 1.689818 \\
\hline 4 & 3 & 0 & 12 & 11 & 0 & 20 & 18.3 & 1.689818 \\
\hline 5 & 4 & 0 & 13 & 12 & 0 & 21 & 22 & 1.624194 \\
\hline 6 & 5 & 0 & 14 & 13 & 0 & 22 & 25.2 & 1.624194 \\
\hline 7 & 6 & 0 & 15 & 14 & 0 & 23 & 31.1 & 1.657006 \\
\hline 8 & 7 & 0 & 16 & 15 & 0 & 24 & 33.6 & 1.706224 \\
\hline & & & & & & & 36.4 & 1.55857 \\
\hline
\end{tabular}


Table 3.5: Static Pressure Sensor Data for HSILS Amplitude Tests

\begin{tabular}{|c|c|c|c|c|c|c|c|c|}
\hline $\begin{array}{l}\text { Test } \\
\text { No. }\end{array}$ & $\begin{array}{l}\text { Drive } \\
\text { Pulse } \\
\text { Ampl. } \\
\text { (volts) }\end{array}$ & $\begin{array}{c}\text { Thrust } \\
\text { (newtons) }\end{array}$ & $\begin{array}{l}\text { Test } \\
\text { No. }\end{array}$ & $\begin{array}{l}\text { Drive } \\
\text { Pulse } \\
\text { Ampl. } \\
\text { (volts) }\end{array}$ & $\begin{array}{c}\text { Thrust } \\
\text { (newtons) }\end{array}$ & $\begin{array}{l}\text { Test } \\
\text { No. }\end{array}$ & $\begin{array}{l}\text { Drive } \\
\text { Pulse } \\
\text { Ampl. } \\
\text { (volts) }\end{array}$ & $\begin{array}{c}\text { Thrust } \\
\text { (newtons) }\end{array}$ \\
\hline 1 & 100 & 0.234278 & 19 & 160 & 0.457448 & 37 & 200 & 0.501203 \\
\hline 2 & 160 & 0.032664 & 20 & 160 & 0.837116 & 48 & 200 & 0.654599 \\
\hline 8 & 160 & 0.021615 & 28 & 160 & 0.577959 & 39 & 200 & 0.484715 \\
\hline 3 & 100 & 0.225894 & 22 & 170 & 0.50396 & 46 & 200 & 1.197433 \\
\hline 5 & 140 & 0.191901 & 23 & 170 & 0.601764 & 41 & 200 & 0.570109 \\
\hline 6 & 110 & 0.131839 & 20 & 170 & 0.379311 & 42 & 200 & 0.570404 \\
\hline 7 & 120 & 0.284149 & 25 & 180 & 0.668561 & 44 & 210 & 0.659111 \\
\hline 8 & 120 & 0.301378 & 20 & 180 & 0.498988 & 44 & 210 & 1.450619 \\
\hline 8 & 120 & 0.192032 & 27 & 180 & 0.745251 & 45 & 210 & 0.674992 \\
\hline 10 & 130 & 0.247732 & 28 & 180 & 0.933034 & 46 & 210 & 0.980012 \\
\hline 11 & 130 & 0.365854 & 29 & 180 & 0.845705 & 47 & 210 & 1.534371 \\
\hline 12 & 140 & 0.430805 & 36 & 180 & 1.362682 & 48 & 220 & 1.146779 \\
\hline 13 & 140 & 0.462042 & 31 & 190 & 0.390528 & 44 & 220 & 1.263262 \\
\hline 11 & 140 & 0.332222 & 32 & 190 & 1.176556 & 50 & 220 & 1.091573 \\
\hline 15 & 150 & 0.408714 & 33 & 190 & 1.242919 & 51 & 220 & 0.885104 \\
\hline 10 & 150 & 0.494173 & 34 & 200 & 1.292793 & 52 & 220 & 1.073855 \\
\hline 17 & 160 & 0.31068 & 35 & 200 & 1.254321 & 53 & 220 & 1.14842 \\
\hline \multirow[t]{2}{*}{18} & 160 & 0.776529 & 36 & 200 & 1.3238 & 54 & 220 & 1.015285 \\
\hline & & & & & & 55 & 220 & 1.422072 \\
\hline
\end{tabular}




\subsection{Discussion}

\subsection{Minimum Repeatable Pulse Width Parameters}

A reasonable performance comparison between the HSILS and RCS systems is shown in Figs. 4.1 and 4.2 for the minimum repeatable pulse widths measured during the laboratory prototype tests described in Chapter 3. Table 4.1 presents this comparison data in tabular form.

\begin{tabular}{|c|c|c|c|}
\hline \multicolumn{4}{|c|}{$\begin{array}{l}\text { Table 4.1: Comparison of RCS and HSILS Response } \\
\text { Parameters }\end{array}$} \\
\hline Parameter & $\begin{array}{c}\mathrm{RCS} \\
\text { (solenoid) }\end{array}$ & $\begin{array}{c}\text { HSILS } \\
\text { (piezoelectric) }\end{array}$ & RCS/HSILS \\
\hline $\begin{array}{c}\text { Drive Pulse } \\
\text { Width } \\
\text { (seconds) }\end{array}$ & 0.0035 & 0.0003 & 11.67 \\
\hline $\begin{array}{l}\text { Response } \\
\text { Rise Lag } \\
\text { (seconds) }\end{array}$ & 0.0048 & 0.00037 & 12.97 \\
\hline $\begin{array}{l}\text { Response } \\
\text { Pulse Width } \\
\text { (seconds) }\end{array}$ & 0.0073 & 0.00098 & 7.45 \\
\hline $\begin{array}{l}\text { Response } \\
\text { Fall Lag } \\
\text { (seconds) }\end{array}$ & 0.002 & 0.00068 & 2.94 \\
\hline
\end{tabular}

All of the reponse variables for the RCS actuator presented in Table 4.1 compare favorably with the data presented by Hallauer and Smith (Hallauer and Smith, 1990) for a similar solenoid valve from a different manufacturer. The right-most column in Table 4.1 gives the ratios of the RCS response to those measured for the HSILS prototype. From these it can be seen that the HSILS actuator clearly out-performs the solenoid actuator on all counts. Pulse width control and rise lag for the HSILS are nearly an order of magnitude faster than for the solenoid actuator.

The lowest performance improvement for the HSILS unit is the fall lag which is only three times faster than for the solenoid and four times longer than the HSILS rise lag. This may be attributable to differences in the loading and unloading mechanisms used in the HSILS. Initial expansion of the piezoelectric stack occurs very rapidly (approximately 10 microseconds to full extension, based on the propagation speed of sound within the stack) and the stack is capable of generating extremely high levels of force (upwards of 8000 newtons) at low initial displacements. On the other hand, the return force needed to close the valve is provided by a compression spring with a constant force level of approximately 200 newtons. Given the high degree of damping in the system (provided by the high 
pressure valve core seals, as previously discussed in Chapter 2) this difference in force levels could account for the increased fall lag. Methods for improving this response might include low friction seals and a higher return spring force or, alternatively, a parallel piezoelectric stack used solely for closing the valve. Fig. 4.2 also provides a more detailed picture of the exhaust nozzle ringing (predominant frequency $=4 \mathrm{kHz}$ ) and decay following termination of thrust that was described in Chapter 3.

\subsection{Parameter Correlations}

A number of parameter studies were conducted based on the data presented in Tables 3.1, 3.2, and 3.3. These included correlation plots of response pulse width versus drive pulse width; response pulse width versus drive pulse energy; response rise lag versus drive pulse amplitude; response fall lag versus drive pulse energy and response fall lag versus drive pulse width. These plots are presented in Figs. 4.3 and 4.4 for the RCS and HSILS actuators, respectively.

\subsubsection{RCS Results}

The first correlation considered was that of response pulse width as a function of drive pulse width. The upper left hand plot in Fig. 4.3 indicates that for longer drive pulse widths there is a reasonable degree of correlation between the response and the drive pulse width. However, as observed in Chapter 3, this correlation appears to break down for drive pulse widths of less than $10 \mathrm{~ms}$.

The middle left plot in Fig. 4.3 shows the relationship between RCS response pulse width and drive pulse energy. For this comparison the active energy dissipation in the drive pulse was estimated as follows for the resistive-inductive load provided by the solenoid coil when driven by a constant current pulse power supply:

$$
E_{R C S}=\sum_{i=1}^{n-1}\left(\frac{V(i+1)+V(i)}{2 R}\right)(t(i+1)-t(i))
$$

where:

$$
\begin{aligned}
& n=\text { number of data scans (drive pulse record) } \\
& V(i)=\text { drive pulse voltage at scan } i \\
& R=\text { solenoid resistance (ohms) } \\
& t(i)=\text { time at data scan } i \text { (seconds) }
\end{aligned}
$$


As can be seen in Fig. 4.3 (middle, left graph) there appears to be a power-law relationship between solenoid response pulse width and the amount of energy provided to the coil. This is a somewhat intuitive observation since power must be continuously supplied to the coil to sustain the magnetic field that causes the valve to remain open once the initial opening threshold energy content has been reached. The same cannot be said for RCS fall lag (middle, right graph in Fig. 4.3) which shows no correlation to drive pulse energy nor to drive pulse width (lower, left graph Fig. 4.3). RCS rise lag, on the other hand, does appear to be correlated to the drive pulse amplitude (maximum drive voltage), with shorter rise lag ( $5 \mathrm{~ms}$ vs $9 \mathrm{~ms}$ ) corresponding to the higher of the two voltage plateaus employed in these tests (39 and 21 volts, respectively).

\subsubsection{HSILS}

A similar set of correlation plots for the HSILS prototype is shown in Fig. 4.4. Here it can be seen (upper, left graph) that, unlike the RCS actuator, there is a good linear correlation $\left(\mathrm{R}^{2}=95.5 \%\right)$ between the HSILS response pulse width and the drive pulse width.

Unlike the RCS unit there is no correlation between HSILS response pulse width and drive pulse energy (middle, left graph Fig. 4.4). For the case of a capacitive load (for which a piezoelectric stack is a good emulator) in the face of a constant current pulse power supply the active energy dissipation is given by:

$$
E_{H S I L S}=\frac{1}{2} C V_{\text {peak }}^{2}
$$

where:

$$
\begin{aligned}
& C=\text { capacitance of the piezoelectric element } \\
& V_{\text {peak }}=\text { maximum drive pulse voltage }
\end{aligned}
$$

Once a plateau level has been reached in the drive pulse the piezoelectric stack will remain extended (and will therefore hold the valve open) with no expenditure of energy, as evidenced by the grouping of points at approximately $0.6 \mathrm{~J}$ in Fig. 4.4 (middle, left graph). Similar data could have been collected for any of the lower energy content pulses. The density of data at $0.6 \mathrm{~J}$ is a result of most of the pulse-width tests being conducted with a $200 \mathrm{~V}$ plateau amplitude drive pulse. A similar lack of correlation exists between response fall lag and dissipated energy, as shown in the middle, right graph in Fig. 4.4. Nor does there appear to be any correlation between response fall lag and drive pulse width.

The upper right hand graph in Fig. 4.4 indicates as well that there is no relationship between the drive pulse amplitude and the response rise lag. The data spread in rise lag for the HSILS unit are on the order of $0.2 \mathrm{~ms}$ and do not appear to be a function of any drive pulse characteristics. The HSILS fall lag, on the other hand (middle right hand and lower left graphs, Fig. 4.4), shows local data spread of as much as $1.5 \mathrm{~ms}$, particularly for drive pulse 
widths in excess of $0.5 \mathrm{~ms}$. These may be related to the valve momentarily sticking in the open position following termination of the drive pulse. This would most likely be a result of differences in kinetic and static friction at the location where the valve core rod penetrates the high pressure chamber inboard of the exhaust nozzle throat. Along this section are several o-rings, backup rings, and a guide tube for the valve core which exhibit a high level of damping. As previously mentioned, it is more likely that fall lag and fall lag variances for the HSILS will be greater than rise lag (and its associated variances), due to the fact that the return spring used in the present HSILS prototype is incapable of developing the instantaneous high initial loads that the piezoelectric stack can upon initial valve opening. During initial cracking of the valve, as with closing from a stable open position, static friction at the high pressure seals will be greater than kinetic friction. The longer it takes to overcome the transition from static to kinetic friction the greater will be the expected lag and the level of variance. Since during valve opening the stack is able to adaptively increase the opening force, it can proceed through this friction transition faster, leading to lower variance in rise lag. Further research towards improving pulse width resolution for HSILS-type technology should thus be focused on techniques for reducing response fall-lag.

\subsection{Amplitude Control using HSILS}

As was shown in Fig. 3.14 there exists a linear relationship between output thrust and drive voltage for the HSILS prototype. The actual thrust levels involved were low, on the order of 1-2 $\mathrm{N}$ for an accumulator pressure of $5.5 \mathrm{MPa}$.

Supplementary testing was done at operating pressures as high as $41 \mathrm{MPa}$ with a commensurate improvement in thrust amplitude (i.e. in the range of 7-15 N). At these higher thrust levels there were occasional instances where the valve did not close perfectly, as evidenced by a residual gas leak. This occurred more frequently for the initial valve seat configuration in which the expansion nozzle and valve seat were integrally machined from a rod of 304 stainless steel. The valve core rod was machined from VascoMax 300 maraging steel (yield strength $1884 \mathrm{MPa}$, hardness $15 \mathrm{~N}-86$ ). After several thousand test firings it was noted that the 304 stainless steel at the valve seat developed a localized spall due to impact fatigue (with subsequent detectable blow-by upon closing of the valve). Ultimately, the valve-seat/nozzle-throat segment of the expansion nozzle was re-designed as a replaceable unit. Two new materials were used for the replaceable valve seat: VascoMax 500 (yield strength $2760 \mathrm{MPa}$, hardness 92-HR15N [approx. HRC-65]) and Ferrotic alloy (45\% titanium carbide, balance maraging steel binder; yield strength $3000 \mathrm{MPa} \mathrm{MPa}$, hardness $2470-\mathrm{HK}$ ). Of these the Ferrotic seat performed best and there was no subsequent marring of the valve seat surface. However, after several hundred further firings it was discovered that the blow-by problem had reappeared. This time a small striated patch (approx. 0.05 $\mathrm{mm}^{2}$ ) appeared on the valve core rod sealing surface at the valve tip. While the problem was resolvable in the laboratory by simply replacing the valve core rod, further research is waranted into the design of this detail of the HSILS, particularly for higher operating pressures.

Assuming that existing mechanical design problems can be resolved it may be desirable, particularly for non-spacecraft industrial active control applications, to substantially increase 
the maximum thrust level. Table 4.2 lists design parameters for scaled HSILS units. The gas accumulator operating pressure is presumed to be $41 \mathrm{MPa}$ and the variables listed in Table 4.1 are defined as:

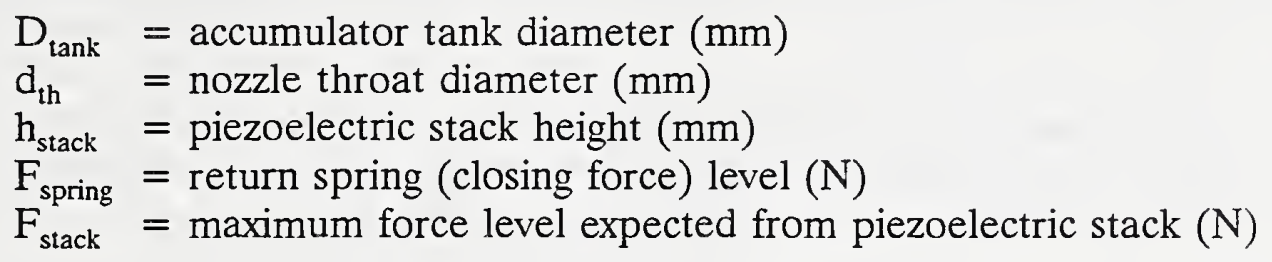

The maximum impulse bit is defined as the product of peak thrust times the longest achievable pulse duration (assumed to be 0.1 second) for an approximate half square wave drive signal. The minimum impulse bit for the current HSILS prototype, for comparison, is approximately 0.0002 newton-seconds (corresponding to a $0.98 \mathrm{~ms} \times 0.2$ newton pulse at an accumulator pressure of $5.5 \mathrm{MPa}$ ). All of the parameters listed in Table 4.2 are achievable with present technology. The larger piezo stacks would have to be custom fabricated. The use of longer actuators to achieve the necessary valve displacements for the larger thrusters should not incurr degradation in the speed of the valve, provided the lamination thickness and electroding procedures remain the same.

\begin{tabular}{|c|c|c|c|c|c|c|}
\hline \multicolumn{2}{|c|}{ Table 4.2: Scaling of HSILS Technology to Industrial Control Levels } \\
\hline $\begin{array}{c}\text { Thrust } \\
\text { (newtons) }\end{array}$ & $\begin{array}{c}\mathrm{D}_{\text {tank }} \\
(\mathrm{mm})\end{array}$ & $\begin{array}{c}\mathrm{d}_{\text {th }} \\
(\mathrm{mm})\end{array}$ & $\begin{array}{c}\mathrm{h}_{\text {stack }} \\
(\mathrm{mm})\end{array}$ & $\begin{array}{c}\mathrm{F}_{\text {spring }} \\
(\text { newtons })\end{array}$ & $\begin{array}{c}\mathrm{F}_{\text {stack }} \\
(\text { newtons })\end{array}$ & $\begin{array}{c}\text { Max. } \\
\text { Impulse } \\
\text { Bit } \\
(\mathrm{n}-\mathrm{sec})\end{array}$ \\
\hline 15 & 102 & 1 & 84 & 209 & 2510 & 1.5 \\
\hline 150 & 230 & 3.2 & 264 & 2042 & 24510 & 15 \\
\hline 1500 & 500 & 10 & 835 & 20394 & 244750 & 150 \\
\hline 15000 & 1000 & 32 & 2642 & 204255 & 2451950 & 1500 \\
\hline
\end{tabular}

\subsection{HSILS Amplitude Control Rate (ACR)}

The development of "intelligent" control pulses requires both the ability to generate short packets of thrust (as measured by pulse width resolution discussed above) as well as the ability to rapidly change the thrust amplitude. A measure of this ability to change thrust is the amplitude control rate which can be estimated by the peak thrust generated by a response pulse divided by the rise time to reach that thrust, in units of newtons per second.

As previously noted, thrust amplitude measurements for the HSILS unit were based on the average of a band of readings taken while the HSILS unit was subjected to a steady state voltage. Rise time data were thus not available for those tests in which actual thrust was measured. However, rise times were available from the acoustic sensor pulse width resolution tests. From these we can infer a level of thrust by means of the thrust equation 
presented in Fig. 3.14. Table 4.3 presents data for several test firings of the HSILS which give an approximate indication of the amplitude control rate that was achievable with the HSILS laboratory prototype. There is a certain amount of imprecision with this method of estimating the ACR since the peak amplitudes in some of the acoustic data were truncated in the analog to digital conversion process. The ACR value of $1500-1600 \mathrm{~N} / \mathrm{s}$ is relative to the present HSILS prototype when operated at $5.5 \mathrm{MPa}$ accumulator pressure. Since the response times for the expansion mechanism are independent of accumulator pressure, an ACR of 12000 newtons/second would be anticipated when the HSILS was operated at its maximum accumulator pressure of $41 \mathrm{MPa}$.

Similar data for the RCS (solenoid) actuator indicated an average ACR value of approximately 500 newtons/second when operated at $5.5 \mathrm{MPa}$ (twice the recommended service pressure). The ACR improvement ratio for the HSILS relative to the RCS system, when both are operated at their maximum recommended pressures is thus $(12000 / 250)=$ 48; i.e. the HSILS has an amplitude change rate 48 times faster than for the solenoid actuator.

\begin{tabular}{|c|c|c|c|c||}
\hline \multicolumn{2}{|c|}{ Table 4.3: HSILS Amplitude Control Rate Tests (5.5 MPa operating Pressure) } \\
\hline \hline Test Name & Peak Voltage & $\begin{array}{c}\text { Rise Time } \\
\text { (RT) } \\
\text { (seconds) }\end{array}$ & $\begin{array}{c}\text { Calculated } \\
\text { Peak Thrust } \\
(\mathrm{N})\end{array}$ & $\begin{array}{c}\text { Amplitude } \\
\text { Control Rate } \\
\text { (ACR) } \\
(\mathrm{N} / \mathrm{s})\end{array}$ \\
\hline qh33.prn & 139 & .00028 & 0.40 & 1430 \\
\hline qh31.prn & 139 & .00023 & 0.40 & 1782 \\
\hline qh41.prn & 139 & .00023 & 0.40 & 1782 \\
\hline & & & Average ACR: & 1664 \\
\hline
\end{tabular}

\subsection{Damping Effects}

Original laboratory measurements of viscous damping (see Chapter 2) yielded an estimate of the HSILS internal damping ratio of $388 \%$ of critical. The laboratory tests reported in Fig. 3.12 confirm this high level of damping. For example, the limiting repeatable HSILS response shown in Fig. 4.2 indicates negligible amplitude oscillation upon reaching the fullopen position and likewise negligible amplitude oscillation following valve closing. The vibrations which decay following closing of the valve are, as previously reported, acoustic resonant ringing of the exhaust nozzle. While the high pressure seals which isolate the valve core drive mechanism from the pressurized gas chamber are likely a strong factor in determining the limiting pulse width resolution (due to increased fall lag), they are both necessary to the isolation of the pressurized portion of the operational device as well as to eliminate bounce as the valve closes (there are, in fact, two examples of situations in which a single "bounce" did occur; these are shown in Fig. 3.12c). Any future enhancements to the device will necessarily have to deal with the tradeoffs inherent in eliminating valve core bounce while minimizing response lag times. 


\subsection{Mechanical Design Observations}

Future use of the HSILS unit on spacecraft, for the purposes of rapid attitude acquisition and precision pointing control, will require significant improvements to the laboratory prototype described in this report.

As was mentioned earlier, no effort was made to optimize the mass or volume of the prototype. It is the author's opinion that a $25 \mathrm{~N}$ thruster employing the HSILS concept, with full onboard intelligence, power and gas storage could be constructed with a mass of under $2 \mathrm{~kg}$ and a volume of approximately $0.015 \mathrm{~m}^{3}$, using composite materials and hybrid IC circuitry. This device is energy efficient and could be scaled to meet higher thrust requirements while not sacrificing control speed.

For long duration use the nozzle seat problem must be addressed and consideration given to possible inclusion of tough elastomers for the valve core tip. It was confirmed, through visual observation, that the core rod had developed a slight permanent curvature during the course of testing, most likely from slightly eccentric axial impact loads sustained during valve closing. This may have accounted for the fact that the previously described metal fatigue on the valve core tip only occurred on one side in a localized patch. Elimination of valve core rod warp would require a stiffer element. In order to minimize mass a hollow composite element should be considered.

Assuming that the above mentioned valve core seating problems can be met, it is the author's opinion that operating pressures as high as $40 \mathrm{MPa}$ should not constitute a problem. In its present configuration the HSILS unit could be operated not only as a cold gas unit but also with standard monopropellants (e.g. $\mathrm{MMH}$ ). 


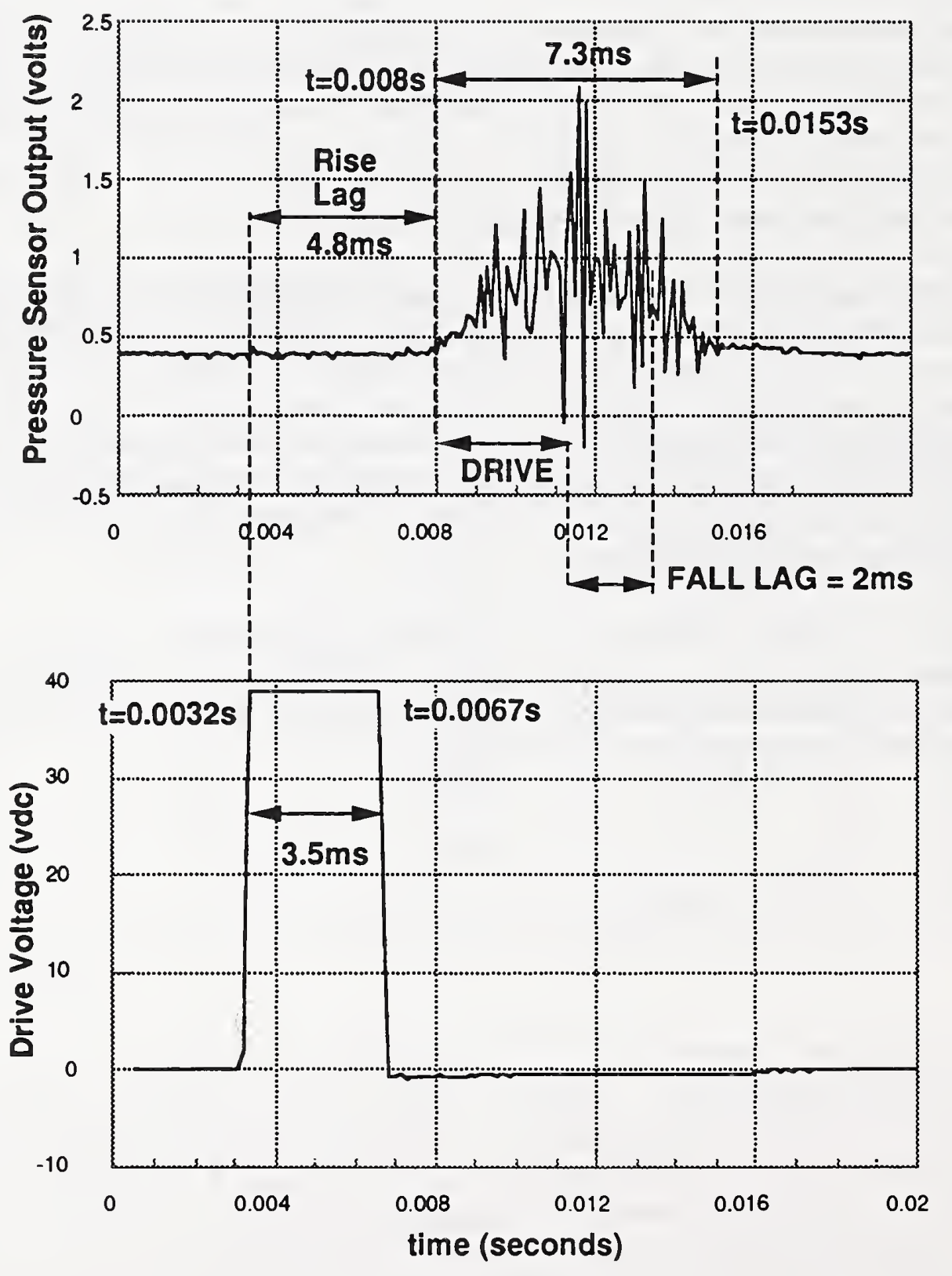

Fig. 4.1: Limiting pulse width response for solenoid-based RCS actuator and the voltagetime drive pulse used to produce the actuator response. 


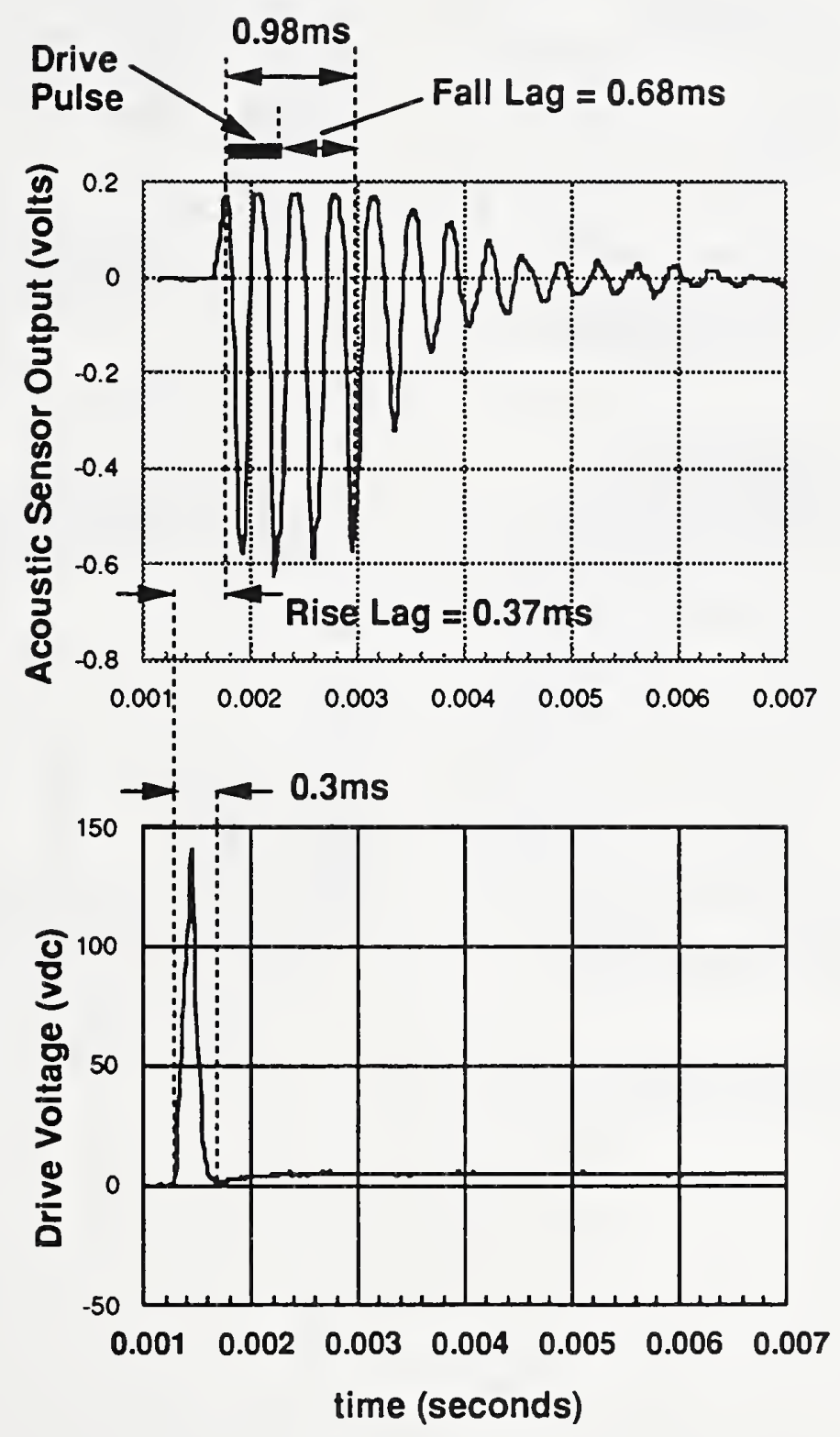

Fig. 4.2: Limiting pulse width response for the HSILS prototype and the voltage-time drive pulse used to produce the actuator response. 

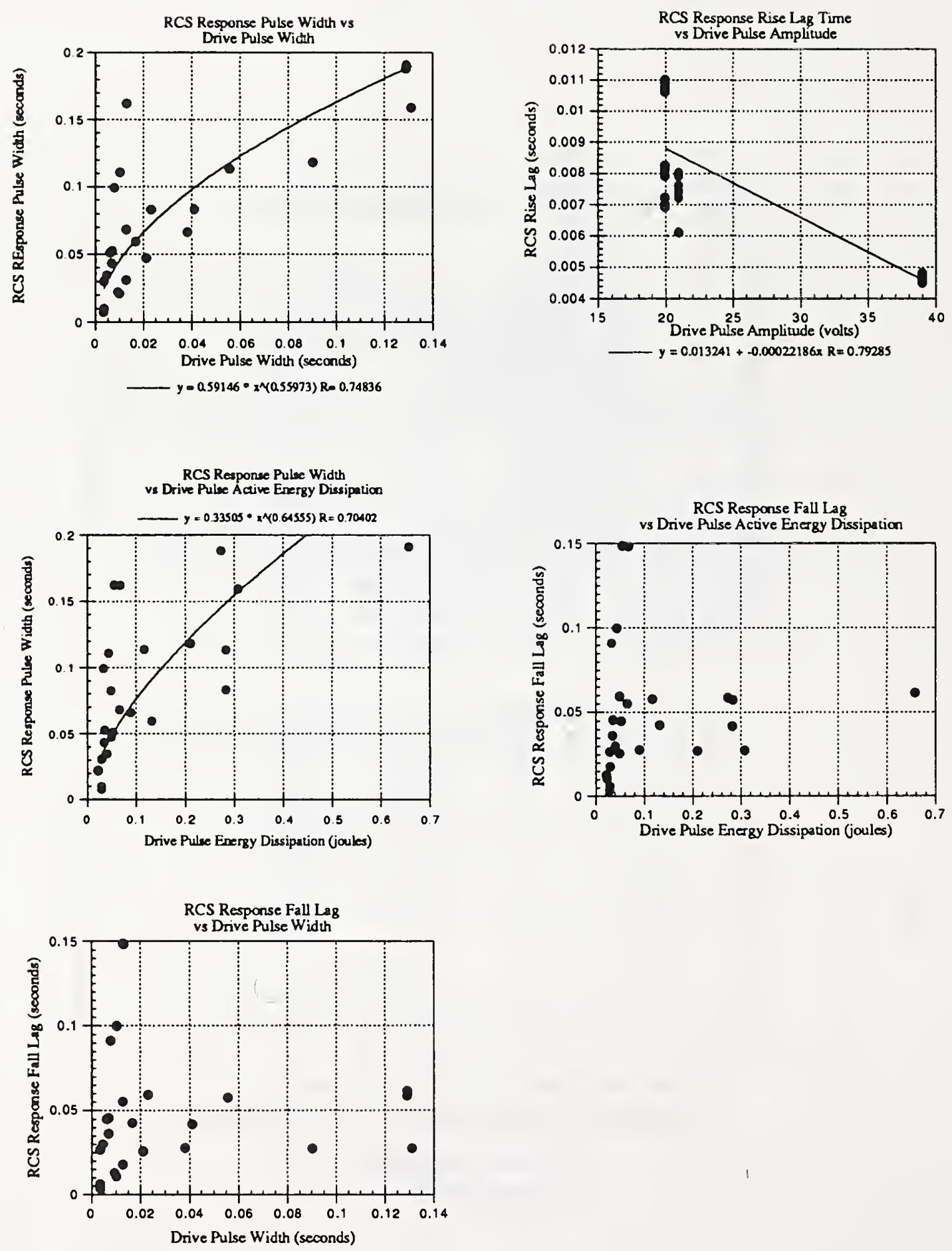

Fig. 4.3: Typical solenoid-based RCS actuator response characteristics. Parameters are defined in Chapter 2 (see Fig. 2.2); drive pulse energy is as defined above in Chapter 4. 


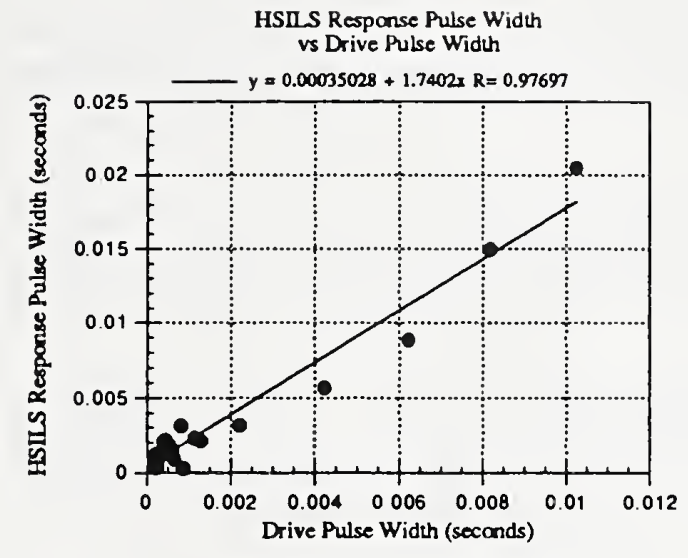

HSILS Response Pulse Width væ Drive Pulse Active Energy Dissipation

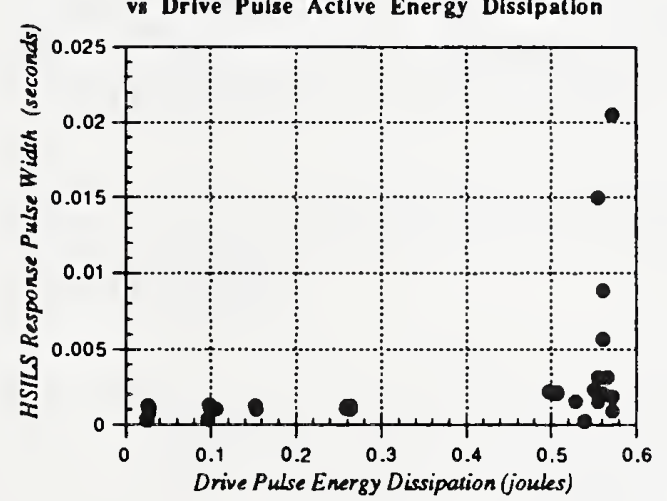

HSILS Response Fall Lag vo Drive Pulse Width

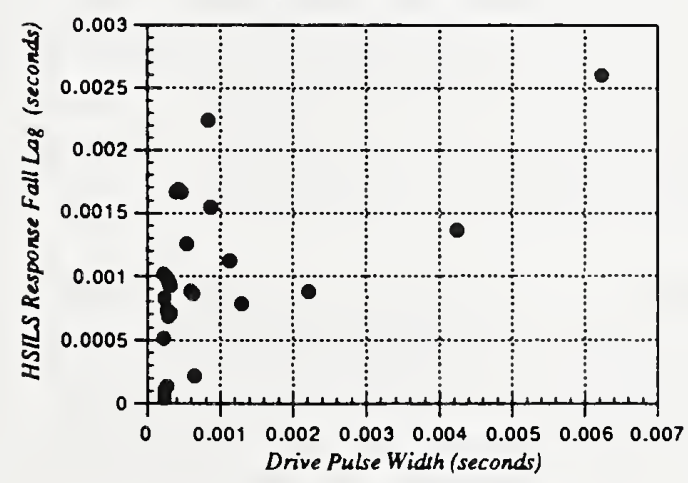

HSILS Response RIse Lag Time vs Drive Pulse Amplitude

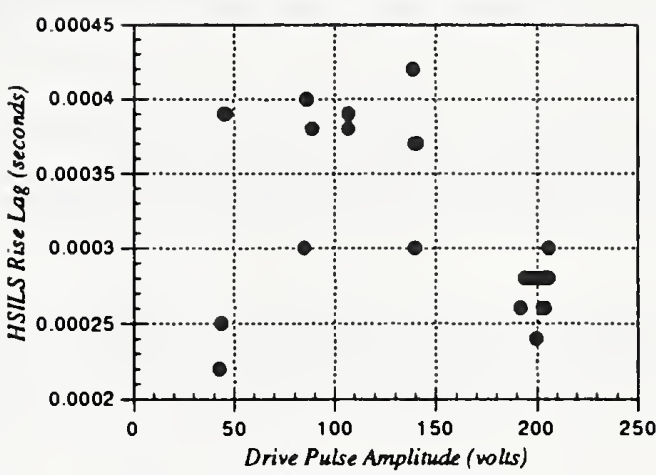

HSILS Response Fall Lag vs Drive Puise Actlve Energy Dissipation

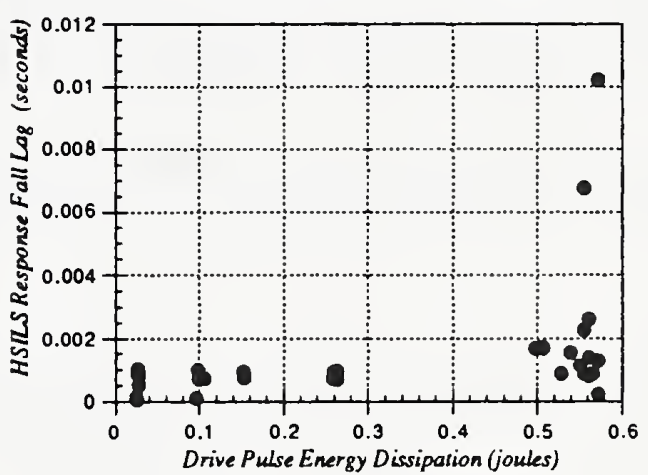

Fig. 4.4: Typical HSILS response characteristics. Parameters are defined in Chapter 2 (see Fig. 2.2); drive pulse energy is as defined above in Chapter 4. 



\subsection{Conclusions}

A working laboratory prototype High Speed Intelligent Loading System (HSILS) was developed and tested at NIST in side-by-side comparisons with traditional solenoid-based reaction control technology. The HSILS concept employed a mechanically amplified piezoelectric stack as the active valve element in a cold gas thruster as opposed to an electro-magnetically operated valve core. The HSILS unit exhibited the following levels of performance improvement:

- Minimum rise lag (time from initiation of drive pulse to the initiation of measureable output thrust) of $0.37 \mathrm{~ms}$. This value is 13 times faster than for equivalent solenoidbased reaction control systems.

- Response pulse width resolution (minimum base to base elapsed time for a repeatable pulse) of $0.98 \mathrm{~ms}$. This value is approximately 8 times faster than for an equivalent solenoid-based system.

- Minimum response fall lag (time from initiation of measurable output thrust to the point at which thrust termination begins minus the drive pulse width) of $0.68 \mathrm{~ms}$. This value is approximately 3 times faster than for an equivalent solenoid-based system.

- Amplitude control rate (thrust rate of change) of $12000 \mathrm{~N} / \mathrm{s}$ when operated at rated pressure of $41 \mathrm{MPa}$. This value is approximately 50 times faster than for solenoidbased technology.

The HSILS unit was shown to exhibit a linear correlation between drive voltage and output thrust. This permits active thrust control within the regime of the performance statistics listed above. More specifically, this permits sub-millisecond "intelligent" (of arbitrary analytical shape) uni-directional control forces to be applied to a structural system. Solenoid-based technology was shown to have binary thrust behavior (either off or full-on). The HSILS laboratory prototype was shown to be capable of delivering a peak thrust of approximately $15 \mathrm{~N}$ at an accumulator pressure of $41 \mathrm{MPa}$. Scaling of the HSILS unit to achieve larger maximum thrust appears feasible without significant penalties to the performance characteristics determined in this study.

The HSILS system was controlled by a dedicated onboard microcontroller and pulse power system which, after being charged, could be operated in a stand-alone mode. Compressed nitrogen accumulators were also an integral part of the laboratory prototype so that the entire package could be attached to any structural system to serve either as a remote, independent active control or system identification node.

Several areas for future improvement and research were identified. Fall lag times were disproportionately high with respect to the observed rise lag times. This was traced to the differences in the opening and closing mechanisms used in the present HSILS design. Currently a fast-acting piezoelectric stack is used for valve opening and a preloaded compression spring for valve closing. The former is capable of dynamically increasing its force level, particularly at small displacements. The resistance to valve opening and closing 
arises from high pressure seals which separate the pressurized section (the valve seat area) from the unpressurized core actuator mechanism. Future improvements may involve twin piezoelectric stacks operated in opposition; the use of higher force levels in both the piezoelectric stack and the return spring; or the development of a low damping high pressure seal.

Additional problems were noted at the valve seat where high strength, high hardness valve elements had to mate precisely, and repeatedly, at closing velocities of $4-5 \mathrm{~m} / \mathrm{second}$. Reasonable sealing performance was obtained by using a $2000 \mathrm{MPa}$ maraging steel valve core rod and an EDM milled and polished valve seat fabricated from a ferritic titanium carbide alloy. Visible warping of the valve core rod, which was quite slender, was observed following several thousand test firings, as was minor galling on the valve core rod tip. Future improvements may involve the design of a tubular composite valve core rod with hardened elastomeric or carbon coatings on the mating surfaces. 


\subsection{References:}

Abe, S., Sakakibara, Y., Tomita, M, and Shinoda, K. (1985), "Piezoelectric Actuator and a Piezoelectric Pump Injector Incorporating the Same," U.S. Patent 4,555,059. U.S. Commissionar of Patents and Trademarks, Crystal City, VA.

Babitzka, R., Beck, W., and Linder, E. (1985), "Electrically Controllable Valve," U.S. Patent 4,494,727. U.S. Commissionar of Patents and Trademarks, Crystal City, VA.

Bailey, T. and Hubbard, J.E. (1985), "Distributed Piezoelectric-Polymer Active Vibration Control of a Cantilever Beam," Journal of Guidance, Control, and Dynamics, Vol. 8, No. 5, Sept.- Oct., 1985, American Institute of Aeronautics and Astronautics, Washington, DC.

Behmer, A., and Hartmut, H. (1986), "Typenraddrucker mit den Druck auslosenden Elementen," Deutsches Patentamt DE-3435024A1. Bundesrepublik Deutschland, 1986.

Belvin, W.K, and Edighoffer, H.H. (1986), "Dynamic Analysis and Experiment Methods for a Generic Space Station Model," Proceedings of the 27th Structures, Structural Dynamics and Materials Conference, May 19-21, 1986, San Antonio, Texas," Part 2, pp 10-18, AIAA paper \#86-0838, American Institute of Aeronautics and Astronautics, Washington, DC.

Cannon, R.H. Jr., and Schmit, E. (1984), "Initial Experiments on the End-Point Control of a Flexible One-Link Robot," The International Journal of Robotics Research, Vol. 3, No. 3, Fall 1984, pp 62-75, Massachusetts Institute of Technology, Cambridge, MA.

Carasso, A.S. (1991), "Probe Waveforms and the Reconstruction of Structural Dynamic Green's Functions," AIAA Journal, Vol. 29, No. 1, January 1991, pp 114-118, American Institute of Aeronautics and Astronautics, Washington, DC.

Carasso, A.S., and Simiu, E. (1988), "Estimation of Dynamic Green's Functions for Large Space Structures by Pulse Probing and Deconvolution," Computational Mechanics '88, S.N. Atluri et.al. eds., Vol 2, Springer-Verlag, New York, 1988.

Carasso, A.S., and Simiu, E. (1988), "Dynamic Characterization of Structures by Pulse Probing and Deconvolution,"Proceedings of the AIAA/ASME/ASCE/AHS 29th Structures, Structural Dynamics, and Materials Conference, Williamsburg, VA, April 1988, AIAA paper \#88-2230, American Institute of Aeronautics and Astronautics, Washington, DC. American Institute of Aeronautics and Astronautics, Washington, DC.

Carasso, A.S., and Simiu, E. (1989), "Identification of Dynamic Green's Functions in Structural Networks," AIAA Journal, Vol 27, April 1989, pp 492-499, American Institute of Aeronautics and Astronautics, Washington, DC. 
Crawley, E.F. and DeLuis, J. (1985), "Use of Piezo-Ceramics as Distributed Actuators in Large Space Structures," Proceedings of the AIAA/ASME/ASCE/AHS 26th Structures, Structural Dynamics, and Materials Conference, Orlando, Fl, April 1985, AIAA paper \#850626, American Institute of Aeronautics and Astronautics, Washington, DC.

Glett, B., and Murphy, M. (1987), "Piezoelectrically Driven Fast Response High-Torque Clutch Unit," U.S. Patent 4,636,679. U.S. Commissionar of Patents and Trademarks, Crystal City, VA.

Hanugud, S., Obal, M.W., Meyyappa, M. (1985), "Electronic Damping Techniques and Active Vibration Control," Proceedings of the AIAA/ASME/ASCE/AHS 26th Structures, Structural Dynamics, and Materials Conference, Orlando, Fl, April 1985, AIAA paper \#850752, American Institute of Aeronautics and Astronautics, Washington, DC.

Hallauer, W.L., and Smith, J.C. (1990) "Air-Jet Thrusters for Active Vibration Control: Design and Calibration," Journal of Experimental Techniques, November/December 1990, pp 47-50.

Hiratsuka, H., Kawasaki, K, and Miyo, Y. (1991), "Flow-Control Type Piezoelectric Element Valve,",U.S. Patent 5,029,610 U.S. Commissionar of Patents and Trademarks, Crystal City, VA.

Janner, K, and Gregorius, K. (1984), "Slit Nozzle and Fast-Acting Shutoff Valve," U.S. Patent 4,431,136. U.S. Commissionar of Patents and Trademarks, Crystal City, VA.

Kattchee, N. (1967), "Piezoelectric Injection System for Vernier Impulse Thrusters," Report No. AFRPL-TR-67-201, June 1967, Physics International Co., San Leandro, CA, 123pp.

Kippenham, D. (1962), "Electrostriction Valve," U.S. Patent 3,055,631, U.S. Commissionar of Patents and Trademarks, Crystal City, VA.

Knappe, L.F. (1972), "Betatigungsvorrichtung fur mit hoher Geschwindigkeit hin- und her zu bewegende Maschinenteile," Deutsches Patentamt DE-2134655. Bundesrepublik Deutschland, 1972.

Kushida, T. (1987), "High Speed Electromagnetic Valve," U.S. Patent 4,678,000. U.S. Commissionar of Patents and Trademarks, Crystal City, VA.

Mitsuhashi, S., Wakamatsu, K., Aihara, Y., and Okihara, N., 1985, "The Development of a Piezoelectric Relay with a Multilayer Piezoelectrtic Ceramic Actuator," Proceedings, 33rd Annual National Relay Conference, Oklahoma State University, Stillwater, Oklahoma, April 23-24, 1985. pp 7.1 - 7.11 .

Moloney, P. (1986), "Valve Operating Mechanism for Internal Combustion and Like-Valved Engines,",U.S. Patent 4,593,658. U.S. Commissionar of Patents and Trademarks, Crystal City, VA. 
Moog (1990), "760 Series Electrohydraulic Servovalve Service Manual," Mood, Inc., Industrial Division, East Aurora, NY 14052

Moritugu, M., Kawai, H., and Tokura, N. (1987), "Power Supply for Piezoelectric-Element Driving Device,",U.S. Patent 4,644,212 U.S. Commissionar of Patents and Trademarks, Crystal City, VA.

Piezoelectric Ceramics, J.V. Randeraat and R.E. Setterington, eds., Mullard Limited, Mullard House, Torrington Place, London WC1E 7HD, 2nd Ed. 1974.

Simiu, E., and Cook, G.R. (1989), "Impulse Response Functions for Elastic Structures with Rigid-Body Degrees of Freedom," Journal of Sound and Vibration, 135(2), pp 275-288,

Stone, W.C. (1990), "High Speed, Amplitude Variable Thrust Control," Patent Pending, U.S. Patent and Trademark Office, Crystal City, VA.; Ser.No. 07/873,020

Sutton, G.P. (1986), "Rocket Propulsion Elements -- An Introduction to the Engineering of Rockets," John Wiley \& Sons, New York, ISBN 0-471-80027-9.

Takahashi, S., 1985, "Development of New Piezoelectric Ceramic Actuators," New Materials \& New Processes, Vol. 3 (1985), pp 63-68.

Tomono, A. (1986), "Piezoelectric Actuator Using Bimorph Element," U.S. Patent 4,625,137. U.S. Commissionar of Patents and Trademarks, Crystal City, VA.

von Flotow, A.H. (1984), "Disturbance Propagation in Structural Networks; Control of Large Space Structures," Ph.D. Dissertation, Stanford University, June 1984. 144pp.

Weber,K, and von Blanckenhagen, P. (1987), "Pulse Valve,",U.S. Patent 4,669,660. U.S. Commissionar of Patents and Trademarks, Crystal City, VA.

Weiger, G, Dorrie, D, and Schwerdt, P. (1986), "Actuating Device for Two Mutually Dependently Actuable Valves," U.S. Patent 4,617,969. U.S. Commissionar of Patents and Trademarks, Crystal City, VA.

Yamauchi, T., Nogi, T., and Ohyama, Y. (1991), "Fuel Injection Valve and Fuel Supply System Equipped Therewith for Internal Combustion Engines," U.S. Patent 5,029,610 U.S. Commissionar of Patents and Trademarks, Crystal City, VA.

Zimmerman, D.C., Horner, G.C., and Inman, D.J. (1986), "Microprocessor Controlled Force Actuator," Proceedings of the 27th Structures, Structural Dynamics and Materials Conference, May 19-21, 1986, San Antonio, Texas," Part 1, pp 243-251, AIAA paper \#860916, American Institute of Aeronautics and Astronautics, Washington, DC. 



\section{Appendix A Program: THRUSTER}

Parametric Design of HSILS Components 


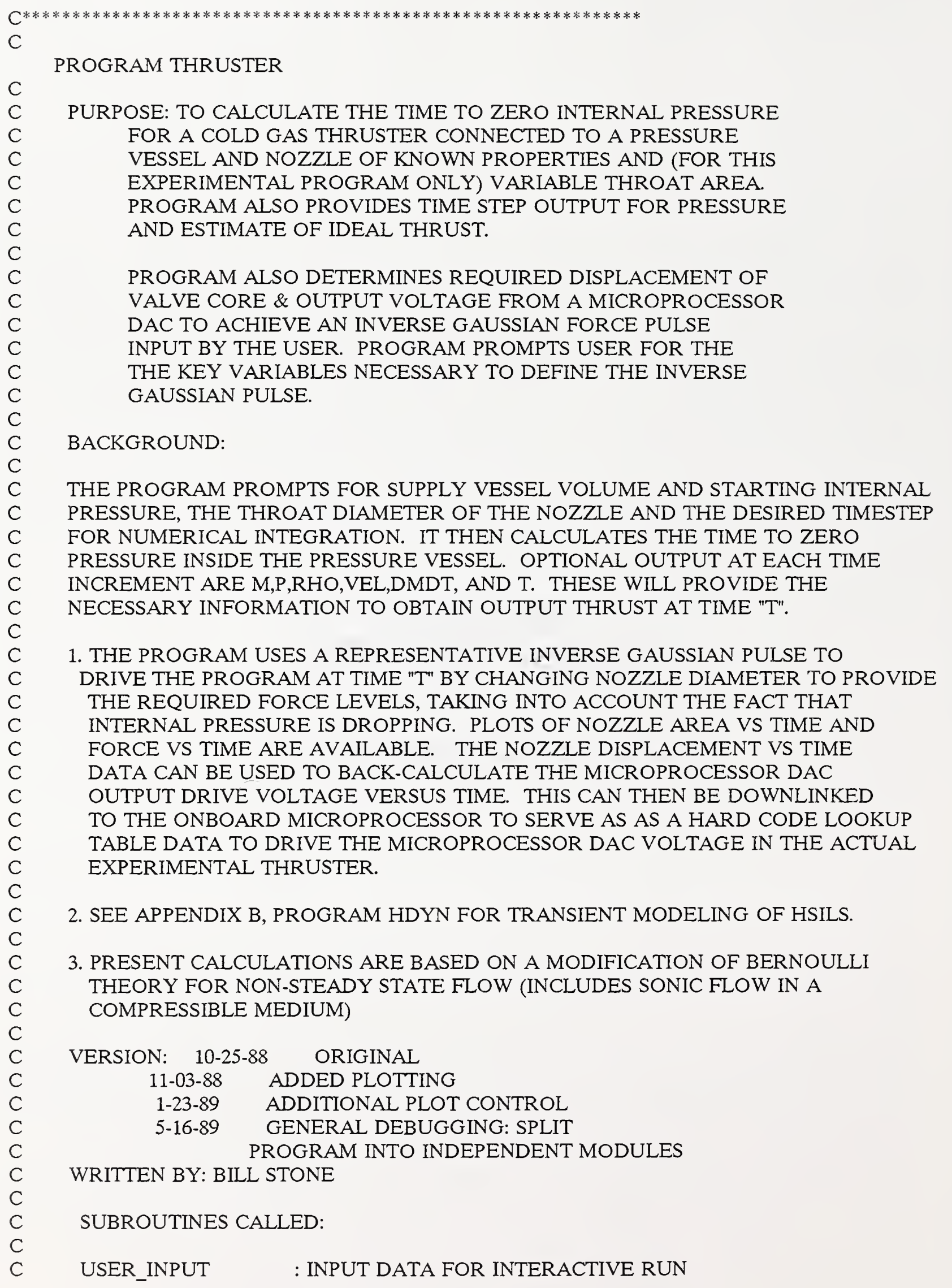




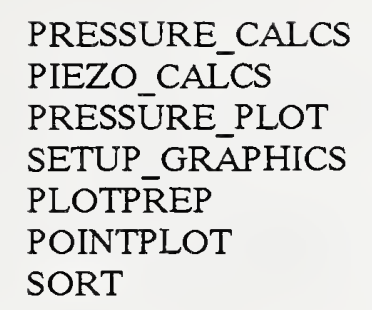

NOTE: THE FOLLOWING LINK COMMAND IS NECESSARY TO ASSEMBLE THE VARIOUS PROGRAM MODULES:

SLINK/NOMAP/EXECUTABLE $=$ THRUSTER-

THRUSTER_MAIN,USER_INPUT,PRESSURE_CALCS,PIEZO_CALCS,-

PRESSURE_PLOT,SETUP_GRAPHICS,LINEFIT,PLOTPREP,CHGCOLOR,POINTPLOT,LINEPLOT,SLIDE1,GRAB3,SORT,GDATA,ORDER,-OUTPUT,MINV,MULTR,USER:[RASTER.ONELIB]ONELIB/LIB

OPERATIONAL NOTES:

1. "THRUSTER" WAS WRITTEN FOR A VAX 11/750 COMPUTER AND A RASTER TECHNOLGIES ONE/80 1280 X 1024 PIXEL HIGH RESOLUTION COLOR RASTER DISPLAY. THE GRAPHICS ARE HARD-CODED TO THIS MACHINE SETUP, BUT TRANSFER TO MORE RECENT GRAPHICS BASED WORKSTATIONS, SUCH AS A SILICON GRAPHICS 4D/420, IS RELATIVELY STRAIGHT FORWARD WITH REGARDS TO GRAPHICS CODE; COMPUTATIONAL CODE IS $100 \%$ COMPATIBLE FORTRAN.

C

$C^{* * * * * * * * * * * * * * * * * * * * * * * * * * * * * * * * * * * * * * * * * * * * * * * * * * * * * * * * * * * * * * * * * * * * * * * * * * * *}$

$\mathrm{C}$

COMMON TMASS(5000),P(5000),RHO(5000),VEL(5000),DMDT(5000)

COMMON T(5000),CMASS(5000),CRHO(5000),CPRES(5000)

COMMON THRUST(5000),AT(5000),DISP(5000)

COMMON FGAUSS(5000),DELTA(5000),FTHRUST(5000)

COMMON DELTASTACK(5000),VDAC(5000),ATEFF(5000)

$\mathrm{C}$

C MAIN MENU

C

5666 TYPE *,',

TYPE *,'

TYPE *,'

TYPE *, PROGRAM THRUSTER:'

TYPE *, ,

TYPE *,' A SIMULATOR FOR PARAMETRIC DESIGN OF THE NIST'

TYPE *', INTELLIGENT HIGH SPEED LOADING SYSTEM'

TYPE *, ,

TYPE *,'MAIN MENU:'

TYPE *,'

TYPE *, 1 = ENTER NEW DATA SET'

TYPE *', 2 = CHANGE TANK PRESSURE'

TYPE *', 3 = CHANGE TANK DIAMETER'

TYPE *', 4 = CHANGE TEMPERATURE'

TYPE *, 5 = CHANGE NOZZLE DIAMETER'

TYPE *, 6 = CHANGE INTEGRATION TIME STEP' 


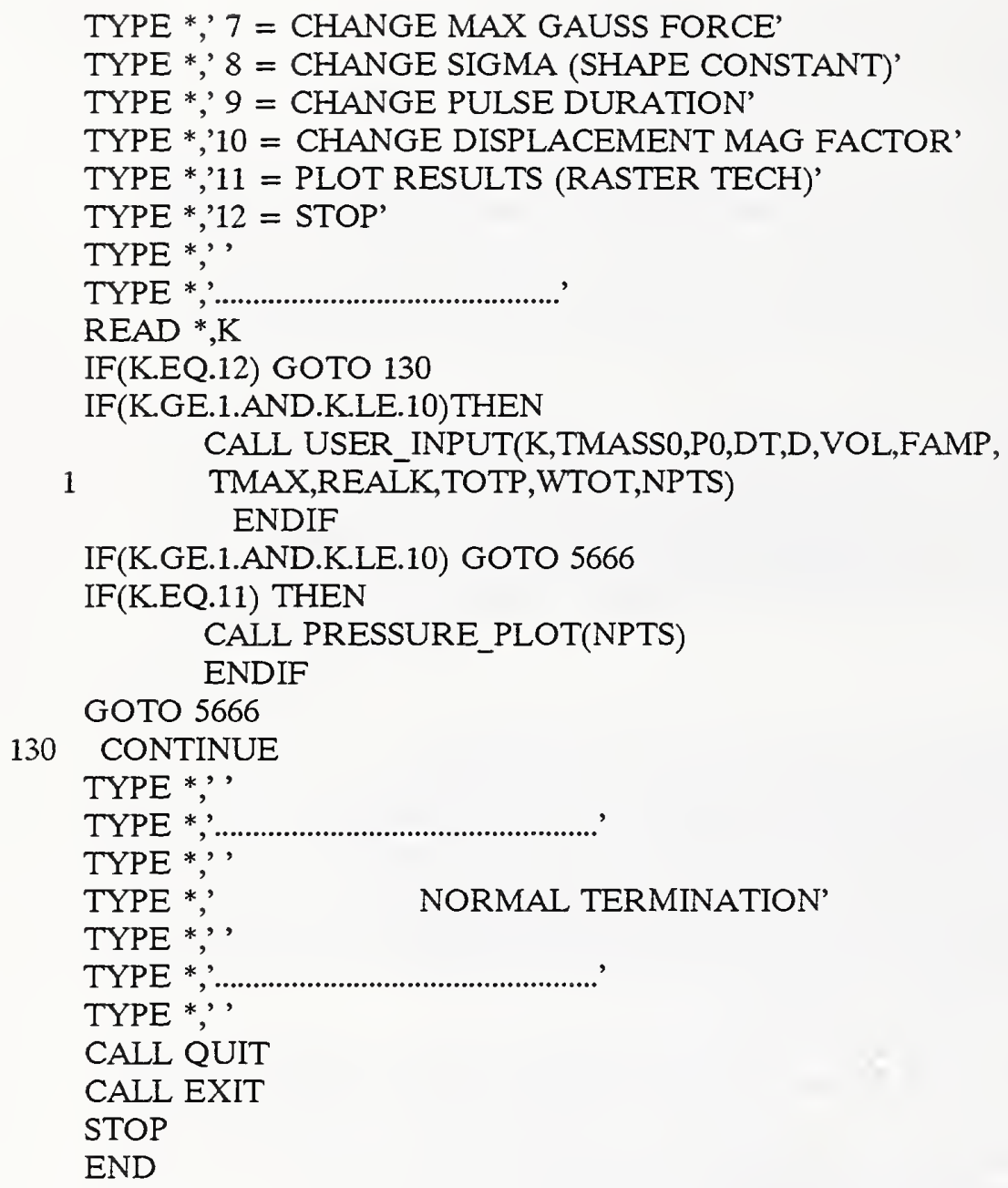


SUBROUTINE USER_INPUT(NFLAG,TMASS0,P0,DT,D,VOL,FAMP,

C

C

C

C

C

C

C

C

C

$\mathrm{C}^{*}$

C

C

$\mathrm{C}$

C

C

603 CONTINUE

IF(NFLAG.EQ.2) GOTO 802

IF(NFLAG.EQ.3) GOTO 803

IF(NFLAG.EQ.4) GOTO 804

IF(NFLAG.EQ.5) GOTO 805

IF(NFLAG.EQ.6) GOTO 806

IF(NFLAG.EQ.7) GOTO 807

IF(NFLAG.EQ.8) GOTO 808

IF(NFLAG.EQ.9) GOTO 809

IF(NFLAG.EQ.10)GOTO 810
!LOOP BACK FROM VERIFICATION MENU

!CHANGE TANK PRESSURE

!CHANGE TANK DIAMETER

!CHANGE TEMPERATURE

!CHANGE NOZZLE DIAMETER

!CHANGE INTEGRATION TIME STEP

!CHANGE MAX GAUSS FORCE

!CHANGE SIGMA (SHAPE CONST)

!CHANGE PULSE DURATION

!CHANGE DISP AMPLIFICATION

$\mathrm{C}$

C PROMPT FOR INITIAL VALUES

C

TYPE *,'

TYPE *,'

TYPE *,'

TYPE *,PROBLEM DEFINITION: ENTER VALUES REQUESTED FOLLOWED'

TYPE *', BY A CARRIAGE RETURN'

TYPE *,',

TYPE *,

$\mathrm{C}$

TYPE *,'

C.

$\mathrm{C}$

C

STARTING COLD GAS STORAGE VESSEL INTERNAL PRESSURE

C

802 CONTINUE

TYPE *, ,

TYPE *,'ENTER INTERNAL PRESSURE OF STORAGE SPHERE (PSI)' 
TYPE *,'

READ *,TOTP

IF(NFLAG.EQ.2) GOTO 8021

C

C.

$\mathrm{C}$

C

$\mathrm{C}$

803 CONTINUE

TYPE *,

TYPE *,'

TYPE *,'ENTER DIAMETER OF SPHERICAL PRESSURE VESSEL (INCHES)'

TYPE *,'

READ *,SPHDIA

$\mathrm{R}=\mathrm{SPHDIA} / 2$.

VOL $=\left(\left(4 * 3.14159 * R^{* * 3}\right) / 3\right) /(1728$.$) \quad !VOLUME IN CUBIC FEET$

IF(NFLAG.EQ.3) GOTO 8022

C

$\mathrm{C}$

C

$\mathrm{C}$

804 CONTINUE

TYPE *,'

TYPE *,'

TYPE *,'ENTER AMBIENT TEMPERATURE OF GAS (DEGREES F)'

TYPE *,'

READ *,TEMP

$\mathrm{C}$

C CONVERT TEMPERATURE TO DEGREES RANKIN

$\mathrm{C}$

$\mathrm{TEMP}=\mathrm{TEMP}+459.67$

$\mathrm{C}$

C

C

CALCULATE THE WEIGHT OF GAS (LBS) INITIALLY INSIDE PRESSURE VESSEL:

NOTE THAT DRY NITROGEN, MOLECULAR WEIGHT 14 LB/MOLE

C IS ASSUMED. IDEAL GAS THEORY IS USED TO CONVERT INTERNAL PRESSURE,

C VOLUME, AND TEMPERATURE, AND MOLECULAR WEIGHT TO WEIGHT OF GAS

C IN POUNDS. FORMULA IS FROM CHEMISTRY TEXT; WT $=\left(\mathrm{P}^{*} \mathrm{~V}\right) * \mathrm{MOL}$. WT. $/ \mathrm{RT}$

C OUTPUT IS POUNDS WEIGHT (NOT MASS).

C

C A NOTE ON UNITS:

C

C TOTP = TANK STARTING PRESSURE [POUNDS(FORCE)/SQUARE FOOT]

$\mathrm{C}$ VOL $=$ TANK INTERNAL VOLUME [CUBIC FEET]

C TEMP $=$ TEMPERATURE [DEG. R = DEG. F + 459.67]

C $\mathrm{RCON}=$ UNIVERSAL GAS CONSTANT [FT-LBF/LB-MOLES DEG.RANKIN]

C [NOTE THAT POUND-MOLES ARE USED]

$\mathrm{C}$ MOLWT $=$ MOLECULAR WEIGHT OF GAS [LB/MOLE]

C [FOR NITROGEN, $M=28$ LB/MOLE]

C [FOR OXYGEN, $M=32 \mathrm{LB} / \mathrm{MOLE}]$

C WTOT $=$ WEIGHT OF GAS STORED IN THE TANK [LBF]

$\mathrm{C}$

8021 CONTINUE

8022 CONTINUE 
C

C USE MOLECULAR NITROGEN FOR PRESENT DESIGN

C
MOLWT $=28$.
!POUNDS/MOLE
$\mathrm{RCON}=1545$.
!UNIV. GAS CONSTANT

801 WTOT $=($ TOTP*VOL $*$ MOLWT $) /($ RCON $*$ TEMP $) \quad !$ UNITS $=$ POUNDS FORCE

C

C

CONVERT WEIGHT OF GAS TO MASS (SLUGS)

C

TMASSO $=$ WTOT

!USE WEIGHT HERE SINCE WE WILL

C

C

C

IF(NFL.AG.EQ.3) GOTO 601

IF(NFLAG.EQ.4) GOTO 601 !USE POUND/SEC FLOW RATES IN !SUBSEQUENT CALCULATIONS, !FOLLOWING FAGET, 1962,P266. !JUMP TO VERIFICATION MENU !JUMP TO VERIFICATION MENU

C

C CONVERT INITIAL INTERNAL PRESSURE TO PSF FROM PSI

C

P0 $=$ TOTP*144. !PRESSURE NOW IN PSF

IF(NFLAG.EQ.2) GOTO $601 \quad$ !JUMP TO VERIFICATION MENU

C

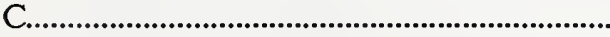

C

C GET NOZZLE THROAT DIAMETER (INCHES)

C

805 CONTINUE

TYPE *,

TYPE *,'

TYPE *',ENTER FIXED NOZZLE THROAT DIAMETER (INCHES)'

TYPE *,'

$\mathrm{READ} *, \mathrm{D}$

C

C CALCULATE THROAT AREA (SQ.FT.)

C

$\mathrm{A}=\left((\mathrm{D} / 12 .)^{* *} 2\right)^{*} 3.14159 / 4 . \quad$ !NOTE, DIAMETER CONVERTED TO FEET

$\mathrm{C}$ !FROM INCHES

C

IF(NFLAG.EQ.5) GOTO 601 !JUMP TO VERIFICATION MENU

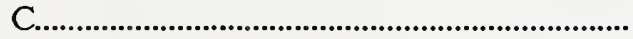

C

C GET INTEGRATION TIME STEP (SECONDS)

C

806 CONTINUE

TYPE *,

TYPE *,

TYPE *',ENTER INTEGRATION TIME STEP, DECIMAL SECONDS'

TYPE *,',

READ *,DT

C

IF(NFLAG.EQ.6) GOTO 601 !JUMP TO VERIFICATION MENU

C....................................................................

C

C SET UP THE INVERSE GAUSSIAN PULSE EQUATION

C 
CONTINUE

TYPE *,

TYPE *,'

TYPE *',ENTER THE MAXIMUM IMPULSE FORCE (POUNDS) DESIRED'

TYPE *,'

READ *,FIMP

IF(NFLAG.EQ.7) GOTO 8071 !ADJUST FIMP, K BUT NOT SIGMA

TYPE *,

TYPE *,'

808 CONTINUE

TYPE *,'ENTER SHAPE CONSTANT SIGMA (TYPICAL VALUE IS 0.15)'

TYPE *,'

READ *,SG

8071 CONTINUE

C

C CALCULATE CONSTANT "K" (SEE INVENTION NOTEBOOK \#2, PP 66-67)

C

REALK $=($ FIMP*SQRT $(4 * 3.14159 *((\mathrm{SG} * * 2) / 6) * 3)) /.(0.033469524)$

TYPE *, ,

TYPE *,

TYPE *,',

TYPE *, REALK [IN USER-INPUT] = ',REALK

TYPE *,'

IF(NFLAG.EQ.7) GOTO 601 !JUMP TO VERIFICATION MENU

IF(NFLAG.EQ.8) GOTO 601 !JUMP TO VERIFICATION MENU

C

C.

C

C GET DESIRED PULSE WIDTH IN SECONDS

C

809 CONTINUE

TYPE *,

TYPE *,'

TYPE *',ENTER DESIRED PULSE WIDTH IN SECONDS'

TYPE *,'

READ *,TMAX

C

IF(NFLAG.EQ.9) GOTO 601

C.........................................................'

C GET THE FIXED DISPLACEMENT MAGNIFICATION FACTOR FOR

C THE PIEZOELECTRIC STACK [THIS AFFECTS HARDWARE DESIGN]

C

810 CONTINUE

TYPE *,

TYPE *,',

TYPE *',ENTER FIXED DISPLACEMENT AMPLIFICATION FACTOR'

TYPE *,'

C

READ *,RA

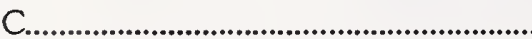

C REVIEW THE INPUT, PERMIT EDITING

$\mathrm{C}$ 
601 TYPE *,

TYPE *,'

TYPE *,'

TYPE *,' ECHO OF DATA INPUT'

TYPE *,'

TYPE *', $1:$ OK'

TYPE *',2:INITIAL PRESSURE (PSI) = ',P0/144.

TYPE *,'3:TANK DIAMETER (INCH) = ',SPHDIA

TYPE *,'4:TEMPERATURE (DEG. F) = ',TEMP-459.67

TYPE *',5:NOZZLE DIAMETER (INCH) = ', D

TYPE *,'6:TIME STEP (SECONDS) = ',DT

TYPE *,'7:MAX GAUSS FORCE (POUNDS) = ',FIMP

TYPE *',8:SHAPE CONSTANT SIGMA = ',SG

TYPE *,'9:PULSE DURATION (SECONDS) = ',TMAX

TYPE *', 10:DISPLACEMEMT MAG FACTOR = ',RA

TYPE *,'

TYPE *,'ENTER A NUMBER [2-10] IF CHANGES ARE TO BE MADE,'

TYPE *,'OTHERWISE, TYPE 1 TO CONTINUE'

TYPE *,'

TYPE *,

TYPE *,'

READ *,NFLAG

IF(NFLAG.EQ.1) GOTO 604 !EVERYTHING OK, PROCEED WITH CALCS

GOTO 603

!CHANGES TO BE MADE, LOOP BACK

604 CONTINUE

C

C

SEND INPUT TO MAIN CALCULATION MODULES

C

CALL PRESSURE_CALCS(TMASSO,P0,DT,D,VOL,FAMP,TMAX,REALK,TOTP,

1 WTOT,NPTS,SG,DELTAMAX,RA)

C

CALL PIEZO_CALCS(TMASSO,P0,DT,D,VOL,FAMP,TMAX,REALK,TOTP,

1 WTOT,NPTS,DELTAMAX,RA)

C

C EXIT TO MAIN PROGRAM

C

NFLAG $=1$

RETURN

END

!INSURE FLAG IS SET TO NORMAL

!FOR COMPLETE DATA ENTRY UNLESS

!OVERRIDDEN BY USER 


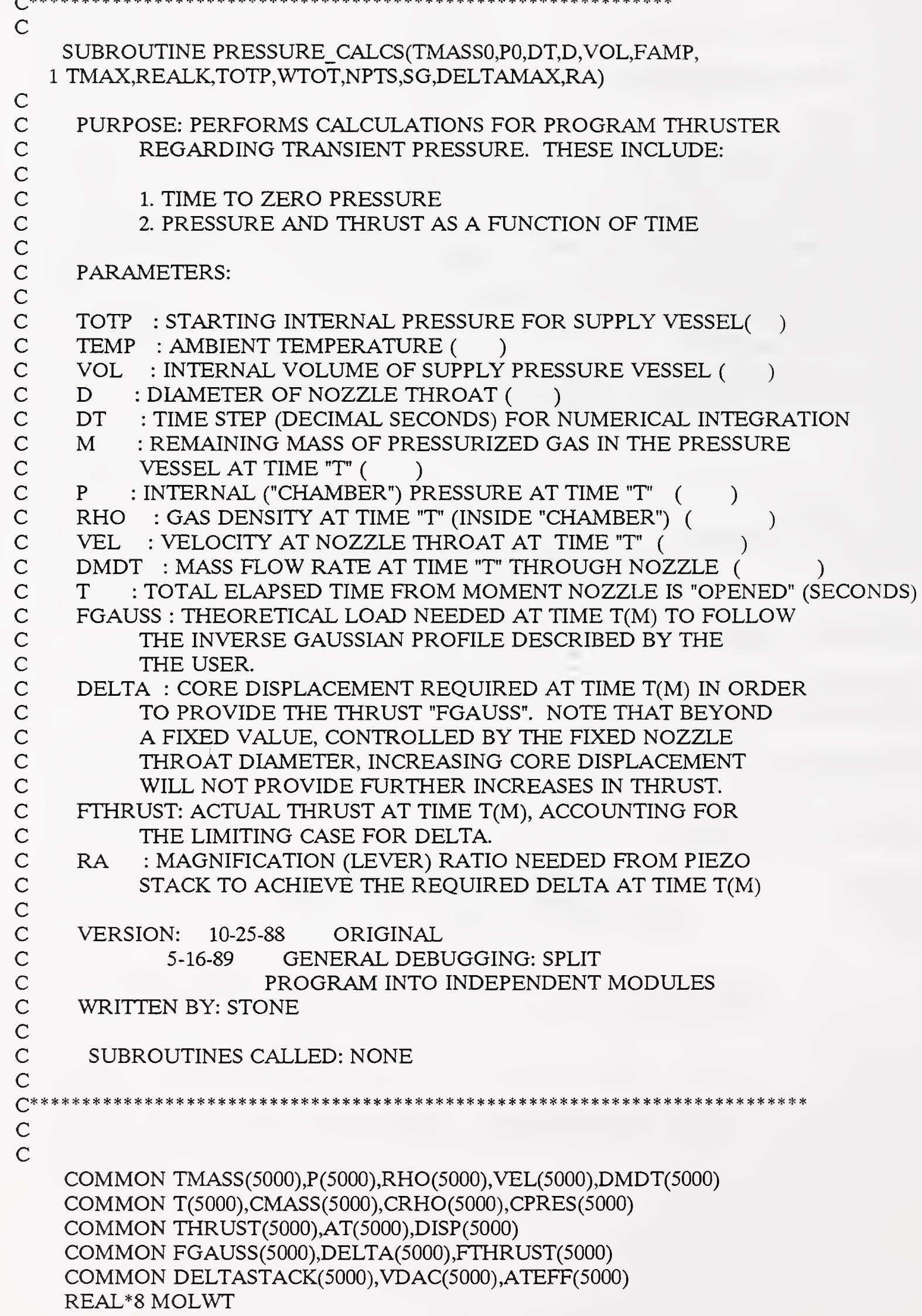

C

PURPOSE: PERFORMS CALCULATIONS FOR PROGRAM THRUSTER REGARDING TRANSIENT PRESSURE. THESE INCLUDE:

1. TIME TO ZERO PRESSURE

2. PRESSURE AND THRUST AS A FUNCTION OF TIME

\section{PARAMETERS:}

TOTP : STARTING INTERNAL PRESSURE FOR SUPPLY VESSEL( ）

TEMP : AMBIENT TEMPERATURE ( )

VOL : INTERNAL VOLUME OF SUPPLY PRESSURE VESSEL ( ）

D : DIAMETER OF NOZZLE THROAT ( )

DT : TIME STEP (DECIMAL SECONDS) FOR NUMERICAL INTEGRATION

M : REMAINING MASS OF PRESSURIZED GAS IN THE PRESSURE VESSEL AT TIME "T" $(\quad)$

$\mathrm{P} \quad$ : INTERNAL ("CHAMBER") PRESSURE AT TIME "T" （）

RHO : GAS DENSITY AT TIME "T" (INSIDE "CHAMBER") ( )

VEL : VELOCITY AT NOZZLE THROAT AT TIME "T" ( )

DMDT : MASS FLOW RATE AT TIME "T" THROUGH NOZZLE ( )

$\mathrm{T}$ : TOTAL ELAPSED TIME FROM MOMENT NOZZLE IS "OPENED" (SECONDS)

FGAUSS : THEORETICAL LOAD NEEDED AT TIME T(M) TO FOLLOW

THE INVERSE GAUSSIAN PROFILE DESCRIBED BY THE THE USER.

DELTA : CORE DISPLACEMENT REQUIRED AT TIME T(M) IN ORDER TO PROVIDE THE THRUST "FGAUSS". NOTE THAT BEYOND A FIXED VALUE, CONTROLLED BY THE FIXED NOZZLE THROAT DIAMETER, INCREASING CORE DISPLACEMENT WILL NOT PROVIDE FURTHER INCREASES IN THRUST.

FTHRUST: ACTUAL THRUST AT TIME T(M), ACCOUNTING FOR THE LIMITING CASE FOR DELTA.

RA : MAGNIFICATION (LEVER) RATIO NEEDED FROM PIEZO STACK TO ACHIEVE THE REQUIRED DELTA AT TIME T(M)

VERSION: $\quad 10-25-88$ ORIGINAL 5-16-89 GENERAL DEBUGGING: SPLIT PROGRAM INTO INDEPENDENT MODULES

WRITTEN BY: STONE

SUBROUTINES CALLED: NONE

COMMON TMASS(5000),P(5000),RHO(5000),VEL(5000),DMDT(5000)

COMMON T(5000), CMASS(5000), CRHO(5000), CPRES(5000)

COMMON THRUST(5000),AT(5000),DISP(5000)

COMMON FGAUSS(5000),DELTA(5000),FTHRUST(5000)

COMMON DELTASTACK(5000),VDAC(5000),ATEFF(5000)

REAL*8 MOLWT 
C

C

C

C

$12 \quad \begin{aligned} & \mathrm{M}=\mathrm{M}+1 \\ & \mathrm{~L}=\mathrm{M}-1\end{aligned}$

C

C.

C

C

C

C

C

C

C

C

C

C

C

C

C

C

C

$\mathrm{T}(1)=\mathrm{DT}$

$\operatorname{CPRES}(1)=\mathrm{P}(1) / 144$.

DELTAMAX $=0.0$

$\mathrm{M}=0$

IF(M.GT.1) GOTO 13

$\mathrm{P}(1)=\mathrm{PO}$

DIMENSION VL(5000),ACC(5000)

INITIALIZE INTEGRATION

FIRST STEP INITIALIZES ALL VARIABLES

TMASS $(1)=$ TMASSO !STARTING MASS OF GAS IN PRESSURE VESSEL

!INITIAL PRESSURE. NOTE: UNITS FOR PRESSURE

!ARE (PSF); MASS IS (LB-SEC**2/FT)

RHO(1) $=$ TMASS $(1) /$ VOL !DENSITY $\left(\right.$ LB-SEC $\left.* * 2 / F^{* *} 4\right)$

VEL $(1)=$ SQRT $\left(1.405^{*} \mathrm{P}(1) / \mathrm{RHO}(1)\right) \quad$ !THROAT VELOCITY $=$ SPEED OF SOUND

!IN FEET/SECOND

!(SEE PRANDTL, P261, EQ.4)

!"ESSENTIALS OF FLUID DYNAMICS"

!BLACKIE \& SON, 1952 (NIST LIBRARY)

!UNITS ARE (FT/SEC)

!NOTE THAT DUE TO CHANGES IN DENSITY

!WITH TIME, SPEED OF SOUND ALSO

!CHANGES

!SEE PRANDTL, P267, EQ.11)

!INCREMENT TIME STEP

!CONVERT PRESSURE BACK TO PSI

C.

C

C CALCULATE THEORETICAL INVERSE GAUSSIAN IMPULSE FUNCTION FORCE

$\mathrm{C}$

ACONST $=\operatorname{EXP}\left(\left(-1 .{ }^{*} S G^{* *} 2\right) /(4 . * T(1))\right)$

FGAUSS $(1)=($ REALK $*$ SG $/(\operatorname{SQRT}(4 * 3.14159 * \mathrm{~T}(1) * * 3))) * \mathrm{ACONST}$

C TYPE *,'ACONST $=$ ',ACONST

C TYPE *,'FGAUSS(1) = ',FGAUSS(1)

C

C.

C

C CORE DISPLACEMENT (LIMIT SET SUCH THAT EFFECTIVE THROAT AREA

C DOES NOT EXCEED THAT OF THE FIXED NOZZLE)

C

C

$\operatorname{DELTA}(1)=$ FGAUSS $(1) /(\operatorname{CPRES}(1) * 3.14159 * \mathrm{D} * 1.8) \quad$ !INCHES

$\mathrm{DLIM}=\mathrm{D} / 4.0 \quad ! 1 / 4$ NOZZLE THROAT DIAMETER (INCHES)

C

IF (DELTA(1).GT.DLIM) DELTA(1) = DLIM 


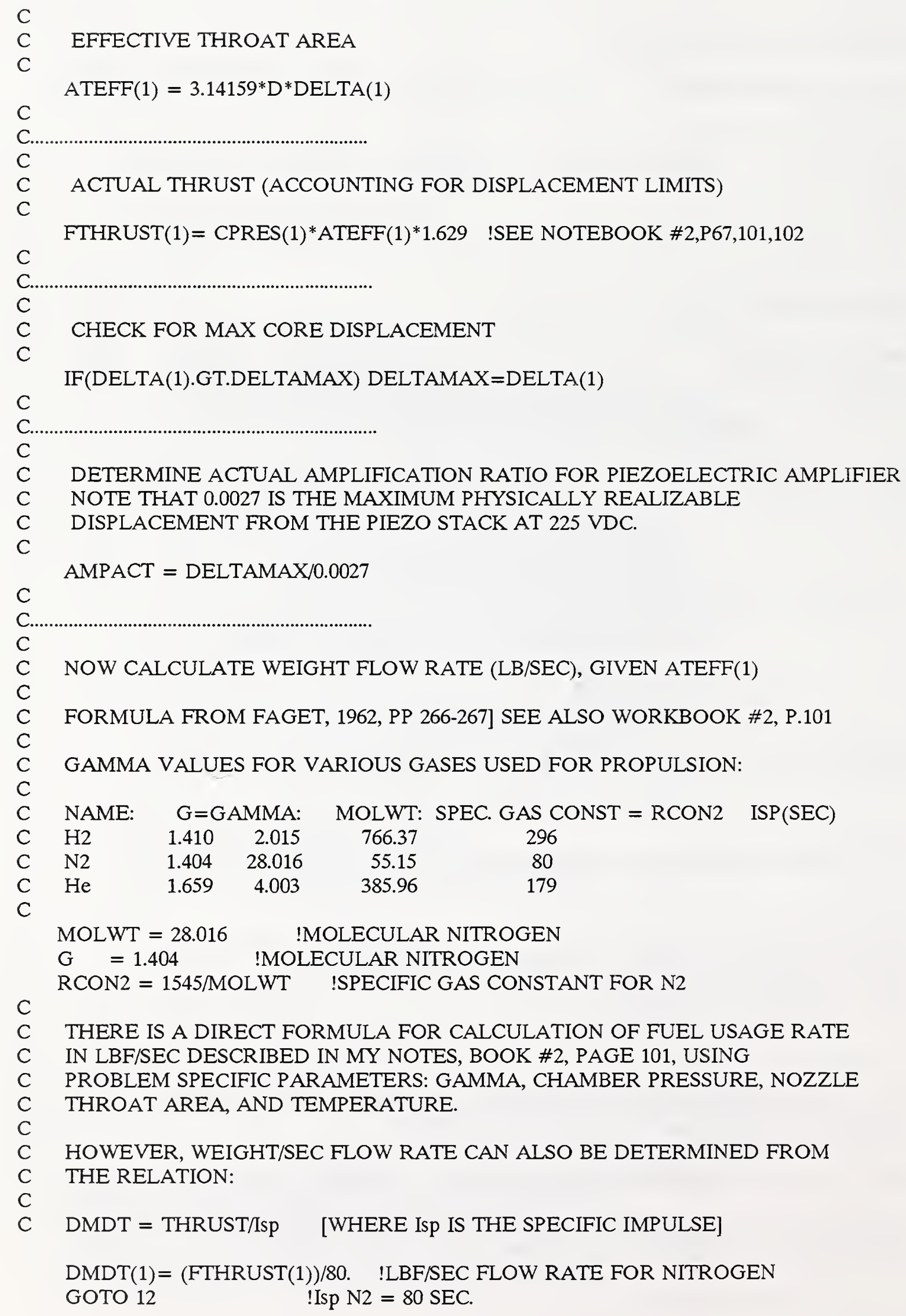

C.

C

C..

C

C CHECK FOR MAX CORE DISPLACEMENT

C

C

IF(DELTA(1).GT.DELTAMAX) DELTAMAX=DELTA(1)

C.

C

DETERMINE ACTUAL AMPLIFICATION RATIO FOR PIEZOELECTRIC AMPLIFIER NOTE THAT 0.0027 IS THE MAXIMUM PHYSICALLY REALIZABLE DISPLACEMENT FROM THE PIEZO STACK AT 225 VDC.

AMPACT $=$ DELTAMAX/0.0027

C

C

C

MOLWT $=28.016 \quad$ !MOLECULAR NITROGEN

$\mathrm{G}=1.404 \quad$ !MOLECULAR NITROGEN

C

RCON2 $=1545 / \mathrm{MOLWT} \quad$ !SPECIFIC GAS CONSTANT FOR N2

C THERE IS A DIRECT FORMULA FOR CALCULATION OF FUEL USAGE RATE

C IN LBF/SEC DESCRIBED IN MY NOTES, BOOK \#2, PAGE 101, USING

C PROBLEM SPECIFIC PARAMETERS: GAMMA, CHAMBER PRESSURE, NOZZLE

C THROAT AREA, AND TEMPERATURE.

C

C HOWEVER, WEIGHT/SEC FLOW RATE CAN ALSO BE DETERMINED FROM

C THE RELATION:

C

C $\quad$ DMDT $=$ THRUST/Isp $\quad$ [WHERE Isp IS THE SPECIFIC IMPULSE]

$\operatorname{DMDT}(1)=($ FTHRUST $(1)) / 80 . \quad$ !LBF/SEC FLOW RATE FOR NITROGEN GOTO 12 !Isp N2 $=80$ SEC. 
C

C.

C.

$\mathrm{C}$

C UPDATE NEW MASS, PRESSURE, DENSITY, VELOCITY, AND MASS FLOW RATE

C FOR NEXT TIME STEP (SEE DETAILED COMMENTS ABOVE FOR DEFINITION

C OF VARIABLES.

C

CONTINUE !DECREMENT THE MASS USING PRESENT FLOW

TMASS $(M)=$ TMASS $($ L) - DMDT $(L) * D T$ !NOTE UNITS $=($ LB-SEC $* 2 / F T) ;$ SLUGS

$\mathrm{P}(\mathrm{M})=\mathrm{P} 0^{*}$ TMASS $(\mathrm{M}) / \mathrm{TMASSO}$ !SCALE PRESSURE LINEARLY WITH MASS

RHO $(M)=\operatorname{TMASS}(\mathrm{M}) / \mathrm{VOL} \quad$ !DENSITY

$\operatorname{VEL}(\mathrm{M})=\mathrm{SQRT}\left(1.4^{*} \mathrm{P}(\mathrm{M}) / \mathrm{RHO}(\mathrm{M})\right)$ !VELOCITY

$\mathrm{T}(\mathrm{M})=\mathrm{T}(\mathrm{L})+\mathrm{DT} \quad$ !ELAPSED TIME

CPRES $(M)=P(M) / 144 . \quad$ !CONVERT PRESSURE BACK TO PSI

ACONST $=\operatorname{EXP}\left(\left(-1 .{ }^{*} S G^{* *} 2\right) /\left(4 .{ }^{*} \mathrm{~T}(\mathrm{M})\right)\right) \quad$ !CALCULATE IDEAL THRUST

FGAUSS(M) $=($ REALK $*$ SG/(SQRT $(4 * 3.14159 * T(M) * * 3))) *$ ACONST

$\operatorname{DELTA}(\mathrm{M})=$ FGAUSS $(\mathrm{M}) /(\mathrm{CPRES}(\mathrm{M}) * 3.14159 * \mathrm{D} * 1.8)$ !CORE DISPLACEMENT

DLIM $=\mathrm{D} / 4.0 \quad ! 1 / 4$ NOZZLE THROAT DIAMETER (INCHES)

IF (DELTA(M).GT.DLIM) DELTA(M) = DLIM !LIMITING CORE DISPL.

$\operatorname{ATEFF}(\mathrm{M})=3.14159 * \mathrm{D} * \mathrm{DELTA}(\mathrm{M}) \quad$ !EFFECTIVE NOZZLE AREA

FTHRUST $(M)=$ CPRES $(M) * A T E F F(M) * 1.629 \quad$ !ATTAINABLE THRUST

IF(DELTA(M).GT.DELTAMAX) DELTAMAX=DELTA(M) !CHECK MAX DISPL.

AMPACT $=$ DELTAMAX/0.0027 !ACTUAL PIEZO MAG FACTOR

$\operatorname{DMDT}(\mathrm{M})=($ FTHRUST $(\mathrm{M})) / 80 . \quad$ !WEIGHT FLOW RATE $($ LBF/SEC $)$

$\mathrm{C}$

C

C

C CHECK TO SEE IF ELAPSED TIME IS GREATER THAN THE REQUESTED

C PULSE WIDTH

$\mathrm{C}$

IF(T(M).GE.TMAX) THEN

TYPE *,'TIME = REQUESTED PULSE WIDTH'

TYPE *,'NORMAL TERMINATION'

ENDIF

IF(T(M).GE.TMAX) GOTO 103

C

C

C

C CHECK IF LIMITING PRESSURE CUT OFF HAS BEEN REACHED

C

IF(CPRES(M).LE.30)THEN !30 PSI IS ARBITRARY SHUTDOWN

TYPE *,'PRESSURE BELOW 30 PSI;ENDING CALCS'

TYPE *',LARGER GAS BOTTLE NEEDED, OR'

TYPE *,'INCREASE INITIAL CHARGING PRESSURE'

ENDIF

IF(CPRES(M).LE.30) GOTO 103 !KICK OUT OF LOOP WHEN PRESSSURE TOO LOW.

C

C.

$\mathrm{C}$

C PRINT OUT RESULTS (OPTIONAL)

C

C TYPE *',TMASS PRESS RHO VEL DMDT TIME' 


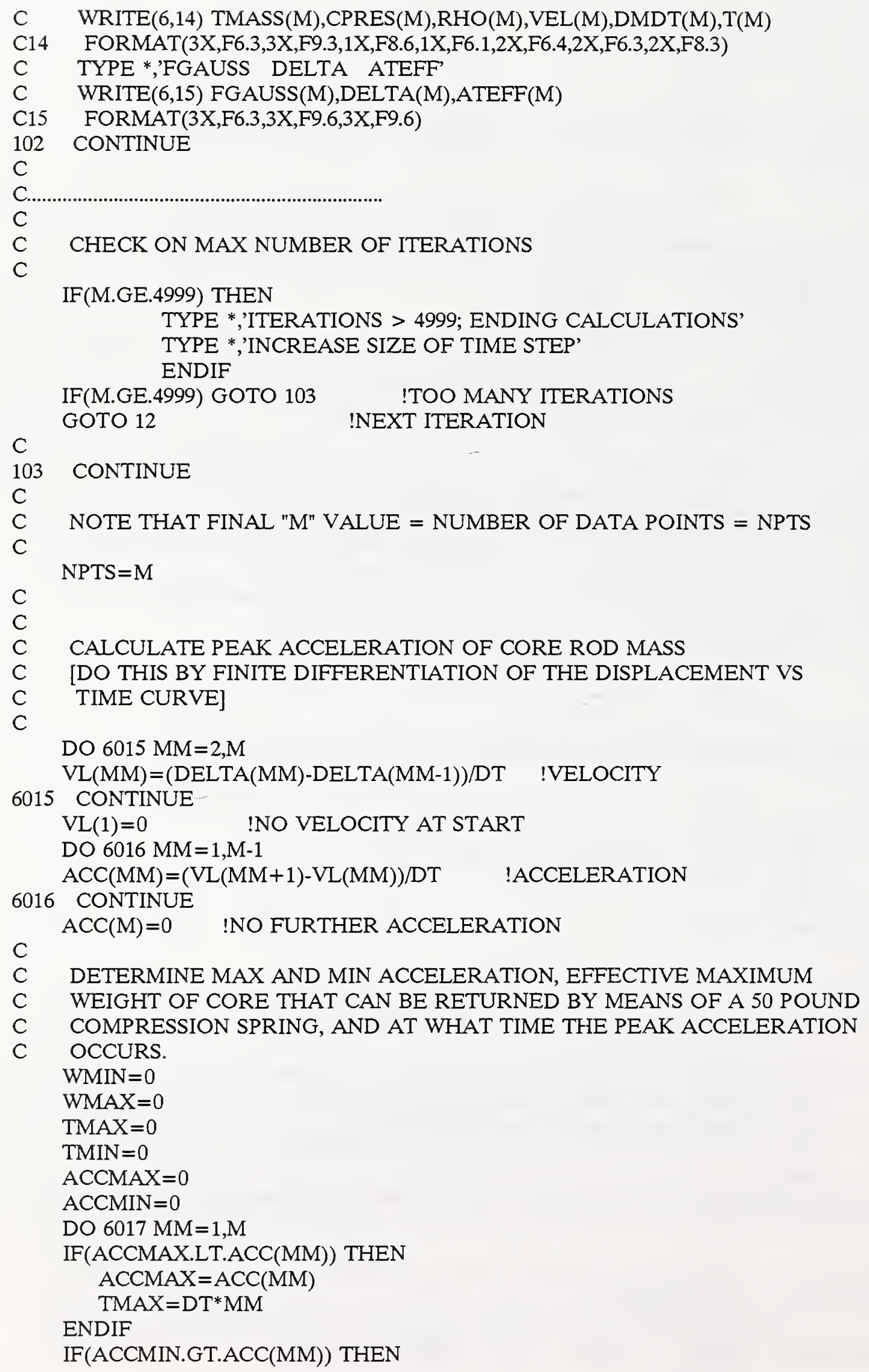




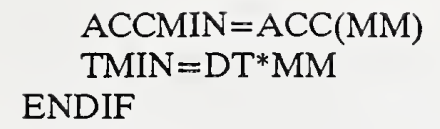

120 TYPE *,ITERATION LIMIT REACHED: RESET TIME STEP TO LARGER VALUE'

130 CONTINUE

RETURN

END 
SUBROUTINE PIEZO_CALCS(TMASS0,P0,DT,D,VOL,FAMP,

C

C

C

C

C

C

C

C

C

C

C

C

C

C

C

C

C

C

C

C

C

C

C

DO $1001 \mathrm{M}=1$,NPTS

PARAMETERS:

WRITTEN BY: STONE

PURPOSE: PERFORMS CALCULATIONS FOR PROGRAM THRUSTER REGARDING PIEZO CRYSTAL DRIVING CHARACTERISTICS AND THEORETICAL THRUST VALUES. THESE INCLUDE:

DELTASTACK: ACTUAL DISPLACEMENT REQUIRED FROM THE PIEZO STACK AT TIME T(M), ASSUMING A FIXED AMPLIFICATION (LEVER) AT TIME T(M).

VDAC : DRIVE VOLTAGE REQUIRED TO BE DELIVERED TO THE PIEZO STACK FROM THE DAC UNIT AT TIME T(M).

ATEFF : EFFECTIVE NOZZLE THROAT AREA AT TIME T(M). THIS IS $<=$ FIXED NOZZLE THROAT AREA AND IS DETERMINED BY VALVE CORE DISPLACEMENT, DELTA. FIXNOZAREA: AREA OF FIXED NOZZLE CROSS SECTION. VERSION: $\quad 10-25-88$ ORIGINAL 5-16-89 GENERAL DEBUGGING: SPLIT PROGRAM INTO INDEPENDENT MODULES

SUBROUTINES CALLED: NONE

COMMON TMASS(5000),P(5000),RHO(5000),VEL(5000),DMDT(5000)

COMMON T(5000),CMASS(5000),CRHO(5000),CPRES(5000)

COMMON THRUST(5000),AT(5000),DISP(5000)

COMMON FGAUSS(5000),DELTA(5000),FTHRUST(5000)

COMMON DELTASTACK(5000),VDAC(5000),ATEFF(5000)

C.

C

C

DETERMINE REQUIRED PIEZOELECTRIC STACK EXPANSION AT TIME T [NOTE THAT RA IS THE FIXED DISPL. AMPLIFICATION FACTOR DEFINED C IN USER_INPUT. AN ERROR FLAG WILL BE SENT TO THE TERMINAL

C IF THE ACTUAL REQUIRED AMPLIFICATION EXCEEDS THIS AMOUNT.

C THIS CHECK TAKES PLACE IN PRESSURE_CALCS.

$\mathrm{C}$

$\operatorname{DELTASTACK}(\mathrm{M})=\operatorname{DELTA}(\mathrm{M}) / \mathrm{RA}$

C

DETERMINE DAC OUTPUT VOLTAGE (TO PIEZO STACK) AT TIME T TO ACHIEVE DESIRED THRUST LEVEL. NOTE THAT 0.000012 INCH/VOLT IS THE CALIBRATED COMPLIANCE OF THE STACK; 50:1 IS THE AMPLIFICATION PROVIDED BY THE LINEAR AMPLIFIER IN THE PRESENT DESIGN TO BOOST THE DAC OUTPUT VOLTAGE TO THAT REQUIRED TO DRIVE THE STACK

$\operatorname{VDAC}(\mathrm{M})=\operatorname{DELTASTACK}(\mathrm{M}) /((.000012) * 50$.

1001 CONTINUE

RETURN

END 


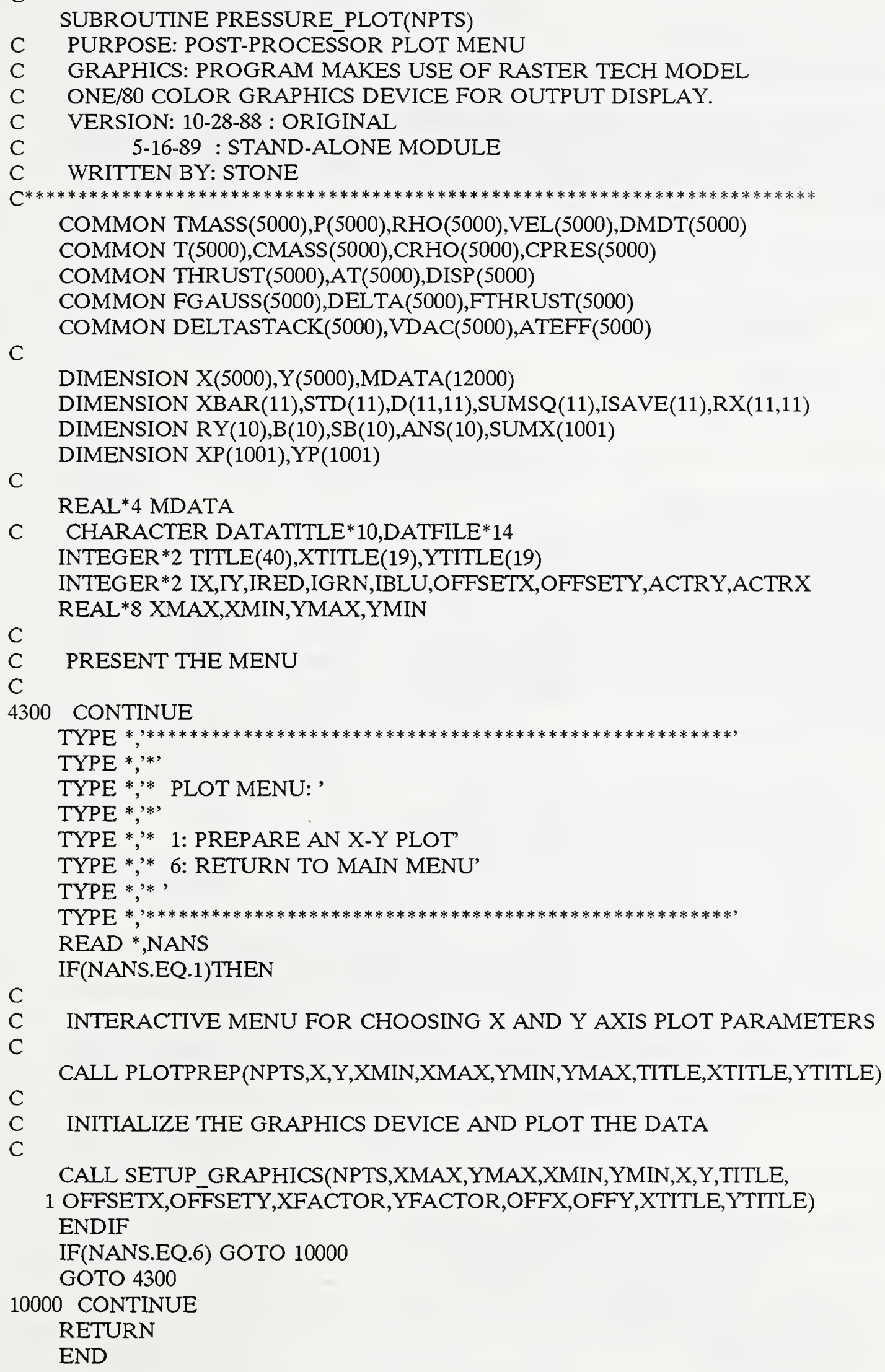




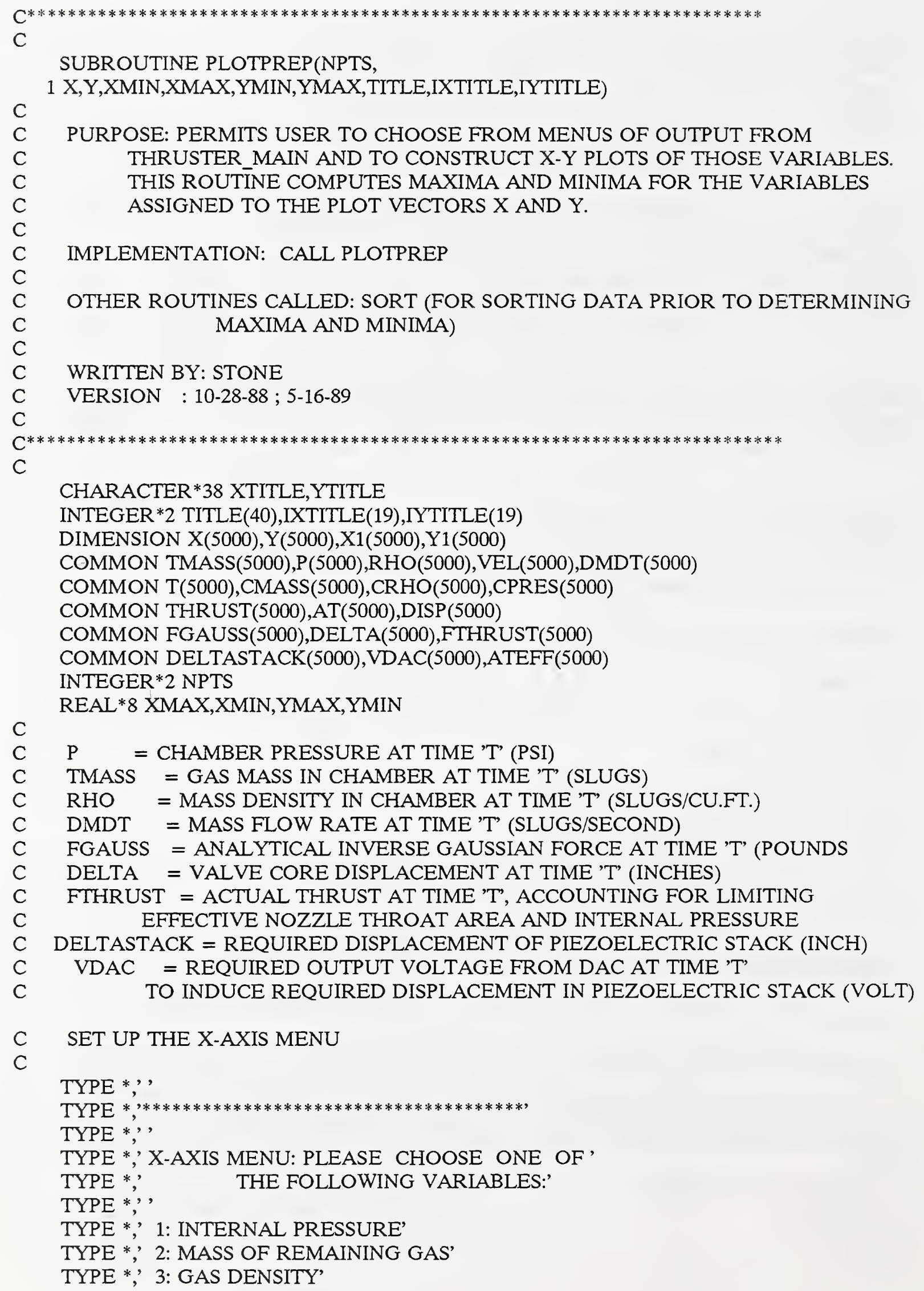


TYPE *, 4: MASS FLOW RATE'

TYPE *,' 5: IDEAL (GAUSSIAN) THRUST'

TYPE *, 6: ACTUAL THRUST,

TYPE *, 7: THRUST ERROR (IDEAL-ACTUAL)'

TYPE *, 8: VALVE CORE DISPLACEMENT'

TYPE *, 9: PIEZO STACK DISPLACEMENT'

TYPE *,' 10: DAC OUTPUT VOLTAGE TO STACK'

TYPE *' 11: ELAPSED TIME'

TYPE *,' 12: STOP'

TYPE *,'

TYPE *,

C

READ *,NANSX

C SET UP THE Y-AXIS MENU

C

TYPE *,

TYPE $*, * * * * * * * * * * * * * * * * * * * * * * * * * * * * * * * * * * * * * * *$,

TYPE *,',

TYPE *', Y-AXIS MENU: PLEASE CHOOSE ONE OF'

TYPE *,' THE FOLLOWING VARIABLES:'

TYPE *, ,

TYPE *' 1: INTERNAL PRESSURE'

TYPE *', 2: MASS OF REMAINING GAS'

TYPE *' 3: GAS DENSITY'

TYPE *, 4: MASS FLOW RATE'

TYPE *, 5: IDEAL (GAUSSIAN) THRUST'

TYPE *, 6: ACTUAL THRUST,

TYPE *, 7: THRUST ERROR (IDEAL-ACTUAL)'

TYPE *, 8: VALVE CORE DISPLACEMENT'

TYPE *, 9: PIEZO STACK DISPLACEMENT'

TYPE *, 10: DAC OUTPUT VOLTAGE TO STACK'

TYPE *', 11: ELAPSED TIME'

TYPE *, 12: STOP'

TYPE *,'

TYPE *,

READ *,NANSY

C

C LOAD THE AXIS TITLES

$\mathrm{C}$

C X-AXIS TITLE

C

IF(NANSX.EQ.1) XTITLE = 'INTERNAL CHAMBER PRESSURE (PSI)

IF(NANSX.EQ.2) XTITLE = 'MASS OF REMAINING GAS (SLUGS)

IF(NANSX.EQ.3) XTITLE = 'GAS DENSITY (SLUGS/CU.FT.)

IF(NANSX.EQ.4) XTITLE = 'MASS FLOW RATE (SLUGS/SEC)

IF(NANSX.EQ.5) XTITLE = 'IDEAL (GAUSSIAN) THRUST (LBS)

IF(NANSX.EQ.6) XTITLE = 'ACTUAL THRUST (LBS)

IF(NANSX.EQ.7) XTITLE = 'THRUST ERROR (IDEAL-ACTUAL)

IF(NANSX.EQ.8) XTITLE = 'VALVE CORE DISPLACEMENT (MILS)

IF(NANSX.EQ.9) XTITLE = 'PIEZO STACK DISPLACEMENT(MILS)

IF(NANSX.EQ.10) XTITLE = 'DAC OUTPUT VOLTAGE TO STACK

$\mathrm{C}$

IF(NANSX.EQ.11) XTITLE = 'ELAPSED TIME (SECONDS)

C Y-AXIS TITLE 
C

IF(NANSY.EQ.1) YTITLE = 'INTERNAL CHAMBER PRESSURE (PSI) ,

IF(NANSY.EQ.2) YTITLE = 'MASS OF REMAINING GAS (SLUGS)

IF(NANSY.EQ.3) YTITLE = 'GAS DENSITY (SLUGS/CU.FT.)

IF(NANSY.EQ.4) YTITLE = 'MASS FLOW RATE (SLUGS/SEC)

IF(NANSY.EQ.5) YTITLE = 'IDEAL (GAUSSIAN) THRUST (LBS)

IF(NANSY.EQ.6) YTITLE = 'ACTUAL THRUST (LBS)

IF(NANSY.EQ.7) YTITLE = 'THRUST ERROR (IDEAL-ACTUAL)

IF(NANSY.EQ.8) YTITLE = 'VALVE CORE DISPLACEMENT (MILS) ,

IF(NANSY.EQ.9) YTITLE = 'PIEZO STACK DISPLACEMENT (MILS)

IF(NANSY.EQ.10) YTITLE = 'DAC OUTPUT VOLTAGE TO STACK

C

IF(NANSY.EQ.11) YTITLE = 'ELAPSED TIME (SECONDS)

C CONVERT TITLES TO INTEGER FORMAT

C

DECODE $(38,1111$, XTITLE)IXTITLE

DECODE (38,1112,YTITLE)IYTITLE

1111 FORMAT(19A2)

1112 FORMAT(19A2)

C

C

LOAD THE VARIABLES CHOSEN INTO THE X AND Y VECTORS

C

C

C

ASSIGNING VALUES TO THE X ARRAY

DO $999 \mathrm{KKK}=1, \mathrm{NPTS}$

IF(NANSX.EQ.1) X $(\mathrm{KKK})=(\mathrm{P}(\mathrm{KKK})) / 144$.

IF(NANSX.EQ.2) X(KKK)=TMASS $(\mathrm{KKK})$

IF(NANSX.EQ.3) X(KKK) $=$ RHO $(\mathrm{KKK})$

IF(NANSX.EQ.4) X(KKK)=DMDT(KKK)

IF(NANSX.EQ.5) X(KKK)=FGAUSS $(\mathrm{KKK})$

IF(NANSX.EQ.6) $\quad X(\mathrm{KKK})=$ FTHRUST $(\mathrm{KKK})$

IF(NANSX.EQ.7) X(KKK)=FGAUSS(KKK)-FTHRUST(KKK)

IF(NANSX.EQ.8) $\quad X(K K K)=\operatorname{DELTA}(\mathrm{KKK}) * 1000$.

IF(NANSX.EQ.9) X(KKK)=DELTASTACK $(\mathrm{KKK}) * 1000$.

IF(NANSX.EQ.10) X(KKK) $=$ VDAC $(\mathrm{KKK})$

C

$\mathrm{IF}(\mathrm{NANSX.EQ.11)} \mathrm{X}(\mathrm{KKK})=\mathrm{T}(\mathrm{KKK})$

C ASSIGNING VALUES TO THE Y ARRAY

C

IF(NANSY.EQ.1) $\mathrm{Y}(\mathrm{KKK})=(\mathrm{P}(\mathrm{KKK})) / 144$.

IF(NANSY.EQ.2) $\mathrm{Y}(\mathrm{KKK})=\mathrm{TMASS}(\mathrm{KKK})$

IF(NANSY.EQ.3) $\mathrm{Y}(\mathrm{KKK})=\mathrm{RHO}(\mathrm{KKK})$

IF(NANSY.EQ.4) Y(KKK)=DMDT(KKK)

IF(NANSY.EQ.5) Y(KKK)=FGAUSS(KKK)

IF(NANSY.EQ.6) $Y(\mathrm{KKK})=$ FTHRUST $(\mathrm{KKK})$

IF(NANSY.EQ.7) Y(KKK)=FGAUSS(KKK)-FTHRUST(KKK)

IF(NANSY.EQ.8) Y(KKK)=DELTA(KKK)*1000.

IF(NANSY.EQ.9) Y(KKK)=DELTASTACK(KKK)*1000.

IF(NANSY.EQ.10) $Y(K K K)=V D A C(K K K)$

C

IF(NANSY.EQ.11) $\mathrm{Y}(\mathrm{KKK})=\mathrm{T}(\mathrm{KKK})$

999 CONTINUE

C

C GET THE TITLE FOR THE PLOT 
C

TYPE *,PLEASE ENTER A TITLE FOR THE PLOT'

READ $(5,1)$ TITLE

1 FORMAT(40A2)

C

C CONVERT TO INTEGER FORMAT

C

C SORT THE X,Y PAIRS AND DETERMINE MAXIMA AND MINIMA

C

DO $104 \mathrm{I}=1$, NPTS

$\mathrm{X} 1(\mathrm{I})=\mathrm{X}(\mathrm{I})$

$\mathrm{Y} 1(\mathrm{I})=\mathrm{Y}(\mathrm{I})$

104 CONTINUE

CALL SORT(X,Y,NPTS)

$\mathrm{XMAX}=\mathrm{X}(\mathrm{NPTS})$

$\mathrm{XMIN}=\mathrm{X}(1)$

CALL SORT(Y1,X1,NPTS)

$\mathrm{YMAX}=\mathrm{Y} 1$ (NPTS)

$\mathrm{YMIN}=\mathrm{Y} 1(1)$

RETURN

END 


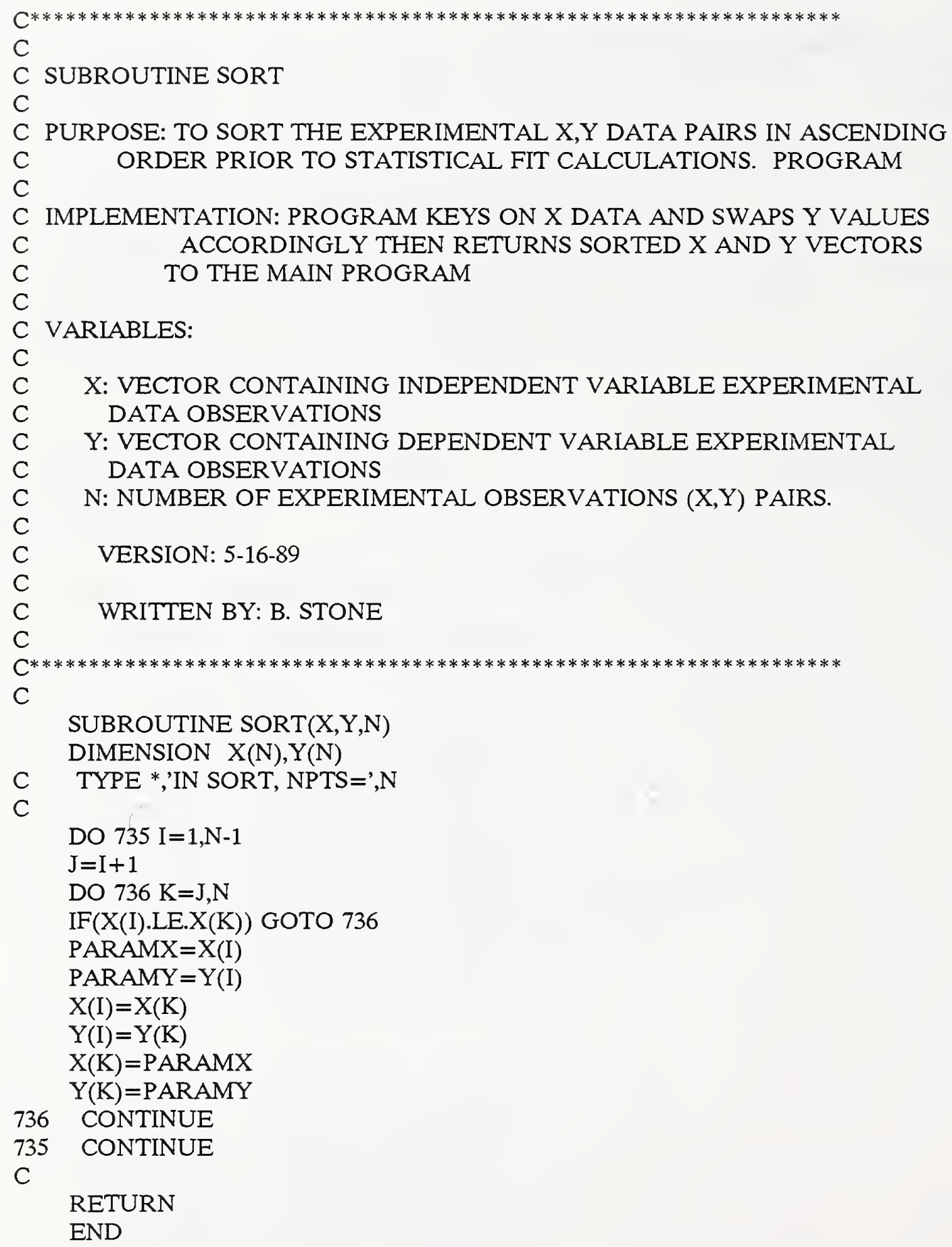




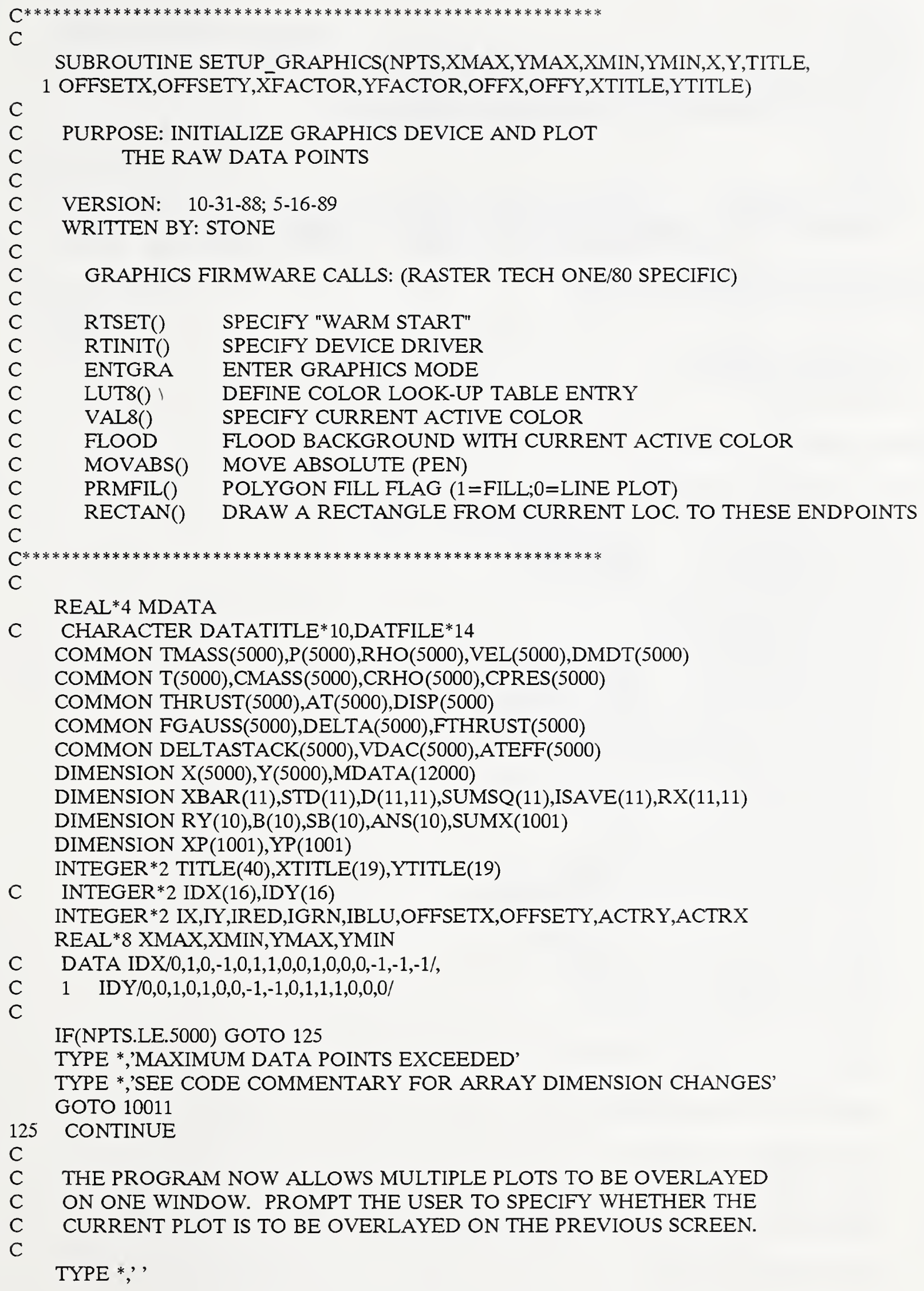




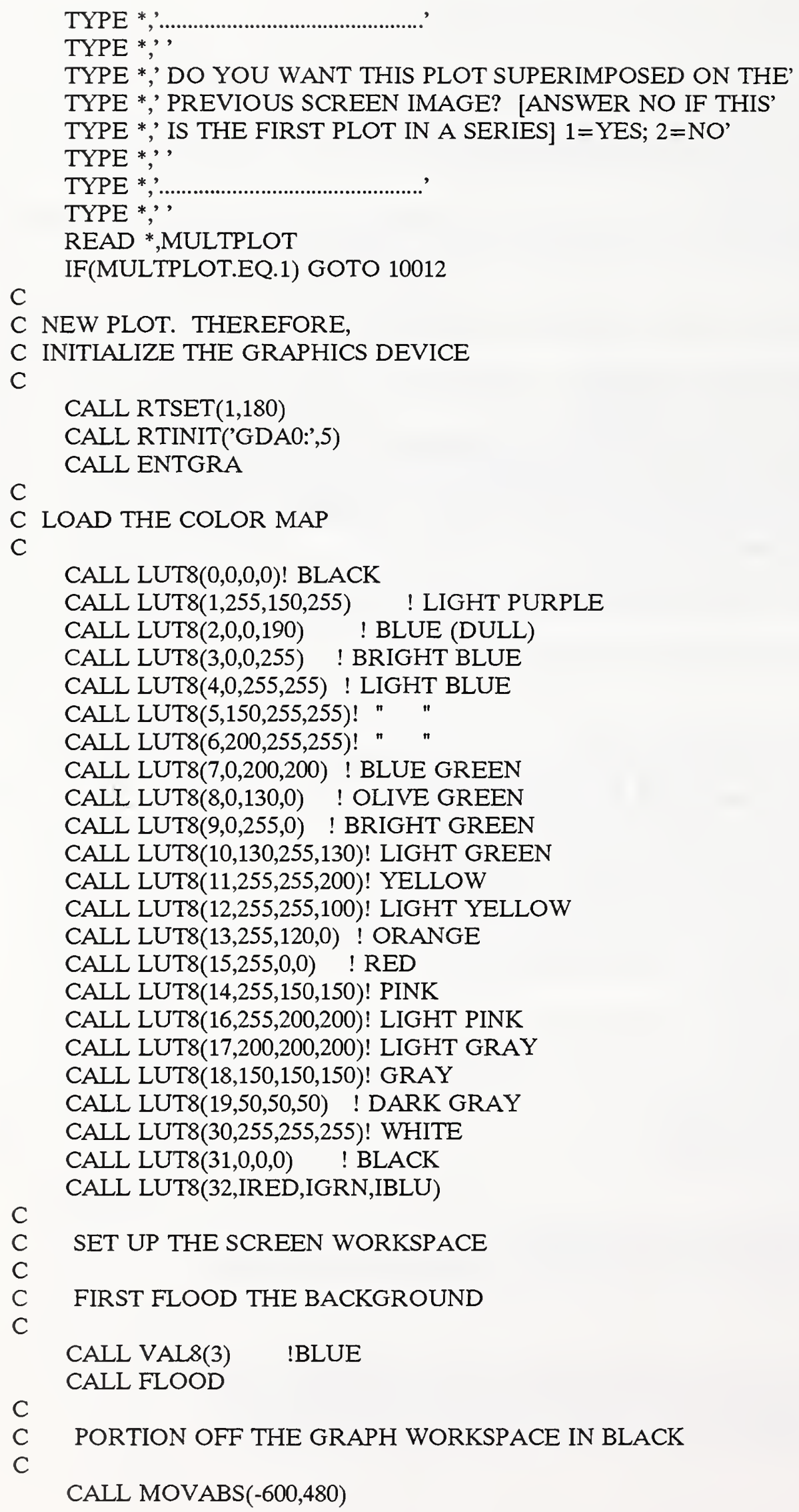


CALL PRMFIL(1)

CALL VAL8(0) !BLACK

CALL RECTAN $(600,-320)$

C

CALL PRMFIL(0)

C DRAW THE AXES AND PLOT THE DATA POINTS

C

10012 CONTINUE

CALL POINTPLOT(NPTS,XMAX,YMAX,XMIN,YMIN,X,Y,TITLE,

1 OFFSETX,OFFSETY,XFACTOR,YFACTOR,OFFX,OFFY,XTITLE,YTITLE,MULTPLOT)

C TYPE *,'XFACTOR=',XFACTOR,' YFACTOR=',YFACTOR,'IN MAIN'

C

10011 CONTINUE

RETURN

END 


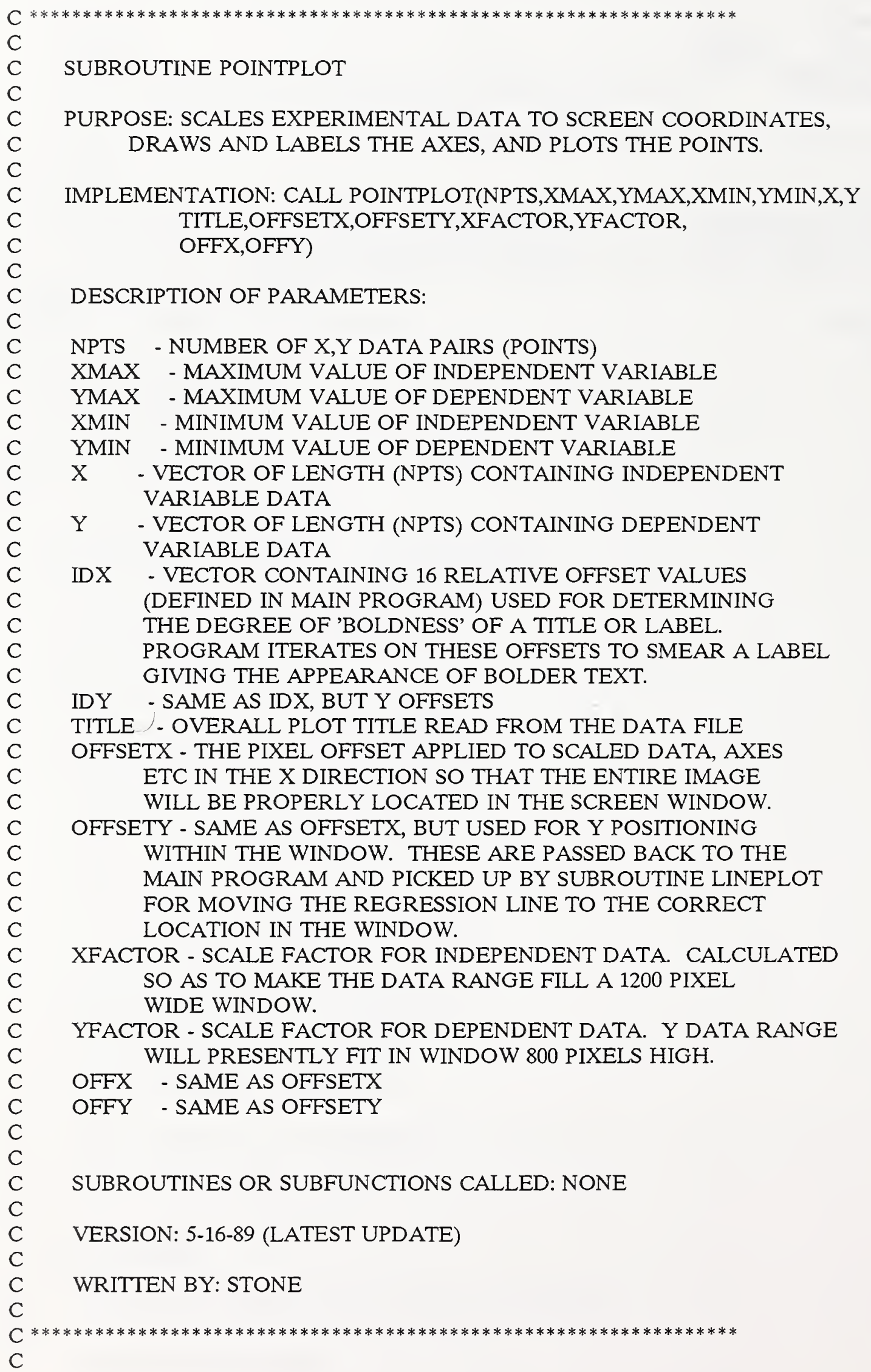


C

SUBROUTINE POINTPLOT(NPTS,XMAX,YMAX,XMIN,YMIN,X,Y,TITLE,

1 OFFSETX,OFFSETY,XFACTOR,YFACTOR,OFFX,OFFY,XTITLE,YTITLE,MULTPLOT) DIMENSION X(NPTS),Y(NPTS)

C

COMMON TMASS(5000),P(5000), RHO(5000),VEL(5000),DMDT(5000)

COMMON T(5000),CMASS(5000),CRHO(5000),CPRES(5000)

COMMON THRUST(5000),AT(5000),DISP(5000)

COMMON FGAUSS(5000),DELTA(5000),FTHRUST(5000)

COMMON DELTASTACK(5000),VDAC(5000),ATEFF(5000)

C

INTEGER *2 LEY,REY,OFFSETX,OFFSETY,OFFX1,OFFX2,SIGNX,SIGNY

INTEGER *2 OFFY1,OFFY2,XSIZE,YSIZE,OFFX,OFFY,XTLOC,YTLOC,YTLOCX

CHARACTER *2 XDIV(3),XDIVN(3),YDIV(3),YDIVN(3)

INTEGER *2 TITLE(40),XTITLE(19),YTITLE(19)

INTEGER*2 INTXDIV(3),INTXDIVN(3),INTYDIV(3),INTYDIVN(3)

INTEGER *2 SX(1001),SY(1001),JX,JL,JXN,JLN,JY,JYN

INTEGER $* 2$ SHORTX,SHORTY

INTEGER *2 IDX(16),IDY(16)

REAL*8 XMAX,XMIN,YMAX,YMIN,XRANGE, YRANGE,XFACTOR,YFACTOR

DATA IDX/0,1,0,-1,0,1,1,0,0,1,0,0,0,-1,-1,-1/,

1 IDY/0,0,1,0,1,0,0,-1,-1,0,1,1,1,0,0,0/

EQUIVALENCE (XDIV,INTXDIV)

EQUIVALENCE (XDIVN,INTXDIVN)

EQUIVALENCE (YDIV,INTYDIV)

EQUIVALENCE (YDIVN,INTYDIVN)

C

C JUMP OVER THIS INITIAL SCALING IF THE CURRENT PLOT IS TO BE

C OVERLAYED ON A PREVIOUSLY GENERATED SCREEN IMAGE

C

IF(MULTPLOT.EQ.1) GOTO 6742

C

C NEW PLOT, RE-INIIALIZE THE PLOT PARAMETERS

C

C SET PROGRAM VARIABLES

C

XSIZE $=1200 \quad !$ USEABLE PIXEL COLUMNS FOR PLOT WINDOW

YSIZE $=800 \quad$ ! USEABLE PIXEL ROWS FOR PLOT WINDOW

$\mathrm{C}$

RATIO $=1.0$

C SCALE THE DATA AND LOAD IT INTO INTEGER VECTORS

C

$\mathrm{Q}=0.0$

IF(YMIN.GT.Q.AND.YMAX.GT.Q) YMIN=0.0 !ENSURE THE ORIGIN IS INCLUDED

IF(XMIN.GT.Q.AND.XMAX.GT.Q) $X M I N=0.0$

IF(XMIN.LT.Q.AND.XMAX.LT.Q) XMAX $=0.0$

$\mathrm{C}$

IF(YMIN.LT.Q.AND.YMAX.LT.Q) YMAX $=0.0$

XRANGE $=(X M A X-X M I N) \quad$ ! RANGE OF EXPERIMENTAL DATA: REAL

TYPE *,'XMAX =',XMAX

TYPE *,'XMIN =',XMIN

TYPE *,'XRANGE=',XRANGE

YRANGE $=($ YMAX - YMIN $)$

TYPE *,'YMAX=',YMAX 


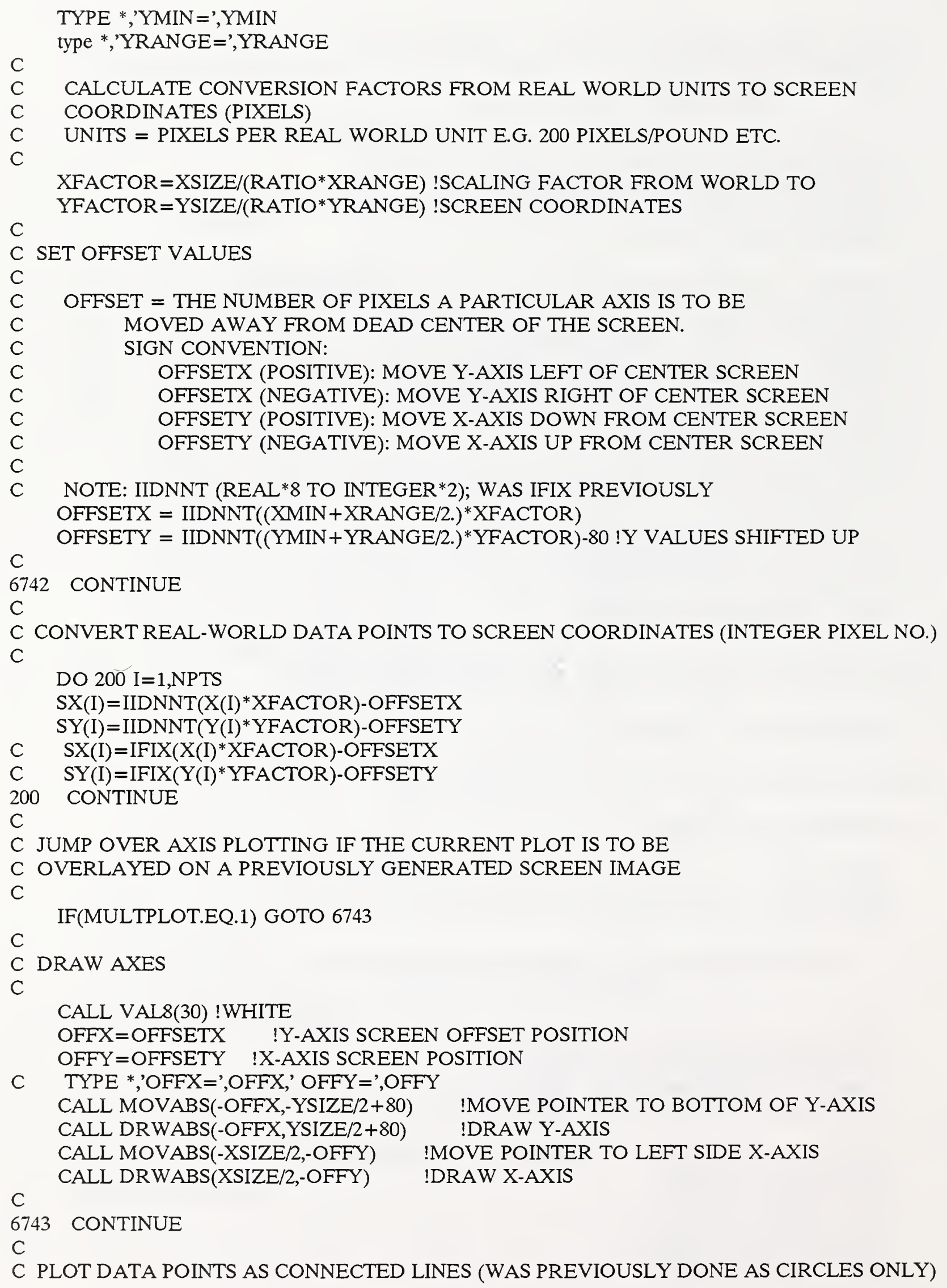


C

CALL VAL8(15) IRED LINES AND CIRCLES

CALL PRMFIL(1) !TURN THE PERIMETER FILL ROUTINE ON (RASTECH)

CALL MOVABS(SX(1),SY(1)) !JUMP TO FIRST DATA POINT

DO 127 I=1,NPTS-1

C CALL MOVABS(OFFSETX,OFFSETY) !MOVE TO ORIGIN [OBSOLETE]

CALL DRWABS(SX(I+1),SY(I+1)) !DRAW THE NEXT LINE SEGMENT

C CALL MOVABS(SX(I),SY(I)) !NOW MOVE TO LOCATION OF EACH DATA POINT

CALL CIRCLE(1) !DRAW A CIRCLE (RADIUS 1 PIXELS) AT THE DATA POINT

127 CONTINUE

C

C JUMP OVER LABELLING ROUTINES IF THE CURRENT PLOT IS TO BE

C OVERLAYED ON A PREVIOUSLY GENERATED SCREEN IMAGE

$\mathrm{C}$

IF(MULTPLOT.EQ.1) GOTO 851 !DUMP THE PLOT BUFFER AND RETURN

$\mathrm{C}$

C LABLE LEGEND (FROM EXPERIMENTAL DATA FILE MASTHEAD)

$\mathrm{C}$

CALL MOVABS(-350,488) !MOVE TO

CALL TEXTC $(40,0) \quad$ !SET THE LETTER SIZE (PIXELS)

C

CALL VAL8(11)

!SET THE COLOR

C BOLD TYPE

$\mathrm{C}$

DO $400 \mathrm{I}=1,9$

!BEGIN BOLD LOOP

CALL MOVREL(IDX(I),IDY(I)) !SHIFTS THE PIXELS TO BLUR THE LETTERS

CALL TEXT1(80,TITLE)

400 CONTINUE

IRASTECH 1/80 WRITES THE MESSAGE OUT

C

PLOT X-AXIS TITLE

TYPE *,'X-AXIS TITLE?'

READ $(5,220) X T I T L E$ !GET THE X-AXIS TITLE FROM THE USER

C220 FORMAT(19A2)

C

$\mathrm{C}$

ACCOUNT FOR NEGATIVE OFFSET IN X DIRECTION

$\mathrm{C}$

$\mathrm{XTLOC}=400-\mathrm{OFFX}$

!X LOCATION, IF OFFSET POS.

IF(OFFX.LT.0) XTLOC=-OFFX-600 !X LOCATION, IF OFFSET NEG.

CALL MOVABS(XTLOC,(-OFFY-50)) !MOVE THERE (50 PIXELS BELOW THE LINE)

CALL TEXTC $(30,0)$

CALL VAL8(11)

DO $401 \mathrm{I}=1,4$

!TEXT WILL BE 30 PIXELS HIGH

!SET THE COLOR

CALL MOVREL(IDX(I),IDY(I)) !BEGIN BOLD LOOP

CALL TEXT1(38,XTITLE)

401 CONTINUE

C

C

PLOT Y-AXIS TITLE

'TYPE *,'Y-AXIS TITLE?'

READ $(5,220)$ YTITLE $\quad$ !GET TITLE FROM USER

CALCULATE VERTICAL LOCATION OF Y-AXIS TITLE 
c
c
c
c

YTLOC $=300-\mathrm{OFFY}$ IF(OFFY.LT.0) YTLOC=-OFFY-600 !ACCOUNT FOR OFFY BEING NEGATIVE

C C C

YTLOCX $=-$ OFFX-26

!MOVE 26 PIXELS TO RIGHT OF AXIS

IF(OFFX.LT.0) YTLOCX=30-OFFX !IF NEGATIVE, MOVE 30 PIXELS LEFT

CALL MOVABS(YTLOCX,YTLOC) !MOVE THERE

CALL TEXTC $(30,90)$

CALL VAL8(11)

DO $6003 \mathrm{~N}=1,4$

!SET TEXT SIZE IN PIXELS

!SET THE COLOR

COLEGIN BOLD LOOP

CALL MOVREL(IDX(N),IDY(N)) !MOVE RELATIVE TO PRESENT LOCATION

CALL TEXT1(38,YTITLE)

6003 CONTINUE

C

C

C

C

C

SHIFT $=-80$

IF(OFFY.LT.0) SHIFT $=+80$

LONGX $=(\mathrm{XSIZE} / 2)+\mathrm{ABS}(\mathrm{OFFX}) \quad$ !NO. PIXELS ON LONG SIDE X-AXIS

SHORTX $=(X S I Z E / 2)-A B S(O F F X) \quad$ !NO. PIXELS ON SHORT SIDE X-AXIS

LONGY $=(Y S I Z E / 2)+A B S(O F F Y)$-SHIFT !NO. PIXEIS ON LONG SIDE Y-AXIS

$\mathrm{C}$

SHORTY $=$ YSIZE/2-ABS(OFFY)+SHIFT !NO. PIXELS ON SHORT SIDE Y-AXIS

C FIND THE NUMBER OF TICK MARKS TO BE INCLUDED

C

NLONGX $=($ LONGX/100 $) \quad$ !TICKS ARE SPACED AT 100 PIXELS

NSHORTX $=($ SHORTX/100)

NLONGY $=($ LONGY $/ 100)$

C

NSHORTY $=($ SHORTY $/ 100)$

C DRAW TICK MARKS FOR X-AXIS (LONG SIDE)

C

C

C

$\mathrm{C}$

C

C

C

C

C LABEL TICK VALUES FOR X-AXIS (LONG SIDE)

C

C

XSCALE $=$ XFACTOR !REDUNDANT LABEL: CONVERSION FACTOR FROM REAL WORLD TO SCREEN COORDINATES 
YSCALE $=$ YFACTOR !REDUNDANT LABEL:

$\mathrm{XL}=\mathrm{L} \quad$ !REM: L IS NUMBER OF TICK MARKS LONG SIDE

$X T I C=(100 . / X S C A L E) * X L *$ SIGNX !GET REAL VALUE AT NEXT TICK LOCATION

ENCODE(11,351,XDIV)XTIC !ENCODE IT FOR THE RASTERTECH

351 FORMAT(G11.4)

$\mathrm{JL}=-15 .+$ SIGNX $* L^{*} 100-$ OFFX $\quad$ !FIND LOCATION OF NEXT LABEL

CALL MOVABS(JL,-20-OFFY) !MOVE THERE

DO $353 \mathrm{~N}=1,4 \quad$ !BEGIN BOLD SMEARING LOOP

CALL MOVREL(IDX(N),IDY(N)) !MOVE RELATIVE TO PRESENT LOCATION

CALL TEXT1(11,INTXDIV) !PRINT THE TEXT ON THE SCREEN

353 CONTINUE

350 CONTINUE

C

C DRAW TICK MARKS FOR X-AXIS (SHORT SIDE)

C

DO $850 \mathrm{~L}=1$,NSHORTX !L IS NOW NUMBER OF TICKS SHORT SIDE

JXN $=-100 *$ SIGNX*L-OFFXC !DETERMINE THE LOCATION OF THE NEXT TICK

CALL MOVABS(JXN,-8-OFFY)!MOVE THERE

C

CALL DRWABS(JXN,-OFFY) !DRAW IT

C LABEL TICK VALUES FOR X-AXIS (SHORT SIDE)

$\mathrm{C}$

$\mathrm{XL}=\mathrm{L} \quad$ !REM: $\mathrm{L}$ IS LOOP INDEX FOR NUMBER TICKS

$\mathrm{XTICN}=-1 .{ }^{*}(100 . / \mathrm{XSCALE}) * \mathrm{XL} *$ SIGNX !DETERMINE THE VALUE AT NEXT TICK

ENCODE $(11,351, \mathrm{XDIVN}) \mathrm{XTICN}$ !ENCODE IT FOR DISPLAY (RASTECH)

C !LOCATE VALUE 15 PIXELS LEFT OF TICK

JLN $=-1 . *$ SIGNX* $(L * 100)-15$-OFFX

CALL MOVABS(JLN,-20-OFFY) !MOVE THERE

DO $6001 \mathrm{~N}=1,4 \quad$ !BEGIN BOLD SMEARING LOOP

CALL MOVREL(IDX(N),IDY(N)) !MOVE LOCATION RELATIVE TO CURRENT POS

CALL TEXT1(11,INTXDIVN) IPRINT THE TEXT STRING

6001 CONTINUE

850 CONTINUE

C

C DRAW TICK MARKS FOR Y-AXIS (LONG SIDE)

C

CALL TEXTC $(25,90)$

DO $360 \mathrm{~L}=1, \mathrm{NLONGY}$

$\mathrm{SIGNY}=1$

IF(OFFY.LE.0) SIGNY=-1

$J Y=S I G N Y * L^{*} 100-O F F Y$

CALL MOVABS(-OFFX,JY)

C

CALL DRWABS(8-OFFX,JY)

!SET THE CHARACTER HEIGHT 25 PIXELS

!LOOP FOR NUMBER OF TICK MARKS

!INITIALIZE SIGN FLAG

!MAKE IT NEGATIVE OF OFFSET IS NEG.

!CALCULATE LOCATION OF NEXT TICK

!MOVE THERE

!DRAW IT

C LABEL TIC VALUES FOR Y-AXIS (LONG SIDE)

C

$\mathrm{YL}=\mathrm{L}$

!INDEX NUMBER FOR CURRENT TICK

YTIC $=(100 / Y S C A L E) * Y L *$ SIGNY !CALCULATE THE VALUE AT THE TICK

ENCODE $(11,352$, YDIV)YTIC

352 FORMAT(G11.4)

$\mathrm{JL}=-40+$ SIGNY* ${ }^{*} 100-$ OFFY !LOCATION IS 40 PIXELS RIGHT OF AXIS

C JLN $=-1 *$ SIGNY* $\left(L^{*} 100+15\right)$-OFFY !CALCULATE LOCATION OF LABEL

CALL MOVABS(-OFFX-10,JL) !MOVE THERE

DO $354 \mathrm{~N}=1,4$

!BEGIN BOLD LOOP 
CALL MOVREL(IDX(N),IDY(N))

CALL TEXT1(11,INTYDIV)

354 CONTINUE

360 CONTINUE

C

C

C

DO $851 \mathrm{~L}=1$,NSHORTY

$J Y N=-100 *$ SIGNY*L-OFFY

CALL MOVABS(-OFFX,JYN)

CALL DRWABS(8-OFFX,JYN)

C

C

C

$\mathrm{YL}=\mathrm{L}$

YTICN $=-1 . *(100 . / Y S C A L E) *$ YL $*$ SIGNY

ENCODE(11,352,YDIVN)YTICN

$\mathrm{JLN}=-40-1 * \operatorname{SIGNY} *(\mathrm{~L} * 100)-\mathrm{OFFY}$

C JLN $=-1 * \operatorname{SIGNY*}\left(L^{*} 100+15\right)$-OFFY

CALL MOVABS(-OFFX-10,JLN)

DO $6002 \mathrm{~K}=1,4$

CALL MOVREL(IDX(K),IDY(K))

CALL TEXT1(11,INTYDIVN)

6002 CONTINUE

851 CONTINUE

CALL EMPTYB

C

C

C

C
!SMEAR RELATIVE TO PRESENT LOCATION !PRINT THE TEXT TO THE SCREEN

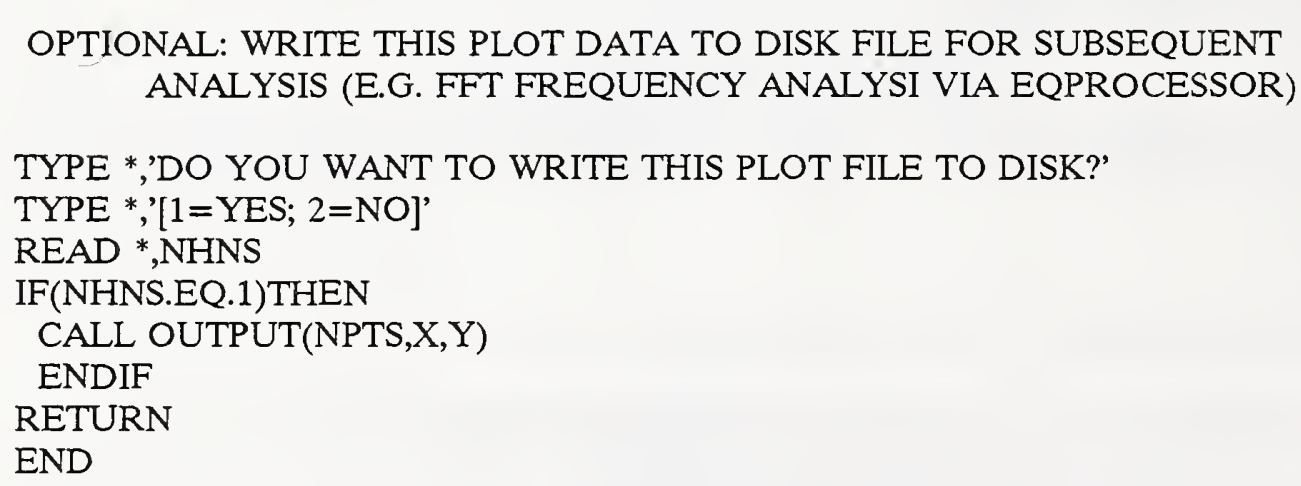

!LOOP ON NUMBER OF TICK MARKS

!CALCULATE CURRENT TICK LOCATION !MOVE THERE

!DRAW IT !MOVE THERE
!BEGIN BOLD LOOP
!SMEAR THE LABEL RELAT
!PRINT LABEL TO SCREEN !MOVE THERE
!BEGIN BOLD LOOP
!SMEAR THE LABEL RELAT
!PRINT LABEL TO SCREEN !MOVE THERE
N BOLD LOOP
!SMEAR THE LABEL RELATIVE
!PRINT LABEL TO SCREEN !MOVE THERE
B BOLD LOOP
!SMEAR THE LABEL RELATIV
!PRINT LABEL TO SCREEN

!CALCULATE VALUE THERE !ENCODE IT FOR RASTERTECH !CALCULATE LOCATION OF LABEL !CALCULATE LOCATION OF LABEL 


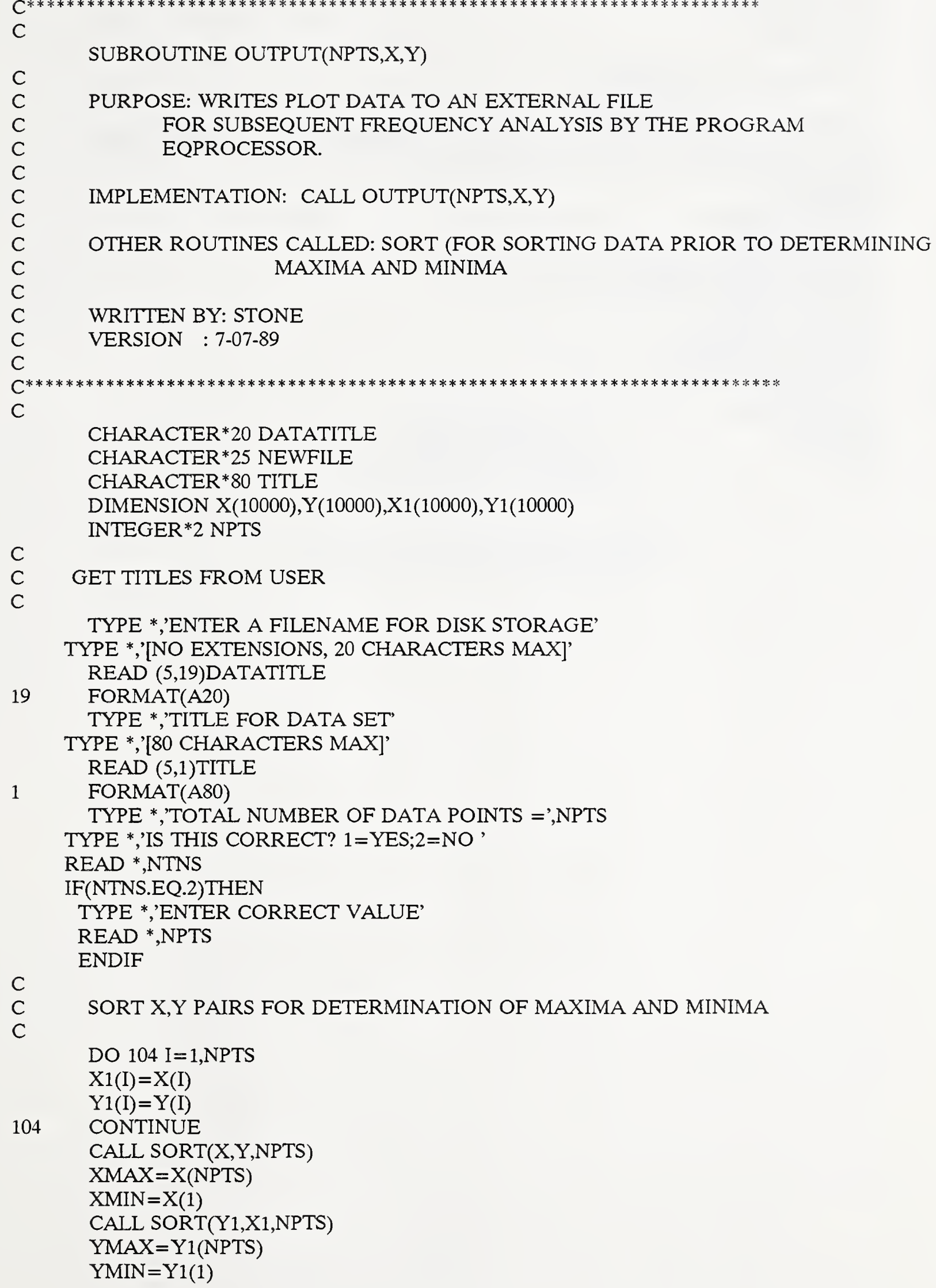

C

C WRITTEN BY: STONE

C VERSION : 7-07-89

C

C

C

IMPLEMENTATION: CALL OUTPUT(NPTS,X,Y)

OTHER ROUTINES CALLED: SORT (FOR SORTING DATA PRIOR TO DETERMINING MAXIMA AND MINIMA

FOR SUBSEQUENT FREQUENCY ANALYSIS BY THE PROGRAM

EQPROCESSOR.

C GET TITLES FROM USER

C

TYPE *,'ENTER A FILENAME FOR DISK STORAGE'

TYPE *,'[NO EXTENSIONS, 20 CHARACTERS MAX]'

READ (5,19)DATATITLE

19

FORMAT(A20)

TYPE *,'TITLE FOR DATA SET'

TYPE *,'[80 CHARACTERS MAX]'

READ (5,1)TITLE

1 FORMAT(A80)

TYPE *,'TOTAL NUMBER OF DATA POINTS =',NPTS

TYPE *,'IS THIS CORRECT? $1=$ YES; $2=\mathrm{NO}$,

READ *,NTNS

IF(NTNS.EQ.2)THEN

TYPE *'ENTER CORRECT VALUE'

READ *,NPTS

ENDIF

C

C SORT X,Y PAIRS FOR DETERMINATION OF MAXIMA AND MINIMA

C

DO $104 \mathrm{I}=1, \mathrm{NPTS}$

$\mathrm{X} 1(\mathrm{I})=\mathrm{X}(\mathrm{I})$

$\mathrm{Y} 1(\mathrm{I})=\mathrm{Y}(\mathrm{I})$

104

CONTINUE

CALL SORT(X,Y,NPTS)

$\mathrm{XMAX}=\mathrm{X}(\mathrm{NPTS})$

$\mathrm{XMIN}=\mathrm{X}(1)$

CALL SORT(Y1,X1,NPTS)

$Y M A X=Y 1(N P T S)$

$\mathrm{YMIN}=\mathrm{Y} 1(1)$ 


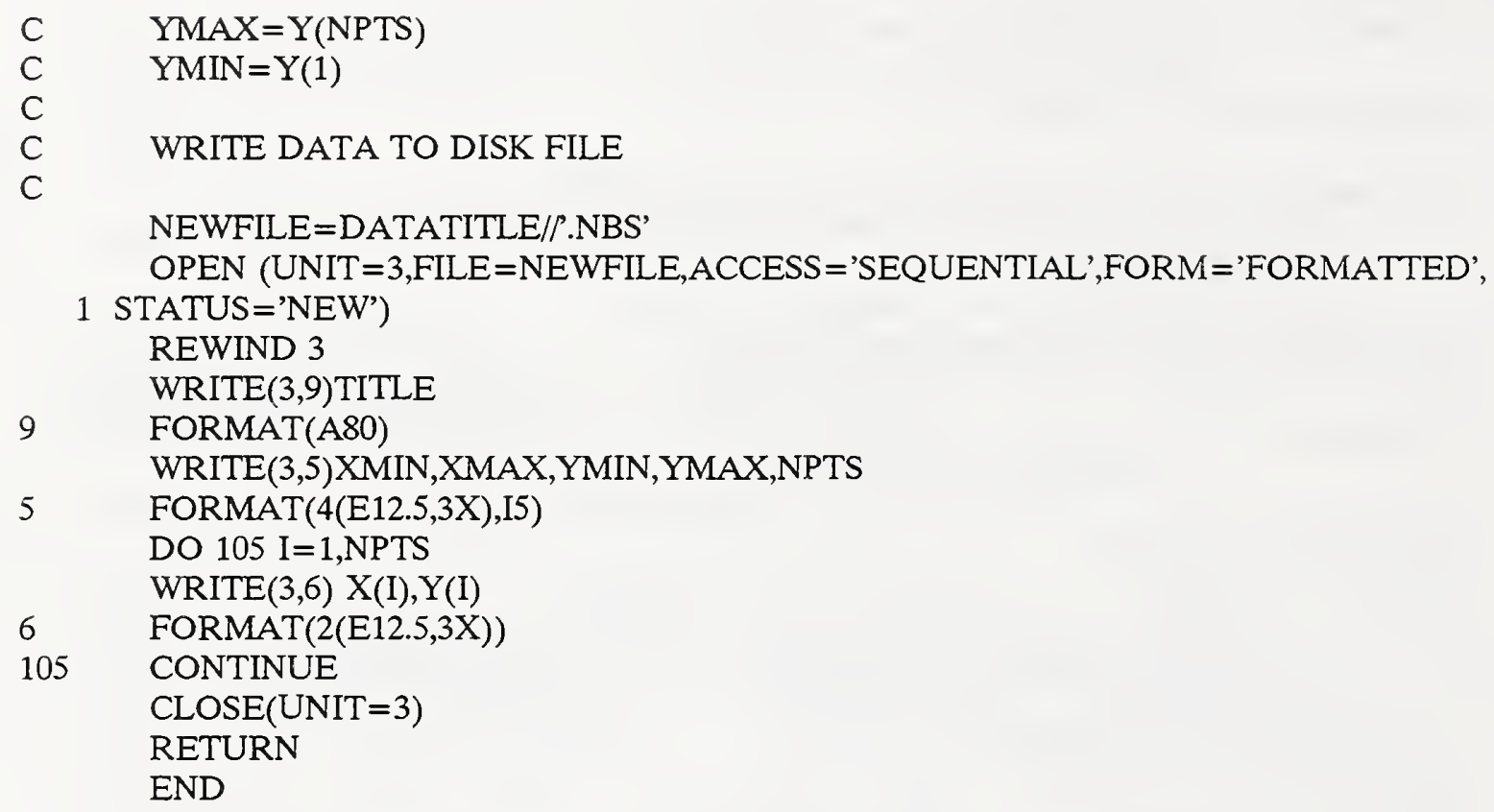




\section{Appendix B \\ Program: HDYN}

Transient Response of HSILS Subjected

to Random Voltage-Time Histories 


\section{program: HDYN}

purpose: allows real-time graphics solution of generalized transient dynamic analysis of single degree of freedom systems with or without damping and/or time varying forcing function. The program is written for a Silicon Graphics workstation and allows for real-time user modification of key parameters such as stiffness and damping by means of a dial box. Dial box assignments are listed below.

The capability also exists for superimposing the results of experimental data over a theoretical response to the same force-time history and allows for real-time $y$-ordinate scaling, $\mathrm{x}$-axis shifting (time) and examination of individual data point values.

HDYN was developed for real time analysis of the transient reponse of the NIST High Speed Intelligent Loading System (HSILS).

revision history:

a) 11-14-91: version 1.0 written by B.Stone

external subroutines called: dderkf.f

linkage requirements:

"cc stone1.f -lfgl -lgl_s -lm -o stone1 dderkf.o" to compile and link

Notes: a) Press the "Esc"[ape] key to exit.

b) Dial0 is the lower left knob on the dial box and is used to vary damping ratio (\%)

c) Dial1 is the lower right knob on the dial box and is used to vary stiffness.

IMPLICIT REAL*8 (A-H,O-Z) real*8 DATA1(2500),DATA2(2500),DATA3(2500)

real*8 DATA4(2500),ACCEL(4000),data6(4000)

real*8 olddata $1(2500)$,olddata $2(2500)$

real*8 lastdamp,laststiff

real*8 signal $(4000)$

integer*4 size $(2)$

integer*2 mdev(8), mval(8), lastval(8),npointer,npointer_last

integer dev,init,min, $\max$

integer*2 time(2500), displacement(2500), velocity (2500)

integer*2 time2(2500),signal_pix(2500)

integer*2 oldtime(2500),olddisplacement(2500),oldvelocity(2500) 
character*2 fxchar_last(12),fychar_last(12)

COMMON /SYSTEMP/ X0,XOPRIME,BETA,CEE,OMEGAN,SMASS,FREQ

COMMON /CONTROL/ NPTS,DT,TTIME,NTOTAL,IPRINT,IRESP,M

COMMON /EARTHQ/ ACCEL,NACCEL,ADT,TIMEREC,AG

common /plotstuff/ data 1,data2,data3

common/sensordata/ signal,nsignalpts,sig_time_step,data6

EXTERNAL FCN

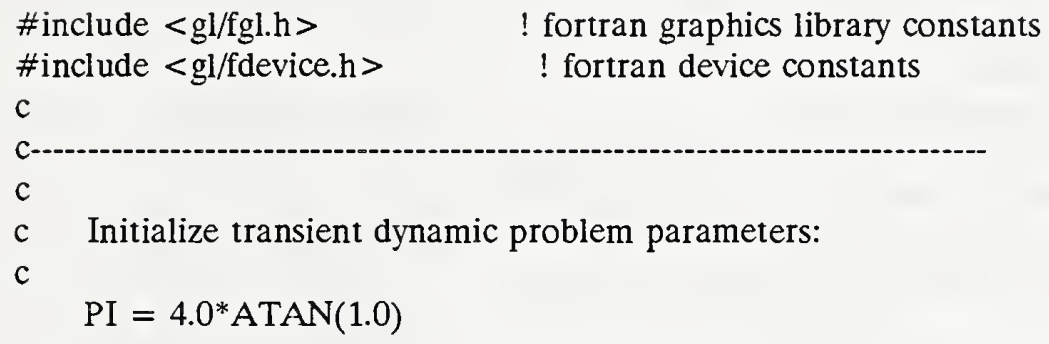

CALL XSETF(-1)

CALL XSETUN(10)

$\mathrm{M}=2500$

call initialize

damp = cee lassign the initial damping ratio $(\mathrm{C}$ (system)/C(critical), decimal value)

stiffness $=\left(\left(2^{*} \mathrm{pi}^{*} \text { freq }\right)^{* *} 2\right)^{*}$ smass !assign initial stiffness

ichange $=0$

c

$\mathrm{c}$

c

c

c initialize and open the window:

c

call prefpo(10,XMAXSC-10,300,YMAXSC-30)

winid = winope('SDOF1-SGI',9)

call qdevic(ESCKEY)

call color(BLUE)

call clear

call getsiz(size(1),size(2))

$\mathrm{c}$ !reset the replot flag !disable error interupts
!dump error messages to file

!initial dial maxima 


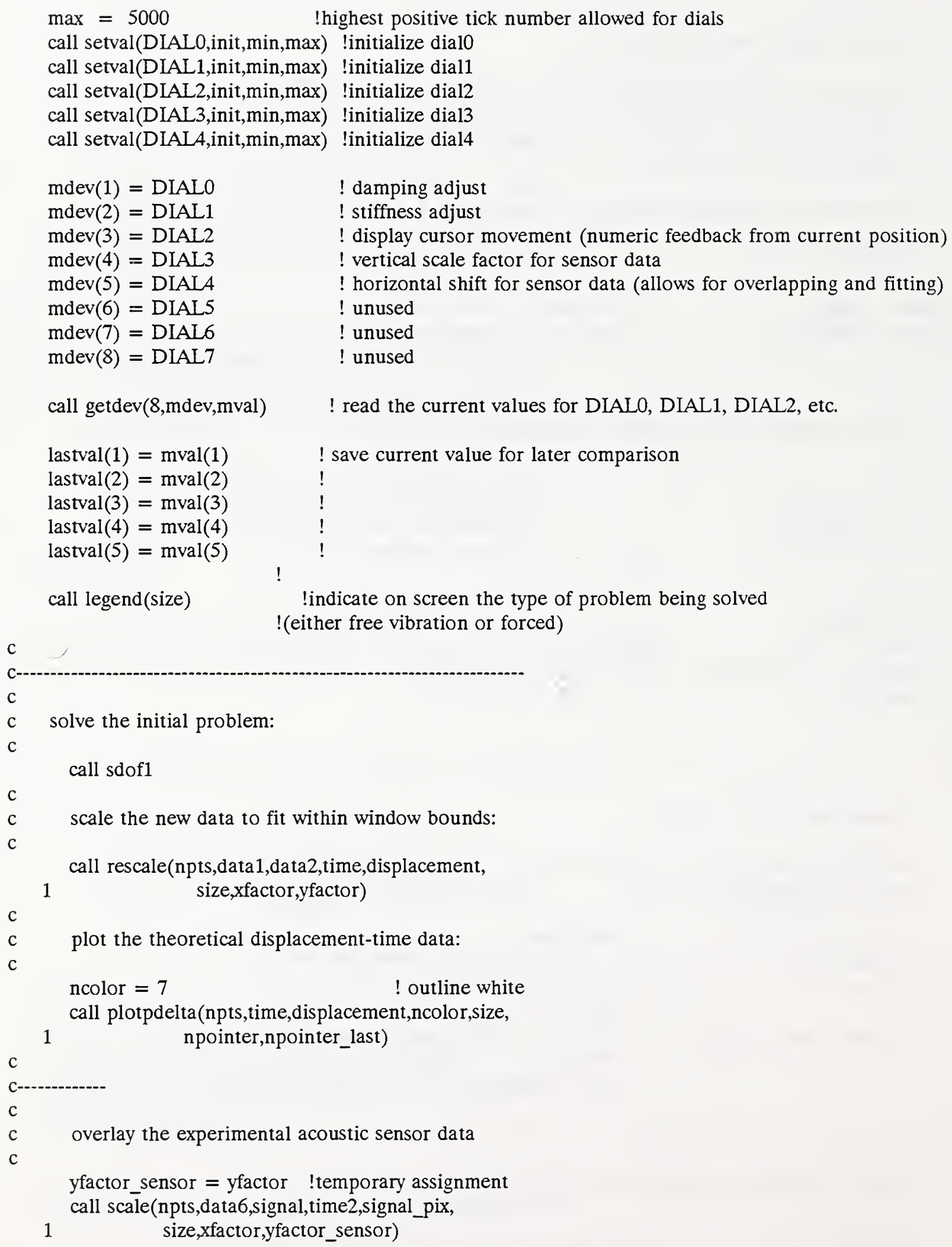


ncolor $=3$

call plotpdelta(npts,time2,signal_pix,ncolor,size, npointer,npointer_last)

c

C-----------

c

c update the displayed values of stiffness and damping:

c

call drwtxt(size,npointer)

$\mathrm{C}$

c store current values:

c

do $i=1$, npts

oldtime $(\mathrm{i})=$ time $(\mathrm{i})$

olddisplacement $(\mathrm{i})=$ displacement $(\mathrm{i}) \quad$ ! new displacements

enddo

lastdamp $=$ damp

laststiff $=$ stiffness

lastval $(1)=\operatorname{mval}(1)$

$\operatorname{lastval}(2)=\operatorname{mval}(2)$

$\operatorname{lastval}(3)=\operatorname{mval}(3)$

$\operatorname{lastval}(4)=\operatorname{mval}(4)$

$\operatorname{lastval}(5)=\operatorname{mval}(5)$

! save current value of damping ratio

! save current value of stiffness

! damping

! stiffness

! feedback cursor

! y-scaling of sensor data

! x-translation of sensor data

ichange $=0$

! reset the replot flag

c

c window manager check loop

c

25 continue

C

c Read devices:

c

$\operatorname{dev}=$ qtest ()

if (dev.ne.0) then

$\mathrm{dev}=\operatorname{qread}(\mathrm{val})$

endif

if(dev .eq. ESCKEY) go to 1090

call reshap

call getdev $(8, \mathrm{mdev}, \mathrm{mval})$

! read the current values of

c

\section{c}

c

c Adjust Damping via Dial 0:

c

if(mval(1).eq.lastval(1)) then goto 999

! no change in damping; leave value displayed

else

damp $=$ damp $+(\operatorname{mval}(1) \text {-lastval }(1))^{*} 0.001 \quad$ ! assign new damping value

cee $=$ damp

! reload common parameter with current damping value 
ichange $=1$

endif

999 continue

c

c

$\mathrm{c}$

C

$$
\text { if(mval(2).eq.lastval(2)) then }
$$
goto 998

else

stiffness $=$ stiffness $+(\operatorname{mval}(2)-$ lastval $(2)) * 10 . \quad$ ! assign new stiffness value omegan $=$ sqrt(stiffness/smass)

freq $=$ omegan $/\left(2^{*}\right.$ pi $)$

ichange $=1$

endif

998 continue

c

c

c Adjust location of cursor (for feedback of numerical quantities) via Dial 2

$\mathrm{c}$

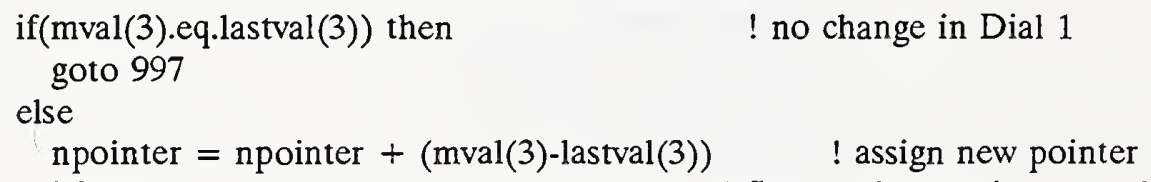




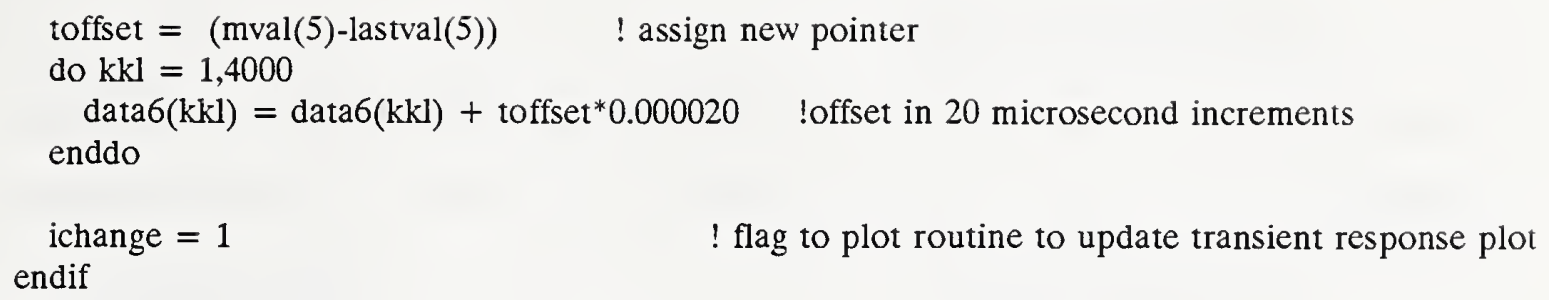

overlay the experimental acoustic/pressure sensor data

erase the last plot

ncolor $=4$ 


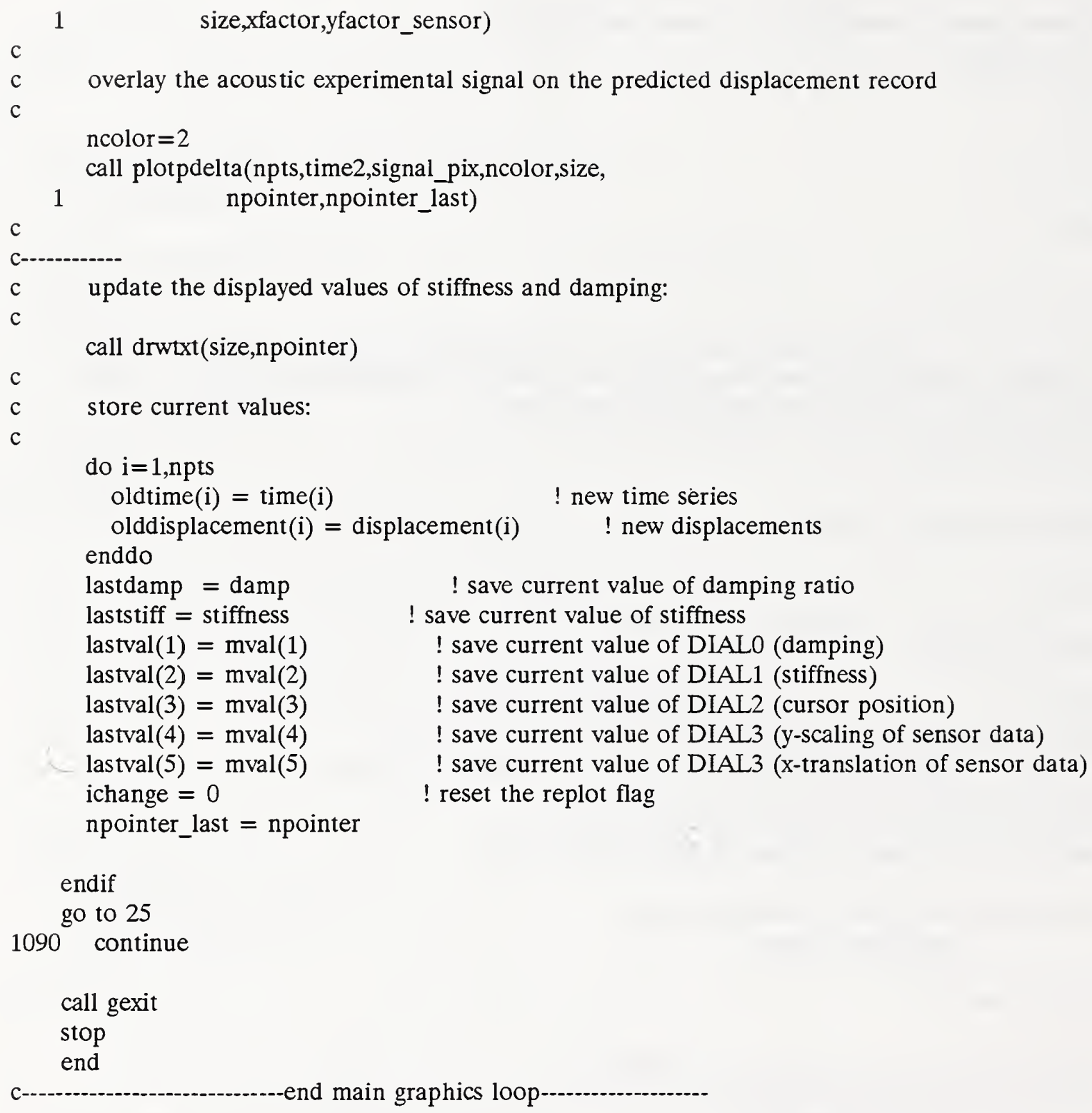


subroutine drwtxt(size,npointer)

c

c purpose: plots screen text; updates pointer values

c

c version: $12 / 91$ B.Stone

c subroutines called: none

c

C

IMPLICIT REAL*8 (A-H,O-Z)

real*8 DATA1(2500),DATA2(2500),DATA3(2500)

real*8 DATA4(2500),ACCEL(4000)

real*8 olddata $1(2500)$,olddata2(2500)

real*8 lastdamp,laststiff

character*2 fxchar(12),fxchar_last(12),fychar(12),fychar_last(12)

character*2 fzchar(12),fwchar(12), gxchar(12),gychar(12)

integer*2 npointer

integer* 4 xstart,ystart,xend,yend

integer* 4 xtext,vspc,ytext1,ytext2,ytext3,ytext 4

integer* 4 size(2),ystart2,yend2,y2txt1,y2txt2

COMMON /SYSTEMP/ X0,XOPRIME,BETA,CEE,OMEGAN,SMASS,FREQ

COMMON /CONTROL/ NPTS,DT,TTIME,NTOTAL,IPRINT,IRESP,M

COMMON /EARTHQ/ ACCEL,NACCEL,ADT,TIMEREC,AG

common /plotstuff/ data1,data2,data3

EXTERNAL FCN

\#include $<\mathrm{gl} / \mathrm{fgl} . \mathrm{h}>$

C

C-

C

erase the old values of damping, stiffness, frequency, and mass

xtext $=\operatorname{size}(1)-305$

vspc $=15$

ytext1 $=5$

ytext $2=y t e x t 1+v s p c$

ytext $3=y t e x t 2+v s p c$

ytext $4=y t e x t 3+v s p c$

$\mathrm{xstart}=\mathrm{xtext}+195$

ystart $=$ ytext 1

xend $=$ xstart +110

yend $=4 * v s p c+$ ytext 1

!beginning $\mathrm{x}$-coord for titles

!vertical line spacing for titles

!starting y-position for first line of text !second line of text etc.

ystart $2=$ yend +20

yend $2=$ ystart $2+50$

$\mathrm{y} 2 \mathrm{txt} 1=\mathrm{ystart} 2+10$

$\mathrm{y} 2 \mathrm{txt} 2=\mathrm{y} 2 \mathrm{txt} 1+\mathrm{vspc}$

call color(BLUE)

!background color, erase

call rectfi(xstart,ystart,xend,yend)

!x-coordinate lower left corner of box to erase values !y-coordinate of lower left corner of box to erase values !x-coordinate of top right corner !y-coordinate of top right corner

!draw the box, fill with blue 
$\mathrm{PI}=4.0^{*} \mathrm{ATAN}(1.0)$

stiffness $=($ omegan $* * 2) *$ smass !assign initial stiffness

encode(12,300,fxchar)cee

encode( 12,300 ,fychar)stiffness

encode(12,300,fzchar)smass

encode $(12,300$, fwchar)omegan/(2*PI)

encode(12,300,gxchar)data1(npointer) encode(12,300,gychar)data2(npointer) ! displacement at cursor position

300 format $(g 12.5)$

c

c

c

now plot the $\mathrm{x}$ and $\mathrm{y}$ positions with appropriate information text
! convert damping value to character string

! convert stiffness value to character string ! convert system mass value to character string ! convert nat.frequency (hertz) into character string ! time at cursor position

call cmov2i(xtext,ytext2)

call charst('Damping Ratio

! move to the location to print out the $\mathrm{x}$-value call cmov2i(xstart,ytext2) call charst(fxchar,12) $=, 20) \quad ! \mathrm{x}$-title

call cmov2i(xtext,ytext1) ! move to the fixed position for plotting $x$-data

! write out the $\mathrm{x}$-position

call charst('Stiffness (lb/in) $=$ ',20)

! move the location to print out the $y$-value

call cmov2i (xstart,ytext1)

call charst(fychar,12)

! y-title

! move to the fixed position for plotting y-data

! write out the y-position

call cmov2i(xtext,ytext3)

! move the location to print out the y-value

call charst('Mass (lb-s^2/in) = ',20) ! y-title

call cmov2i(xstart,ytext3)

call charst(fzchar,12)

! move to the fixed position for plotting y-data

! write out the y-position 
call cmov2i(xtext,ytext4) ! move the location to print out the y-value call charst('Nat. Freq. $\left.(\mathrm{Hz})={ }^{\prime}, 20\right) \quad$ ! y-title

call cmov2i(xstart,ytext4) ! move to the fixed position for plotting y-data

call charst (fwchar,12)

! write out the y-position

call cmov2i(xtext,y2txt1) ! move the location to print out the y-value

call charst('Time (seconds) $={ }^{\prime}, 20$ ) $\quad$ ! y-title

call cmov2i(xstart,y2txt1) ! move to the fixed position for plotting y-data

call charst (gxchar,12)

! write out the y-position

call cmov2i(xtext,y2txt2) ! move the location to print out the $y$-value

call charst('Displacement (in) $={ }^{\prime}, 20$ ) $\quad$ !y-title

call cmov2i (xstart,y2txt2) ! move to the fixed position for plotting y-data

call charst(gychar,12)

! write out the y-position

c

return

end 


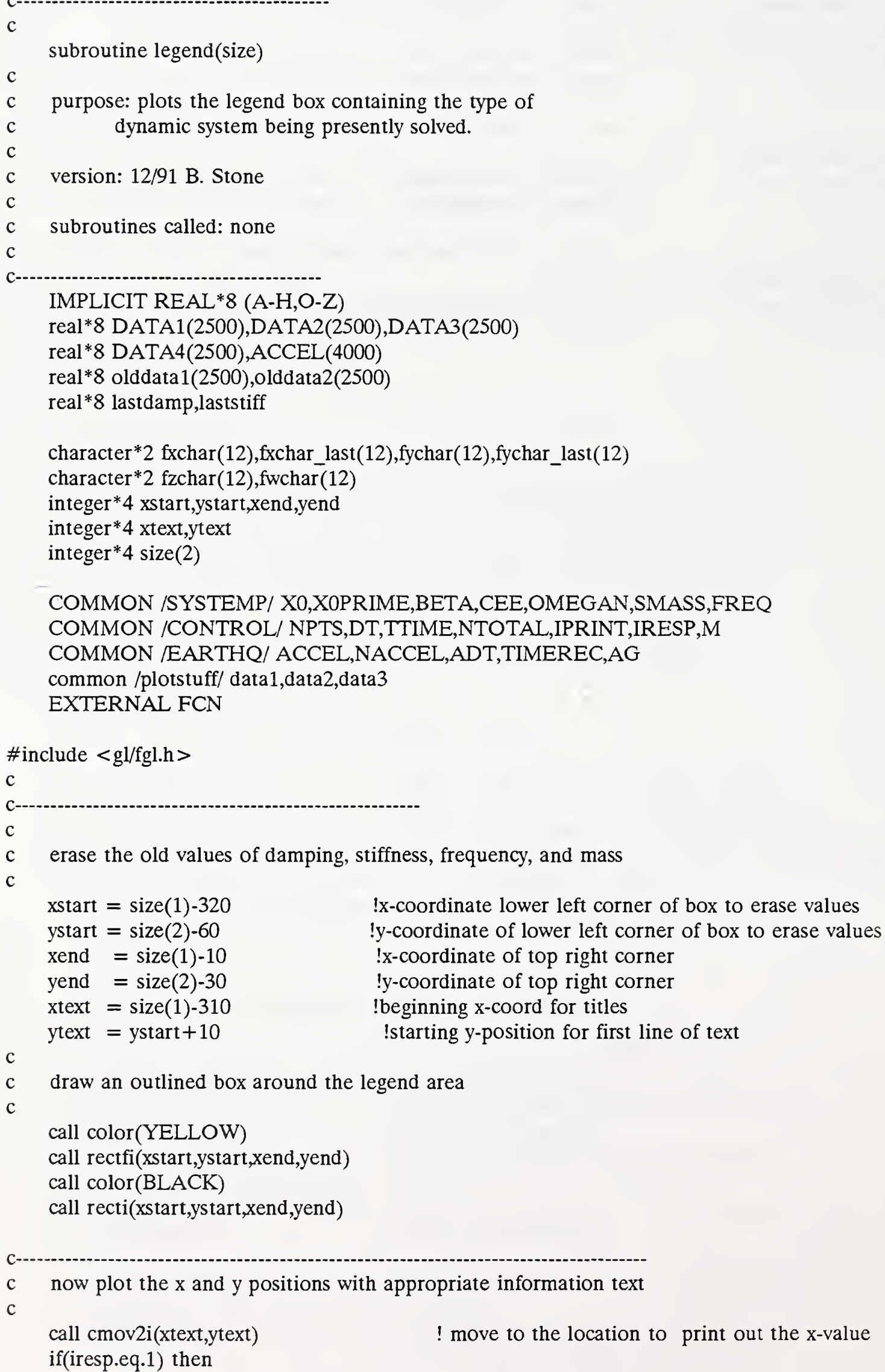


call charst('Solving: $\mathrm{Mx}^{* *}+\mathrm{Cx}^{*}+\mathrm{Kx}=0$ ',29) $\quad$ ! $\mathrm{x}$-title elseif(iresp.eq.2) then

call charst('Solving: $\left.\mathrm{Mx}^{* *}+\mathrm{Cx}^{*}+\mathrm{Kx}=\mathrm{P}(\mathrm{t})^{\prime}, 32\right)$

endif

c

return

end 
c

subroutine plotpdelta(kptstop,delta,p,ncolor,size,

1

npointer,npointer_last)

c

c Purpose: plots values of two vectors (displacement, load) between the low index "kptsbottom"

c and the high index "kptstop" on

c

c

c

c

c

c

Revision History: 1) 10-25-90 Initial code development

2) 11-13-90 Code documentation added

B. Stone

the screen using color "ncolor". If the data goes outside of screen coordinates an advisory message is plotted in the message box and the offending vector entry is not plotted; the advisory indicates that the rescale button should be picked.

Subroutines called: none

B. Stone

$\mathrm{c}$

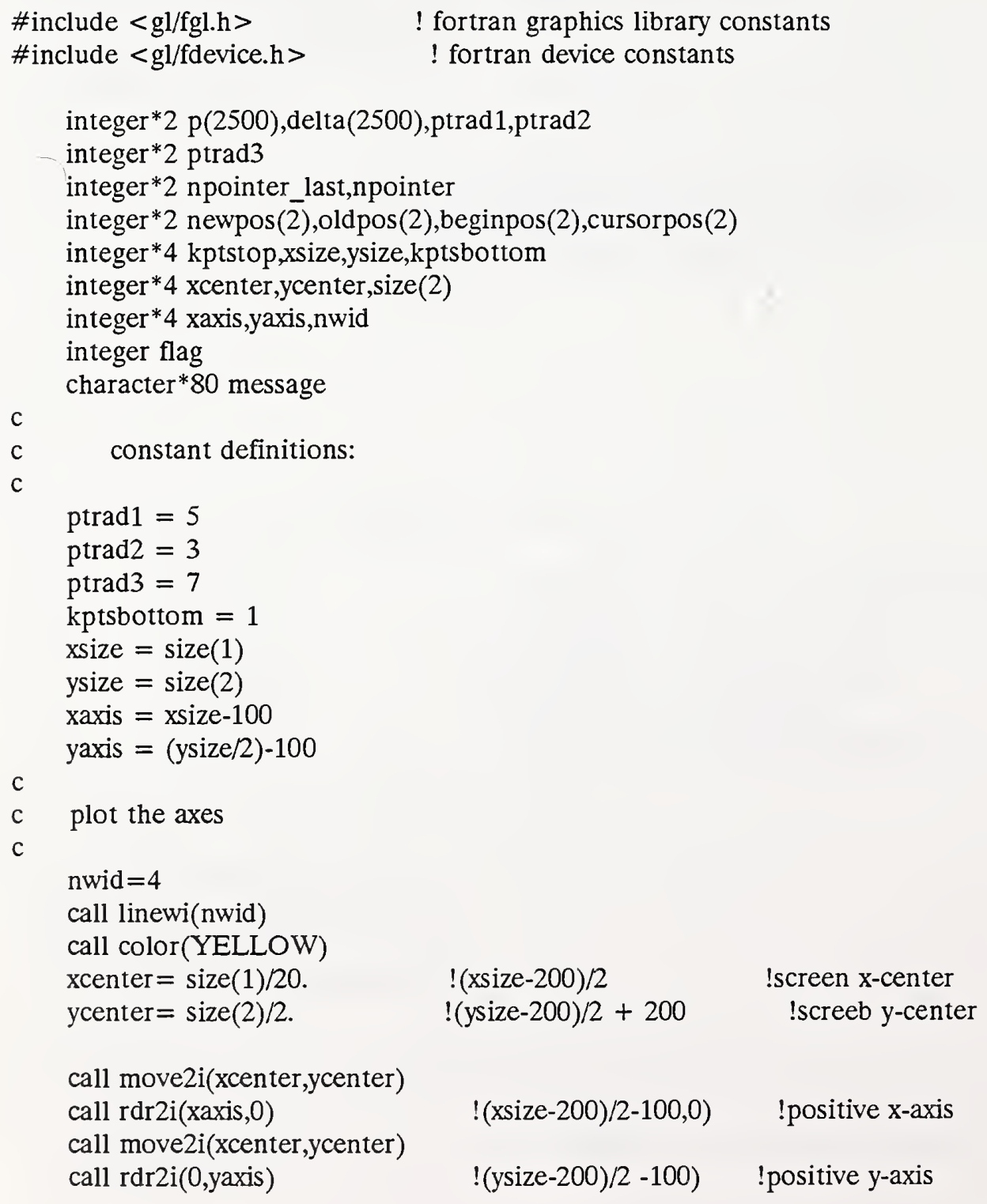


call move2i(xcenter,ycenter)

call $\operatorname{rdr} 2 \mathrm{i}(0,-$ yaxis $) \quad ! 100-($ ysize-200)/2) !negative y-axis

\section{nwid $=2$}

call linewi(nwid)

do $832 \mathrm{i}=\mathrm{kpts}$ bottom,kptstop-1 !notice that only the data between kptsbottom !and kptstop is plotted.

newpos $(1)=\operatorname{delta}(\mathrm{i}+1) \quad$ !set the "to" $\mathrm{x}$-coordinate

newpos $(2)=p(i+1) \quad$ !set the "to" $y$-coordinate

call bgnlin

call v2s(oldpos)

call v2s(newpos)

call endlin

$\operatorname{oldpos}(1)=\operatorname{newpos}(1)$

$\operatorname{oldpos}(2)=$ newpos $(2)$ !set the initial "from" $\mathrm{x}$-coordinate

!set the initial "from" y-coordinate

!set the line color to that passed from the calling routine

\section{2 continue}

c plot the data feedback cursor:

C

if(ncolor.eq.4) then

call color(BLUE)

cursorpos $(1)=$ delta(npointer_last)

cursorpos $(2)=p($ npointer_last $)$

c

filled white circle, full diameter, if ncolor $=7$; otherwise blue

call circfs(cursorpos(1),cursorpos(2),ptrad3)

elseif (ncolor.ne.4) then

cursorpos $(1)=$ delta(npointer)

cursorpos $(2)=p($ npointer $)$

call color(YELLOW)

!outline black circle, full diameter

call circs(cursorpos(1),cursorpos(2),ptrad1)

call color(RED)

call circfs(cursorpos(1),cursorpos(2),ptrad2) !red center dot

endif

return

end 


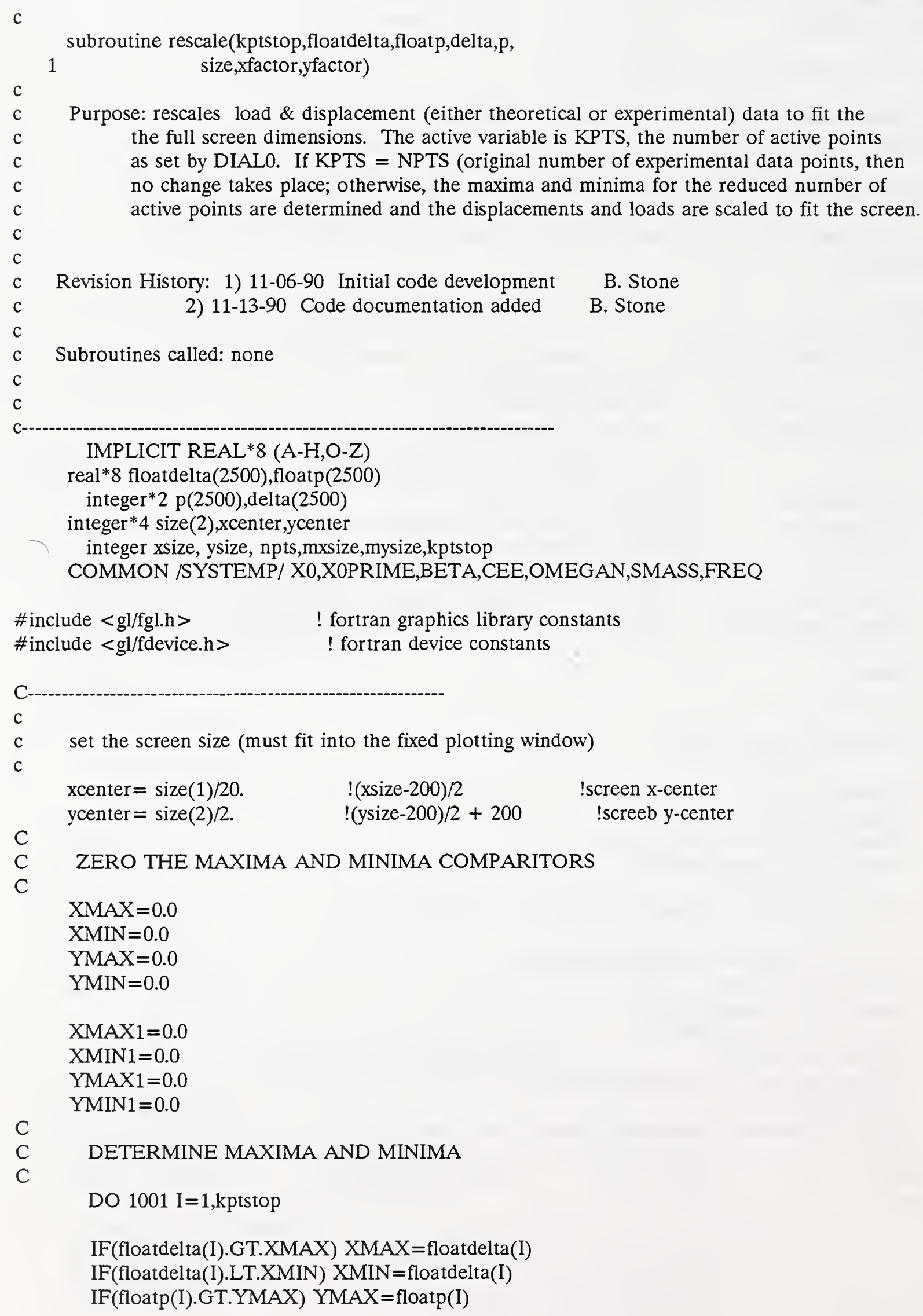


IF(floatp(I).LT.YMIN) YMIN=floatp(I)

\section{CONTINUE}

c

c

c

compute real data range

xrange $=\operatorname{amax} 1(\operatorname{abs}(x m i n), \operatorname{abs}(x m a x)) \quad$ !take larger of xmax or xmin; range equals twice this yrange $=\operatorname{amax} 1(\operatorname{abs}(y m i n), \operatorname{abs}(y m a x))^{*} 2$. !since we assume $x \min$ to be negative; assymetric graphs

c

c determine screen scaling factors

c $\begin{array}{ll}\text { xfactor }=(\text { real(size }(1)) / \text { xrange })^{*} .8 & \text { !will therefore always get displayed in all quadrants } \\ \text { yfactor }=(\text { real(size }(2)) / \text { yrange })^{*} .8 & \text { !scaling down factor (arbitrary) }\end{array}$

c

c re-compute the screen coordinates of the $p$, and delta vectors

c using the new values of xfactor and yfactor

c
do $100 \mathrm{i}=1$, kptstop
!kptstop $=$ npts
delta(i) $=$ floatdelta $(\mathrm{i}) *$ xfactor + xcenter $\mathrm{p}(\mathrm{i})=$ float $\mathrm{p}(\mathrm{i}) *$ yfactor + ycenter
!offset to the center of the plot window continue !offset to the center of the plot window

100

return

end 


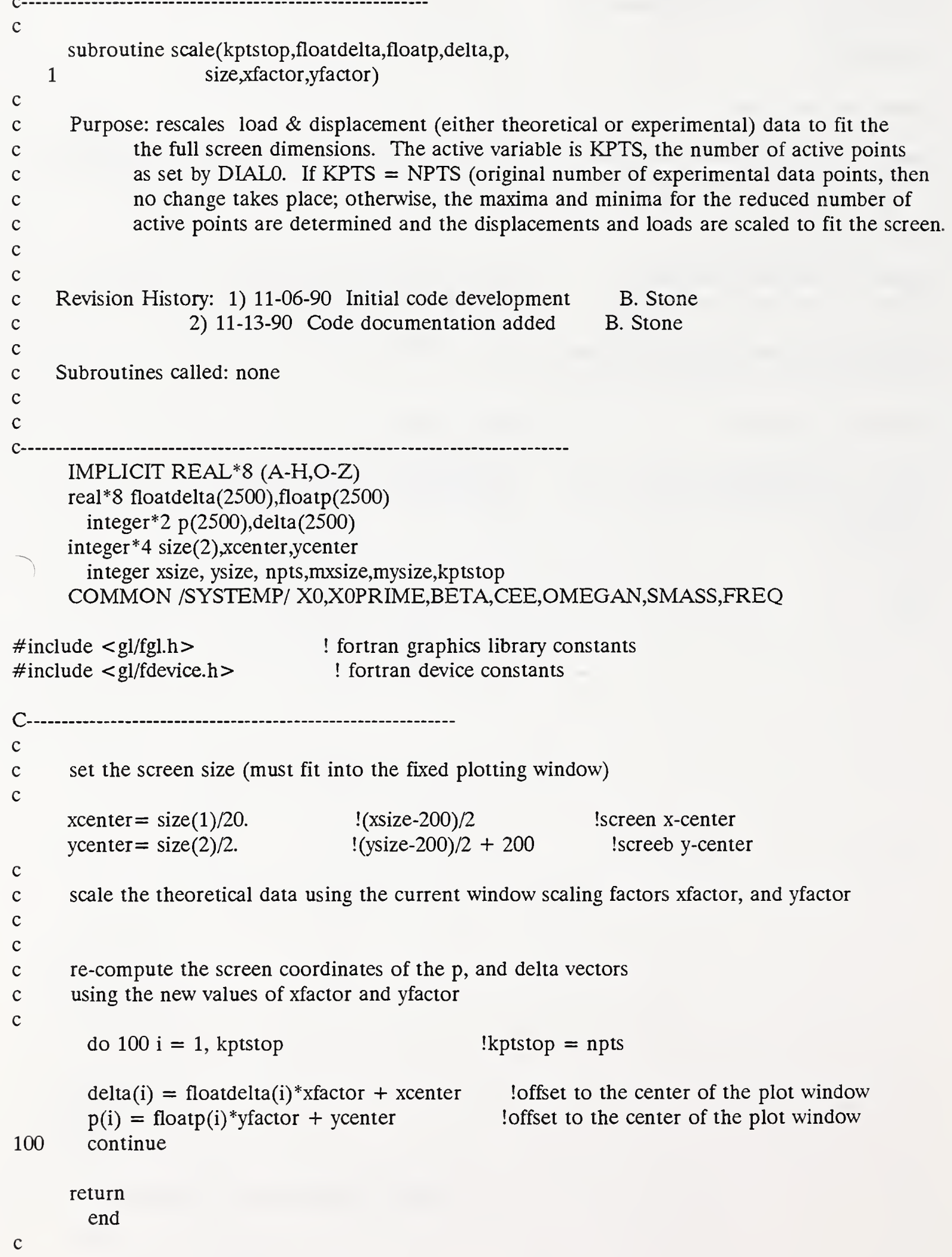

Subroutines called: none

c

c-

IMPLICIT REAL*8 (A-H,O-Z)

real $* 8$ floatdelta(2500),floatp $(2500)$

integer*2 $\mathrm{p}(2500)$,delta(2500)

integer* 4 size $(2)$,xcenter,ycenter

integer xsize, ysize, npts,mxsize,mysize,kptstop

COMMON /SYSTEMP/ X0,XOPRIME,BETA,CEE,OMEGAN,SMASS,FREQ 
Subroutine sdof 1

c

c Response of an SDOF to various forcing functions, solved using

c the DEPAC subroutine DDERKF (NIST - out of Sandia National

c Laboratory)

c

c Solution basedon IMSL subroutine DVERK- restricted to VAX use

c

c Program Re-written : 11-7-91 B.Stone

c Solution based on DEPAC subroutine DDERKF - FORTRAN source available

c suitable for many machines (uncomment "IMACH" and "DIMACH" subroutine

c lines for machine dependent constants). Should be portable to PC.

c

$\mathrm{c}^{*}$

IMPLICIT REAL*8 (A-H,O-Z)

REAL*8 DATA1(2500),DATA2(2500),DATA3(2500),DATA4(2500),

*ACCEL(4000)

COMMON /SYSTEMP/ X0,XOPRIME,BETA,CEE,OMEGAN,SMASS,FREQ

COMMON /CONTROL/ NPTS,DT,TTIME,NTOTAL,IPRINT,IRESP,M

COMMON /EARTHQ/ ACCEL,NACCEL,ADT,TIMEREC,AG

EXTERNAL FCN

C

OPEN(UNIT $=5$, STATUS $=$ 'UNKNOWN')

OPEN(UNIT=6,STATUS ='UNKNOWN')

C

C $M=$ ARRAY DIMENSION OF MAIN DATA ARRAYS, MUST CORRESPOND TO ACTUAL

C DIMENSION OF ARRAYS AND CONTROLS MAX TIME OF CALCULATION

$\mathrm{M}=2500$

C

CALL STEPPER !solve the transient second order ODE

return

END 


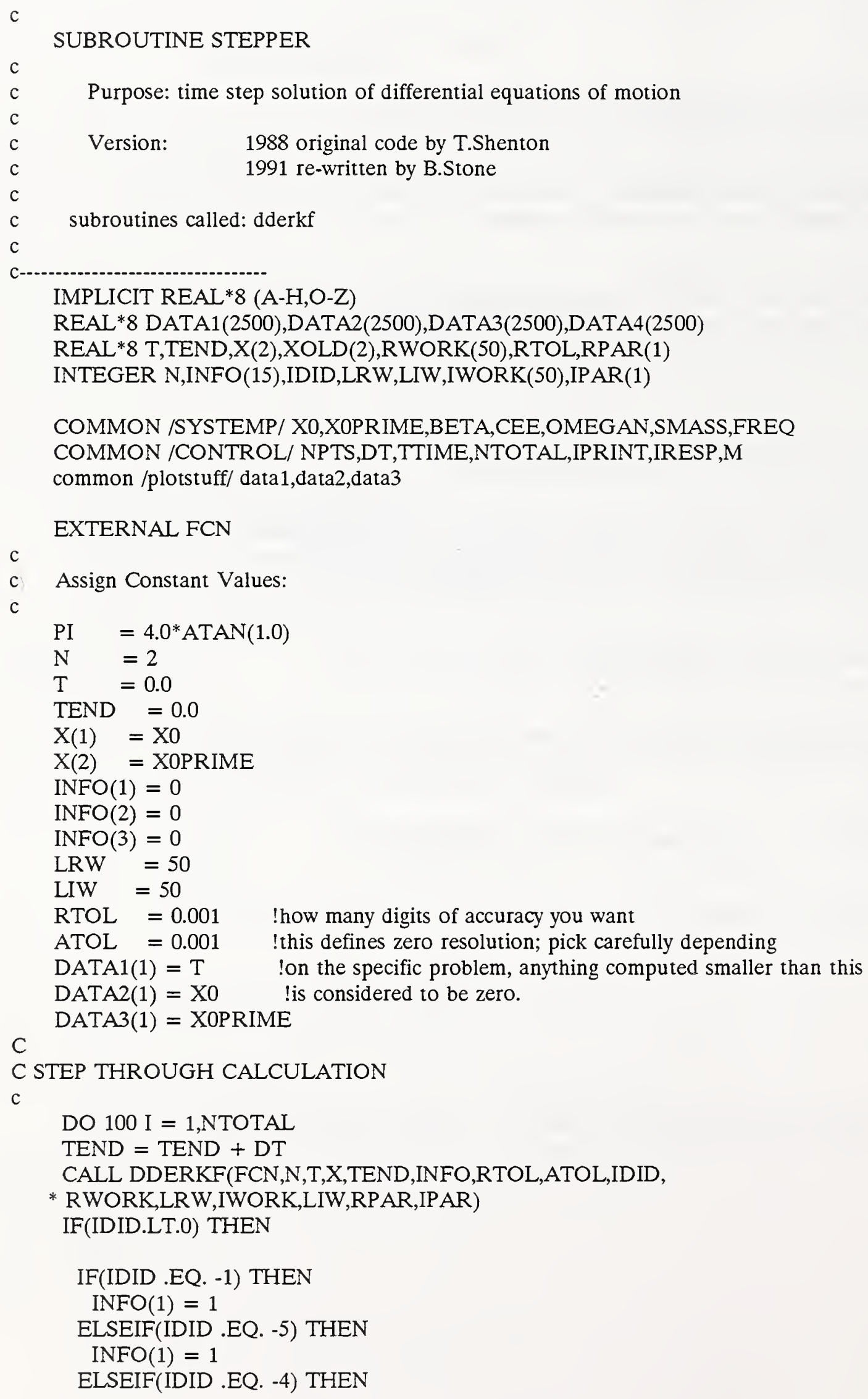




$$
\begin{aligned}
& \operatorname{INFO}(1)=1 \\
& \text { ELSE } \\
& \text { WRITE(6,45)IDID } \\
& \text { ENDIF }
\end{aligned}
$$

\section{ENDIF}

c IF(IPRINT .EQ. 1)THEN

c WRITE $(6,40) \mathrm{T}, \mathrm{X}(1), \mathrm{X}(2)$

c ENDIF

C

C VECTORS OF TIME, DISP AND VELOCITY
$\operatorname{DATA} 1(\mathrm{I}+1)=\mathrm{T}$
$\operatorname{DATA2}(\mathrm{I}+1)=\mathrm{X}(1)$
!TIME (SECONDS)
$\operatorname{DATA} 3(\mathrm{I}+1)=\mathrm{X}(2)$
!DISPLACEMENT (INCH)
!VELOCITY (INCH/SECOND)

100 CONTINUE

$\mathrm{C}$

C WRITE OUT VECTORS TO DISK

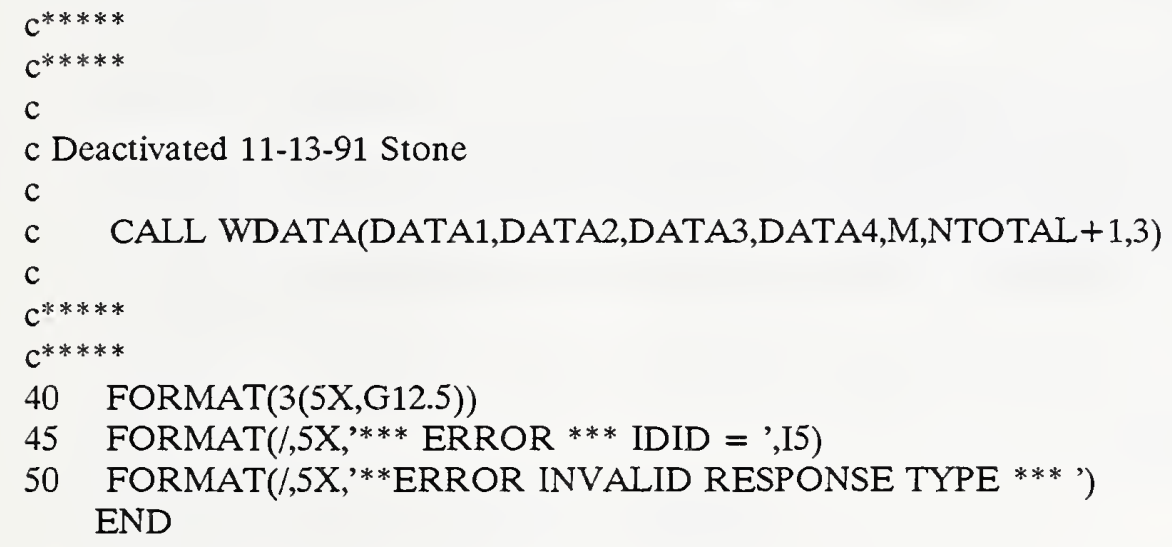




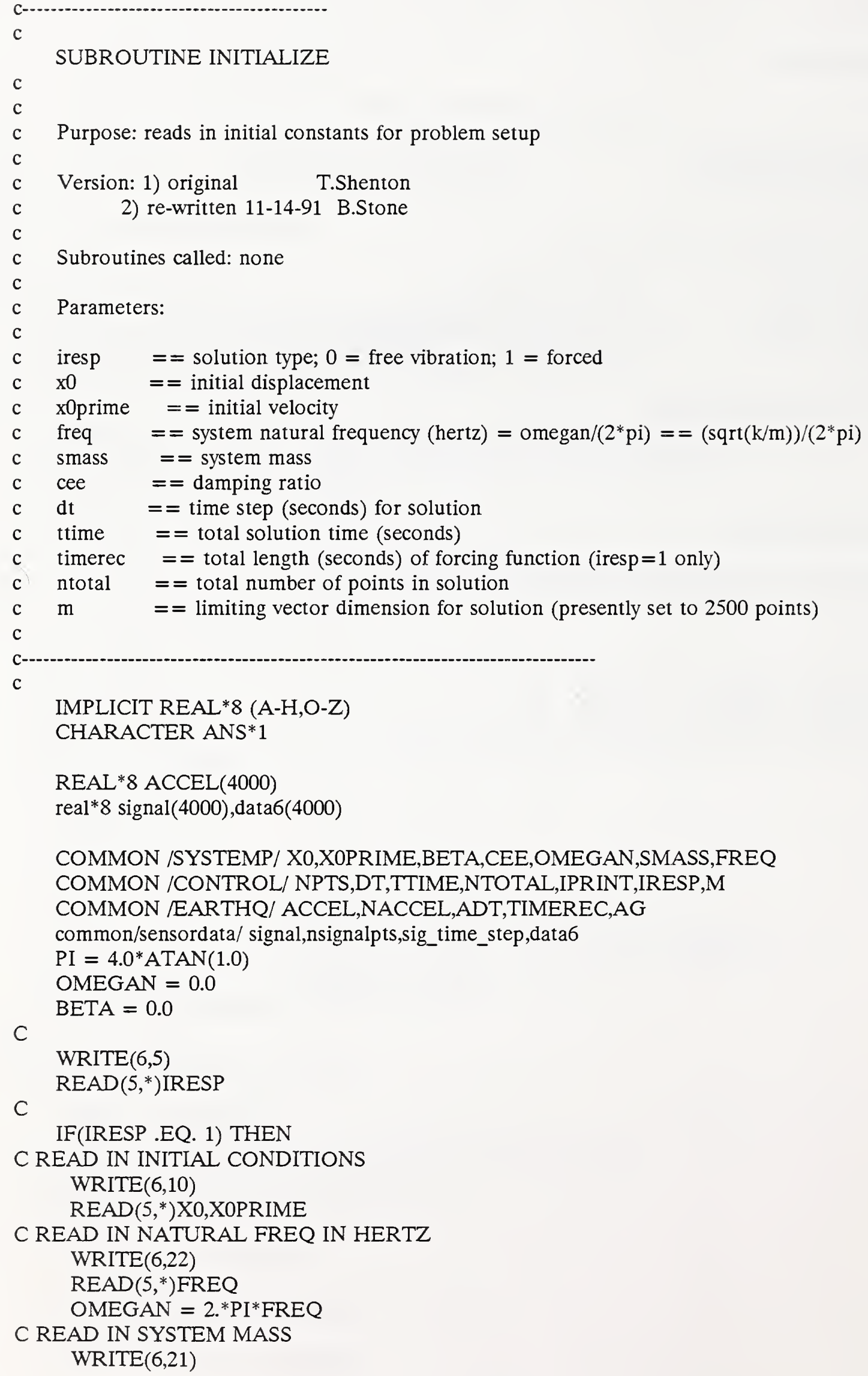


$\operatorname{READ}(5, *)$ SMASS

C READ IN DAMPING RATIO

WRITE $(6,15)$

$\operatorname{READ}(5, *) \mathrm{CEE}$

C READ IN CALCULATION TIME STEP DELTA T

WRITE $(6,26)$

$\operatorname{READ}(5, *) \mathrm{DT}$

C READ IN TOTAL TIME OF CALCULATION

WRITE $(6,30)$

$\operatorname{READ}\left(5,{ }^{*}\right) \mathrm{TTIME}$

ELSEIF (IRESP .EQ. 2) THEN

$\operatorname{WRITE}(6,10)$

$\operatorname{READ}(5, *)$ X0,XOPRIME

WRITE $(6,22)$

$\operatorname{READ}\left(5,{ }^{*}\right) \mathrm{FREQ}$

OMEGAN $=2 .{ }^{*} \mathrm{PI} * \mathrm{FREQ}$

WRITE $(6,21)$

$\operatorname{READ}(5, *)$ SMASS

WRITE $(6,15)$

$\operatorname{READ}\left(5,{ }^{*}\right) \mathrm{CEE}$

CALL FORCEREAD !get the voltage-time history

call responseread !get the acoustic feedback signal

WRITE(6,50)TIMEREC

WRITE $(6,26)$

$\operatorname{READ}(5, *) \mathrm{DT}$

WRITE $(6,30)$

$\operatorname{READ}(5, *)$ TTIME

ENDIF

WRITE $(6,35)$

$\operatorname{READ}(5,36)$ ANS

IF(ANS .EQ. 'Y' .OR. ANS .EQ. 'y')THEN

IPRINT $=1$

ELSE

IPRINT $=0$

ENDIF

NTOTAL $=$ INT $($ TTIME/DT $)+2$

npts $=$ ntotal +1

IF(NTOTAL .GT. M-1)THEN

WRITE $(6,55)(\mathrm{M}-1)^{*} \mathrm{DT}$

NTOTAL $=$ M-1

ENDIF

RETURN

5 FORMAT(/,5X,'RESPONSE MENU: ',/,

*7X,'FREE VIBRATION (1)',/,

*7X,'ARBITRARY FORCED RESPONSE (2)',/,

*5X,'ENTER CHOICE : '\$)

10 FORMAT(/,5X,'ENTER INITIAL CONDITIONS, X0 AND XOPRIME :',S)

15 FORMAT(5X, 'ENTER DAMPING RATIO

20 FORMAT(5X, 'ENTER EXCITATION FREQUENCY :'\$)

21 FORMAT(5X, 'ENTER SYSTEM MASS : 'S)

22 FORMAT(5X, 'ENTER NATURAL FREQUENCY (HERTZ) : '\$)

23 FORMAT(5X, 'ENTER ACCELERATION SCALE FACTOR : 'S)

25 FORMAT(5X, 'ENTER \# PTS IN CYCLE OF HIGHEST FREQ. : ',S)

26 FORMAT(5X, 'ENTER DELTA T : 'S)

30 FORMAT(5X, 'ENTER TOTAL TIME TO COMPUTE RESPONSE : ',S) 
35 FORMAT(5X, 'VIEW THE RESULTS (Y/N) [N]

36 FORMAT(A1)

50 FORMAT( 5X,'TOTAL TAU OF RECORD = ',F10.3)

55 FORMAT(/,5X,'ARRAY SPACE HAS LIMITED TIME TO : ',F10.5) END 


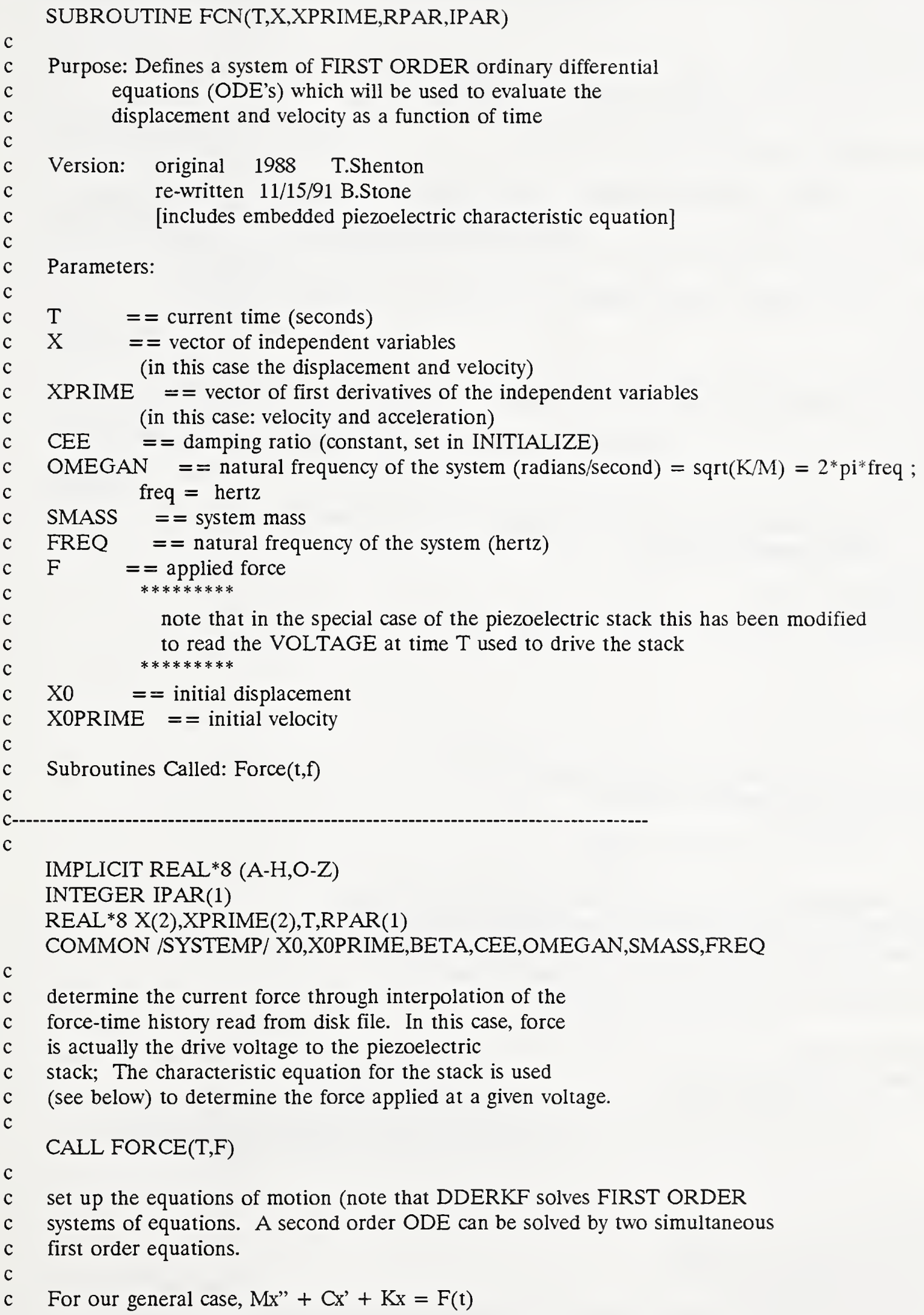


c

c

c

c

c

C

C

c

c

c

c

c

c

c

c

c

$\mathrm{c}$

c

$\mathrm{c}^{* * * * * * * *}$

$\mathrm{c}^{* * * * * * * *}$

c

c

c

$\mathrm{c}$

c

c

c

c

c

c

c

c

$$
\text { xprime(1) }=x(2)
$$$$
\text { xprime }(2)=- \text { omegan } * * 2 * x(1)
$$

$1 \quad-2 .{ }^{*}{ }^{*}{ }^{*}$ omegan $* x(2)$

2

c

c

\section{RETURN}

\section{END}

IMPLICIT REAL*8 (A-H,O-Z)

REAL*8 ACCEL $(4000)$

COMMON /CONTROL/ NPTS,DT,TTIME,NTOTAL,IPRINT,IRESP,M

!stiffness contribution !damping contribution $+\left(-375000 . * \mathrm{x}(1)+35.94 * \mathrm{~F}^{* *} 0.6597\right) /$ SMASS !forcing function $(\mathrm{F}=$ drive voltage $)$ $\mathrm{l} x=$ piezoelectric stack expansion (displacement) 
COMMON /SYSTEMP/ X0,XOPRIME,BETA,CEE,OMEGAN,SMASS,FREQ

COMMON /EARTHQ/ ACCEL,NACCEL,ADT,TIMEREC,AG

IF (IRESP .EQ. 1) THEN

$\mathrm{c}$

$\mathrm{c}$

$\mathrm{c}$

$$
\begin{aligned}
& \mathrm{F}=0.0 \\
& \text { ELSEIF (IRESP .EQ. 2) THEN }
\end{aligned}
$$

$\mathrm{c}$ value of the current force is needed:

determine applied force for this time step. Note that if the solution time step does not coincide with the time step in the forcing function record then an interpolated

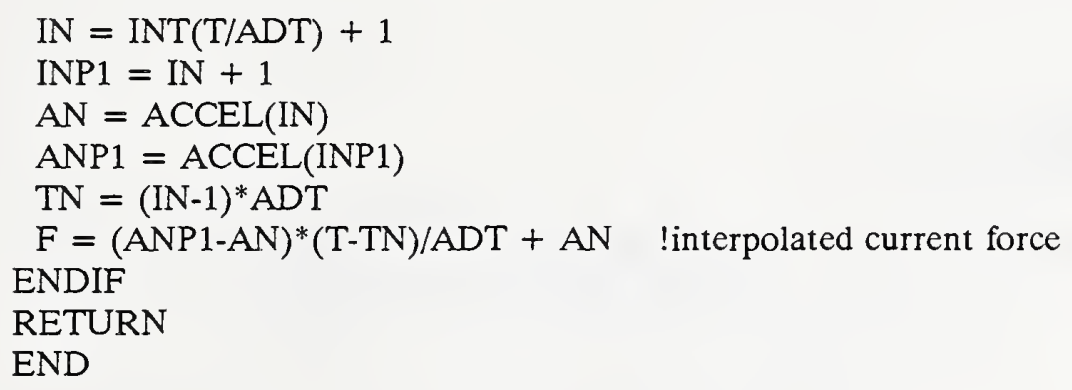




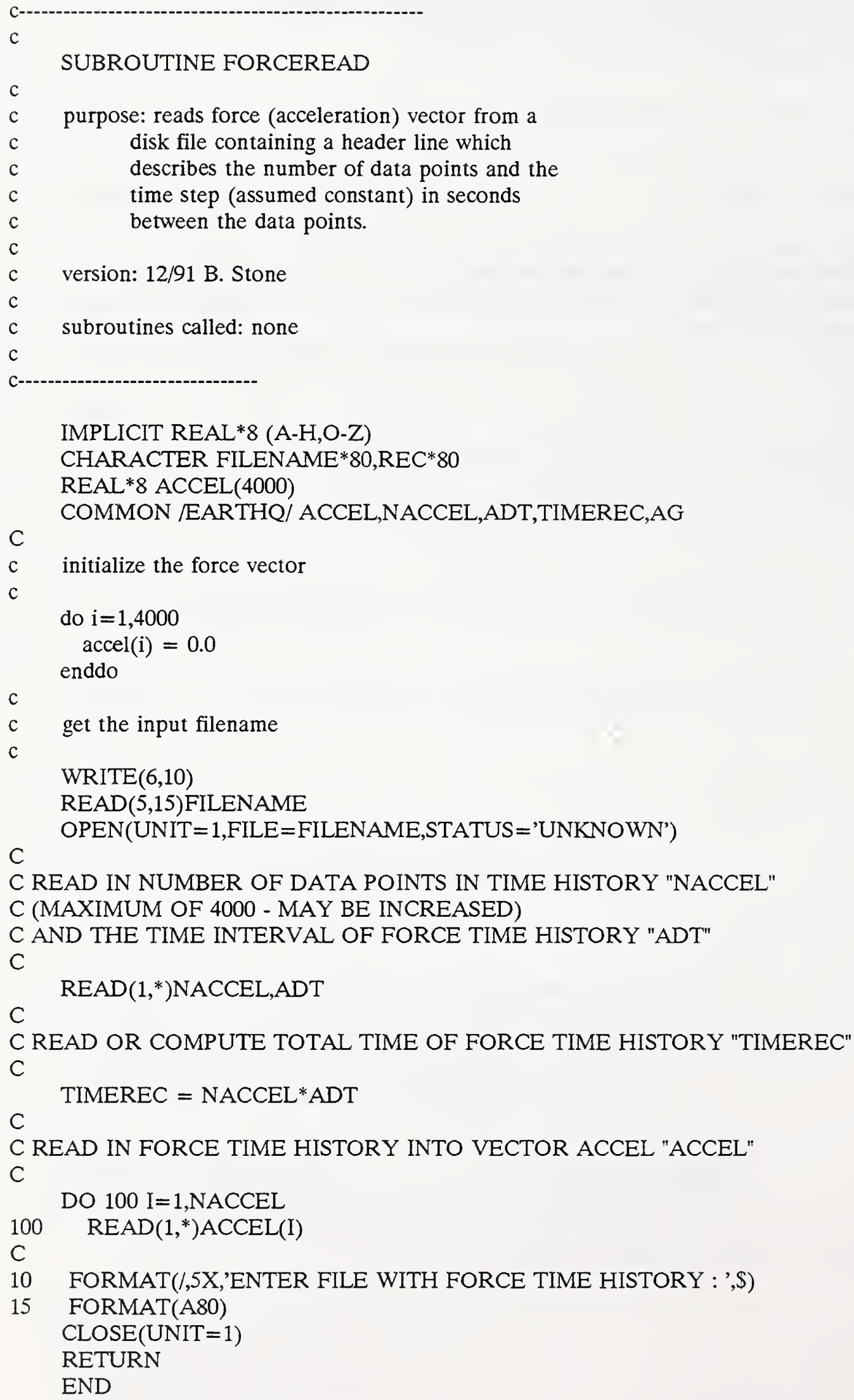


subroutine responseread

c

purpose: reads sensor test data representing HSILS response to a drive voltage pulse. This must be contained in a disk file containing a header line which describes the number of data points and the time step (assumed constant) in seconds between the data points.

version: $12 / 91 \mathrm{~B}$. Stone

subroutines called: none

c c-

$\mathrm{C}$

IMPLICIT REAL*8 (A-H,O-Z)

CHARACTER FILENAME*80,REC* 80

REAL*8 ACCEL(4000),signal(4000),data6(4000)

COMMON /EARTHQ/ ACCEL,NACCEL,ADT,TIMEREC,AG

common/sensordata/signal,nsignalpts,sig_time_step,data6

c initialize the sensor data vector:

c

do $\mathrm{i}=1,4000$

$\operatorname{signal}(\mathrm{i})=0.0$

enddo

c

get the sensor data filename

c

type *,'Please enter the filename containing'

type *,'the acoustic sensor data:'

READ $(5,15)$ FILENAME

C

OPEN(UNIT=1,FILE=FILENAME,STATUS='UNKNOWN')

C READ IN NUMBER OF DATA POINTS IN TIME HISTORY "NACCEL"

C (MAXIMUM OF 4000 - MAY BE INCREASED)

$C$ AND THE TIME INTERVAL OF FORCE TIME HISTORY "ADT"

C

$\operatorname{READ}\left(1,{ }^{*}\right)$ nsignalpts,sig_time_step

C

C READ OR COMPUTE TOTAL TIME OF FORCE TIME HISTORY "TIMEREC"

C

c $\quad$ TIMEREC $=$ NACCEL $* A D T$

C

C Read in the sensor data:

$\mathrm{C}$

DO $I=1$, nsignalpts

$$
\begin{array}{ll}
\operatorname{READ}\left(1,{ }^{*}\right) \text { signal }(\mathrm{i}) & \\
\operatorname{signal}(\mathrm{i})=-1 .{ }^{*} \operatorname{signal}(\mathrm{i}) & \text { !invert the sensor data } \\
\text { data6 }(\mathrm{i})=\text { sig_time_step }(\mathrm{i}-1) & \text { !elapsed time (seconds) }
\end{array}
$$


enddo

C

15 FORMAT(A80)

CLOSE(UNIT $=1$ )

RETURN

END 


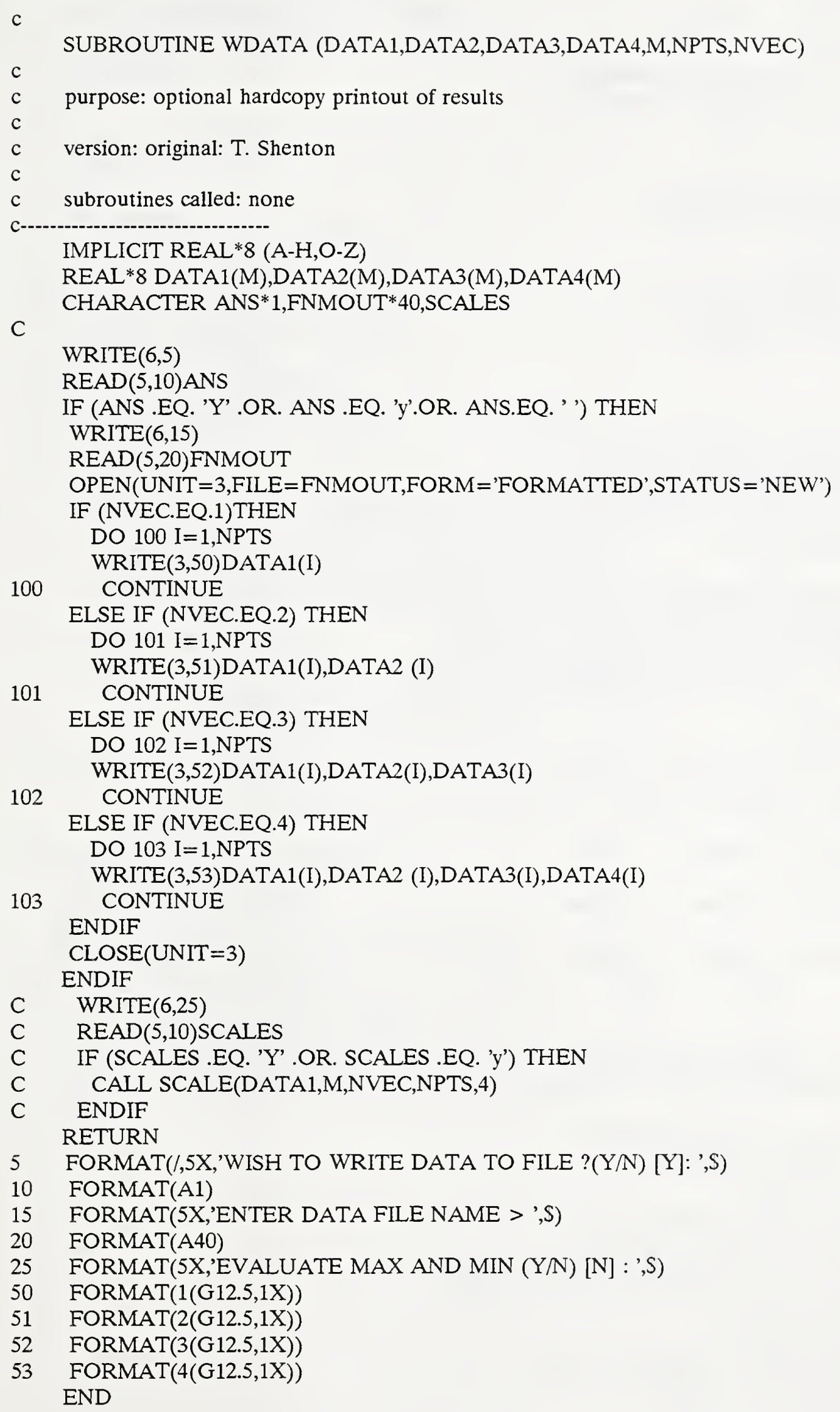




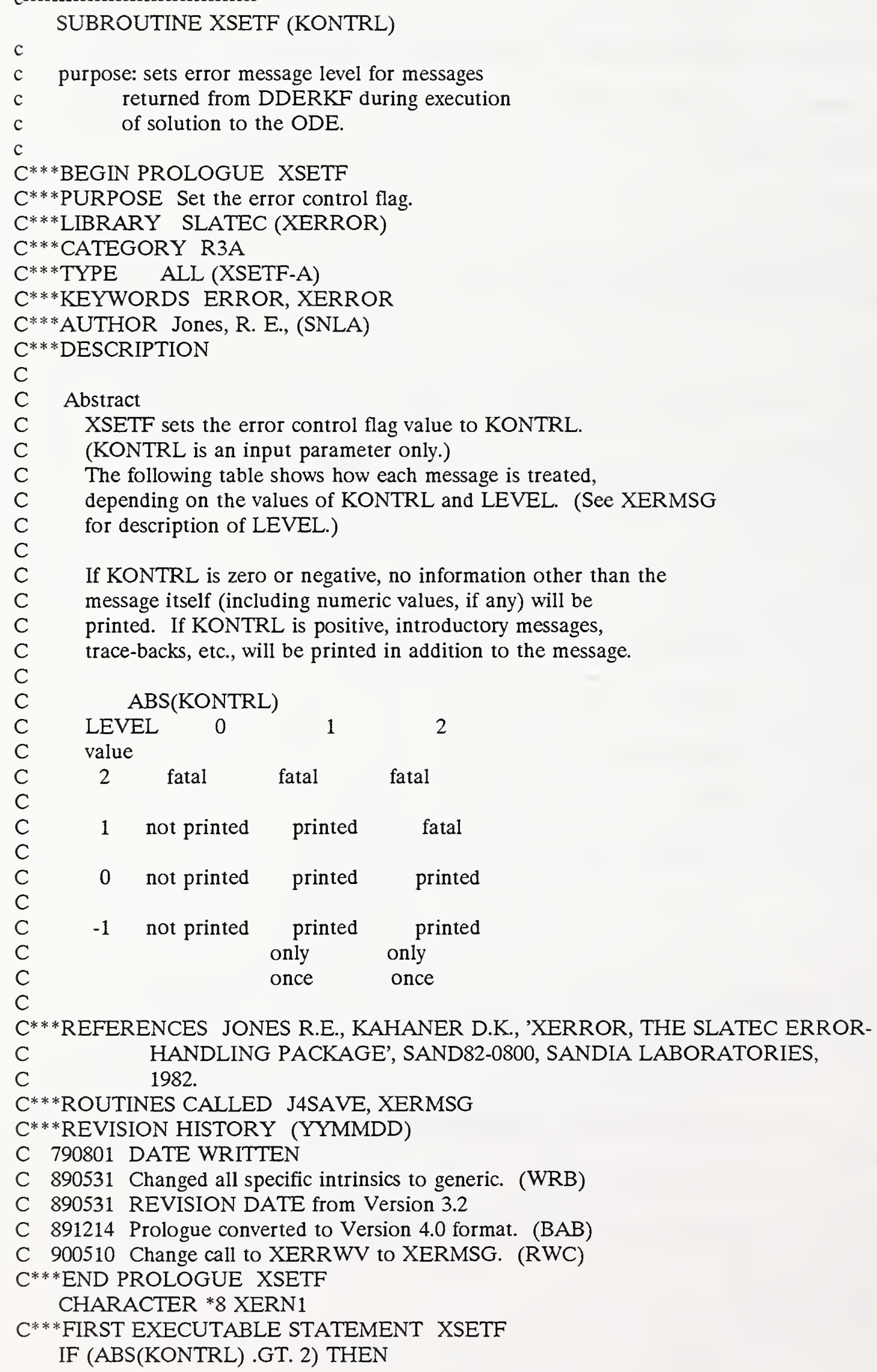


WRITE (XERN1, '(I8)') KONTRL

CALL XERMSG ('SLATEC', 'XSETF',

'INVALID ARGUMENT =' // XERN1, 1, 2)

RETURN

ENDIF

$\mathrm{C}$

JUNK $=$ J4SAVE(2,KONTRL,.TRUE.)

RETURN

END

*DECK XSETUN

SUBROUTINE XSETUN (IUNIT)

$\mathrm{C}^{* * * B E G I N}$ PROLOGUE XSETUN

$C^{* * * P U R P O S E}$ Set output file to which error messages are to be sent.

C***LIBRARY SLATEC (XERROR)

C***CATEGORY R3B

C***TYPE ALL (XSETUN-A)

$C^{* * *}$ KEYWORDS ERROR, XERROR

$C^{* * *}$ AUTHOR Jones, R. E., (SNLA)

C***DESCRIPTION

C

C Abstract

C XSETUN sets the output file to which error messages are to

C be sent. Only one file will be used. See XSETUA for

C how to declare more than one file.

C

C Description of Parameter

C --Input--

C IUNIT - an input parameter giving the logical unit number

C to which error messages are to be sent.

C

$C^{* * *}$ REFERENCES JONES R.E., KAHANER D.K, 'XERROR, THE SLATEC ERROR-

C HANDLING PACKAGE', SAND82-0800, SANDIA LABORATORIES,

C 1982

C***ROUTINES CALLED J4SAVE

C***REVISION HISTORY (YYMMDD)

C 790801 DATE WRITTEN

C 861211 REVISION DATE from Version 3.2

C 891214 Prologue converted to Version 4.0 format. (BAB)

C***END PROLOGUE XSETUN

C***FIRST EXECUTABLE STATEMENT XSETUN

JUNK = J4SAVE(3,IUNIT,.TRUE.)

JUNK $=$ J4SAVE $(5,1$, TRUE. $)$

RETURN

END 

Appendix C

Electrical Schematics

for

HSILS Onboard Microcontroller and Pulse Power Subsystems 

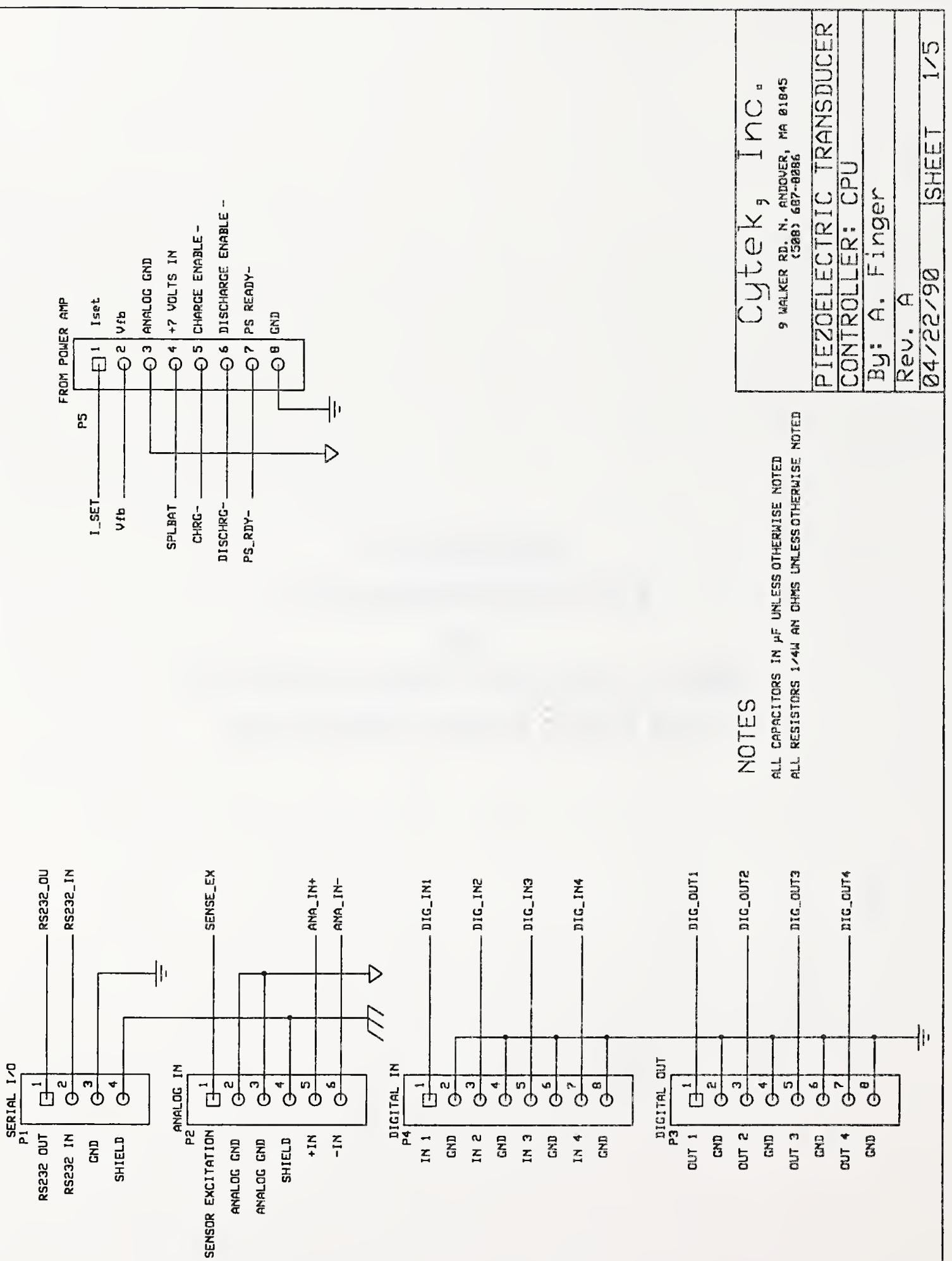


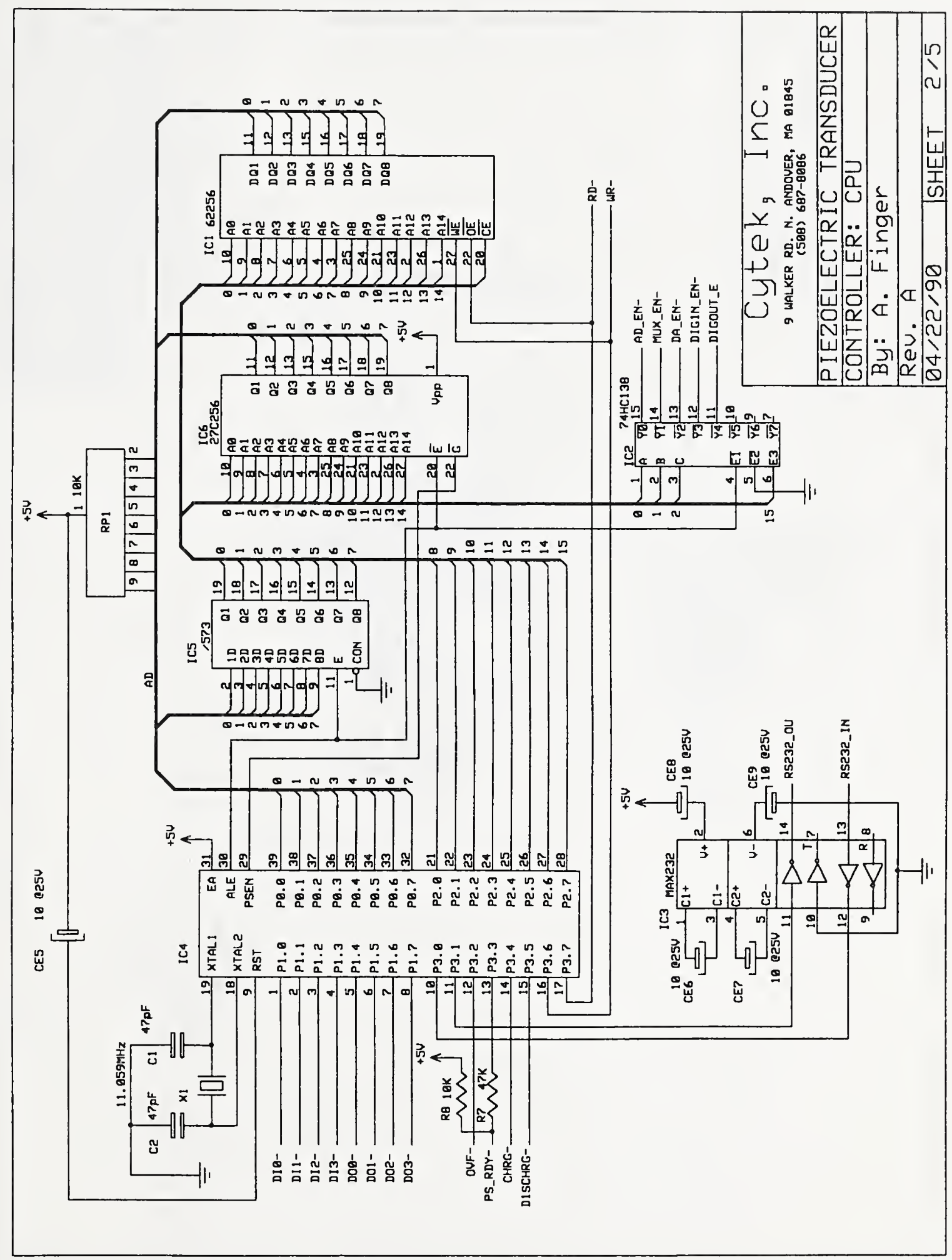



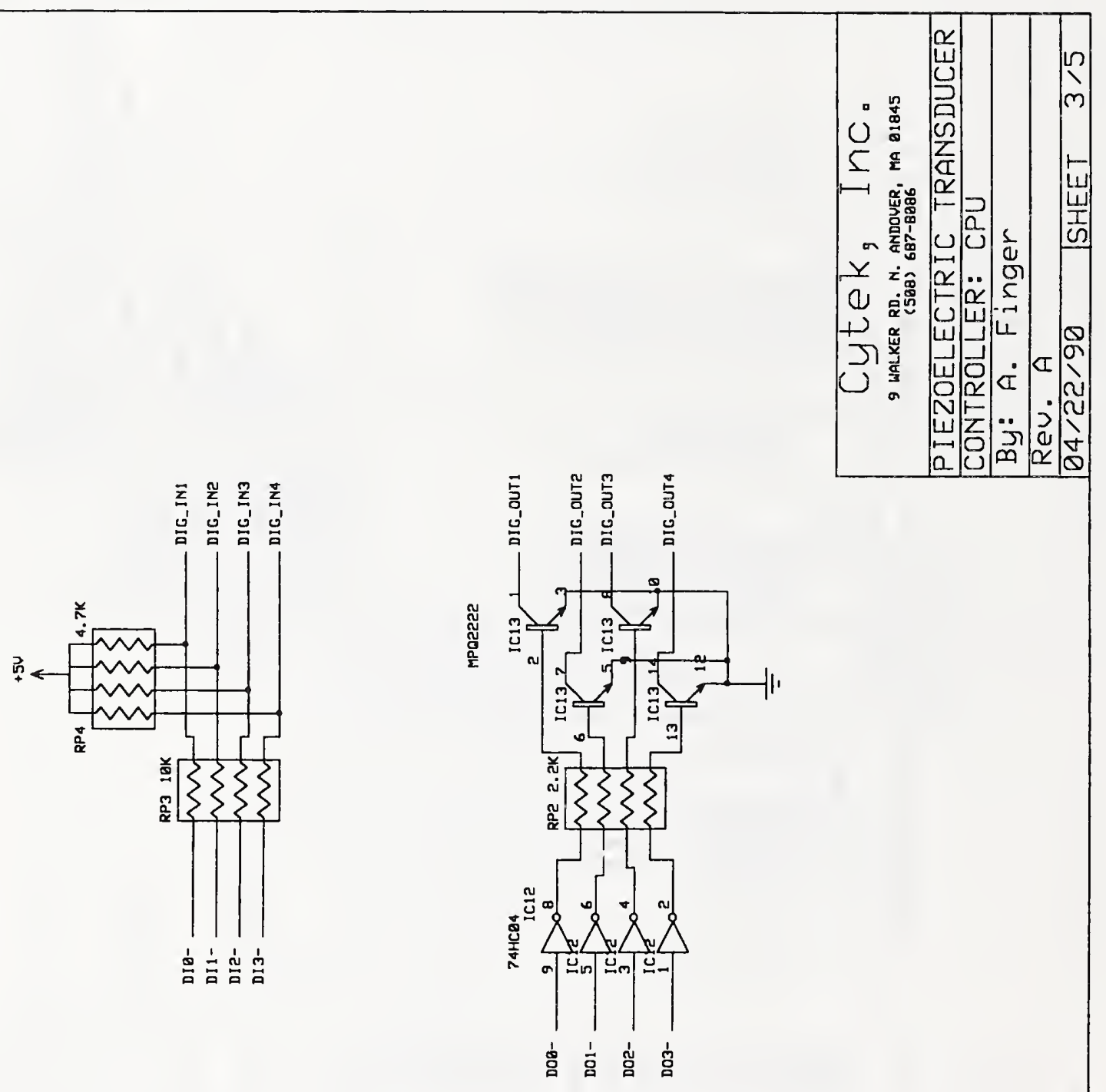


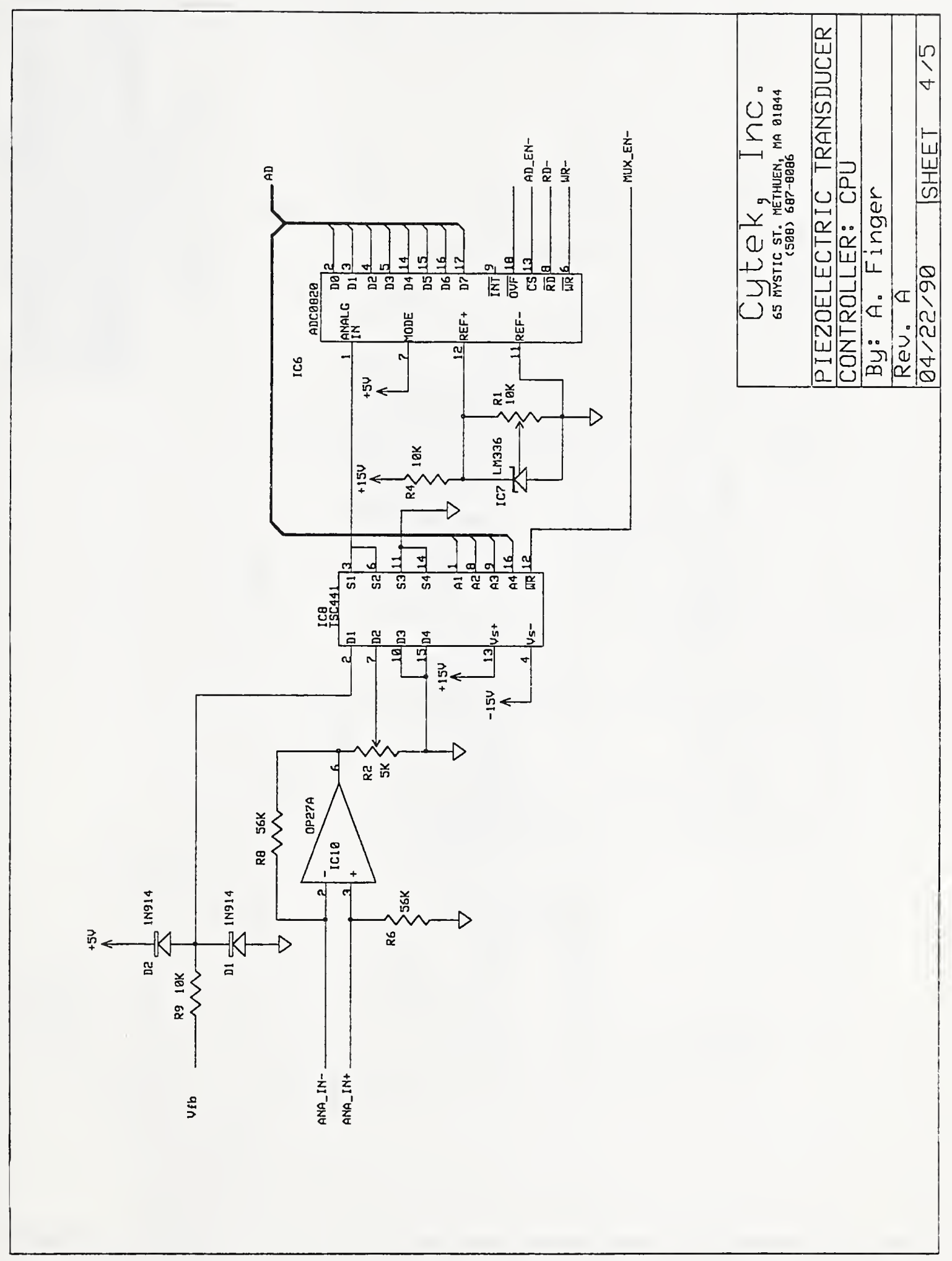




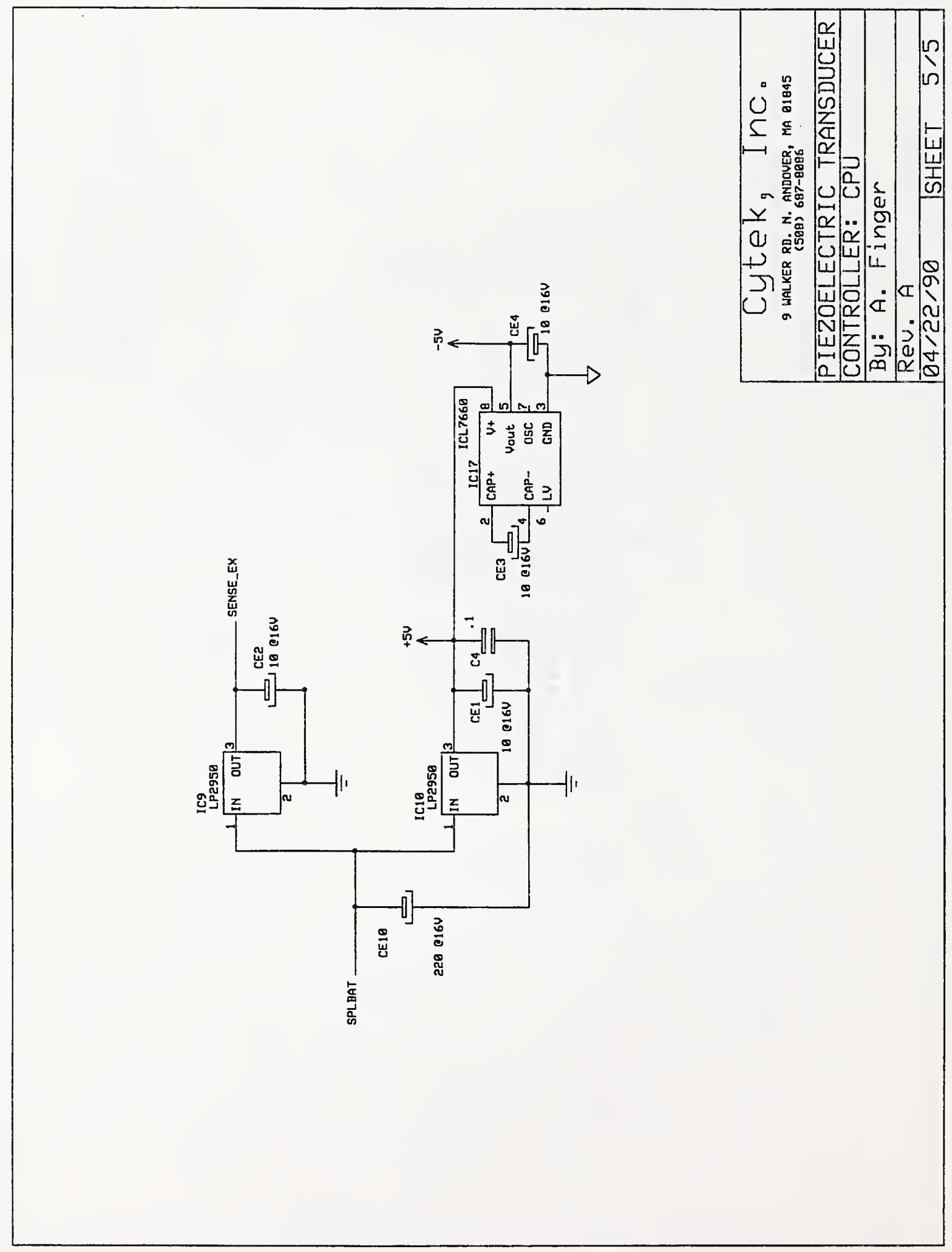




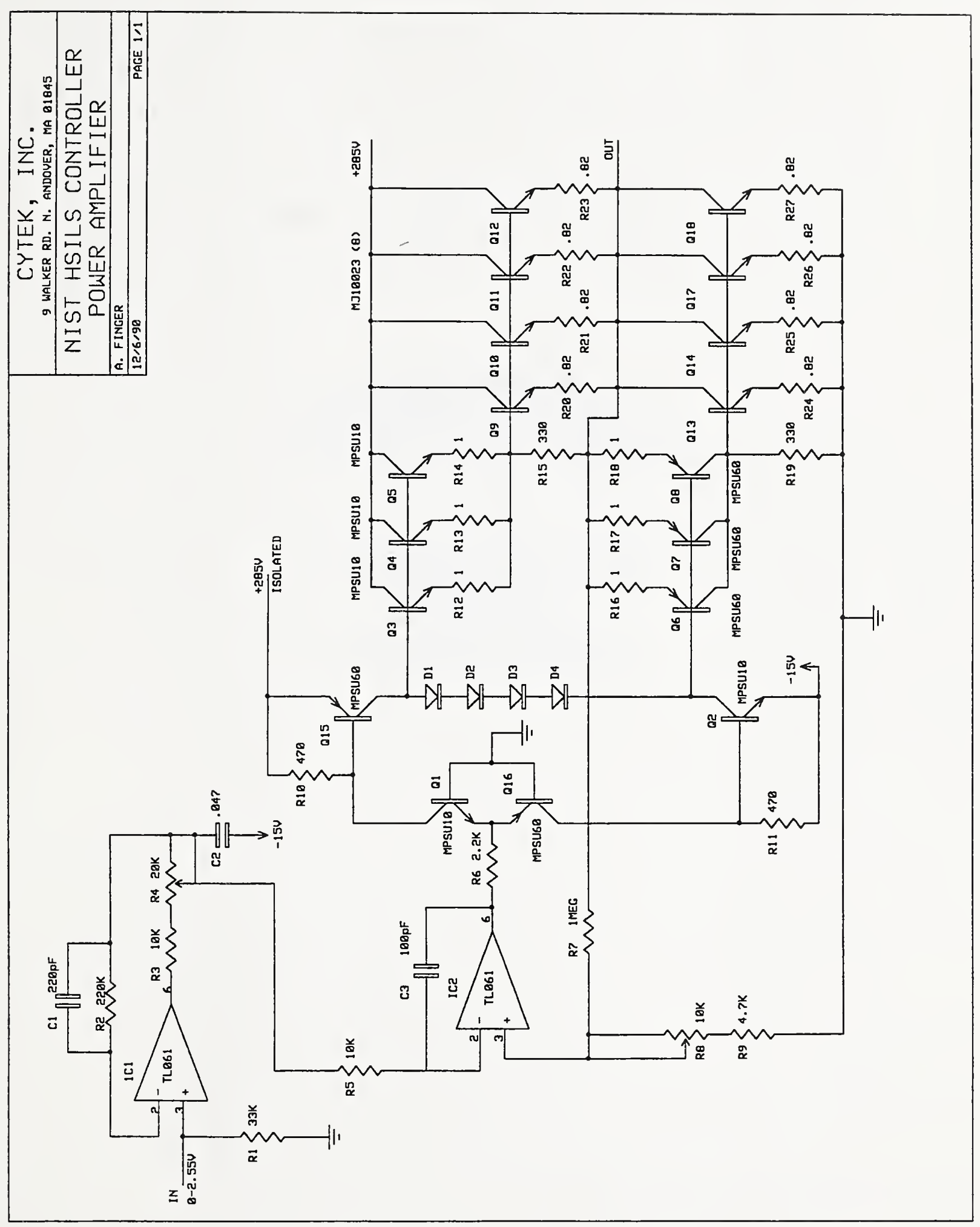





\section{Appendix D \\ HSILS Driver Software}

Developed Under Contract by:

Cytek, Inc.

9 Walker Road

North Andover, MA 01845 


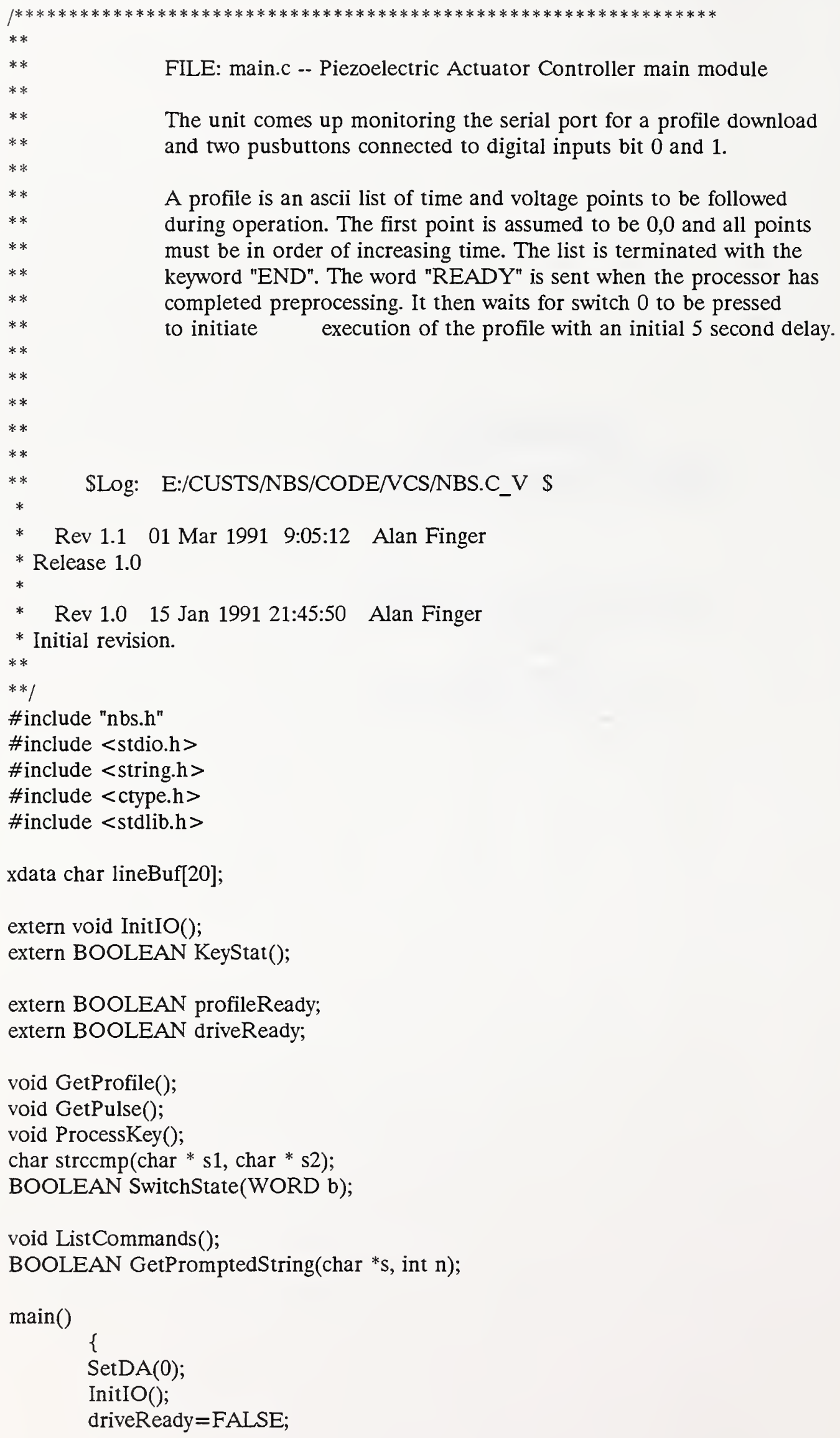

FILE: main.c -- Piezoelectric Actuator Controller main module

The unit comes up monitoring the serial port for a profile download and two pusbuttons connected to digital inputs bit 0 and 1 .

A profile is an ascii list of time and voltage points to be followed during operation. The first point is assumed to be 0,0 and all points must be in order of increasing time. The list is terminated with the keyword "END". The word "READY" is sent when the processor has completed preprocessing. It then waits for switch 0 to be pressed to initiate execution of the profile with an initial 5 second delay.

* Rev 1.1 01 Mar 1991 9:05:12 Alan Finger

* Release 1.0

*

* Rev 1.0 15 Jan 1991 21:45:50 Alan Finger

* Initial revision.

**

$* * /$

\#include "nbs.h"

\#include $<$ stdio.h $>$

\#include <string.h $>$

\#include <ctype. $h>$

\#include <stdlib.h>

xdata char lineBuf[20];

extern void InitIO();

extern BOOLEAN KeyStat();

extern BOOLEAN profileReady;

extern BOOLEAN driveReady;

void GetProfile();

void GetPulse();

void ProcessKey();

char strccmp (char * s1, char * s2);

BOOLEAN SwitchState(WORD b);

void ListCommands();

BOOLEAN GetPromptedString(char *s, int $\mathrm{n}$ );

main()

\{

$\operatorname{SetDA}(0)$;

InitIO();

driveReady=FALSE; 


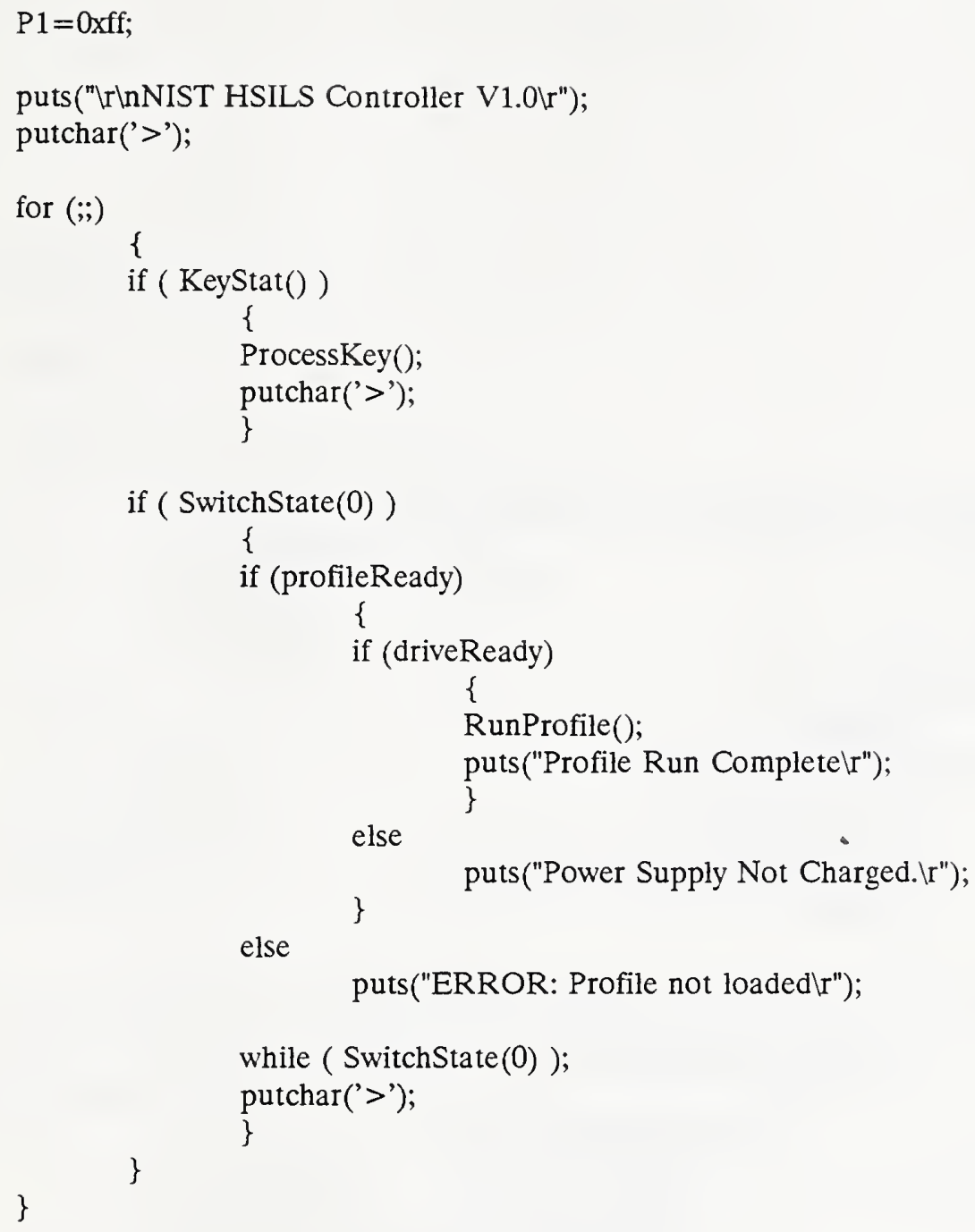




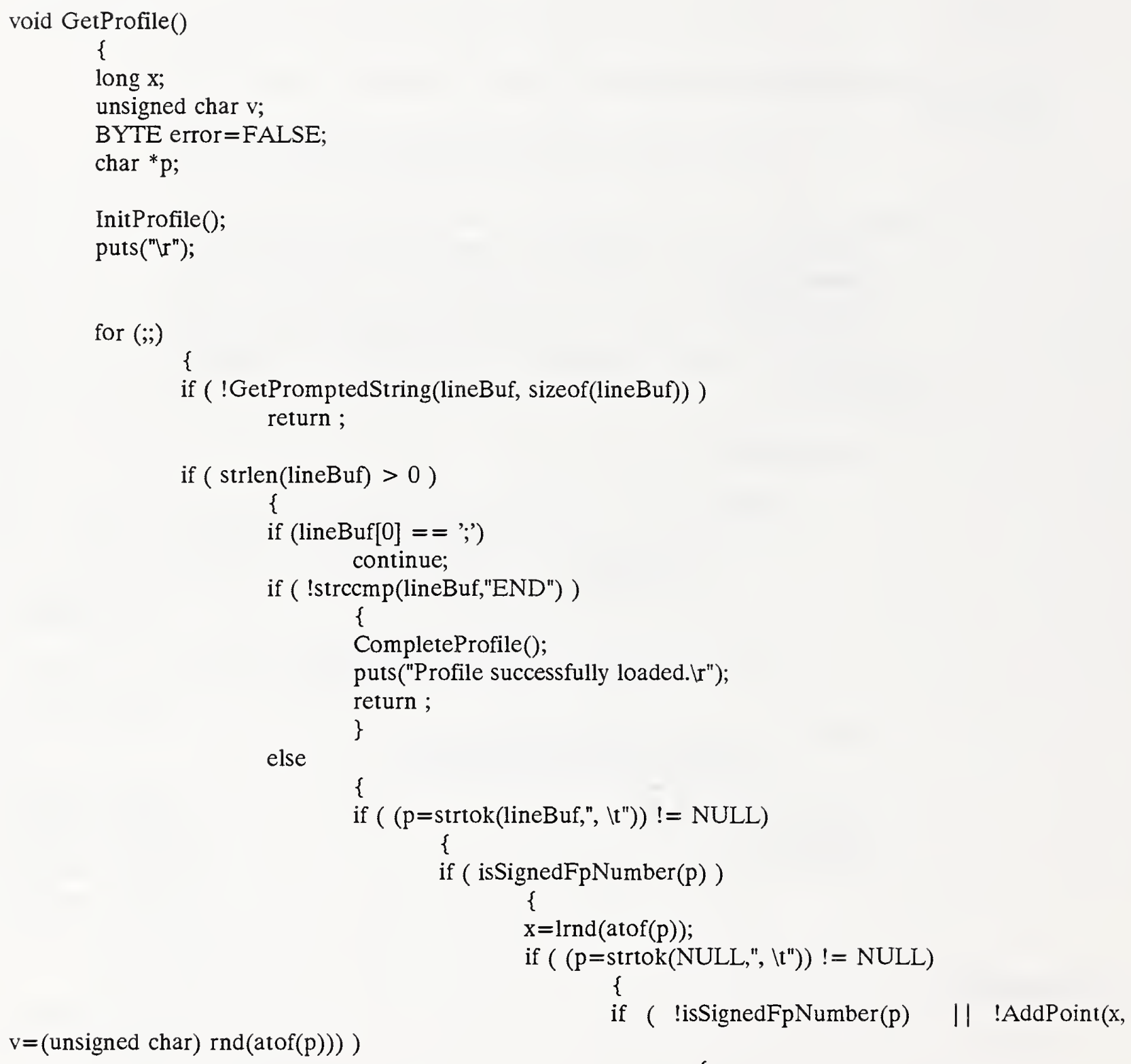

BadLine:

ignored $\left.r^{\prime \prime}\right)$;

sizeof(lineBuf)) )

puts("Invalid line syntax. Rest of load do

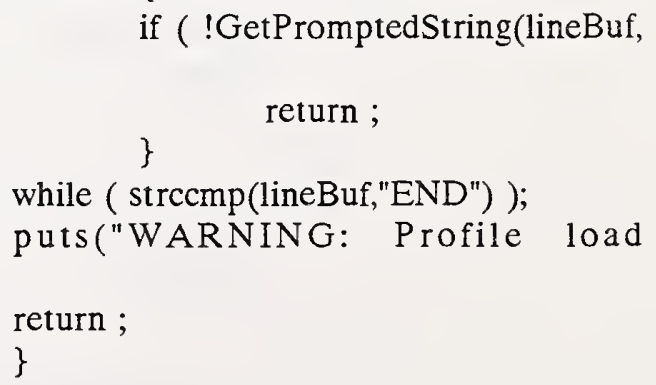

sizeof(ineBuf))

unsuccessfullr"); 


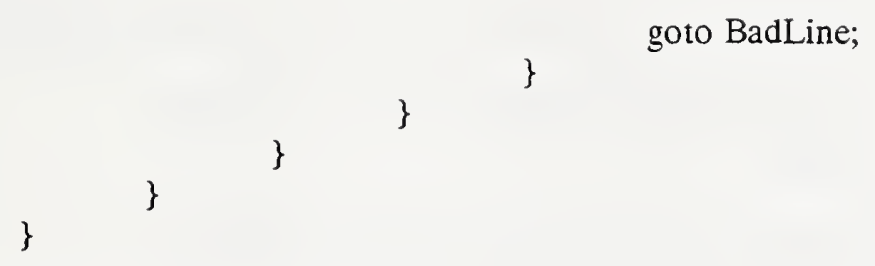

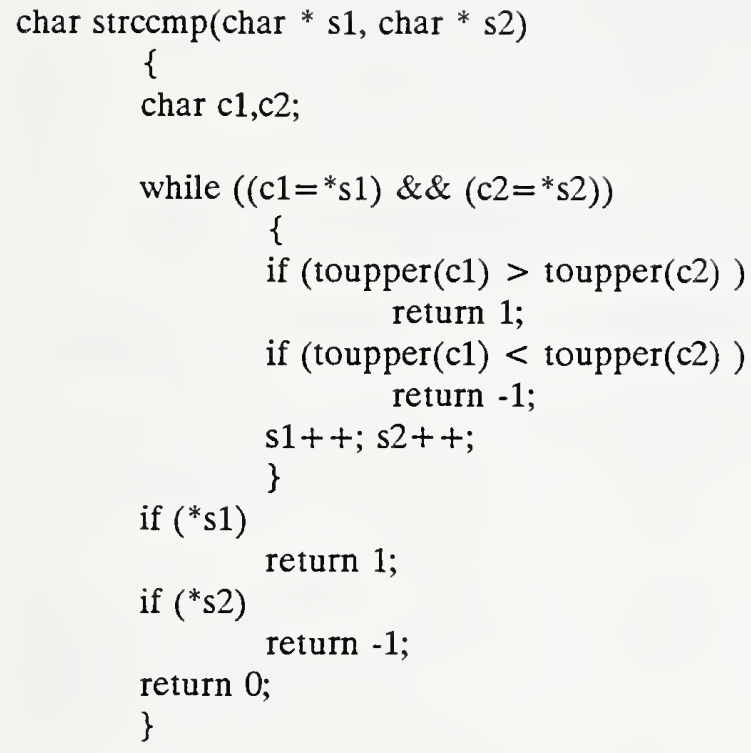

BOOLEAN isnumber(char *s, BOOLEAN negAllowed, BOOLEAN fpAllowed)

\{ BOOLEAN dpFound=FALSE;

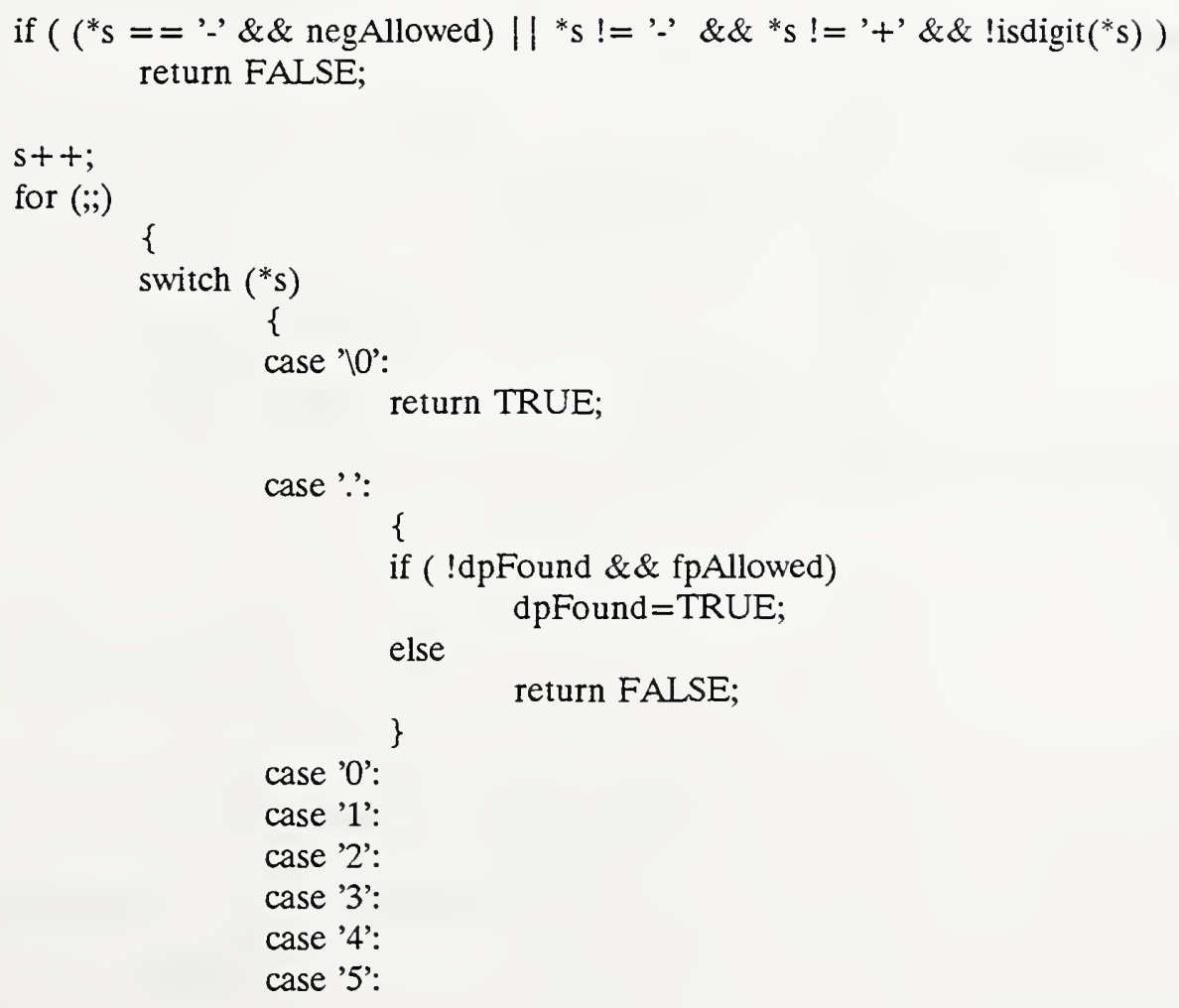




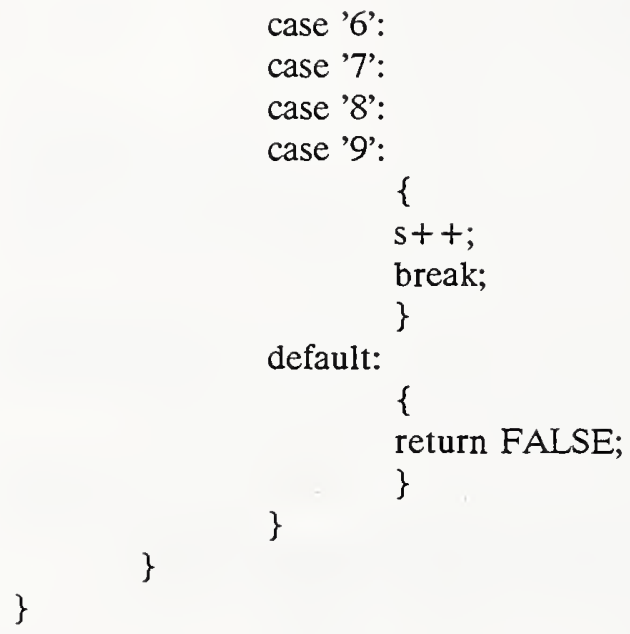


FILE: act.c -- Piezoelectric Actuator Controller actuator control module.

A 'profile' is entered as a series of time-voltage pairs. The first is always assumed to be 0,0 . Each subsequent pair causes the required current to reach that point to be calculated. An empty line terminates entry. The last point must have a zero voltage.

\section{SLog: E:/CUSTS/NBS/CODE/VCS/ACT.C_V S}

$*$

* Rev 1.1 01 Mar 1991 9:05:38 Alan Finger

* Release 1.0

*

* Rev 1.0 15 Jan 1991 21:45:52 Alan Finger

* Initial revision.

$* *$

$* * /$

\#include $<$ stdio.h $>$

\#include < math.h $>$

\#include $<$ stdlib.h $>$

\# include "nbs.h"

/* The following are machine Cycles from profile.asm */

\#define SETUP CYCLES

\#define LOOP CYYCLES

4

\#define POINT_CYCLES

2

\#define MIN_CYCLES

19

(SETUP_CYCLES+POINT_CYCLES+LOOP_CYCLES)

\#define CYCLE TIME

\#define SETUP TIME

1.085

(SETUP_CYCLES*CYCLE_TIME)

I* microseconds/cycle */

\#define MIN TIME

\#define LOOP_TIME

(MIN_CYCLES*CYCLE TIME)

(LOOP_CYCLES*CYCLE_TIME)

\#define PULSE_LOOP_CYCLES

\#define MIN_PULLSE_ČYCLES

9

\#define PULSE LOOP TIME

PULSE LOOP CYCLES+2

\#define MIN_PŪLSE_TIME $(9 *$ CYCLE TIM $\bar{M})$

(MIN_PULSE_CYCLES*CYCLE_TIME)

struct_points

\{

BYTE loopCount;

char Yincr;

\};

\#define MAXPOINTS ( 16384/sizeof(struct_points))

xdata struct_points point[MAXPOINTS];

BOOLEAN profileReady; 


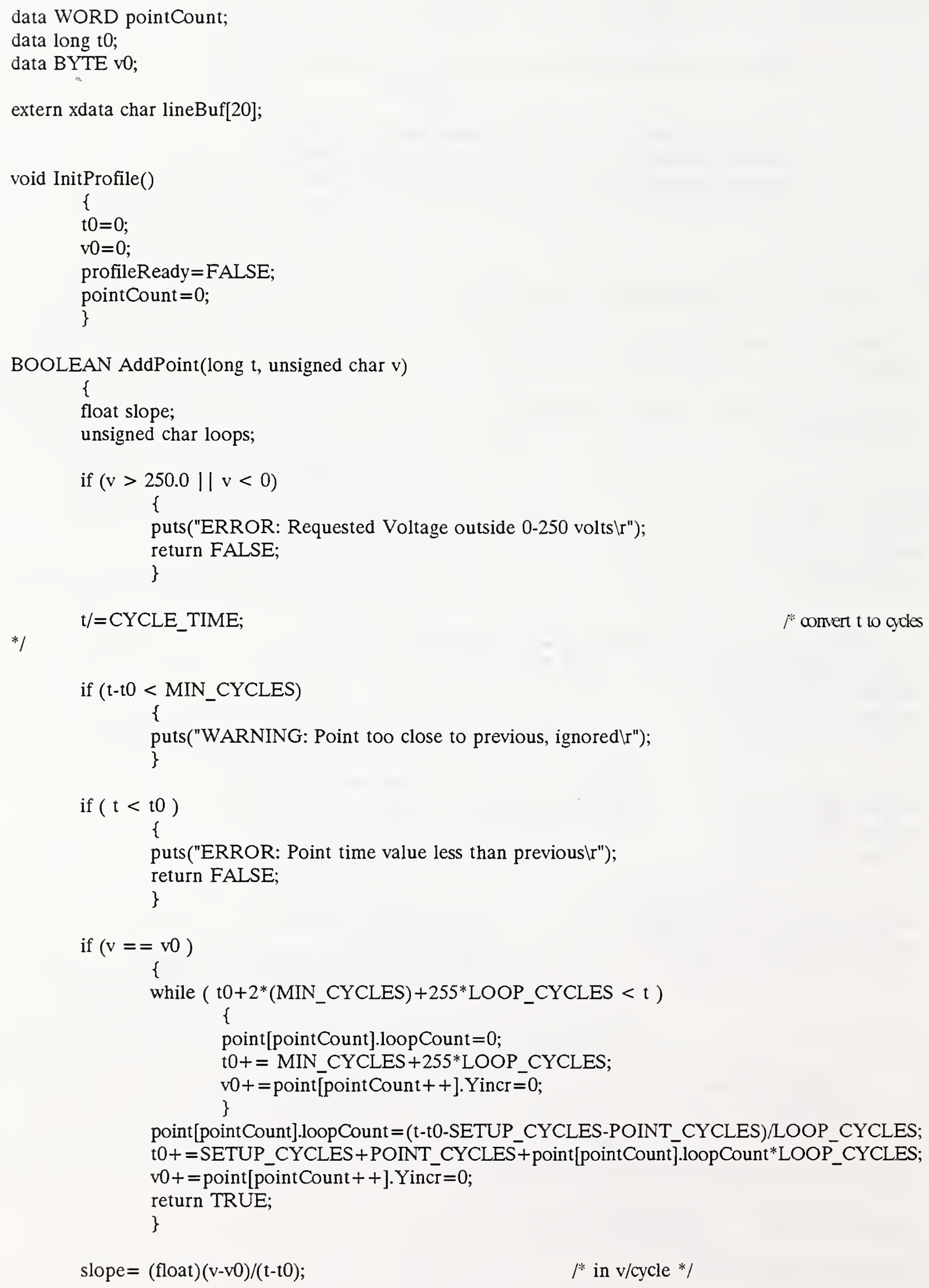




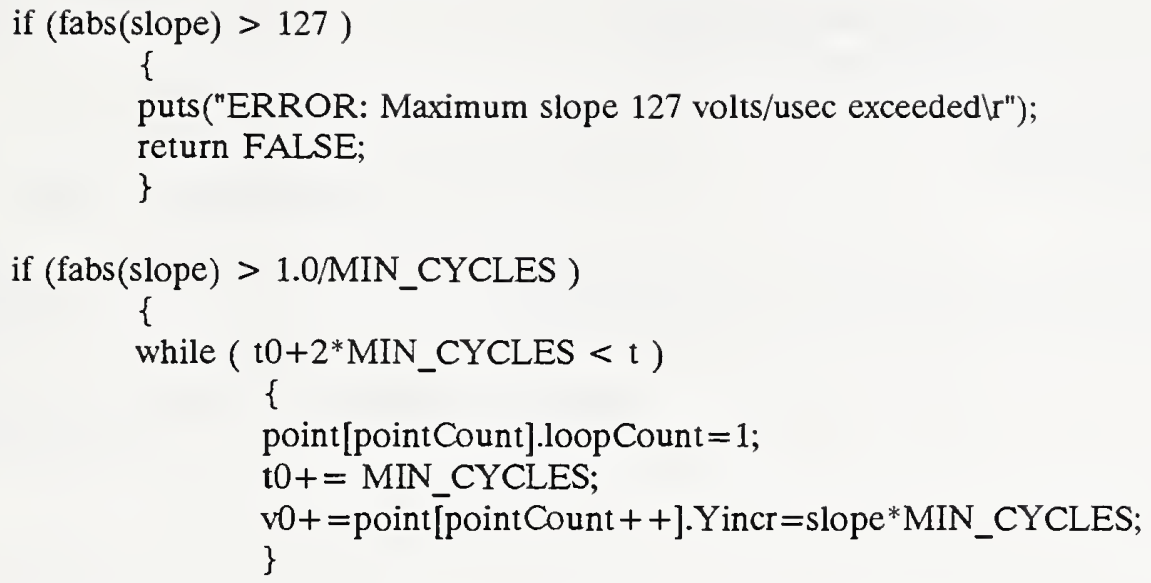

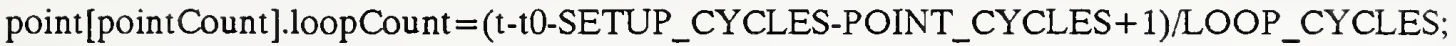

t0+=SETUP_CYCLES +PŌINT_CYCLES + point[pointCount].loopCount ${ }^{*}$ LOOP_CYCLES; $\mathrm{v} 0+=$ point [point Count ++ ]. Yincr $=\mathrm{v}-\mathrm{v} 0$;

else

$$
\text { \} }
$$

\{

$10 \circ \mathrm{ps}=(\mathrm{unsigned} \mathrm{char}) \quad((\mathrm{rnd}(\mathrm{fabs}(1 / \mathrm{s} 10 \mathrm{pe}))$

-SETUP_CYCLES-POINT_CYCLES+1)/LOOP_CYCLES);

while $(v 0 \bar{l}=\mathrm{v}$ )

\{

point[pointCount].loopCount $=$ loops;

t0 $+=$ SETUP_CYCLES + POINT_CYCLES + loops*LOOP_CYCLES;

point [pointCount ++$]$.Yincr $=\operatorname{sgn}($ slope $)$;

v0 $+=\operatorname{sgn}($ slope);

\}

return TRUE;

\}

void CompleteProfile()

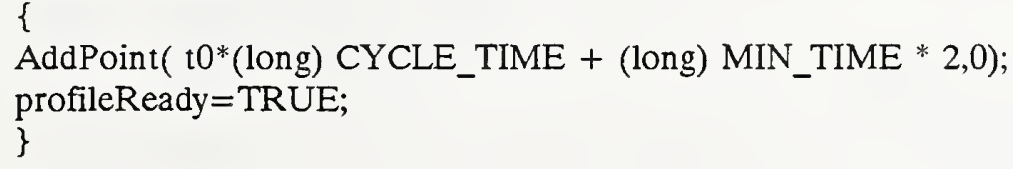

data unsigned pulseWidth;

data unsigned char pulseHeight;

void GetPulse()

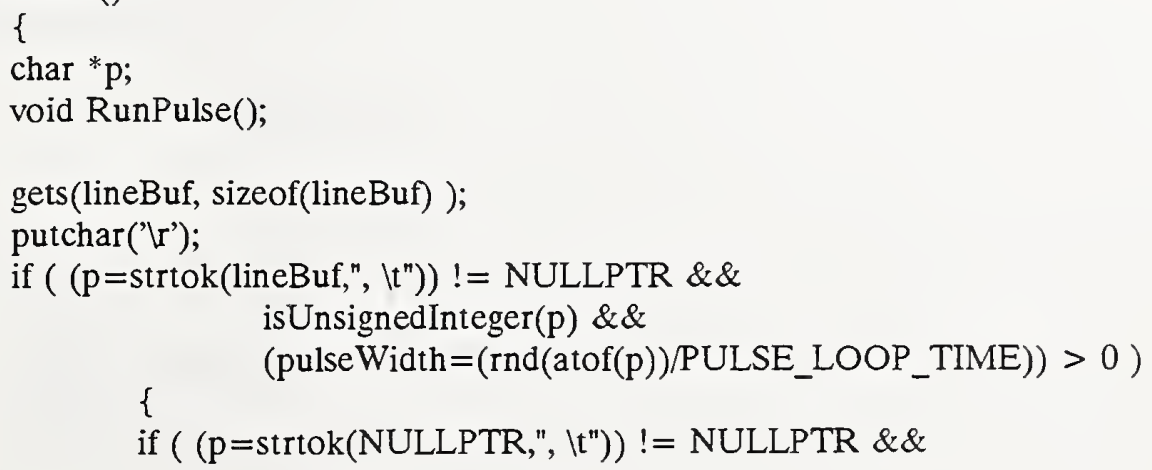




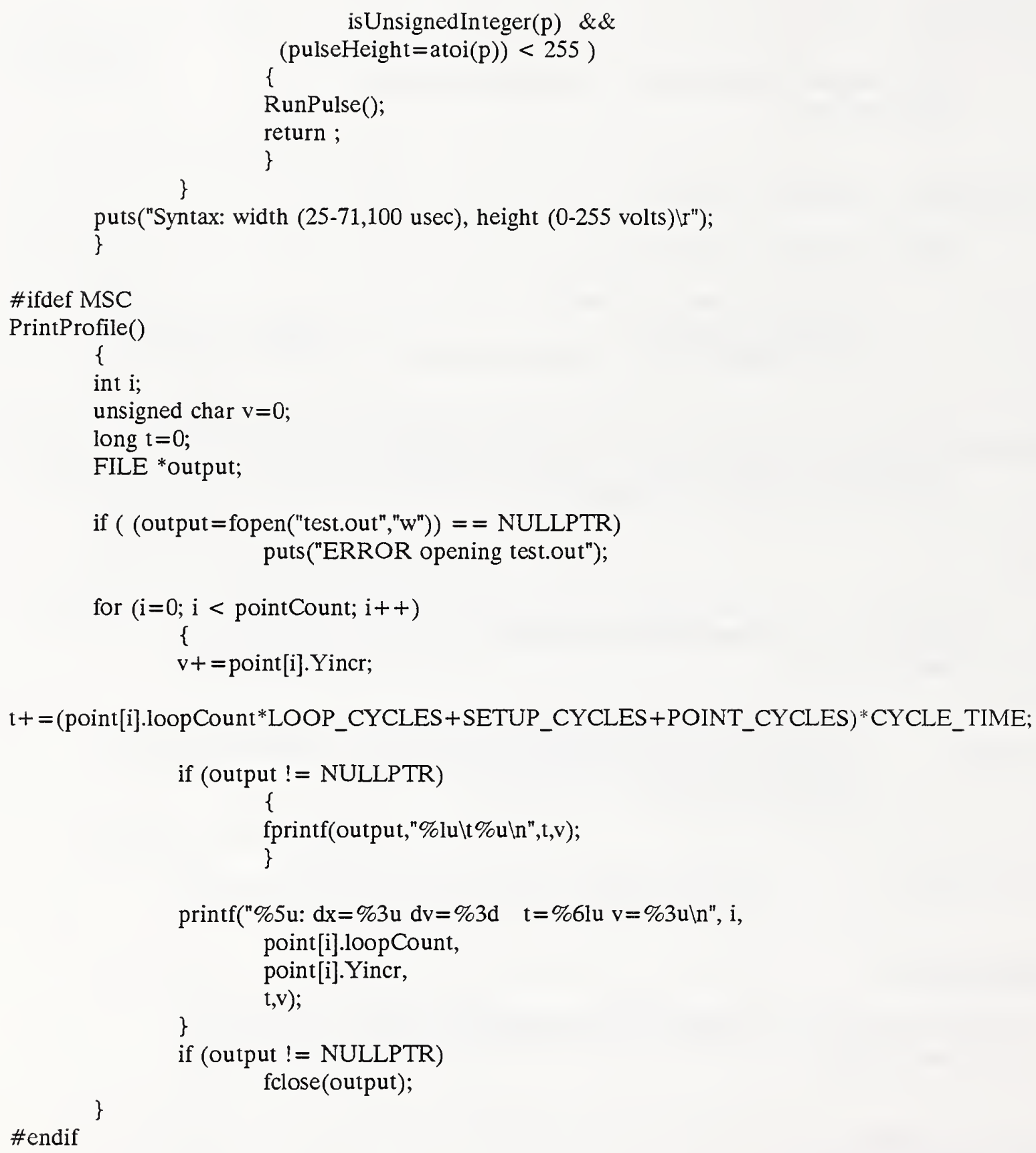




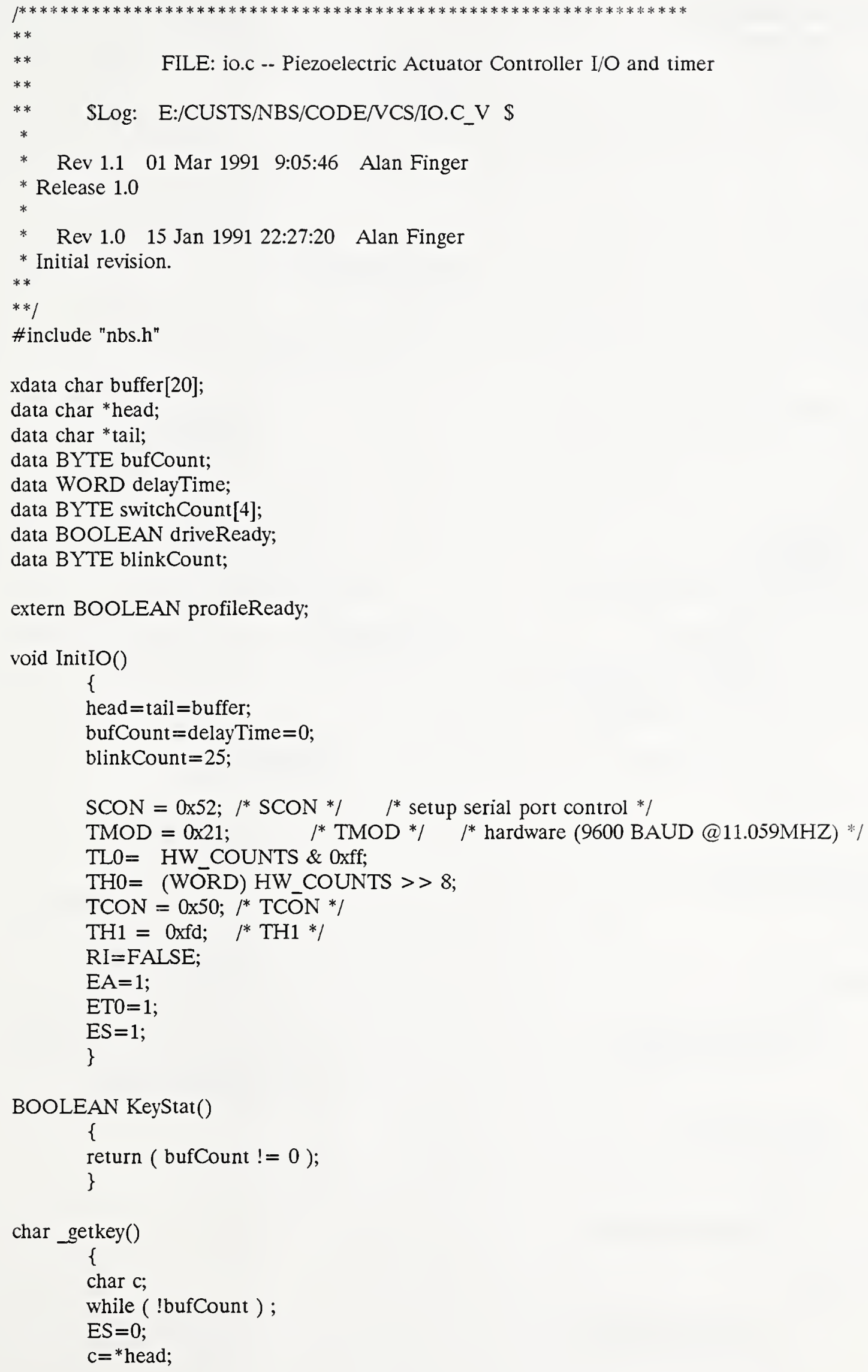

** SLog: E:/CUSTS/NBS/CODE/NCS/IO.C_V \$

* Rev 1.1 01 Mar 1991 9:05:46 Alan Finger

* Release 1.0

* Rev 1.0 15 Jan 1991 22:27:20 Alan Finger

* Initial revision.

$* *$

$* *$ /

\#include "nbs.h"

xdata char buffer[20];

data char *head;

data char *tail;

data BYTE bufCount;

data WORD delayTime;

data BYTE switchCount[4];

data BOOLEAN driveReady;

data BYTE blinkCount;

extern BOOLEAN profileReady;

void InitIO()

\{

head $=$ tail $=$ buffer;

bufCount $=$ delayTime $=0$;

blinkCount $=25$;

$\mathrm{SCON}=0 \times 52 ; l^{*} \mathrm{SCON} * / \quad l^{*}$ setup serial port control $* /$

TMOD $=0 \times 21 ; \quad / *$ TMOD */ $\quad / *$ hardware (9600 BAUD @11.059MHZ) */

$T L O=H W \_C O U N T S \&$ Oxf;

TH0 $=$ (WORD) HW_COUNTS $>>8$;

$\mathrm{TCON}=0 \times 50 ; / \mu^{*} \mathrm{TCON} * /$

$\mathrm{TH} 1=0 \mathrm{xfd} ; \quad{ }^{*} \mathrm{TH} 1 * /$

RI=FALSE;

$\mathrm{EA}=1$;

$\mathrm{ET} 0=1$

$\mathrm{ES}=1$

\}

BOOLEAN KeyStat()

\{ return ( bufCount $!=0$ );

\}

char_getkey()

\{

char c;

while ( !bufCount ) ;

$\mathrm{ES}=0$;

$\mathrm{c}=$ *head; 


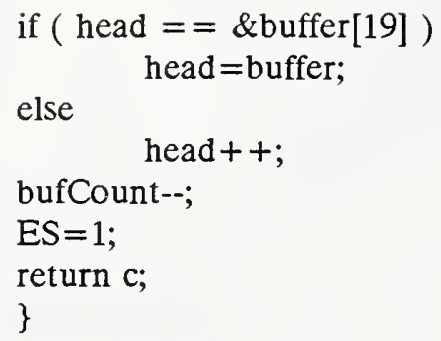

void timer0() interrupt 1 using 1

\{

BYTE i;

if $(!(\mathrm{P} 1 \& 1))$

\{

if (switchCount[0] $:=4$ )

switch Count $[0]++$;

\}

else

$$
\text { switch Count }[0]=0 \text {; }
$$

if $(!(P 1 \& 2))$

\{

driveReady=TRUE;

\}

else

$$
\{
$$$$
\text { driveReady }=\text { FALSE; }
$$$$
\text { \} }
$$ 


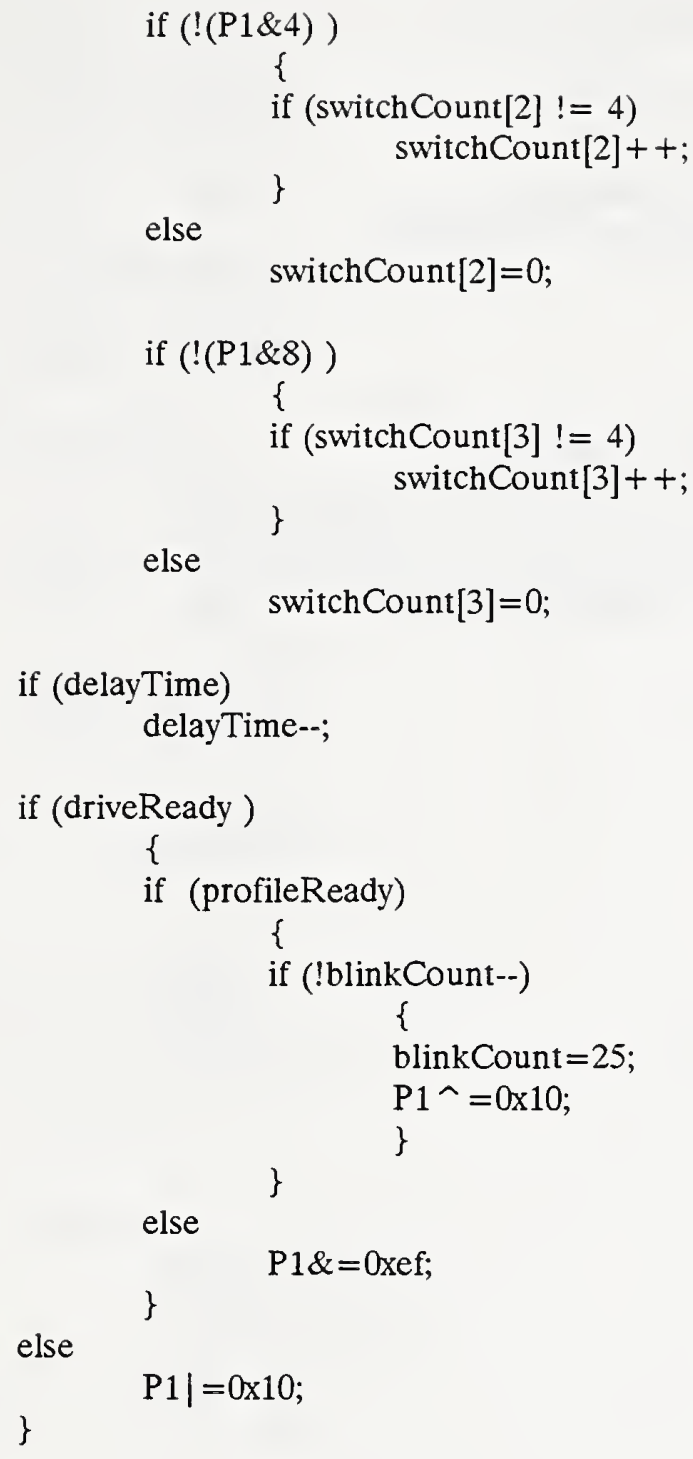




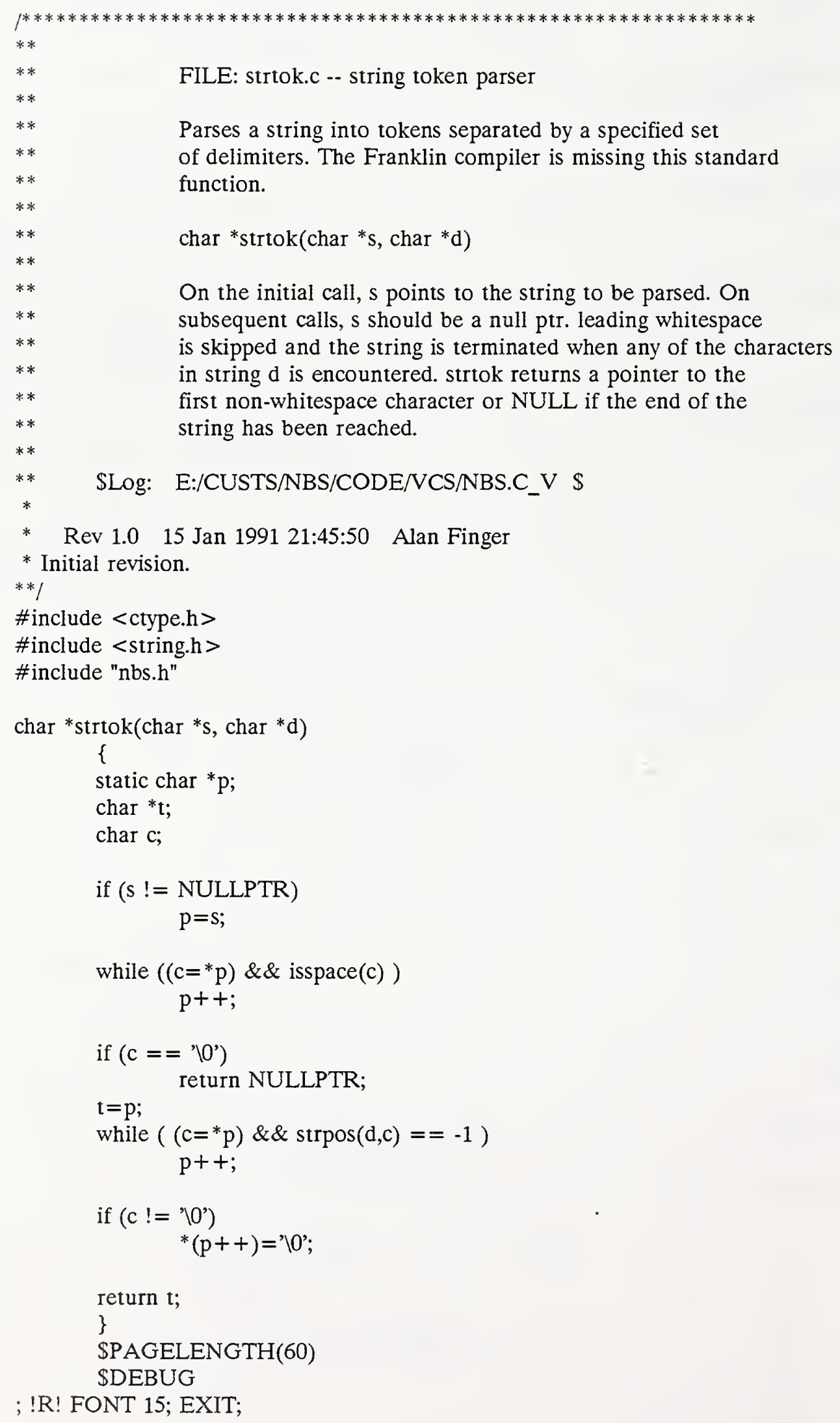


HSILS Controlier Profile Execution Module

Sinclude(c:|c51linclude|reg51.inc)

NAME PROFILE

DtoA EQU 8002h

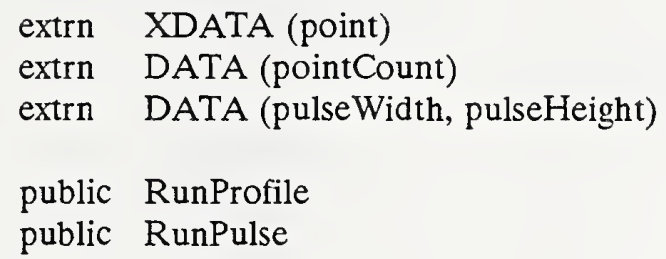

;

; $\quad$ RunPulse

; Inputs:

; $\quad$ struct_point *point

; unsigned pointCount

pointsh EQU R2

pointsl EQU R3

RunProfile:

clr EA ;disable interrupts

; Clear D/A

$\begin{array}{ll}\text { mov } & \text { a,\#0 } \\ \text { mov } & \text { y,a } \\ \text { mov } & \text { dtoaptr,\#LOW DtoA } \\ \text { mov } & \text { P2,\#HIGH DtoA } \\ \text { movx } & \text { @dtoaptr,a }\end{array}$

mov dph,\#HIGH point ;initialize point array pointer

mov dpl,\#LOW point

; Convert the \# of points to a negative \#

;

$\begin{array}{ll}\text { clr } & \mathrm{c} \\ \text { mov } & \text { a,\#0 } \\ \text { subb } & \text { a,pointCount }+1\end{array}$




$\begin{array}{ll}\text { mov } & \text { pointsl,a } \\ \text { mov } & \text { a,\#0 } \\ \text { subb } & \text { a,pointCount } \\ \text { mov } & \text { pointsh,a } \\ \text { anl } & \text { p1,\#0dfh }\end{array}$

NextPoint:

;

; get the delay loop count and wait

;

;

$\begin{array}{ll}\text { movx } & \text { a,@dptr } \\ \text { inc } & \text { dptr }\end{array}$

; Cycles

;2

$;=4$

TightLoop:

$$
\text { djnz acc,Tightloop } \quad ; 2
$$

; Get the delta V and update the D/A and $y$

$\begin{array}{llcc}\text { movx } & \text { a,@dptr } & & ; 2 \\ \text { inc } & \text { dptr } & ; 2 & \\ \text { add } & \text { a,y } & ; 1 & \\ \text { mov } & \text { y,a } & ; 1 & \\ \text { mov } & \text { P2,\#HIGH DtoA } & & ; 2 \\ \text { movx } & \text { @dtoaptr,a } & ; 2 & \end{array}$

; Any more points?

$\begin{array}{lll}\text { mov } & \text { a,pointsl } & ; 1 \\ \text { add } & \text { a,\#1 } & ; 1 \\ \text { mov } & \text { pointsl,a } & ; 1 \\ \text { mov } & \text { a,pointsh } & ; 1 \\ \text { addc } & \text { a,\#0 } & ; 1 \\ \text { mov } & \text { pointsh,a } & ; 1 \\ \text { orl } & \text { a,pointsl } & ; 1 \\ \text { jnz } & \text { NextPoint } & ; 2 \\ & & ;=19 \\ \text { orl } & \text { p1,\#20h } & \\ \text { setb } & \text { EA } & \\ \text { ret } & & \end{array}$

\section{RunPulse}

Inputs:

long pulseWidth

unsigned char pulseHeight

$\begin{array}{lll}\text { loopsl } & \text { EQU } & \text { R2 } \\ \text { loopsh } & \text { EQU } & \text { R3 }\end{array}$


RunPulse:

clr c

mov $a, \# 0$

subb a,PulseWidth +1

mov loopsl,a

mov a,\#0

subb a,PulseWidth

mov loopsh,a

; Set D/A

mov a,\#0

mov dtoaptr,\#LOW DtoA

mov P2,\#HIGH DtoA

clr EA ;disable interrupts

mov a,pulseHeight

anl p1,\#0dfh

movx@dtoaptr,a

PulseLp:

mov a,loopsl ;1

add a,\#1 ;1

mov loopsl,a $\quad ; 1$

mov a,loopsh ;1

addc a,\#0 ;1

mov loopsh,a $\quad ; 1$

orl a,loopsl ;1

jnz PulseLp ;2

; Clear D/A

movx@dtoaptr,a ;2

orl p1,\#20h

setb EA

ret

END 
** FILE: nbs.h -- Piezoelectric Actuator Controller include file

**

$* *$

**

**

** $\quad$ SLog: E:/CUSTS/NBS/CODE/VCS/NBS.H_V S

Rev 1.1 01 Mar 1991 9:05:52 Alan Finger

Release 1.0

Rev 1.0 15 Jan 1991 21:45:52 Alan Finger Initial revision.

$* *$

$* * /$

\#ifndef NBSH

\#define NBSH

\#ifndef MSC

\#include <reg51.h>

\#include <absacc.h>

\#endif

\#ifdef MSC

typedef char BOOLEAN;

\#else

typedef bit BOOLEAN;

\#endif

typedef unsigned char BYTE;

typedef unsigned int WORD;

typedef unsigned long LONGWORD;

\#ifdef MSC

\#define xdata

\#endif

\#define FALSE 0

\#define TRUE (!FALSE)

\#ifndef NULL

\#define NULL ((void *) 0 )

\#endif

\#ifdef SMALL

\#define NULLPTR $\quad$ Ox40000L

\#endif

\#ifdef _LARGE

\#define NULLPTR $\quad$ Ox20000L

\#endif

\#ifndef MSC

\#define OVERFLOW

$\mathrm{P} 3 \wedge 2$

\#define PS READY

$\mathrm{P} 3 \wedge 3$

\#define CHARGE_EN

$\mathrm{P} 3 \wedge 4$ 
\#define DISCHG_EN

\#define SetDA(x)

\#endif

\#define FS_STACK

256

$1^{*}$

** counter runs at 1.0850 usec/count. 9216 counts/clock tick yields

** 10.181 msec per tick.

$* /$

\#define COUNTS_PER_TICK

\#define HW_COUNTS

*I

\#define isSignedFpNumber(s) isnumber(s, TRUE, TRUE)

\#define isUnsignedFpNumber(s) isnumber(s, FALSE, TRUE)

\#define isSignedInteger(s) isnumber(s, TRUE, FALSE)

\#define isUnsignedInteger(s) isnumber(s, FALSE, FALSE)

BOOLEAN isnumber(char *s, BOOLEAN negAllowed, BOOLEAN fpAllowed);

\#define lrnd $(x)$ ( (long) $(x+.5))$

\#define $\operatorname{rnd}(\mathrm{x})($ (int) $(\mathrm{x}+.5))$

\#define $\operatorname{sgn}(x) \quad((x>=0) ? 1:-1)$

char strccmp (char * s1, char * s2);

void InitProfile();

BOOLEAN AddPoint(long t, unsigned char v);

void GetProfile();

void CompleteProfile();

void RunProfile();

void Delay(WORD ticks);

char ${ }^{*}$ strtok $\left(\right.$ char ${ }^{*} \mathrm{~s}$, char $\left.{ }^{*} \mathrm{~d}\right)$;

\#endif
/* FS stack voltage */

$1^{*}$ actually 65536-count 
\#\#\#\#\#\#\#\#\#\#\#\#\#\#\#\#\#\#\#\#\#\#\#\#\#\#\#\#\#\#\#\#\#\#\#\#\#\#\#\#\#\#\#\#\#\#\#\#\#\#\#\#\#\#\#\#\#\#\#\# \#\#\#\#

\#\#

\#\# HSILS Controller Polymake Makefile

\#\#

\#\#

OBJS $\quad=$ nbs.obj act.obj io.obj profile.obj strtok.obj

PATH.c $=$.

PATH.obj $=$.

.PATH.hex $=$.

PATH.h $=$.

nbs.hex: $\quad$ (OBJS)

151 nbs.obj,act.obj,io.obj,profile.obj,strtok.obj PRECEDE (?DT?NBS) NOOVERLAY ohs51 nbs

.c.obj:

c51 $\$<$ DB LARGE CODE DEFINE(_LARGE_)

.asm.obj:

$$
\text { a51 } \$<
$$

clean:

$$
\text { del nbs.hex }
$$

nbs.obj: $\quad$ nbs.h

act.obj: nbs.h

io.obj:

io.c nbs.h 


\section{Appendix E \\ HSILS Fabrication Drawings}




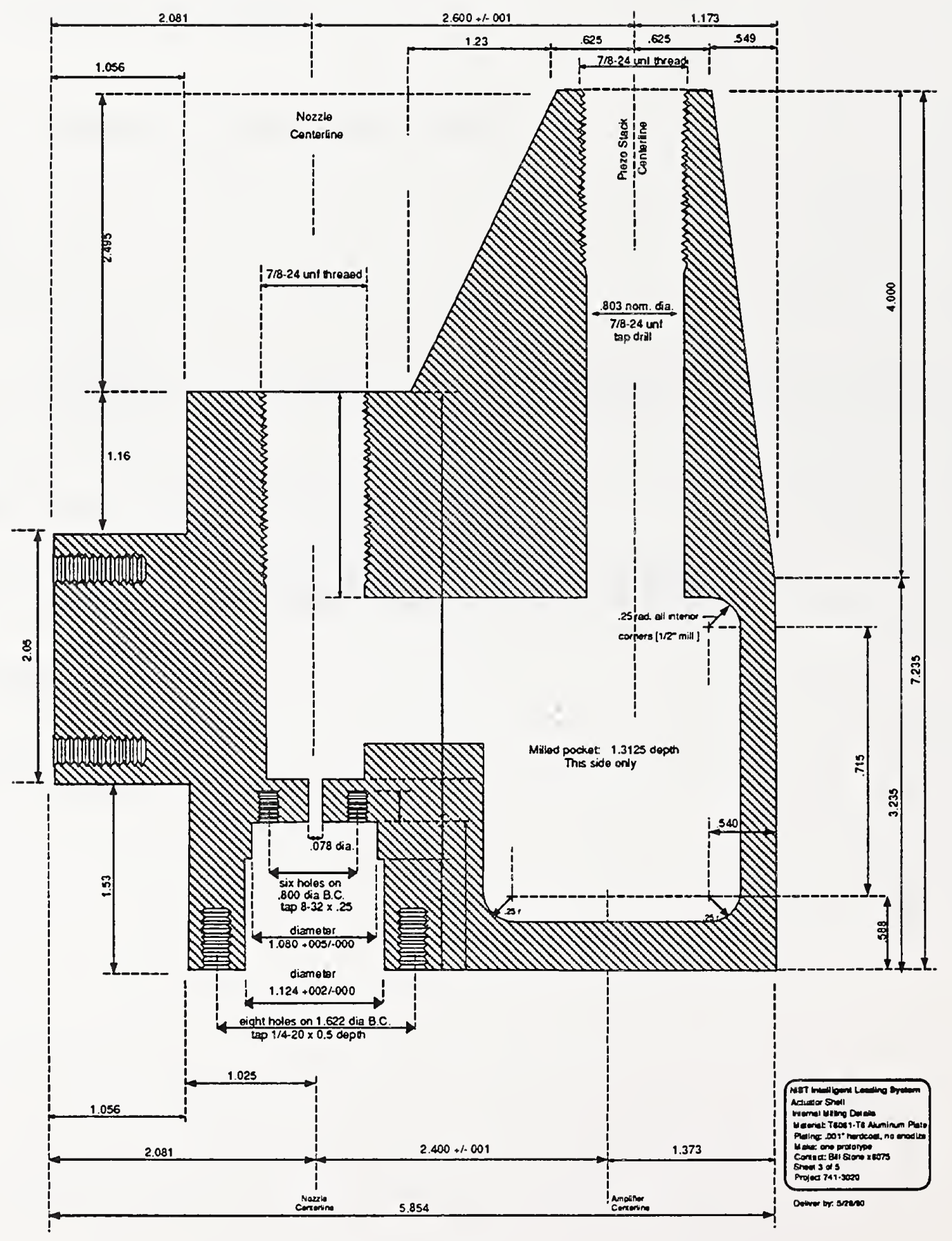

Fig. E.1: Side view cut-away of HSILS housing showing main bore holes for valve core rod, piezoelectric stack, and expansion nozzle. Units shown are inches; 1 inch $=25.4$ $\mathrm{mm}$. 


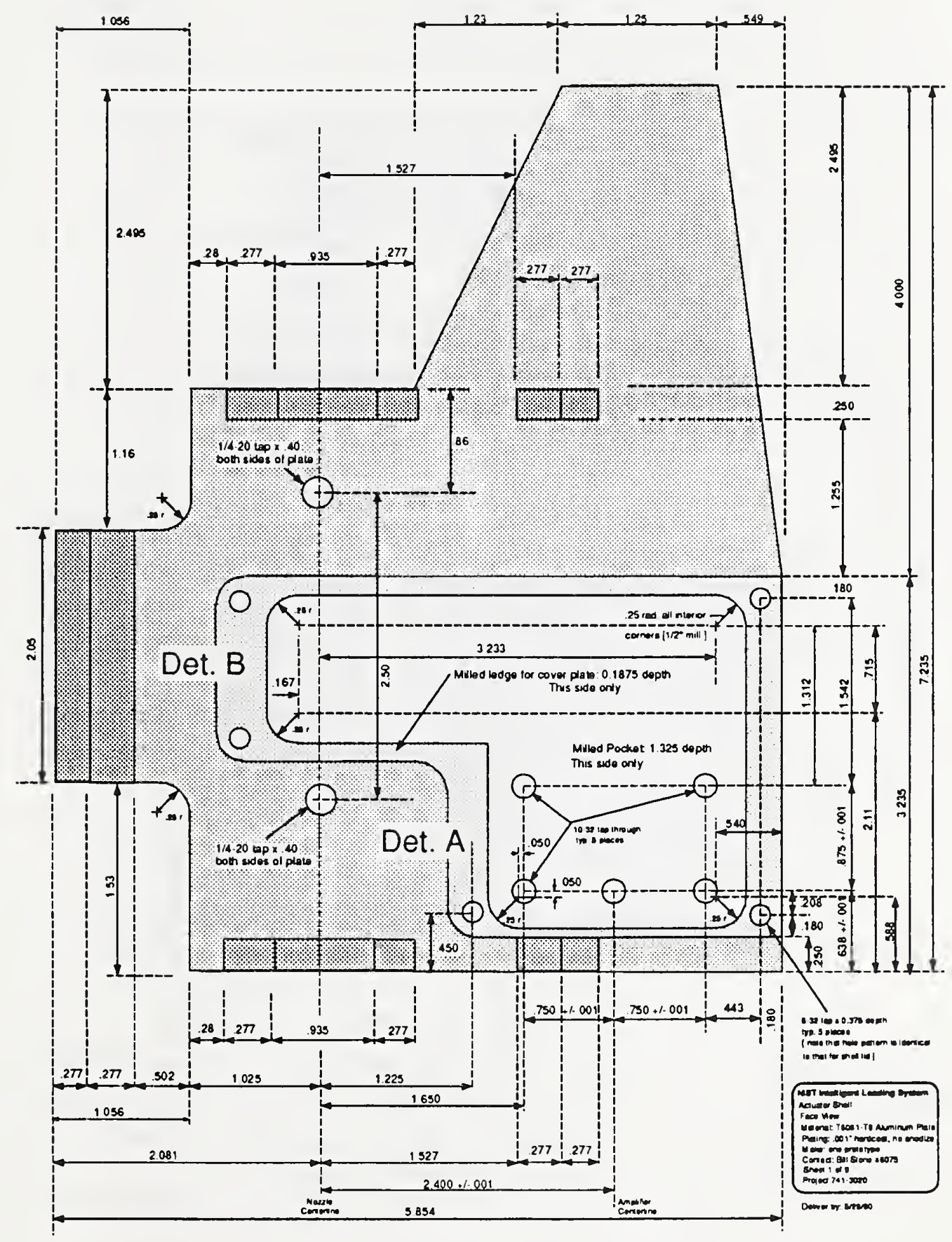

Fig. E.2: Side View of HSILS housing showing exterior milling details and mounting holes for the displacement amplifier. Units shown are inches; 1 inch $=25.4 \mathrm{~mm}$. 


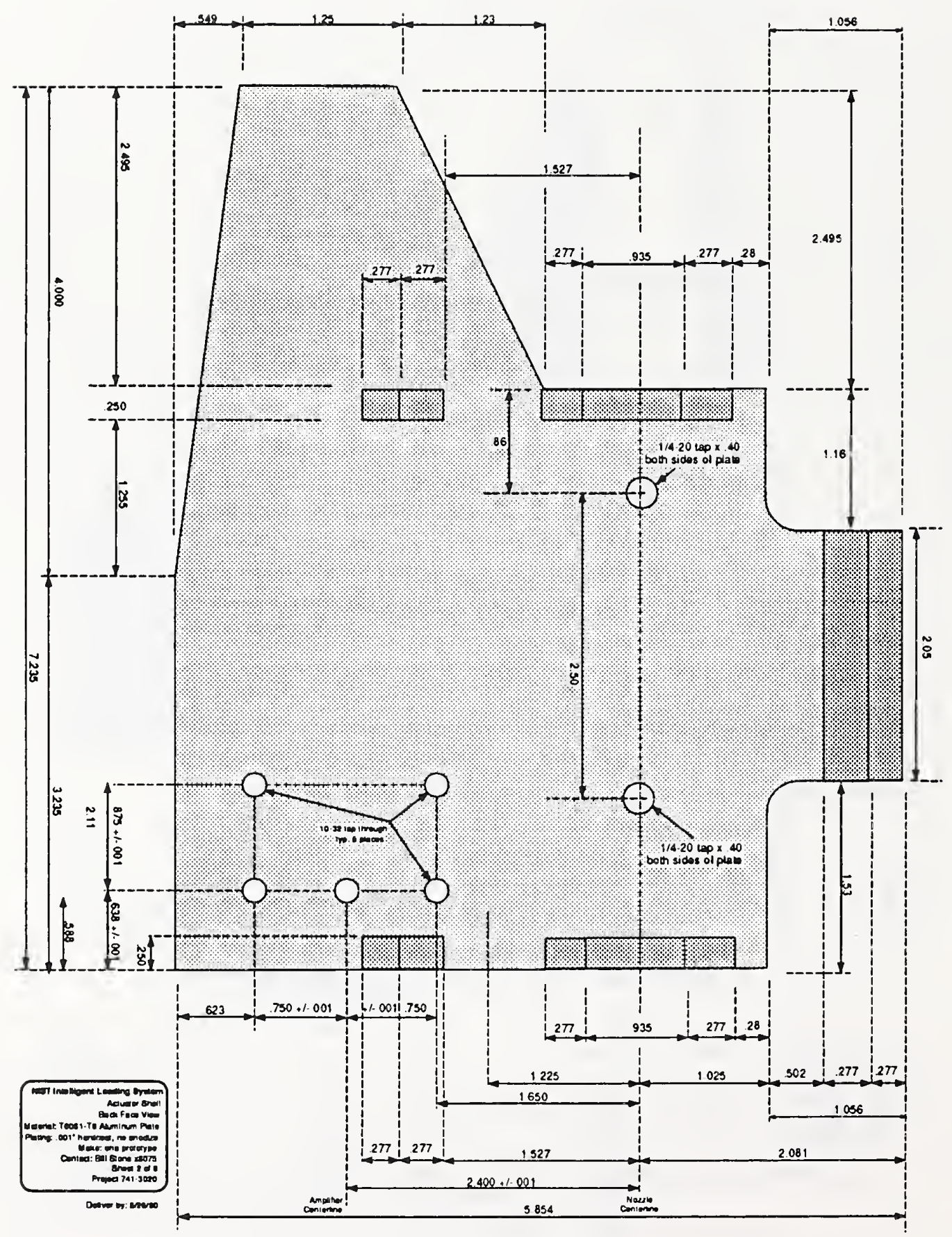

Fig. E.3: Reverse side view of HSILS housing showing accumulator mounting holes and positioning tabs. Units shown are inches; 1 inch $=25.4 \mathrm{~mm}$. 
Top View: Actuator Shell

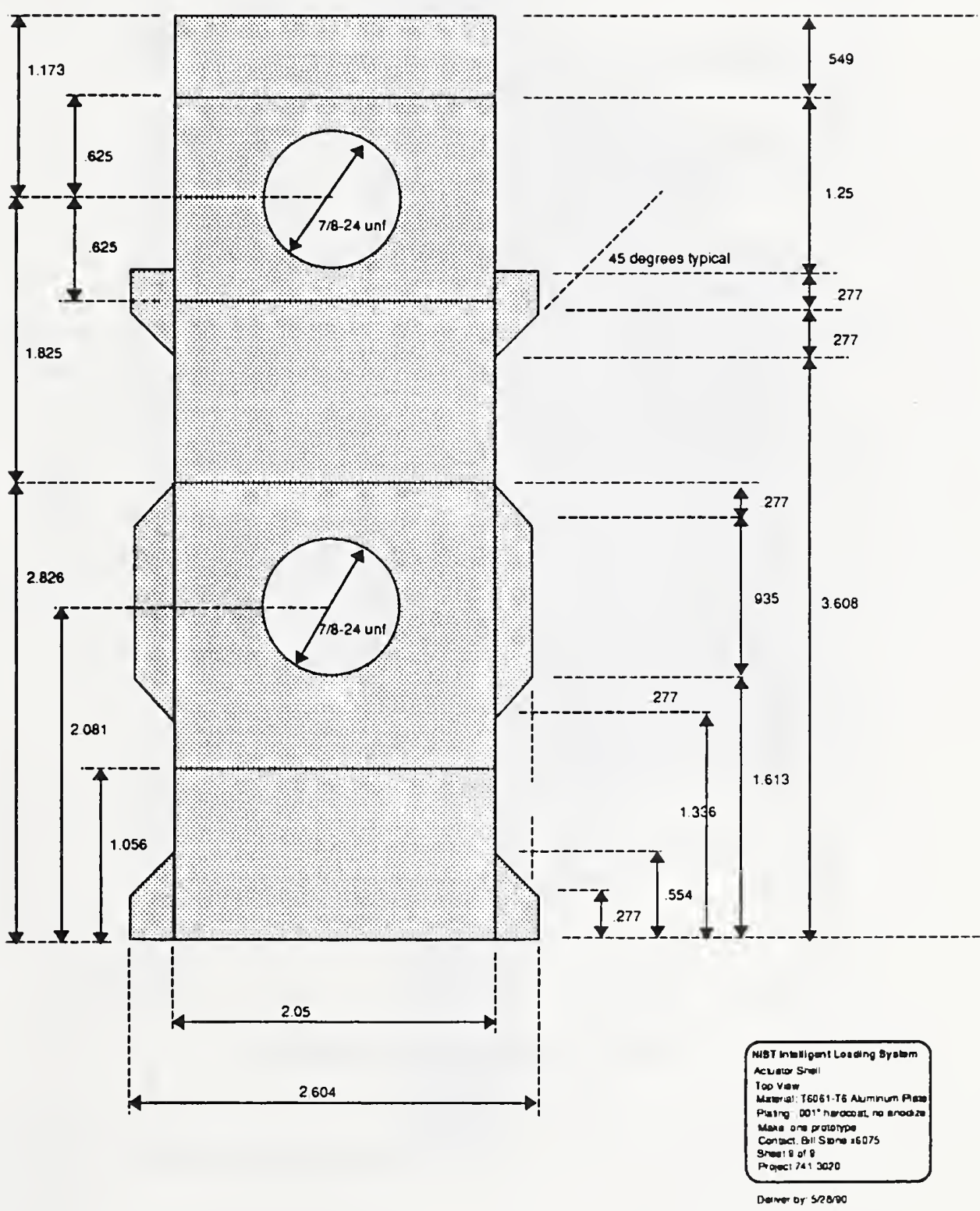

Fig. E.4: Top external view of HSILS housing showing piezoelectric stack and core rod bore holes and mounting tabs for gas accumulators. Units shown are inches; 1 inch = $25.4 \mathrm{~mm}$. 


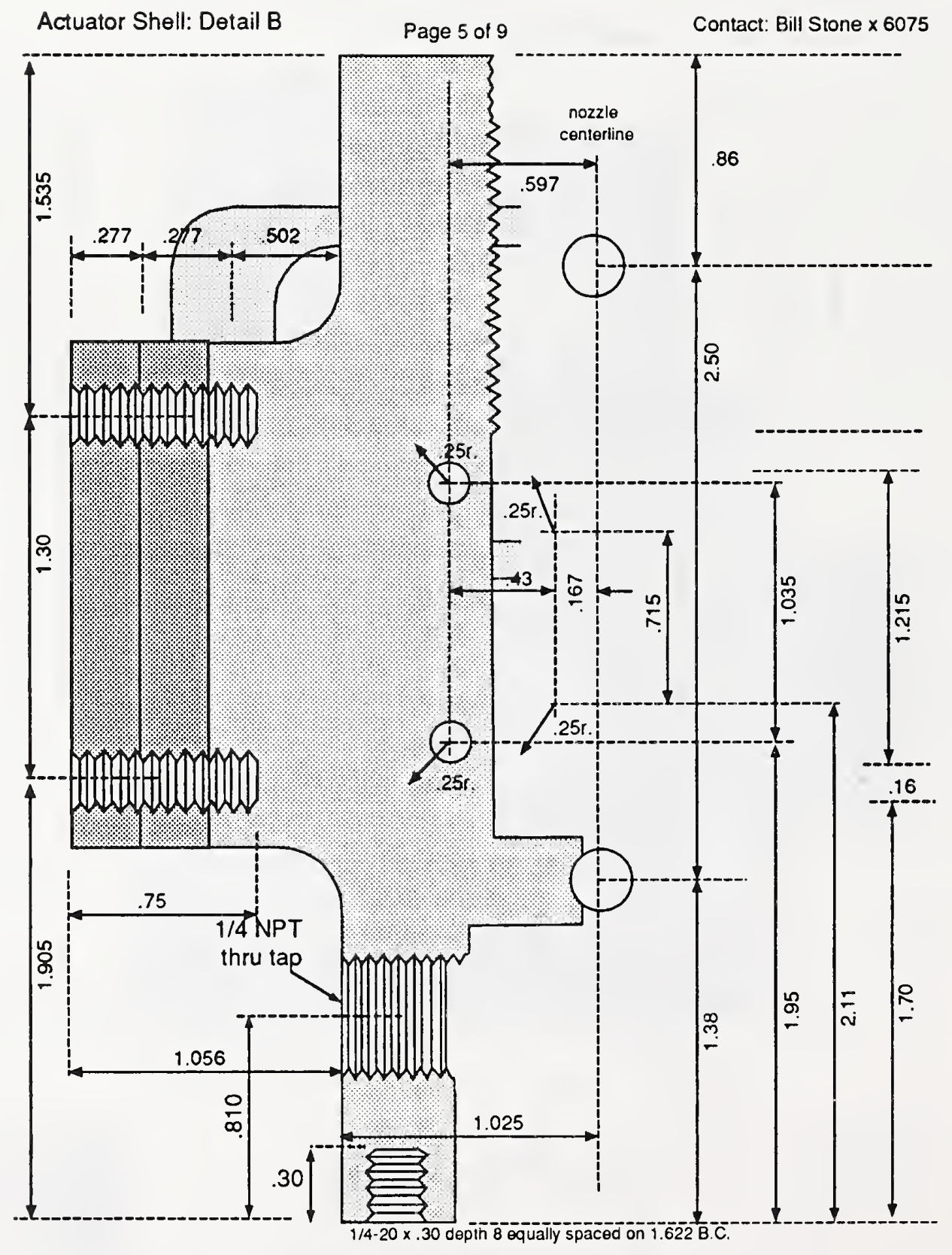

Fig. E.5: Side View detail of HSILS housing in the vicinity of the valve core seat showing threaded connections for the expansion nozzle, high pressure gas inlet from the accumulators, and external mounting bolts (left). Units shown are inches; 1 inch $=25.4 \mathrm{~mm}$. 


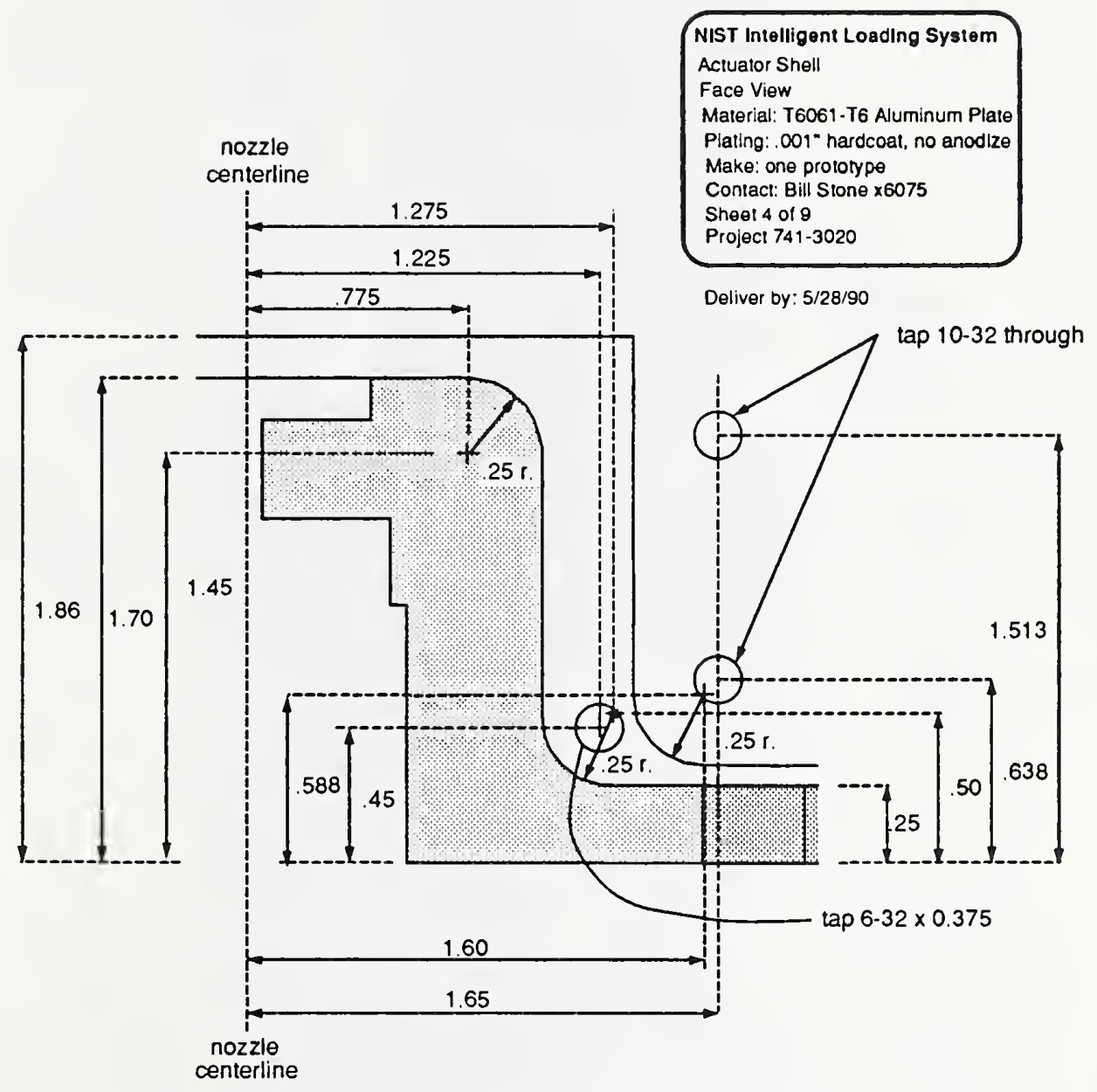

Detail A: Amplifier Shell

Fig. E.6: Side View detail of HSILS Cover plate (see additionally Fig. E.20) fitting tolerances. Units shown are inches; 1 inch $=25.4 \mathrm{~mm}$. 


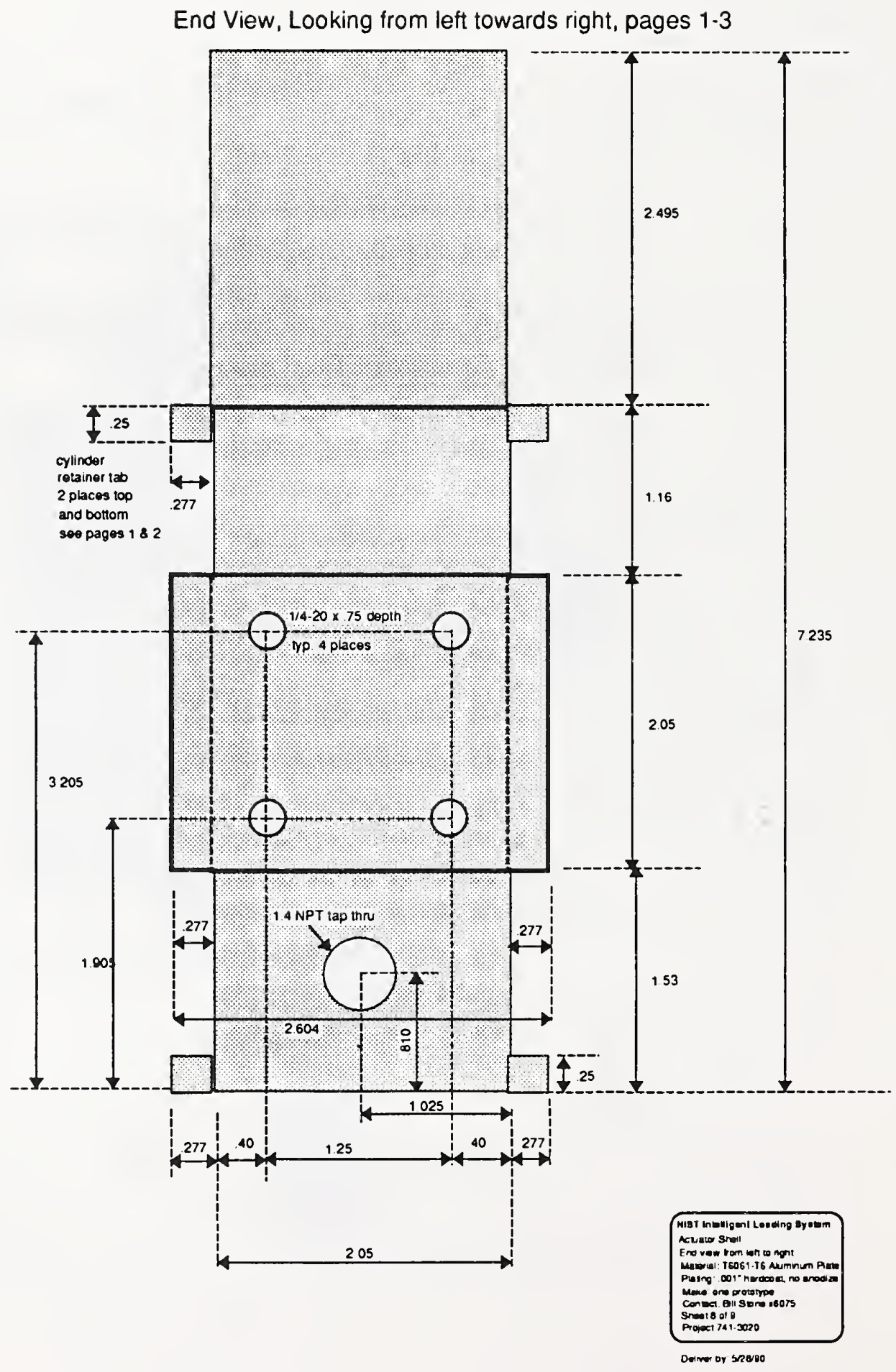

Fig. E.7: End view of HSILS housing showing mounting holes and high pressure gas inlet. Units shown are inches; 1 inch $=25.4 \mathrm{~mm}$. 


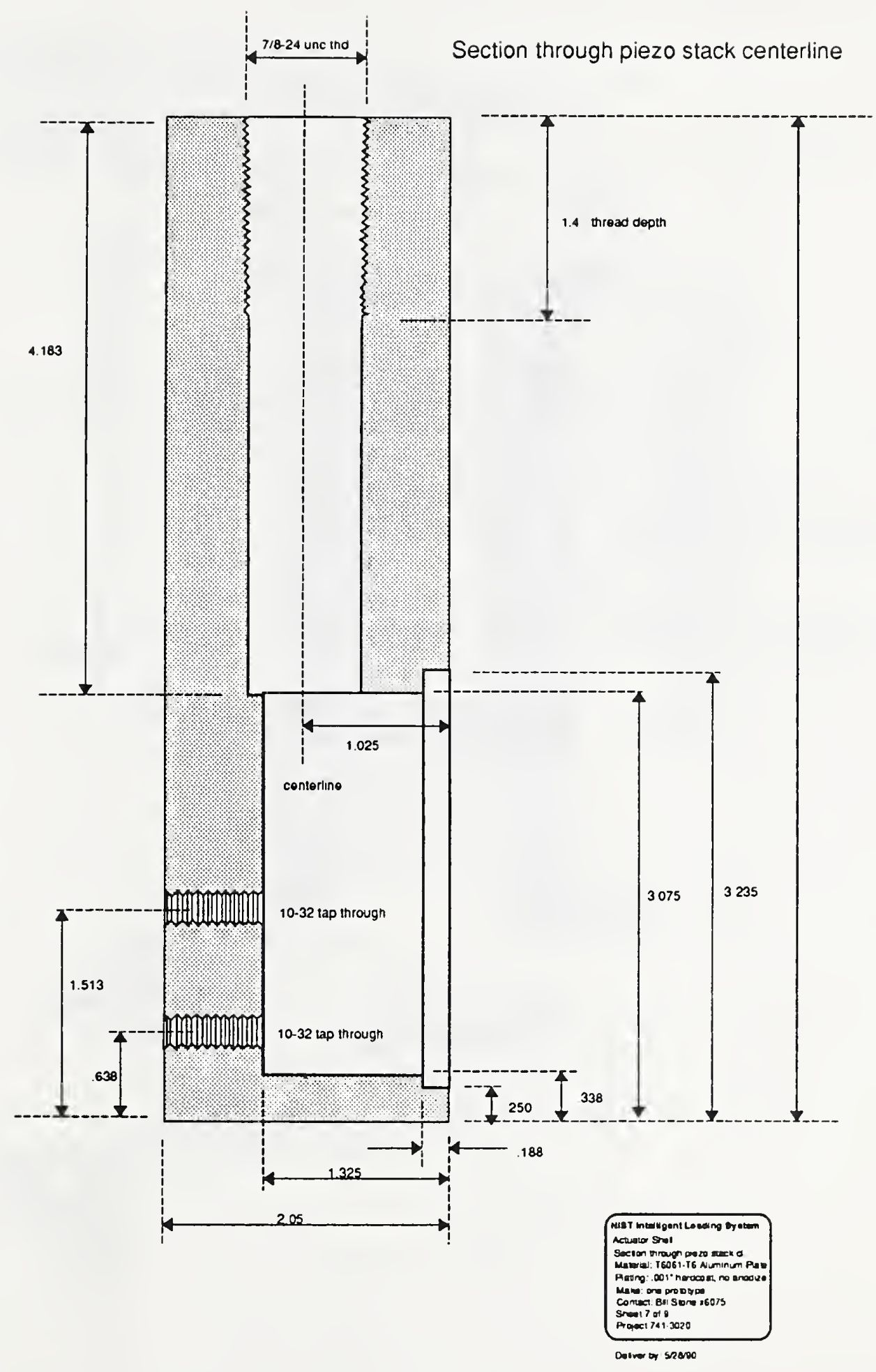

Fig. E.8: End View of HSILS housing interior pockets showing central boreholes for the core rod and stack, milled pocket for the displacement amplifier, and recessed pocket for side cover. Units shown are inches; 1 inch $=25.4 \mathrm{~mm}$. 
Section through nozzle centerline
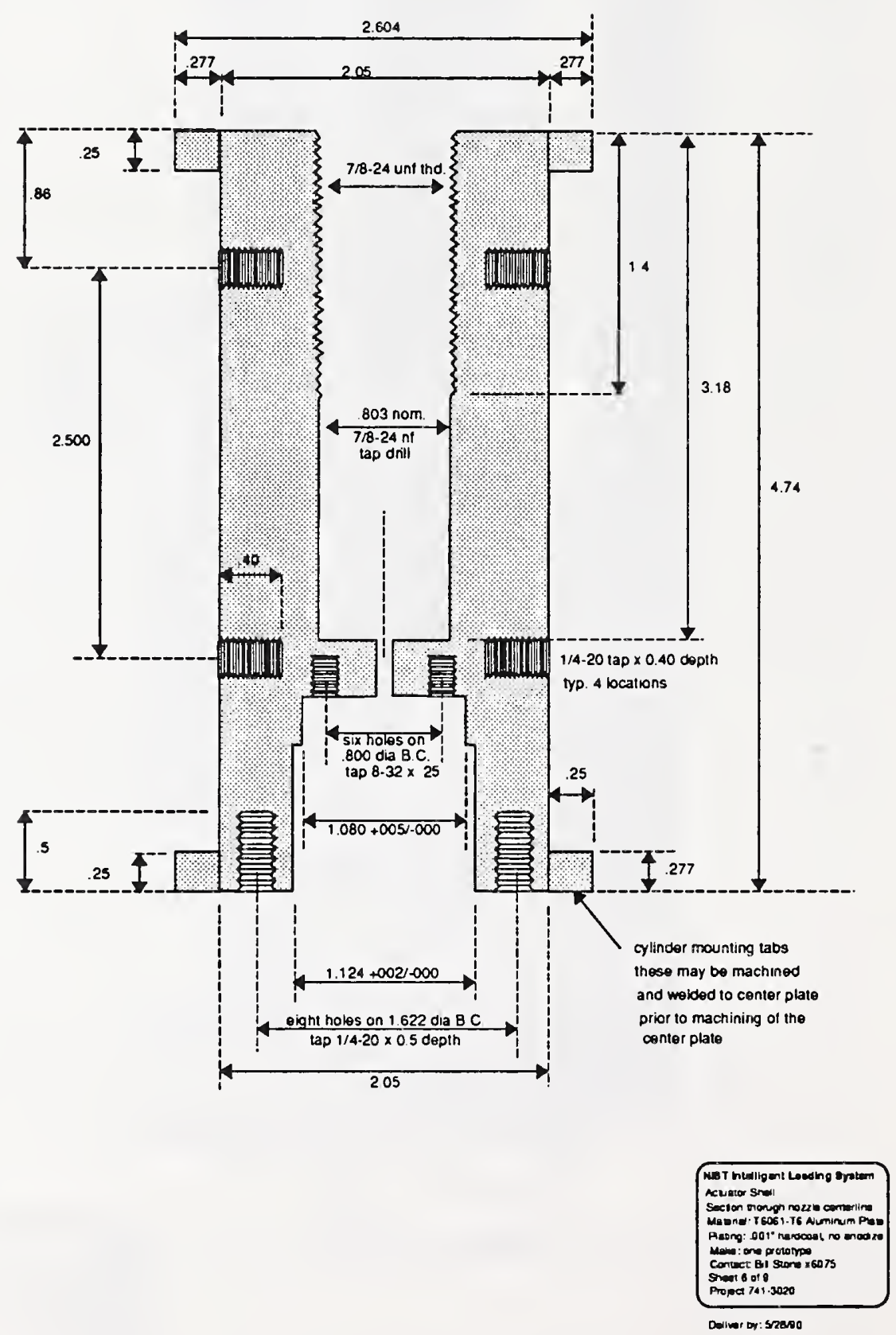

Fig. E.9: End View of HSILS housing showing interior details of high pressure valve seat cavity and alignment of valve core rod borehole. Units shown are inches; 1 inch $=25.4 \mathrm{~mm}$. 


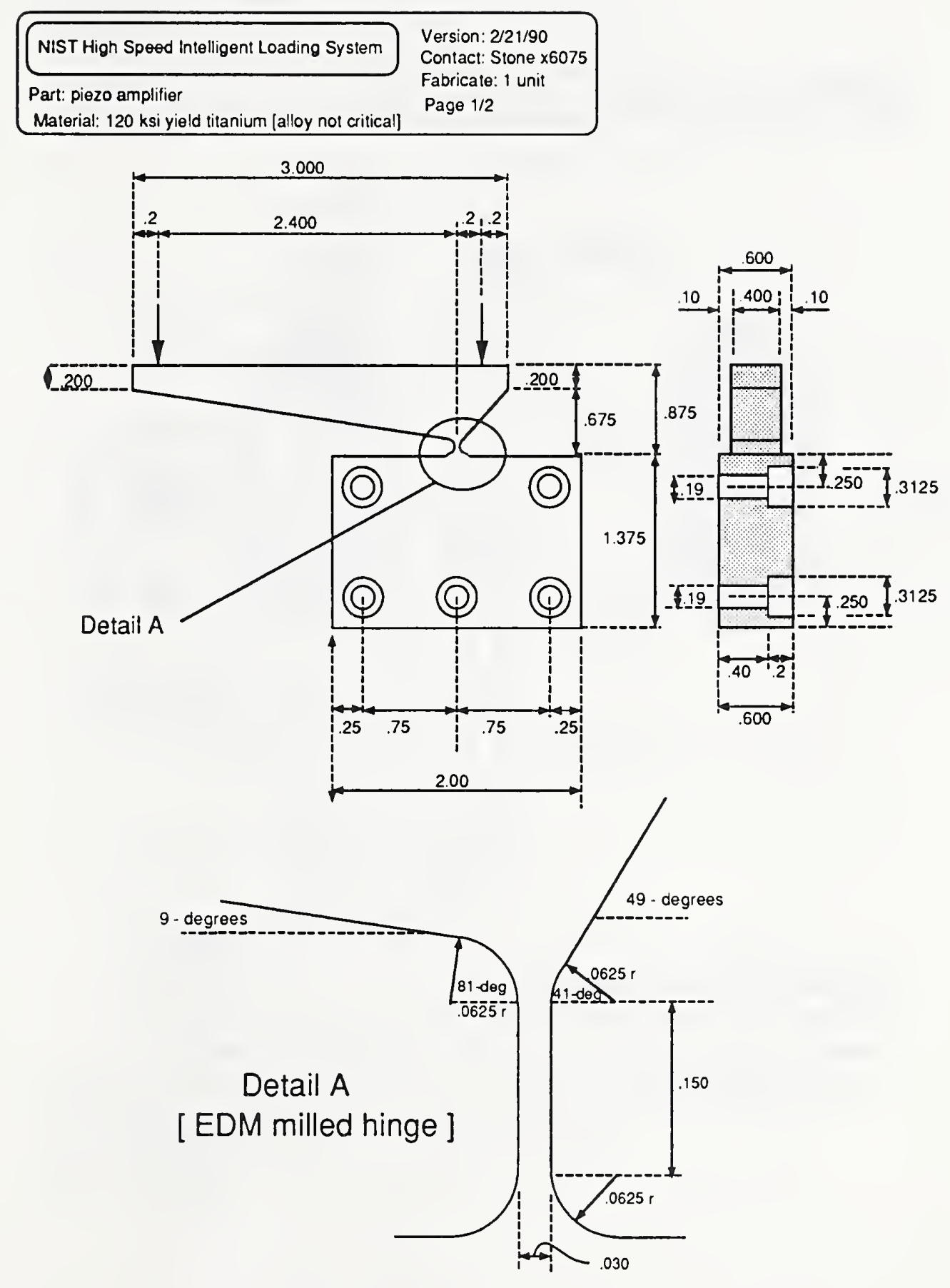

Fig. E.10: Detail of displacement amplifier. This was monolithically wire EDM milled from a solid plate of titanium. Units shown are inches; 1 inch $=25.4 \mathrm{~mm}$. 
NIST HIgh Speed Intelligent Loading System

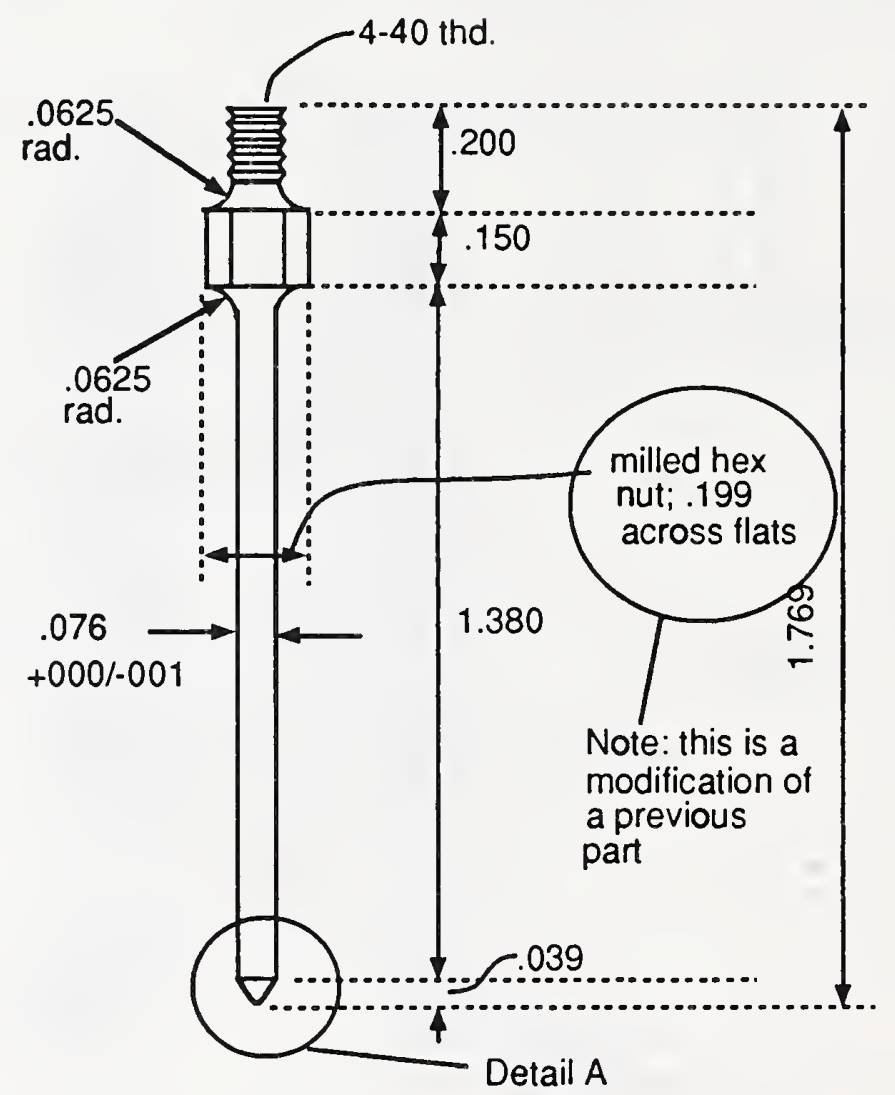

Part: Core Rod

Material: 240 ksi yield, hardened steel

[suggest Vasco-Max 240 or drill rod ]

Make 1 prototype

Contact: Stone x 6075

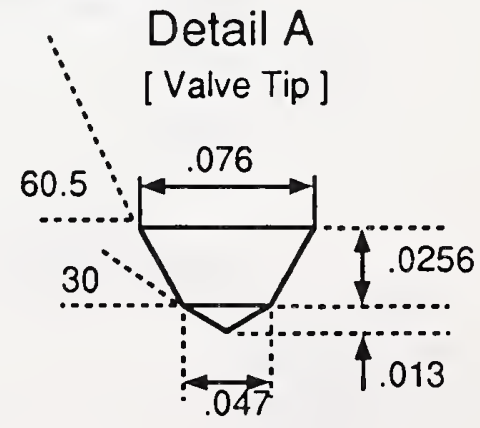

Fig. E.11: Detail of valve core rod. This was first turned from maraging steel bar stock and then heat treated. Units shown are inches; 1 inch $=25.4 \mathrm{~mm}$. 

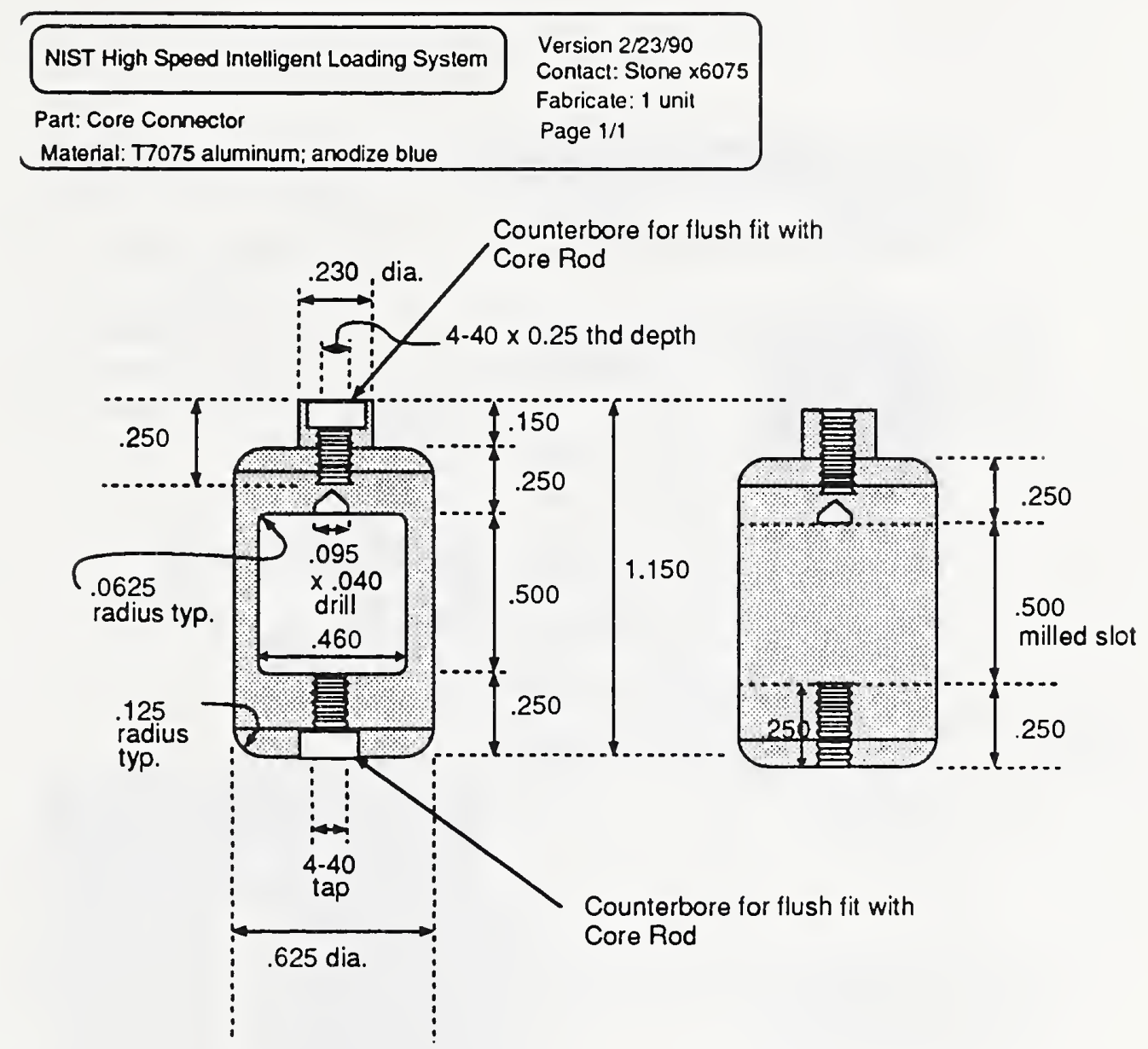

Notes:

1. Material: $5 / 8$ aluminum bar stock;

2. First choice T7075; if not available, use T6061.

3. Anodize blue; allow 002 undersize dia on mating parts

4. taper at end of .095 drilled hole not critical

Fig. E.12: Valve core rod coupler. Valve core rod (Fig. E.11) attaches to the base while displacement amplifier (Fig. E.10) seats in the central milled pocket and bears in compression against the conical interior seat into which is glued a sapphire sphere prior to assembly with the displacement amplifier. Units shown are inches; 1 inch $=25.4 \mathrm{~mm}$. 


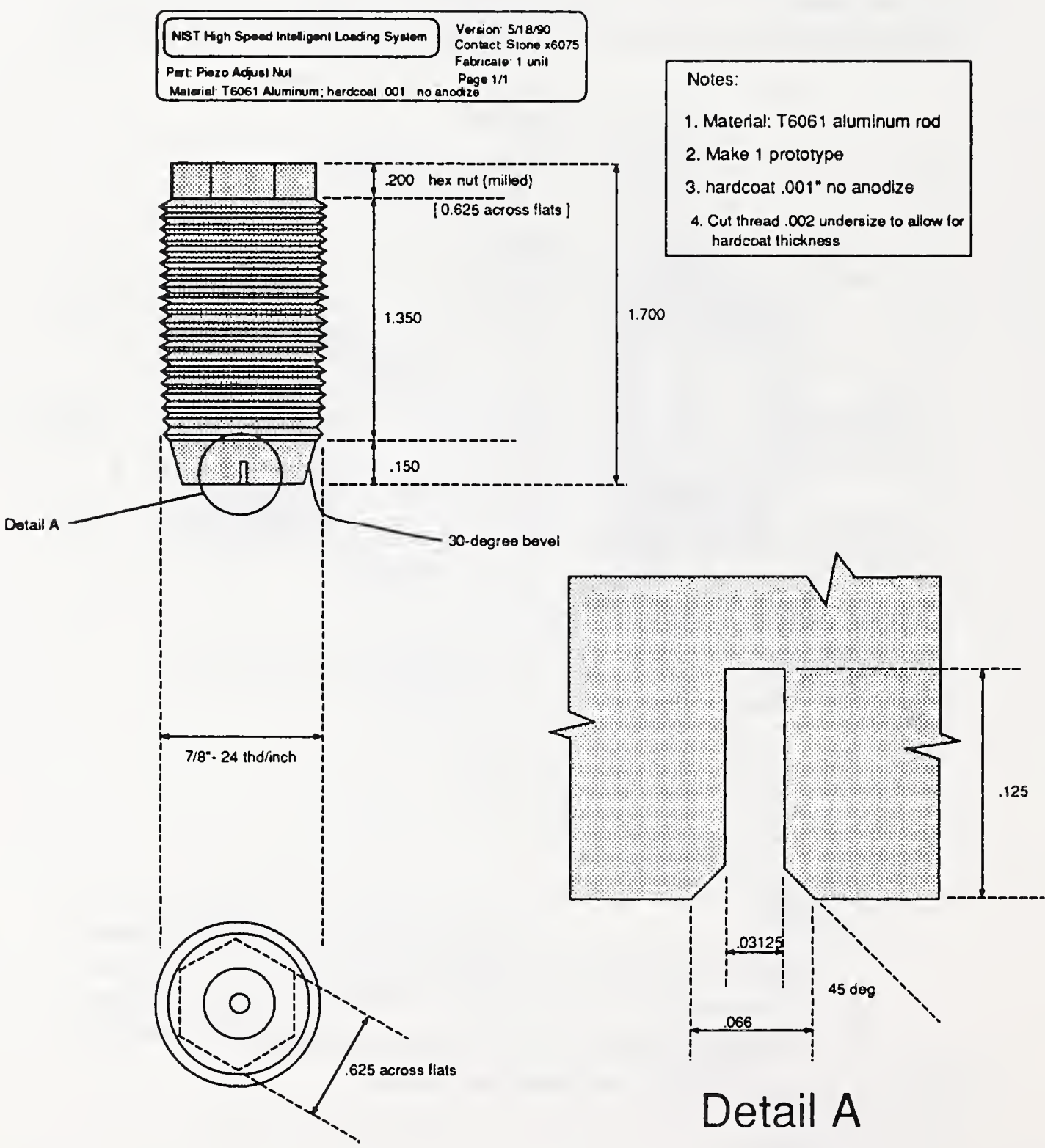

Fig. E.13: Fine thread adjustment screw. One is used to set the precompression in the return spring and a second is used to permit initial setting and loading of the piezoelectric stack. Units shown are inches; 1 inch $=25.4 \mathrm{~mm}$. 


\section{NIST High Speed Intelligent Loading System}

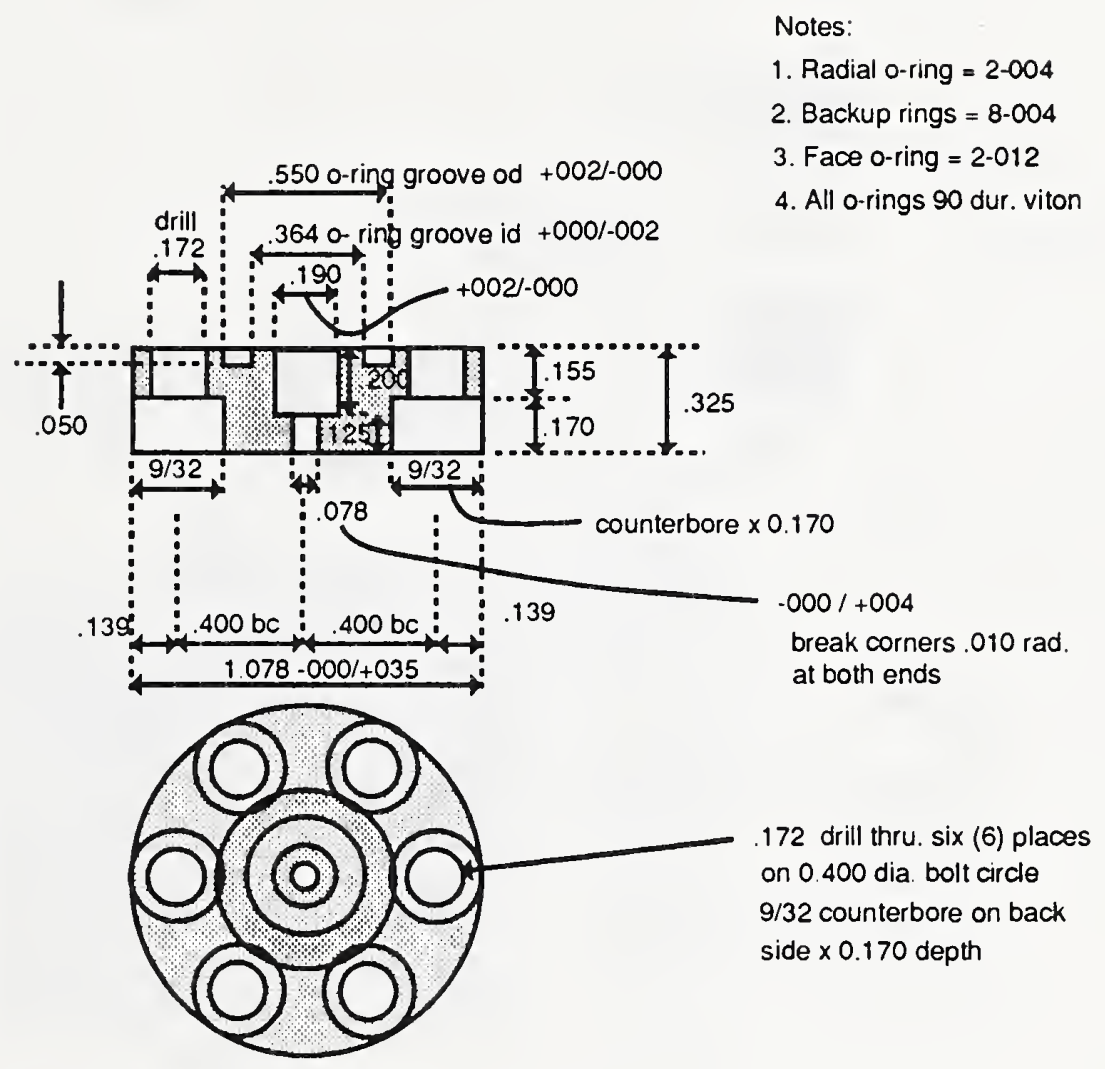

\section{Part: HP Core Valve Seal Plate Material: SS 304 \\ Rev. B, 5/08/90 \\ Contact: Bill Stone $\times 6075$ \\ Fabricate one (1) unit}

Fig. E.14: Valve core sealing plate. Provides the necessary high pressure o-ring and backup ring seals to isolate the high pressure valve seat cavity from the ambient pressure displacement amplification and drive portions of the HSILS unit. Units shown are inches; 1 inch $=25.4 \mathrm{~mm}$. 


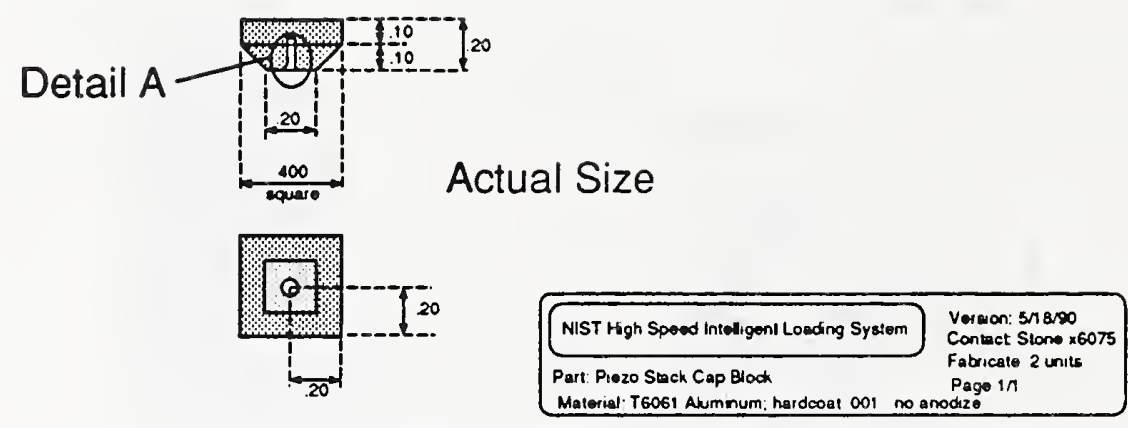

Notes:

1. Material: T6061 aluminum rod

2. Make 2 Coples

3. hardcoat .001" no anodize

4. Cut thread .002 undersize to allow for hardcoat thickness

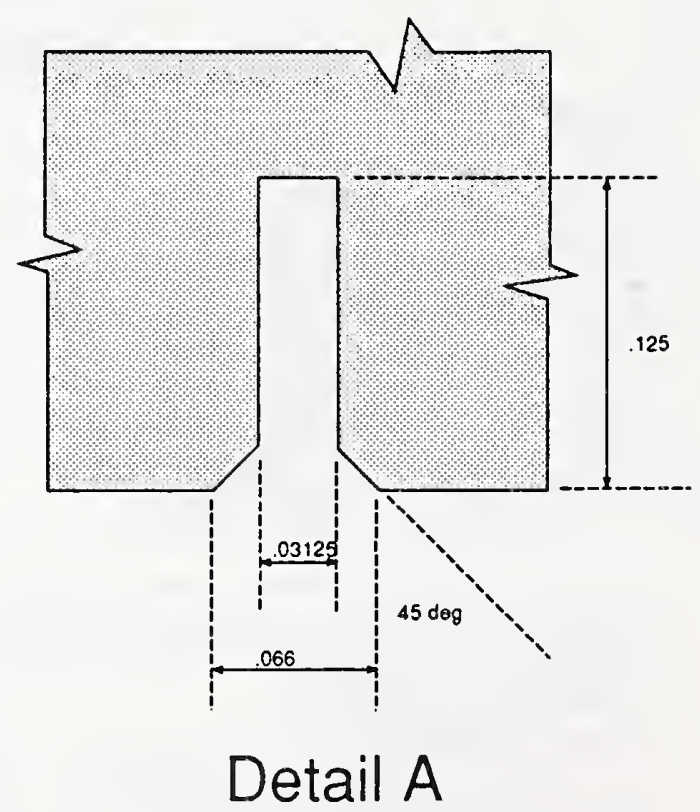

Fig. E.15: Pyramid block with conical seat. These are glued to each end of the piezoelectic stack using strain gage glue. Sapphire bearings are subsequently glued into the conical seats prior to final assembly. Units shown are inches; $1 \mathrm{inch}=25.4 \mathrm{~mm}$. 


\section{NIST High Speod intelligent Loading System}

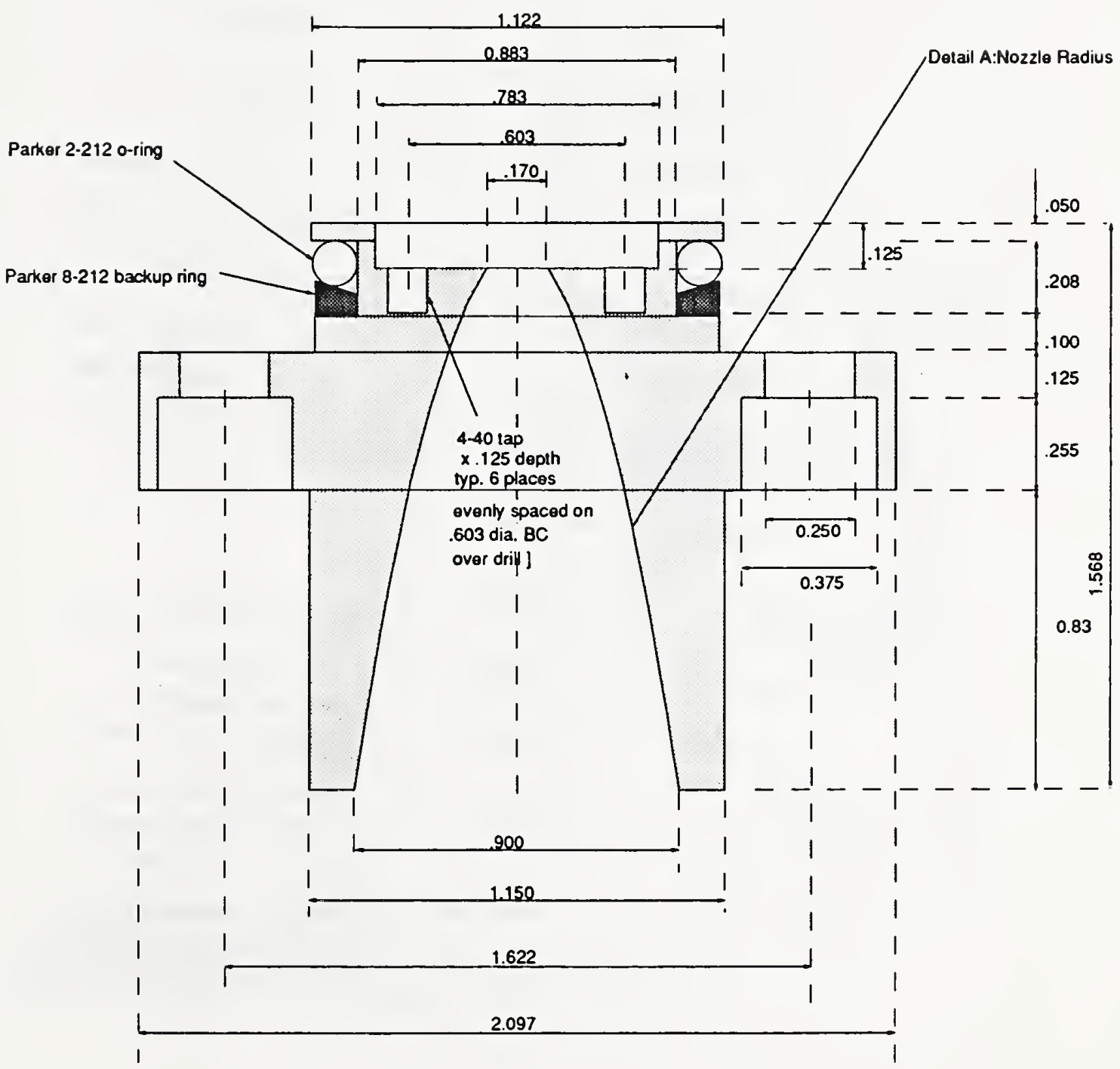

Fig. E.16: Removeable expansion nozzle with recepticle for replacement valve seats (which also comprise the nozzle throat). Units shown are inches; 1 inch $=25.4 \mathrm{~mm}$. 


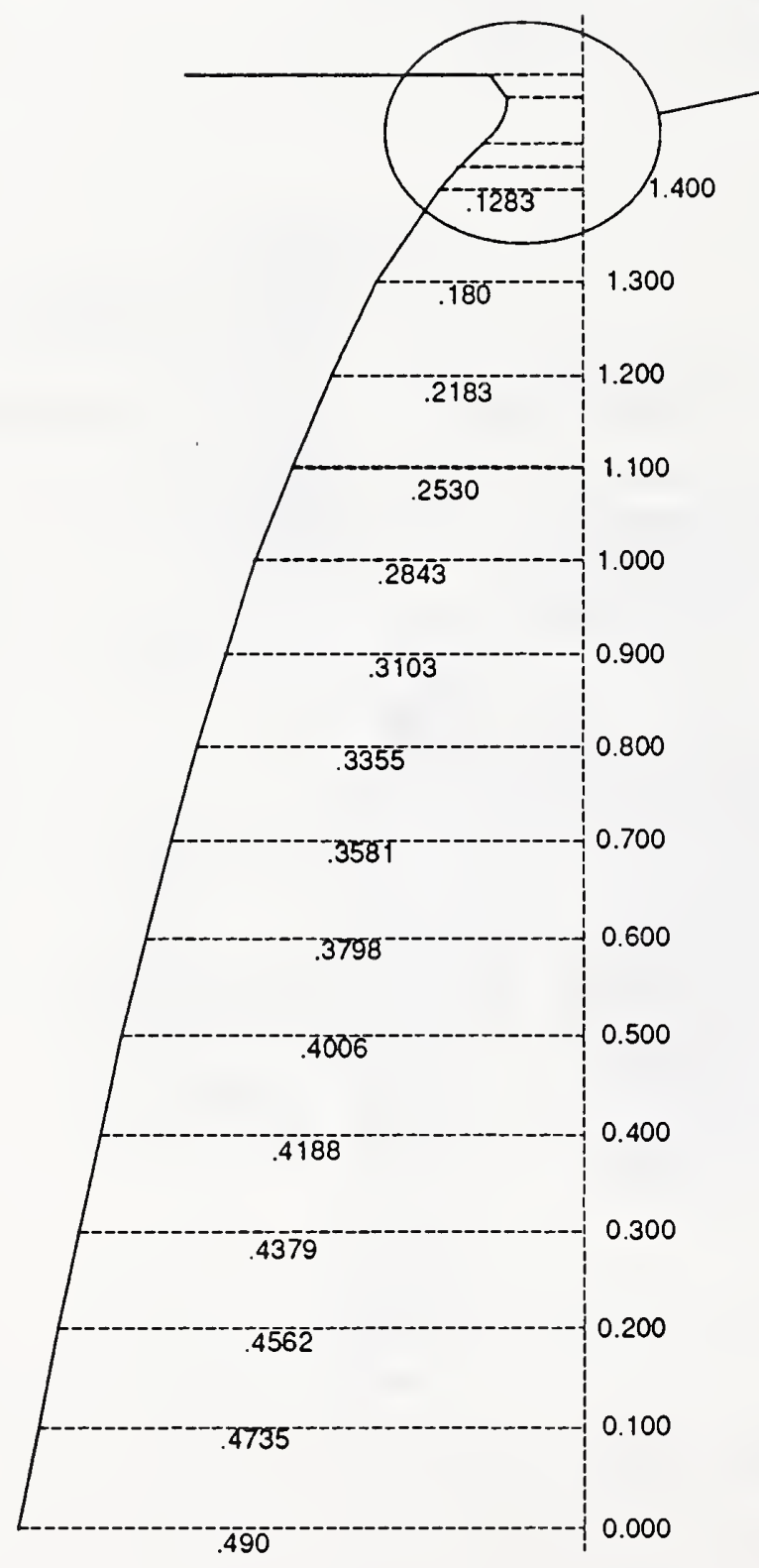

Detail B

Detail B

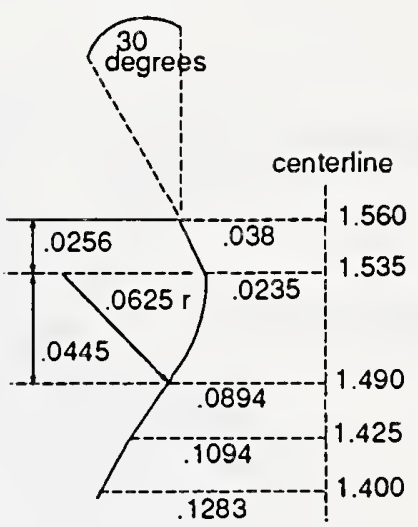

Notes:

1. Polish interior surface of nozzle

2. smooth transition between datum points desireable but not required. Shop generated spline will be fine.

3. Best effort on 0.0625 radius nozzle throat will be acceptable.

4. Dimensions on this sheet control.

5. Modified throat dimensions to add .040 between tangent and last throat control point. Needed to make throat work right. Otherwise a step was present

Fig. E.17: EDM milling profile for the interior of the expansion nozzle. Units shown are inches; 1 inch $=25.4 \mathrm{~mm}$. 


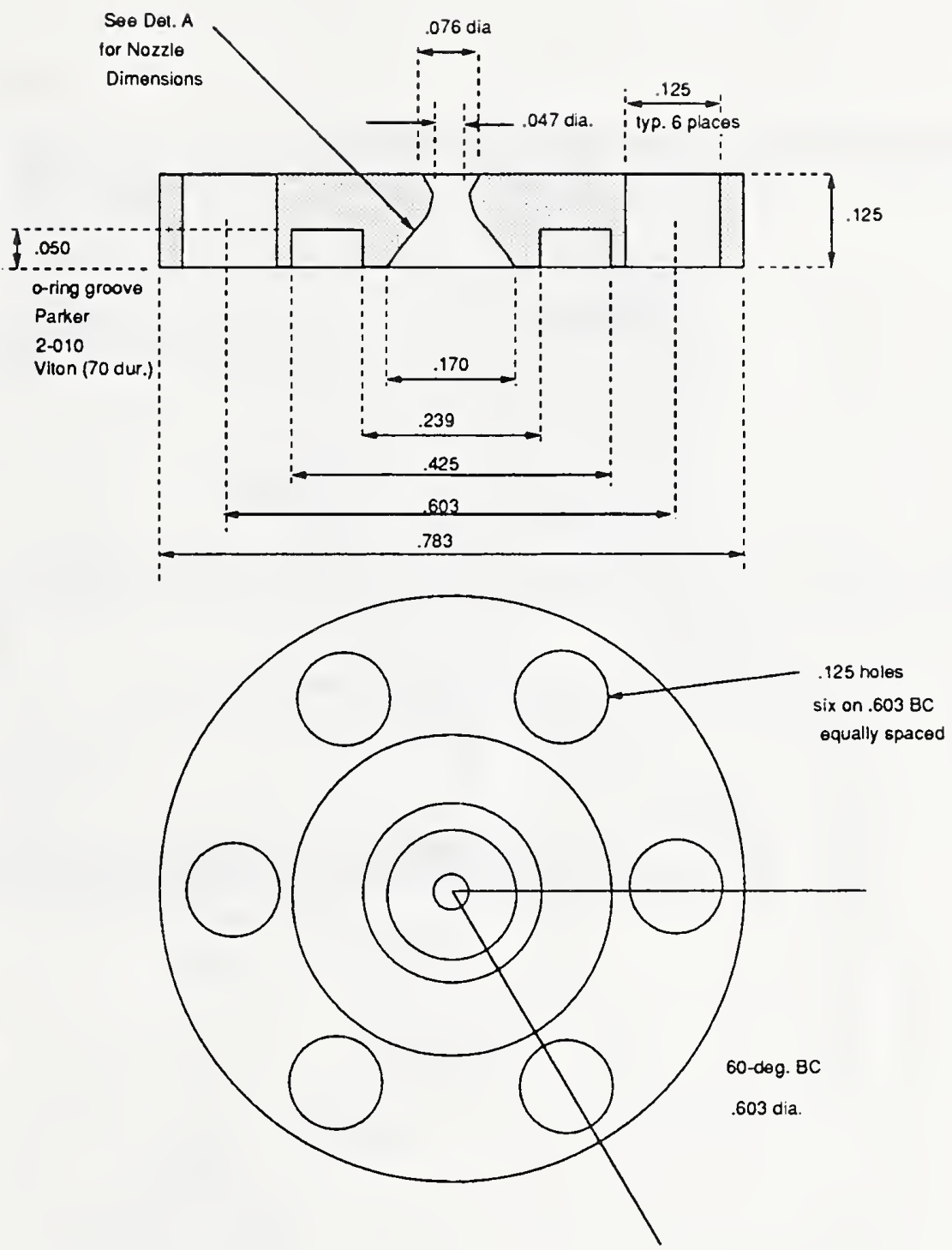

Notes:

1: Fabricate one copy from "Ferro-TiC" (Titanium Carbide)

2: Fabricate one copy from VascoMax 500

3: Comact Bill Stone $\times 6075$

4: See Detail sheet for nozzle dimensions; an existing EDM electrode exists

Fig. E.18: Valve seat insert. This mates to the expansion nozzle (Fig. E.17) and contains an internal o-ring seal. Two such units were made for prototype testing, one from VascoMax 500 maraging steel, a second from FerroTic, a titanium carbide alloy. Units shown are inches; 1 inch $=25.4 \mathrm{~mm}$. 
Detail A: nozzle seat throat dimensions

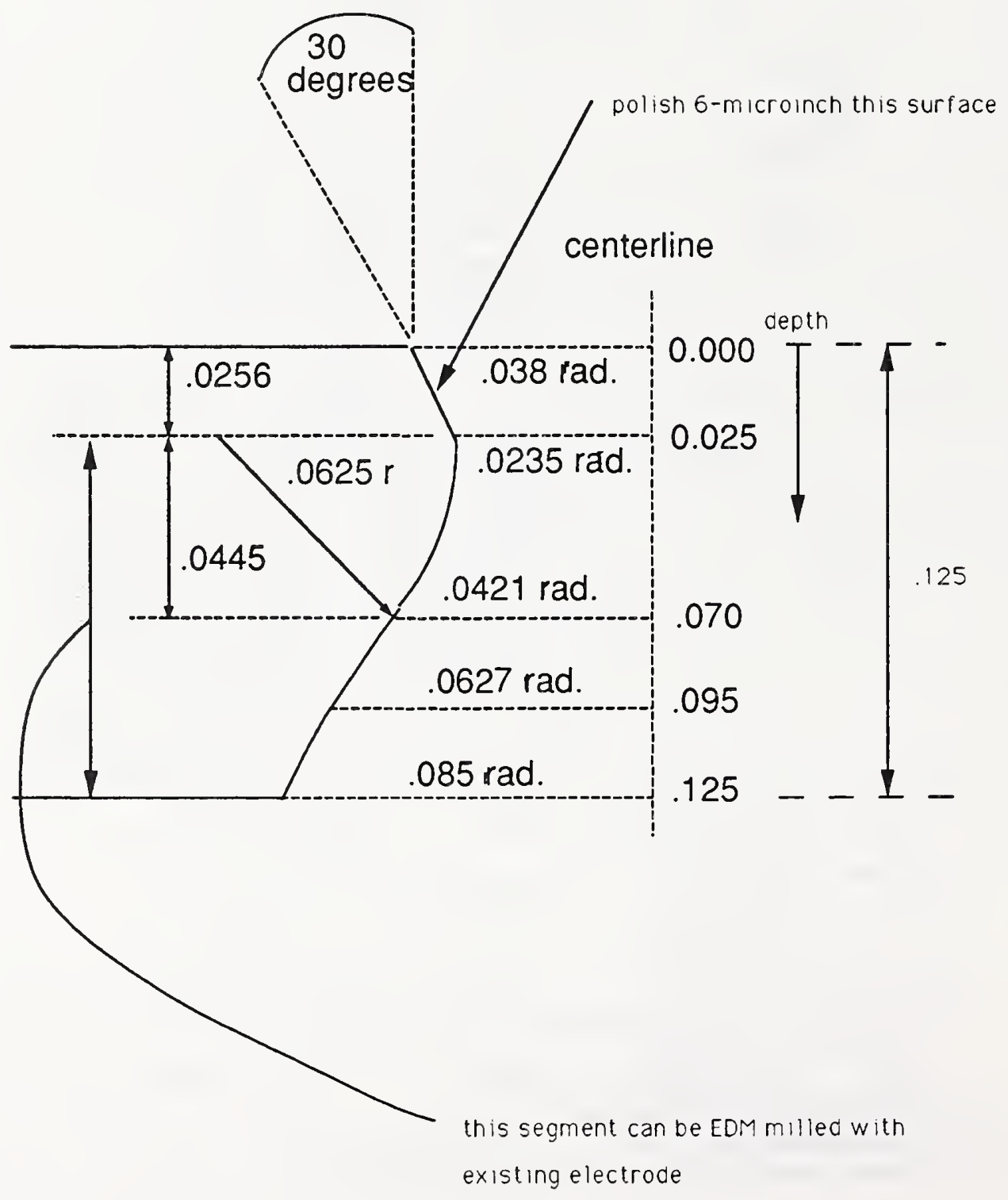

Fig. E.19: EDM milling details for the replaceable nozzle seat insert (see Fig. E.18). Units shown are inches; 1 inch $=25.4 \mathrm{~mm}$. 

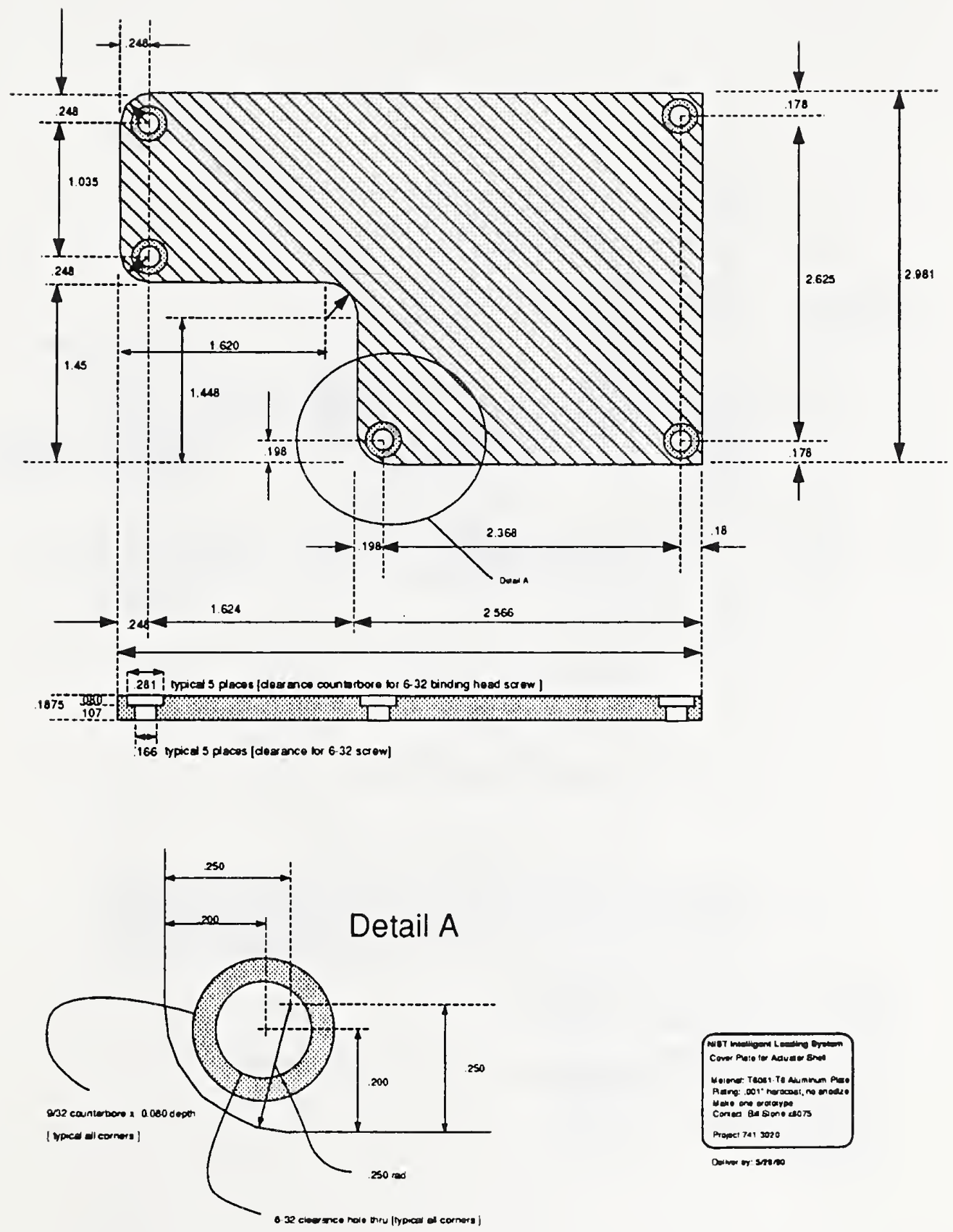

Fig. E.20: Main cover plate for the HSILS housing. Units shown are inches; 1 inch $=25.4$ $\mathrm{mm}$. 


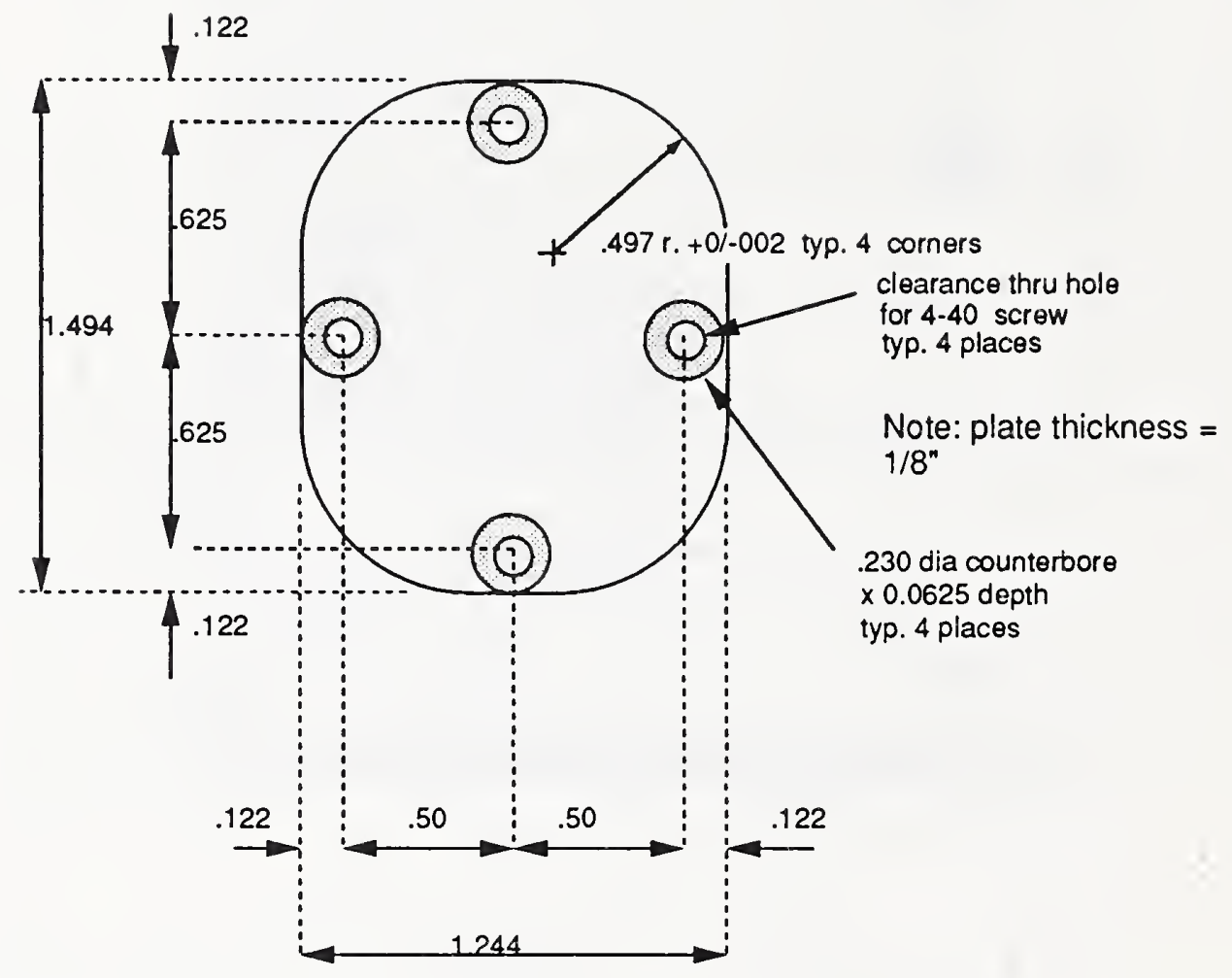

NIST High Speed Intelligent Loading System

Part: Access hole dust cover

Material: T6061 Aluminum; hardcoat .001 ; no anodize Base material: $1 / 8$ plate

Version 6/04/90

Contact: Stone $\times 6075$

Fabricate: 1 unit

Page 1/1

Fig. E.21: Secondary cover for HSILS housing. This allows access to the opposite end of the piezoelectric stack for initial assembly of the unit. Units shown are inches; 1 inch $=25.4 \mathrm{~mm}$. 


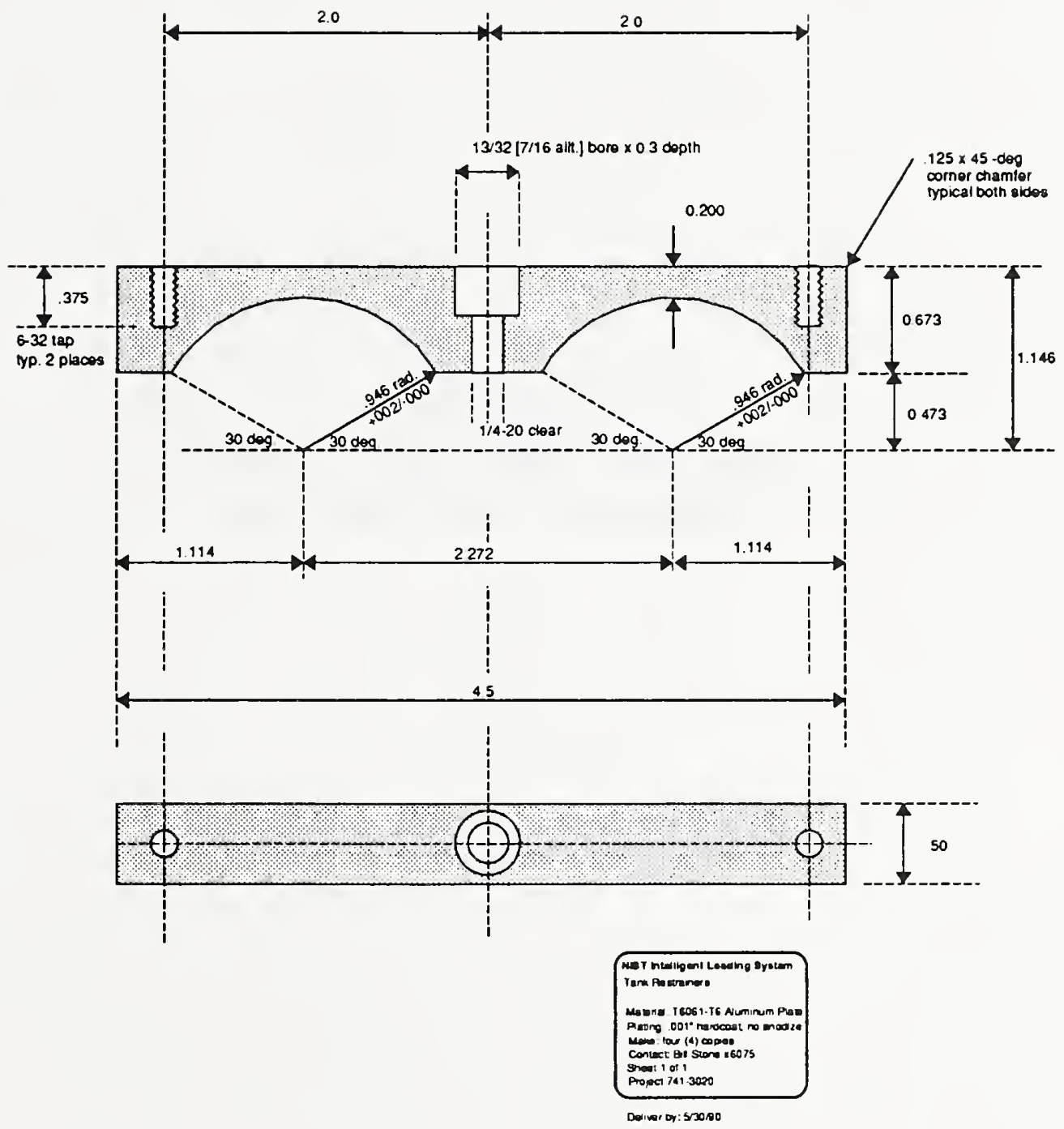

Fig. E.22: Gas accumulator attachment brackets. These bolt to the attachment holes shown in Figs. E.2 and E.3. Units shown are inches; 1 inch $=25.4 \mathrm{~mm}$. 


\section{Introduction}

In the actual hardware implementation of the HSILS prototype the onboard microcontrolier and pulse power supply were housed in a grounded metal box. Various external connections, indicators, and switches were mounted on the front of the box and are shown in Fig. F.1. Onboard software was as described in Appendix C. The host PC contained a common commercial RS232 communications protocol program which permitted downloading of voltage-time profiles.

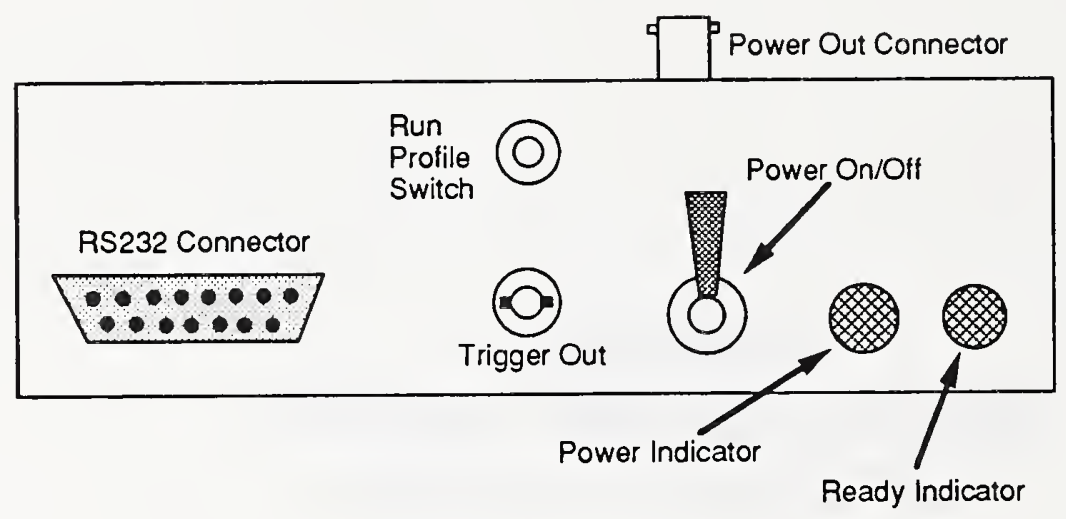

Fig. F.1: HSILS controller front panel.

The basic components shown in Fig. F.1 include:

- RS232 Connector. A 25 pin subminiature D female connector for interfacing to a host computer.

- Run Profile Switch. Pressing this button will cause the controller to execute a download profile.

- Trigger Connector. A BNC connector internally connected to an open collector transistor. This transistor turns on (grounding the center conductor) while a profile or pulse is being run. Use this output to trigger an oscilloscope or other recording device.

- Power Switch. Controls AC power to the unit. Also discharges the high voltage circuits when off.

- Power Indicator. A red LED which is lit whenever ower is applied and the unit is operating normally. If not lit when the power switch is on, check to make sure the unit is plugged in and that the fuse, on the rear panel, has not blown.

- Ready Indicator. This green LED will be on when the high voltage capacitors have reached normal charge. It will flash when a profile has been successfully loaded and the unit is ready to run.

- Power Out Connector. The output of the controller is output to the HSILS unit via this BNC connector directly to the piezoelectric stack. 


\section{Connections}

The controller is configured as a DCE device and may be connected to the host computer using a standard RS232 cable. The communications parameters are 9600 baud, 8 bits, no parity.

\section{Installing the Host Computer Program}

The host computer program is a shareware communication program called Powercomm and is commonly available. Install this on your hard drive. Once the program is installed, you should print out and read the manual. Note that the program comes preconfigured to use COM1. You will have to reconfigure it (using the alt I command) if the controller is connected to a different communications port.

\section{Testing the HSILS Controller}

Once the controller has been hooked up, start powercomm in the "computer to computer" mode by typing:

\section{C $>$ HSILS}

Now turn on the controller and the following prompt should appear on the host PC:

\section{HSILS Controller V1.0}

$>$

Press the enter key. The controller should respond with:

Valid Commands are:

U

$P$ width,height - Issue a pulse

If the system did not behave as above check the RS232 cable, Powercomm configuration, and power connections. Looking at the controller box, the Power (red) LED should be lit and the Ready (green) LED should come on after a one to two minute delay (to allow for charging of the capacitor bank).

\section{Operation}

The controller software has two commands:

- P width, height causes the controller to pulse the output to height volts for width microseconds. This, in effect, creates a half square wave drive pulse. As described earlier in the report, the slope of this "square" wave will be approximately 1 volt/microsecond and is not capable of being modified without changing the pulse power amplifier design.

- U instructs the controller to upload a profile for later execution. A profile is a list of 
time (microseconds) and voltage pairs terminated with a line containing the word "end". Any line starting with a semicolon (;) is ignored. Fig. F.2 lists part of a sample profile.

A profile can be entered manually, by simply typing it in, or it can be uploadeed from a pregenerated file. To upload a file, press ALT A. Powercomm will ask for the name of the file. Once the file name has been entered, Powercomm will upload it and signal when done. If the profile was successfully loaded, the ready LED should begin flashing. To run the profile, press the Run Profile button. When completed the microcontroller sends a "done" message to the host PC.

; This is a comment in a sample profile

3025.82

$60 \quad 49.38$

9070.87

12090.43

$150 \quad 108.20$

180124.34

.

$9810 \quad 3.33$

$\begin{array}{lll}9840 & 3.28\end{array}$

$9870 \cdot 3.24$

$9900 \quad 3.19$

$9930 \quad 3.14$

$\begin{array}{lll}9960 & 3.09\end{array}$

$9990 \quad 3.05$

END

Fig. F.2: Sample download profile for local execution on the HSILS microcontroller. 

